\title{
Sensitivity Analysis of Two Solar Combisystems Using Newly Developed Hot Water Draw Profiles
}

by

Skai Edwards, B.Eng., Environmental Engineering Dalhousie University

A thesis submitted to the

Faculty of Graduate and Postdoctoral Affairs

in partial fulfillment of the requirements for the degree of

Master of Applied Science in Sustainable Energy

Department of Mechanical and Aerospace Engineering

Carleton University

Ottawa, Ontario

May, 2014

(C)Copyright

Skai Edwards, 2014 
The undersigned hereby recommends to the

Faculty of Graduate and Postdoctoral Affairs acceptance of the thesis

\title{
Sensitivity Analysis of Two Solar Combisystems Using Newly Developed Hot Water Draw Profiles
}

\author{
submitted by Skai Edwards, B.Eng., Environmental Engineering \\ Dalhousie University
}

in partial fulfillment of the requirements for the degree of

Master of Applied Science in Sustainable Energy

Professor Ian Beausoleil-Morrison, Thesis supervisor, Department of Mechanical and Aerospace Engineering

Professor Metin Yaras, Chair, Department of Mechanical and Aerospace Engineering

Department of Mechanical and Aerospace Engineering Carleton University

May, 2014 


\section{Abstract}

This research addresses the viability of two solar combisystems, which use solar energy to provide both space heating and domestic hot water, for several single family homes in Ontario.

Hot water use data from seventy three homes were refined to create twelve different draw profiles representing a variety of consumers. These profiles were divided up based on the magnitude of daily draw and the preferred time of use. It was determined that time of use had little to no effect on performance. However, the magnitude of a daily draw was seen to have a significant effect on the final energy use of a home.

Two different combisystem plant configurations, a single tank system and a two tank system, were simulated. It was determined that the single tank system offered superior performance. Unless systems were sized to the upper limits tested here, a solar fraction of $50 \%$ could not be achieved. 
Dedicated to my parents. Your love and support know no bounds. 


\section{Acknowledgments}

I would like to first thank my supervisor, Dr. Ian Beausoleil-Morrison. Your knowledge and advice could not have been more useful.

My appreciation to my friends and colleagues: GJ, PP, AW, SB, JK, SM, BPK, and SH. You were always there for me when I needed you. Whether that be with technical advice, your knowledge still outweighs my own tenfold, or a friendly conversation, you were there for me.

Finally I cannot thank my parents enough. When I called and told you I felt like crawling into corner and crying for the rest of the week you always talked me out of it. 


\section{Table of Contents}

Abstract

Acknowledgments $\quad$ v

Table of Contents vi vi

List of Tables $\quad$ ix

List of Figures $\quad$ xi

Nomenclature $\quad$ Xv

1 Introduction 1

1.1 Canadian Energy Usage . . . . . . . . . . . . . . . . 1

1.2 Canadian Solar Thermal Systems . . . . . . . . . . . . . . 3

1.3 Research Objectives . . . . . . . . . . . . . . . 8

1.4 Thesis Outline . . . . . . . . . . . . . . . . . . . . 8

2 Literature Review 10

2.1 Introduction . . . . . . . . . . . . . . . . . . . . 10

2.2 Domestic Hot Water Usage . . . . . . . . . . . . . . . . . . . . . 10

2.3 Solar Thermal Collectors and Design Principles . . . . . . . . . . . 13

2.4 Solar Combisystems . . . . . . . . . . . . . . . . . . 17

2.4.1 General research on Combisystems ... . . . . . . . 17

2.5 Conclusions . . . . . . . . . . . . . . . . . . . . . 21

3 Simulation tools $\quad 22$

3.1 Introduction . . . . . . . . . . . . . . . . . 22

3.1.1 Primary Concerns . . . . . . . . . . . . . . 22 


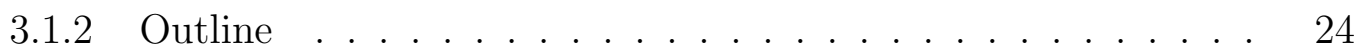

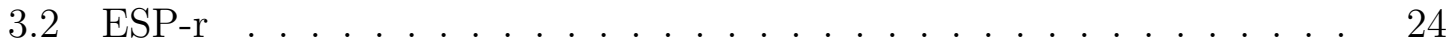

3.2 .1 The Thermal Domain . . . . . . . . . . . . . . . . 25

3.2 .2 The Plant Domain . . . . . . . . . . . . . . . . . . . . . . 29

3.3 CHREM models . . . . . . . . . . . . . . . . . . . . . . . . . . . . . 29

3.4 TRNSYS . . . . . . . . . . . . . . . . . . . . 30

3.4 .1 Storage Tank Models . . . . . . . . . . . . . . . . . . . . 31

3.4 .2 Solar Collector Models . . . . . . . . . . . . . . . . . . . 36

3.5 Co-Simulation . . . . . . . . . . . . . . . . . . . . . . . . . . 38

4 Development of Hot Water Draw Profiles $\quad 39$

4.1 Measured Hot Water Draws . . . . . . . . . . . . . . . . . 39

4.1 .1 Measurement Methods . . . . . . . . . . . . . . . . . . . 39

4.1 .2 Analysis of Measured Data . . . . . . . . . . . . . . 40

4.2 Annual Hot water Draw Profiles . . . . . . . . . . . . . . . . . 44

5 Simulation Methodology 54

5.1 Introduction . . . . . . . . . . . . . . . . . 54

5.2 Baseline Parameters . . . . . . . . . . . . . . . . . . . 54

5.2.1 Solar Collector Baseline Parameters . . . . . . . . . . . . 55

5.2.2 Storage Tank Baseline Parameters . . . . . . . . . . . . . . . 61

5.3 House Models . . . . . . . . . . . . . . . . . . . . . . . . . . . . 64

5.4 General System Setup _ . . . . . . . . . . . . . . . 68

5.4 .1 System A . . . . . . . . . . . . . . . . . . . 69

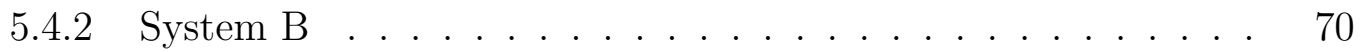

5.5 Summary of Simulations Run . . . . . . . . . . . . . . . 72

5.6 Performance Metrics . . . . . . . . . . . . . . . . . . . . 74

6 Results and Discussion $\quad 78$

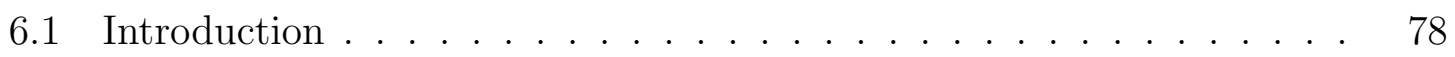

6.2 System A . . . . . . . . . . . . . . . . 78

6.2.1 Interaction of Energy Collection and Tank Losses for System A 78

6.2.2 Energy Collection for System A . . . . . . . . . . . . 81

6.2.3 Solar Fraction for System A . . . . . . . . . . . . . . . . 81

6.2.4 Solar Loop Safety Cutoff for System A . . . . . . . . . . 85 
6.2.5 Auxiliary Energy Use for System A . . . . . . . . . . . . . . 88

6.2.6 Summary, General Comments, and Recommendations on System A . . . . . . . . . . . . . . . . . . . . 92

6.3 System B . . . . . . . . . . . . . . . . . . . . . 94

6.3.1 Interaction of Energy Collection and Tank Losses for System B 94

6.3.2 Energy Collection for System B . . . . . . . . . . . . 96

6.3.3 Solar Fraction for System B . . . . . . . . . . . . . . . . . . . 99

6.3.4 Solar Loop Safety Cutoff for System B . . . . . . . . . . . . . 102

6.3.5 Auxiliary Energy Use for System B . . . . . . . . . . . . . . . 105

6.3.6 Summary, General Comments, and Recommendations on System B . . . . . . . . . . . . . . . . . . . . 108

6.4 Comparison of System A and System B performance . . . . . . . . . 110

7 Conclusions and Recommendations 112

7.1 Conclusions and Contributions . . . . . . . . . . . . . . . . . . . . 112

7.2 Recommendations for Future Work . . . . . . . . . . . . . . . . . . 114

$\begin{array}{ll}\text { List of References } & 117\end{array}$

Appendix A Results of System A plant configuration for all Homes Aside from Mid-size 1955

Appendix B Results of System B plant configuration for all Homes Aside from Mid-size 1955 


\section{List of Tables}

2.1 Summary of domestic installations of solar thermal collectors, by collector area, in Canada in $2009[5]$. . . . . . . . . . . . . 15

4.1 Occupancy levels of houses measured in study . . . . . . . . . . . . . 40

4.2 Statistical summary of measured data from 73 houses . . . . . . . . . 42

4.3 Per capita usage . . . . . . . . . . . . . . . . . . . . 43

4.4 Per capita usage observed in other studies $[12,17,52] \ldots 43$

4.512 representative annual DHW load profiles . . . . . . . . . . . . 48

5.1 Frequency outlet temperatures were above $55{ }^{\circ} \mathrm{C} \ldots \ldots . . . . . \quad 57$

5.2 Incidence angle modifier provided by Enerworks . . . . . . . . . . . . 57

5.3 Annual auxiliary energy use for various tilt angles for Toronto . . . . 60

5.4 Annual auxiliary energy use for various tilt angles for Thunder Bay . 60

5.5 Comparison of insulation levels in $750 \mathrm{~L}$ and $2000 \mathrm{~L}$ tank . . . . . . . 64

5.6 Summary of information on homes used . . . . . . . . . . . 65

5.7 Average annual DHW and space heating energy usage of the homes and DHW load profiles used in this research (GJ) . . . . . . . . . 77

6.1 Range of results for differences in solar energy collected and storage tank losses when varying collector area and storage volume for remainder of homes studied . . . . . . . . . . . . . . . . . . . . . 82

6.2 Range of results for differences in solar energy collected when varying collector area and storage volume for remainder of homes studied . . 84

6.3 Range of results for solar fraction when varying collector area and storage volume for remainder of homes studied . . . . . . . . . . . . 87

6.4 Range of results for solar loop cutoff when varying collector area and storage volume for remainder of homes studied . . . . . . . . . . . . . 90

6.5 Range of results for auxiliary energy use when varying collector area and storage volume for remainder of homes studied . . . . . . . . . . 93 
6.6 Range of results for differences in solar energy collected and DHW tank Losses when varying collector area and storage volume for remainder of homes studied . . . . . . . . . . . . . . . . . . . . 97

6.7 Range of results for differences in solar energy collected when varying collector area and storage volume for remainder of homes studied . . 100

6.8 Range of results for solar fraction when varying collector area and storage volume for remainder of homes studied . . . . . . . . . . . 103

6.9 Range of results for solar loop cutoff when varying collector area and storage volume for remainder of homes studied . . . . . . . . . . 106

6.10 Range of results for auxiliary energy use when varying collector area and storage volume for remainder of homes studied . . . . . . . . . 109 


\section{List of Figures}

1.1 Energy consumption and GHG emissions in Canada 1990-2010 [1] . . 2

1.2 Summary of Canadian energy use [1] . . . . . . . . . . . . . . 4

1.3 GHG emissions for residential space and DHW heating [1] . . . . . 5

2.1 Cross section of a flat plate collector . . . . . . . . . . . . . 14

2.2 A simple solar combisystem with an internal auxiliary heater . . . . . 18

3.1 Discretization of storage tank in TRNSYS . . . . . . . . . . . . . 32

3.2 Simplified schematic of a three tank nodes . . . . . . . . . . . . . . 34

4.1 Distribution of daily averaged hot water consumption of the 73 houses. 41

4.2 Temporal consumption patterns of four of the houses. (The hourly integrated consumptions have been averaged over each day of the monitoring period.) . . . . . . . . . . . . . . . . . . . 45

4.3 Histogram of daily DHW consumption for the average predominantly evening consuming house, H14 . . . . . . . . . . . . . . . . . . . . . 49

4.4 Daily DHW consumption of the three average houses for a two-week period in January . . . . . . . . . . . . . . . . . . 50

4.5 Histograms showing the daily consumption patterns for the draw profiles used in this research . . . . . . . . . . . . . . . . . . . . . 52

4.6 Hourly consumption patterns for the draw profiles used in this research 53

5.1 Examples of 2, 3, and 4 collectors connected in series in 2 parallel branches. . . . . . . . . . . . . . . 56

5.2 Calculated incidence angle modifier . . . . . . . . . . . . . . 58

5.3 Average monthly ambient temperatures for the homes simulated. . . . 67

5.4 System A configuration . . . . . . . . . . . . . . 69

5.5 System A configuration when DHW heating is required . . . . . . . . 70

5.6 System A configuration when additional heating is required for the radiators . . . . . . . . . . . . . . . . . . . . . . . . . 71 
5.7 System A configuration when no additional heating is required for the radiators . . . . . . . . . . . . . . . . . . . . . 72

5.8 System B configuration . . . . . . . . . . . . . . . . 73

5.9 System B configuration with heat extraction from the preheat tank . 73

5.10 System B configuration with heat extraction from the DHW tank . . 74

6.1 Difference in solar energy collected and DHW tank Losses when varying collector area and storage volume for mid-size 1955 home. . . . . . . 80

6.2 Difference in solar energy collected when varying collector area and storage volume for mid-size 1955 home. . . . . . . . . . . . . . . . . . 83

6.3 Difference in solar fractions when varying collector area and storage volume for mid-size 1955 home. . . . . . . . . . . . . . . . . . . . . . 86

6.4 Difference in solar pump cutoffs when varying collector area and storage volume for mid-size 1955 home. . . . . . . . . . . . . . . . . . . 89

6.5 Difference in auxiliary energy use when varying collector area and storage volume for mid-size 1955 home. . . . . . . . . . . . . . . . . . . . 91

6.6 Difference in solar energy collected and DHW tank losses when varying collector area and storage volume for mid-size 1955 home. . . . . . . 95

6.7 Difference in solar energy collected when varying collector area and storage volume for mid-size 1955 home. . . . . . . . . . . . . . . . . 98

6.8 Difference in solar fractions when varying collector area and storage volume for mid-size 1955 home. . . . . . . . . . . . . . . . . . . . . . 101

6.9 Difference in solar pump cutoffs when varying collector area and storage volume for mid-size 1955 home. . . . . . . . . . . . . . . . . . . . 104

6.10 Difference in auxiliary energy use when varying collector area and storage volume for mid-size 1955 home. . . . . . . . . . . . . . . . . . . . 107

A.1 Difference in solar energy collected when varying collector area and storage volume for mid-size 1974 home. . . . . . . . . . . . . . . . . . 122

A.2 Difference in solar energy collected when varying collector area and storage volume for mid-size 1974 home. . . . . . . . . . . . . . . . . 123

A.3 Difference in solar fractions when varying collector area and storage volume for mid-size 1974 home. . . . . . . . . . . . . . . . . . . . . . 124

A.4 Difference in solar pump cutoff times when varying collector area and storage volume for mid-size 1974 home. . . . . . . . . . . . . . . . 125 
A.5 Difference in auxiliary energy use when varying collector area and storage volume for mid-size 1974 home. . . . . . . . . . . . . . . . . . . . 126

A.6 Difference in solar energy collected and DHW tank Losses when varying collector area and storage volume for for mid-size 1990 home. . . . . . 127

A.7 Difference in solar energy collected when varying collector area and storage volume for for mid-size 1990 home. . . . . . . . . . . . . . . . 128

A.8 Difference in solar fractions when varying collector area and storage volume for for mid-size 1990 home. . . . . . . . . . . . . . . . . . . . 129

A.9 Difference in solar pump cutoffs when varying collector area and storage volume for for mid-size 1990 home. . . . . . . . . . . . . . . . . . 130

A.10 Difference in auxiliary energy use when varying collector area and storage volume for for mid-size 1990 home. . . . . . . . . . . . . . . . . . 131

A.11 Difference in solar energy collected and DHW tank Losses when varying collector area and storage volume for large 1990 home. . . . . . . . . 132

A.12 Difference in solar energy collected when varying collector area and storage volume for large 1990 home. . . . . . . . . . . . . . . . . . . . 133

A.13 Difference in solar fractions when varying collector area and storage volume for large 1990 home. . . . . . . . . . . . . . . . . . . . . . . . 134

A.14 Difference in solar pump cutoffs when varying collector area and storage volume for large 1990 home. . . . . . . . . . . . . . . . . . 135

A.15 Difference in auxiliary energy use when varying collector area and storage volume for large 1990 home. . . . . . . . . . . . . . . . . . . . . . 136

B.1 Difference in solar energy collected and DHW tank Losses when varying collector area and storage volume for mid-size 1974 home. . . . . . . 138

B.2 Difference in solar energy collected when varying collector area and storage volume for mid-size 1974 home. . . . . . . . . . . . . . . . . . 139

B.3 Difference in solar fractions when varying collector area and storage volume for mid-size 1974 home. . . . . . . . . . . . . . . . . . . . . . 140

B.4 Difference in solar pump cutoffs when varying collector area and storage volume for mid-size 1974 home. . . . . . . . . . . . . . . . . . . . 141

B.5 Difference in auxiliary energy use when varying collector area and storage volume for mid-size 1974 home. . . . . . . . . . . . . . . . . . . . 142

B.6 Difference in solar energy collected and DHW tank Losses when varying collector area and storage volume for mid-size 1990 home. . . . . . . 143 
B.7 Difference in solar energy collected when varying collector area and storage volume for mid-size 1990 home. . . . . . . . . . . . . . . . 144

B.8 Difference in solar fractions when varying collector area and storage volume for mid-size 1990 home. . . . . . . . . . . . . . . . . . . 145

B.9 Difference in solar pump cutoffs when varying collector area and storage volume for mid-size 1990 home. . . . . . . . . . . . . . . . 146

B.10 Difference in auxiliary energy use when varying collector area and storage volume for mid-size 1990 home. . . . . . . . . . . . . . . . . 147

B.11 Difference in solar energy collected and DHW tank Losses when varying collector area and storage volume for large 1990 home. . . . . . . . . 148

B.12 Difference in solar energy collected when varying collector area and storage volume for large 1990 home. . . . . . . . . . . . . . . . . . . . 149

B.13 Difference in solar fractions when varying collector area and storage volume for large 1990 home. . . . . . . . . . . . . . . . . . . . . 150

B.14 Difference in solar pump cutoffs when varying collector area and storage volume for large 1990 home. . . . . . . . . . . . . . . . . . . . . 151

B.15 Difference in auxiliary energy use when varying collector area and storage volume for large 1990 home. . . . . . . . . . . . . . . . . . . 152 


\section{Nomenclature}

\begin{tabular}{|c|c|c|}
\hline ASHRAE & $\begin{array}{l}\text { American Society of Heating, Refrigeration, } \\
\text { and Air-conditioning Engineeers }\end{array}$ & \\
\hline BPS & Building Physics Simulation & \\
\hline $\mathrm{C}$ & Capacitance & {$[\mathrm{kJ} / \mathrm{K}]$} \\
\hline $\mathrm{CAD}$ & Canadian Dollars & {$[\$]$} \\
\hline $\mathrm{CFD}$ & Computational Fluid Dynamics & \\
\hline CHREM & Canadian Hybrid Residential End-use Energy Model & \\
\hline $\mathrm{CO}_{2}$ & Carbon Dioxide & \\
\hline $\mathrm{CMHC}$ & Canada Mortgage and Housing Corporation & \\
\hline$C_{\mathrm{p}}$ & Specific Heat & {$[\mathrm{kJ} / \mathrm{kg} \mathrm{K}]$} \\
\hline CSDDRD & Canadian Single Detached and Double Row Database & \\
\hline CV & Control Volume & \\
\hline CWEC & Canadian Weather for Energy Calculation & \\
\hline DHW & Domestic Hot Water & \\
\hline DLL & Dynamic Link Library & \\
\hline ESP-r & Environmental System Performance - Research Edition & \\
\hline$F^{\prime}$ & Plate Efficiency Factor & {$[-]$} \\
\hline$F^{R}$ & Collector Heat Removal Factor & {$[-]$} \\
\hline
\end{tabular}




\section{Nomenclature}

\begin{tabular}{|c|c|c|}
\hline GHG & Greenhouse Gas Emissions & \\
\hline HVAC & Heating, Ventilation, and Air conditioning & \\
\hline IAM & Incidence Angle Modifier & {$[-]$} \\
\hline$I_{T}$ & Hourly Radiation on Surface & {$\left[\mathrm{kJ} / \mathrm{m}^{2} \mathrm{hr}\right]$} \\
\hline$\dot{m}$ & Mass Flow Rate & {$[\mathrm{kg} / \mathrm{hr}]$} \\
\hline NRCan & Natural Resources Canada & \\
\hline NREL & National Renewable Energy Laboratory & \\
\hline$Q$ & Heat Transfer & {$[\mathrm{kj} / \mathrm{hr}]$} \\
\hline$S$ & Hourly Radiation Absorbed on Surface & {$\left[\mathrm{kJ} / \mathrm{m}^{2} \mathrm{hr}\right]$} \\
\hline $\mathrm{SHC}$ & Solar Heating and Cooling & \\
\hline$T$ & Temperature & {$[\mathrm{K}]$} \\
\hline$t$ & Time & [hours] \\
\hline$T_{a}$ & Ambient Temperature & {$[\mathrm{K}]$} \\
\hline TESS & Thermal Energy Systems Specialist & \\
\hline TRNSYS & Transient System Simulation Software & \\
\hline$U_{L}$ & Overall Collector Loss Coefficient & {$\left[\mathrm{kJ} / \mathrm{m}^{2} \mathrm{~K} \mathrm{hr}\right.$} \\
\hline USD & US Dollars & {$[\$]$} \\
\hline
\end{tabular}

Greek symbols

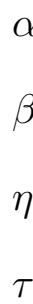

$\beta$

$\eta$

$\tau$
Absorptance

Collector slope

Collector efficiency

Transmitance
[-]

[deg]

$[\%]$

[-] 


\section{Chapter 1}

\section{Introduction}

\subsection{Canadian Energy Usage}

The Canadian energy mix has traditionally been heavily reliant upon energy sources which produce greenhouse gases (GHG). Historically, this has included a combination of natural gas, oil, and coal. The consumption of energy, and by proxy, the production of GHGs, within Canada has been seen to increase over the past twenty years. Between 1990 and 2010 energy consumption has increased by $22.3 \%$ and GHG emissions have increased by $21.5 \%$ [1]. This trend can be seen in Figure 1.1. While the general trend is towards an increase in energy use, there have been periods of reduced consumption. These periods of reduced energy consumption can be linked to periods of economic recession. During these periods commercial and industrial activity decline and, subsequently, energy consumption is reduced.

An increase in the production of GHG emissions lies in direct contradiction to the energy policy established by the Canadian government in the 2010 Federal Sustainable Development Strategy [2]. This document presents the government's aim to reduce GHG emissions to $17.0 \%$ below 2005 levels by the year 2020. Between 2005 and 2010 GHG emissions within Canada have been reduced from $489.4 \mathrm{MT}$ of $\mathrm{CO}_{2}$ to 484.4 MT of $\mathrm{CO}_{2}$. This represents a drop in production of a mere $1.02 \%$ or $5 \mathrm{MT}$ of $\mathrm{CO}_{2}$. If the government of Canada hopes to meet the goal they established, a further 78.4 MT of $\mathrm{CO}_{2}$ must be displaced from annual Canadian energy production. One of two strategies can be employed to reduce the production of energy related GHG emissions. The first of these strategies reduces the end use of energy by employing energy efficiency measures. The second strategy displaces the energy produced by such GHG intensive energy sources with renewable means of energy production such 


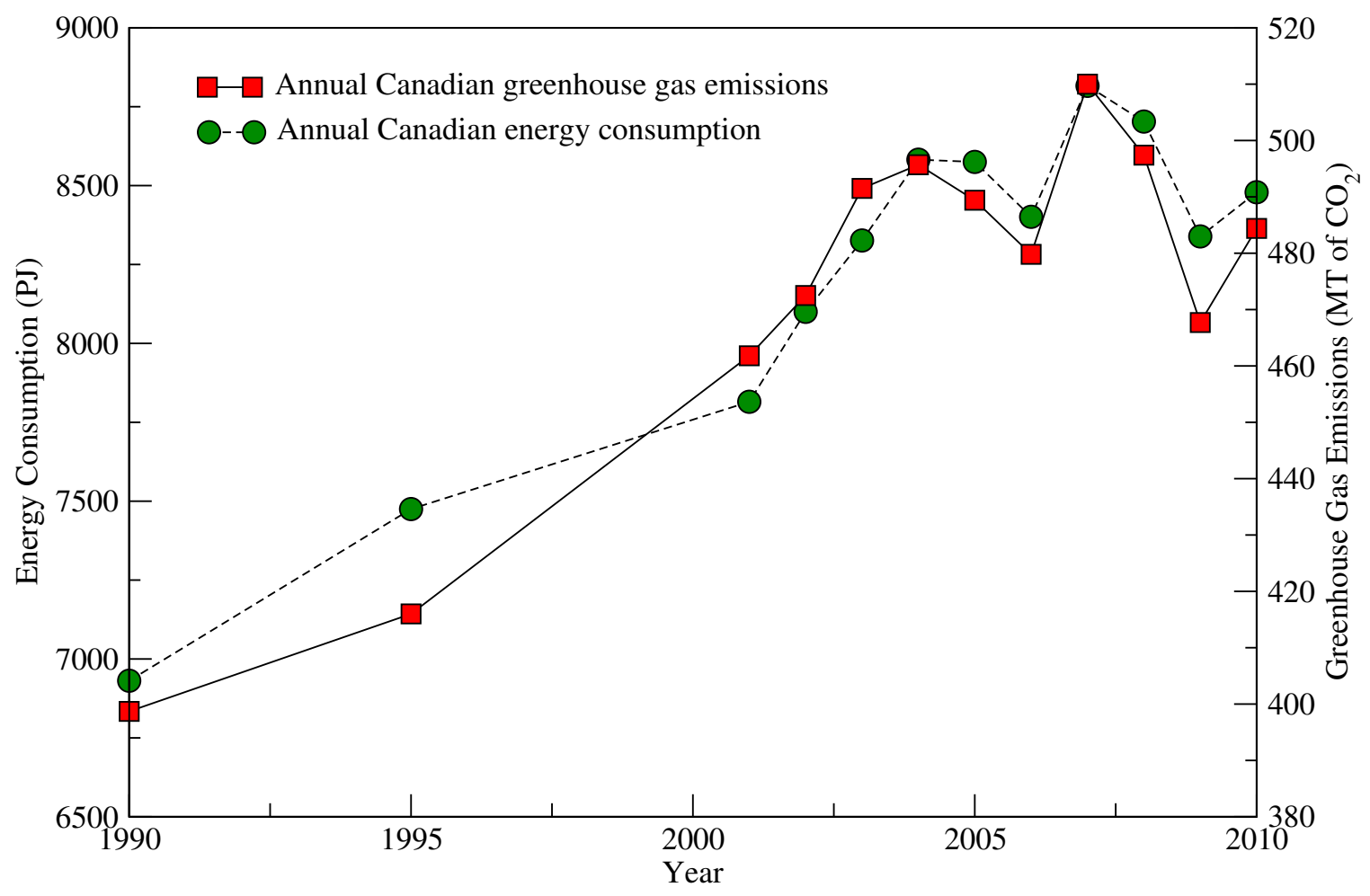

Figure 1.1: Energy consumption and GHG emissions in Canada 1990-2010 [1]

as wind energy, hydro, or solar.

While goals of reduced GHG emissions have been established by the Canadian government there has been limited federal funding, or incentivization, dedicated towards renewable energy programs and energy efficiency projects in the last several years. The federal budget in 2009 established 800 million Canadian dollars (CAD) for building energy efficiency projects, 270 million CAD for renewable energy projects, and 540 million CAD for transit and vehicle efficiency [3]. These funds were expected to last from 2009 to 2011. This is substantially different than the investments made by the United States federal government for the period between 2009 to 2011. Under the Obama administration the federal government invested 25.3 billion US dollars (USD) for building energy efficiency projects, 26.73 billion USD for projects relating to renewable energy systems, and 24.5 billion USD for projects relating to transit and vehicle efficiency [3]. When looking at the funding on a per capita basis this reveals a stark contrast in the approach to energy policy between the two countries. The United States spends 6.5 times more per capita on projects related to sustainable development when compared to Canada. If Canada is to make strides towards their 
goal, then smaller scale projects must be examined as possible solutions for reducing GHG emissions.

Looking at energy end-use by sector in 2010, as displayed in Figure 1.2(a), energy was primarily consumed by industrial facilities. This amounted to 3227.6 PJ in 2010. Residential homes consumed substantially less energy with a total use of 1360.7 PJ. However, this still accounts for $16 \%$ of Canadian energy usage [1]. In residential homes the end uses of energy include space heating, water heating, appliances, lighting, and cooling. Figure 1.2(b) shows that the largest consumers of energy within the residential sector were space heating and water heating. The increasingly stringent building codes across Canada are helping to reduce the space heating energy requirements of homes. However, these codes only apply to newly constructed homes. In older homes, where retrofits to the building envelope would be considered prohibitively expensive, alternative means of displacing GHG emissions must be explored. By displacing traditional, centrally located energy production, with decentralized energy sources that do not emit GHGs, Canada can take steps to approaching their goals for sustainable development.

Solar combisystems, which are the focus of this research, offer a method of meeting domestic hot water (DHW) and space heating demands. If these are the energy demands that are being targeted then it would be prudent to first examine the GHG emissions resulting from their consumption. Figure 1.3 shows the emissions of these two end uses. The general trend is towards a reduction in emissions over the last 20 years. Using the 2005 baseline cited in the Federal Sustainable Development Strategy

space heating emissions have been reduced by $2.6 \%$ and hot water emissions have been reduced by $5.4 \%$. This is a step towards meeting the goal. However, significant adjustments must be made to meet the goals for 2020. One such step is the inclusion of solar combisystems for the provision of space and DHW heating.

\subsection{Canadian Solar Thermal Systems}

As of 2007 it is estimated that, collectively, there are $544,000 \mathrm{~m}^{2}$ of solar thermal collectors operating in Canada. However, the majority of these collectors are either unglazed plastic collectors, which account for $71 \%$ of the installed surface area, or unglazed perforated air collectors, which account for $26 \%$ of the installed surface 


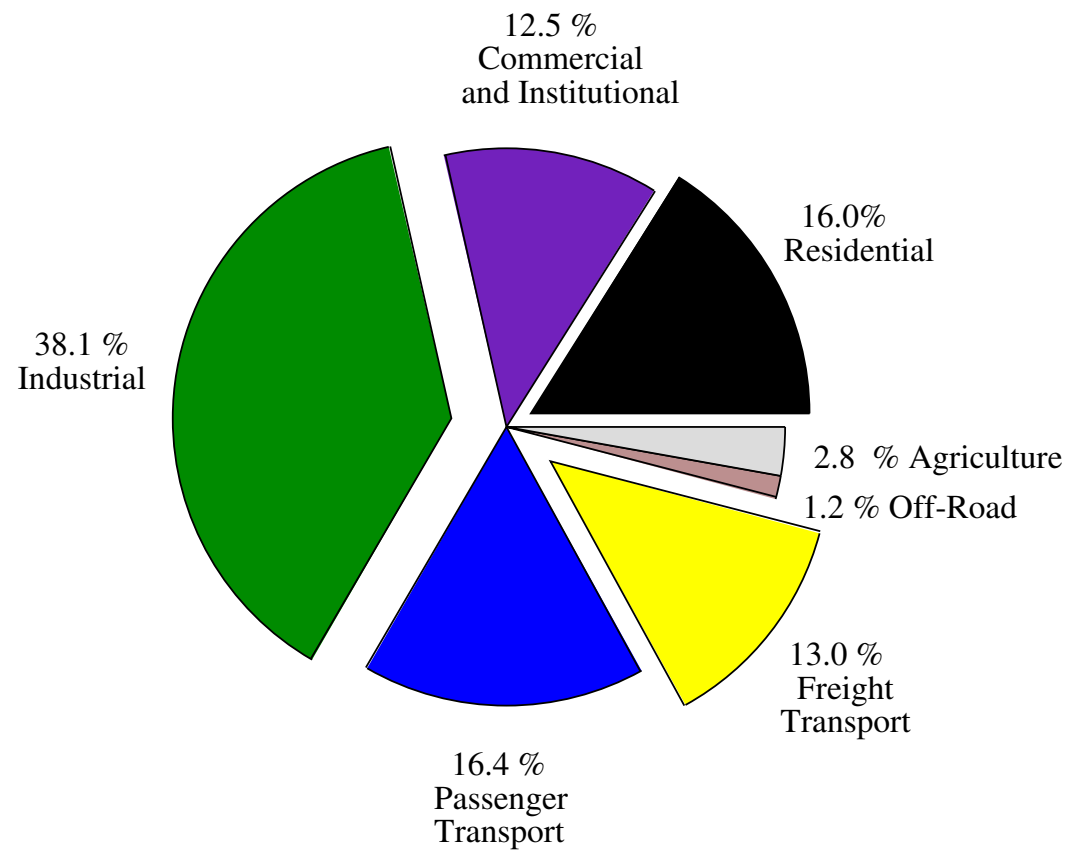

(a) Canadian energy Use by sector

$63 \%$

Space Heating

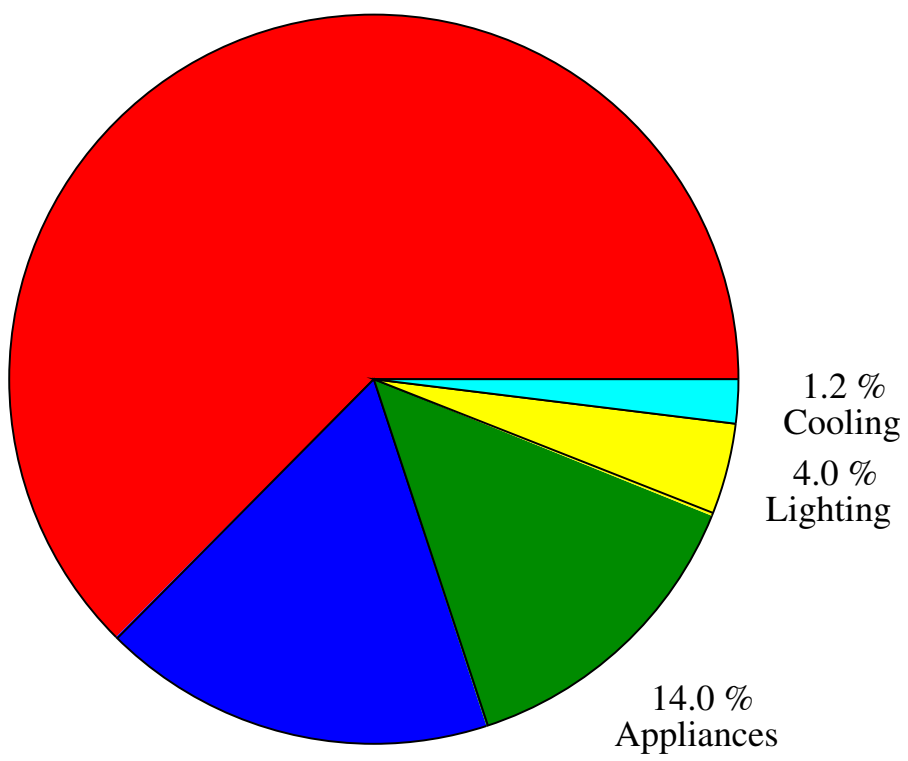

$17.5 \%$

Water Heating

(b) Residential energy consumption

Figure 1.2: Summary of Canadian energy use [1] 


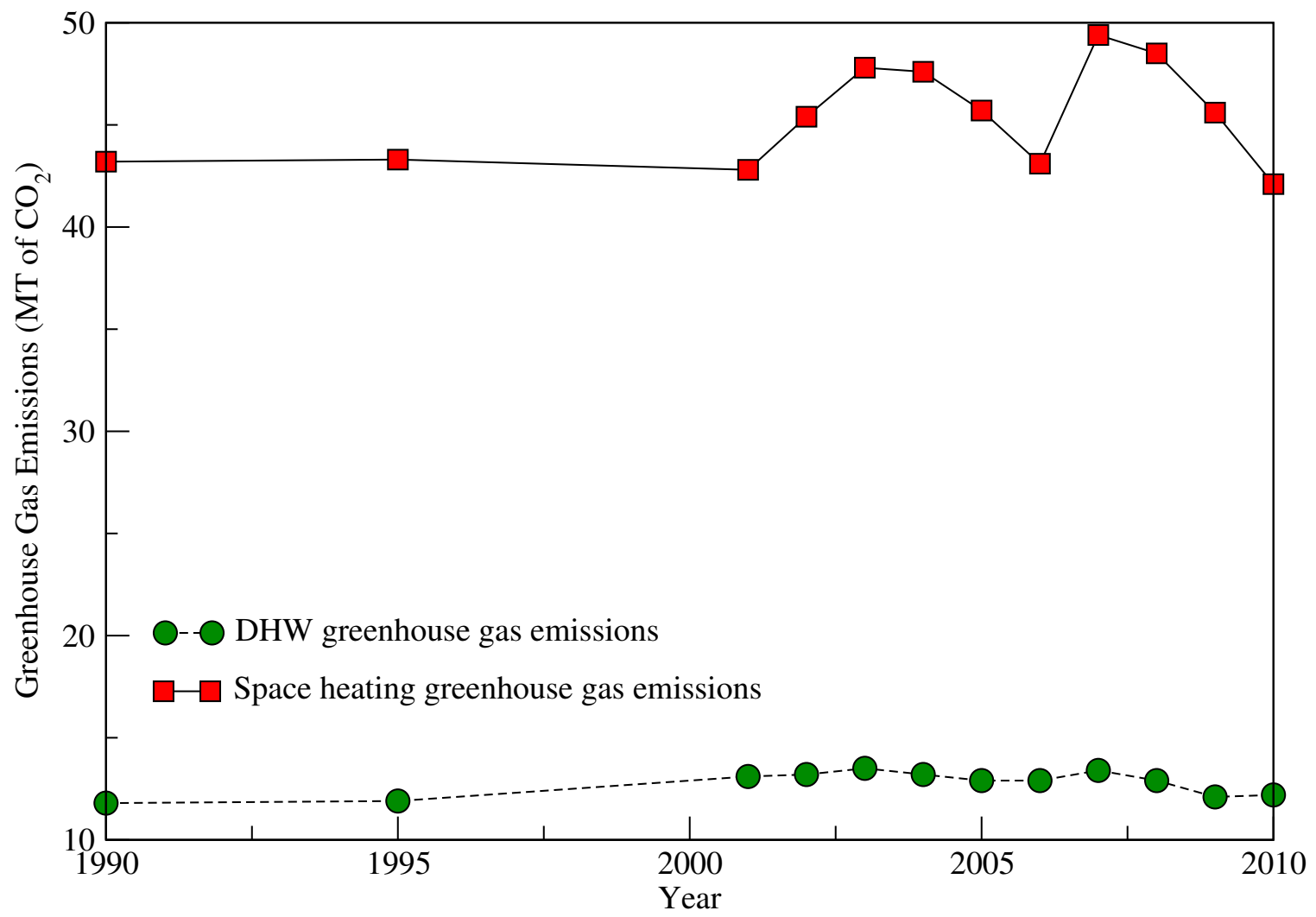

Figure 1.3: GHG emissions for residential space and DHW heating [1] 
area [4]. This trend has continued in recent years with unglazed plastic and perforated air collectors accounting for $155,664 \mathrm{~m}^{2}$ of the $171,279 \mathrm{~m}^{2}$ total collector sales by area in 2009 [5]. These types of collectors are predominately used for pool heating and commercial building air heating respectively. The benefits that such technologies offer are their low cost and relatively limited maintenance requirements. In 2009 it cost, on average, $262 \mathrm{CAD}$ to install a $6.7 \mathrm{~m}^{2}$ prepackaged solar pool heating system, whereas it cost, on average, 4,156 CAD to install a $5.7 \mathrm{~m}^{2}$ prepackaged solar DHW system [5]. While these unglazed systems are relatively cheap to install they are not suitable for the preparation of DHW or the provision of space heating as they operate at too low a temperature. Even unglazed perforated air collectors are typically not capable of heating air to a sufficient temperature to allow for heating commercial buildings. Instead, these unglazed perforated collectors are used as a preheat treatment for space heating [6]. After the initial heating by the perforated air collectors the incoming air is further heated by an auxiliary heating unit. It is estimated that, on an annual basis, Canadian solar thermal systems are offsetting the production of 60,297 tonnes of GHG emissions.

In addition to the use of glazed flat plate collectors for the production of DHW there is a smaller subset of these systems which can also be used to provide space heating. These systems are known in the industry as solar combisystems. These systems, which provide both DHW and space heating through the use of solar energy, will be the focus of this work.

Due to the limited market penetration of glazed collectors it might appear that these systems are incompatible with the Canadian climate. However, there have been a number of recent projects established in order to demonstrate the viability of such systems. In 2006, in conjunction with the Canada Mortgage and Housing Corporation (CMHC), Natural Resources Canada (NRCan) established the EQuilibrium Sustainable Housing Demonstration Initiative. This project resulted in funding fifteen housing projects which demonstrated the viability of renewable technologies in Canadian homes. These technologies included natural ventilation, daylighting, solar photovoltaics, and solar thermal among others. The homes provided Canadians with a vision of possible home designs which integrate renewable systems and are functionally comparable to conventional systems. In addition, performance monitoring, while home owners are occupying the space, is continuing for many of these homes. This information will help researchers in determining the efficacy of various design 
features and the effects that occupancy have on performance.

Three such homes constructed as part of this challenge were the Southfield Solar Model Home, in Guelph, Ontario, The Factor 9 home, in Regina, Saskatchewan, and the Urban Ecology home, in Winnipeg Manitoba. All of these homes integrate solar combisystems in some way and they represent homes located in some of the harshest urban climates in Canada: the prairies and central Canada.

The $208.2 \mathrm{~m}^{2}$ Southfield Solar Model Home utilized 2 flat plate solar collectors, measuring 2.97 square metres each, with a total collector area of 5.94 square metres. These collectors were primarily used to provide DHW. However, during the fall and winter months, there would be an additional space heating demand; the collector loop was tied to a radiant floor heating system. Due to the modest size of the array there was limited space heating supplied by them. The designers estimated that only $4 \%$ of the annual space heating load would be satisfied by the combisystem. However, even with such a small system they were able to satisfy $39 \%$ of the DHW demand of a family of four. In the fall months the solar DHW system performed exceptionally well producing enough energy to satisfy $94 \%$ of the home's hot water needs. This project showcases the fact that even with a relatively small system, for a home whose focus was not the optimization of a solar combisystem, a fair portion of energy demands for a home can be satisfied [7].

The $301 \mathrm{~m}^{2}$ Factor 9 home focused more on the use of solar combisystems for space heating than the Southfield Solar Model Home. They nearly quadrupled the collector array size to 20.4 square metres. In addition they used a large $2350 \mathrm{~L}$ hot water storage tank to allow for the storage of solar energy during extended cloudy periods. Traditionally combisystems have been estimated to have superior performance at a tilt angle of latitude $\pm 10-20$ degrees [8]. However, due to the high tilt angle this would necessitate, and the additional installation costs, the designers opted to place the collectors vertically along the side of the building. This suboptimal orientation will be discussed in Section 2.3. In combination with energy efficiency measures and photovoltaics the Factor 9 house was able to reduce energy consumption by almost a factor of 9 when compared to a home of the same floor area constructed in 1970. They provide no specifics on the proportion of demand satisfied by the solar combisystem [9].

The $103.4 \mathrm{~m}^{2}$ Urban Ecology home is one of the smaller EQuilibrium homes designed. It employed $11.9 \mathrm{~m}^{2}$ of flat plate collectors to provide both space heating 
and DHW. In addition they separated their DHW and space heating systems into two separate tanks. The priority of energy use was placed on the DHW system. It was estimated that $50 \%$ of the home's DHW needs and $26 \%$ of the space heating needs of the home would be satisfied through the use of this system [10].

These three homes are examples of solar combisystems integrated into already energy efficient homes. However, other researchers, as will be discussed in Section 2.4, have suggested that combisystems are most beneficial when installed in homes with high heating demands. This is due to the fact that additional solar energy can be used to heat living space during the shoulder seasons of fall and spring.

\section{$1.3 \quad$ Research Objectives}

This thesis aims to improve the design of solar combisystems for single family homes in Canada. Solar fraction is one of the metrics that will be used to evaluate performance. A goal of a $50 \%$ solar fraction has been set. Solar fraction here is defined, generally, as the percentage of total energy use met through the use of solar energy. Auxiliary energy use will be examined and compared with a base case in which no solar combisystem is used. The base case scenario will meet the homes' loads through the use of an idealized plant system, providing heat to maintain zone temperatures at $20^{\circ} \mathrm{C}$, and an auxiliary heating system installed in a standard $500 \mathrm{~L}$ DHW tank. This research aims to reduce auxiliary energy use by $50 \%$ when compared to the base case.

The area of the solar collector array, the volume of the storage tanks used, the insulation levels on the storage tanks, and the collector tilt angle were investigated in order to determine the most advantageous values for these parameters in various locations within Canada.

\subsection{Thesis Outline}

Having established a cursory background of the Canadian energy mix, and solar thermal systems in Canada, the remainder of this thesis will progress as follows:

1. Chapter 2 will provide a literature review describing the current state of solar combisystems. This will include research performed internationally as well as 
within Canada. This will be used to inform initial design considerations for the research.

2. Chapter 3 will provide details on the two simulation tools used in this research. The solution methodology and the strengths and weaknesses of the two software packages will be enumerated and explicated.

3. Chapter 4 will detail the newly developed DHW draw profiles used in this research.

4. Chapter 5 will describe the simulation methodology employed and the establishment of baseline parameters used.

5. Chapter 6 will provide the results of the simulations run.

6. Chapter 7 will conclude this work and provide recommendations for further research. 


\section{Chapter 2}

\section{Literature Review}

\section{$2.1 \quad$ Introduction}

Canadian energy usage, solar thermal systems in Canada, a basic outline of the research approach, and the objectives of this research have been elaborated in Chapter 1. At this point it is pertinent to detail the work completed by previous researchers relating to solar thermal systems in a more general sense. In addition, DHW draw profiles currently used for research will be discussed.

\subsection{Domestic Hot Water Usage}

The solar combisystems examined in this work are designed to satisfy the demands for space heating and DHW of a residential home. The first step to an appropriate design is knowing what these demands are. If you do not know the magnitude and the timing of a demand you cannot accurately design a system to satisfy that demand. In this research the space heating load is determined through the use of simulation tools, which are detailed in Chapter 3, the determination of DHW use is not as straightforward. There has been a great deal of research from the mid 1980s through recent years attempting to answer the question of when and how residents use DHW in their homes. Space heating dominates the energy use of homes in Canada. However, energy used for DHW cannot be ignored. Jordan and Vajen explored the influence of DHW load profiles on combisystem performance in Europe and found the selection of draw profile is a non-trivial matter [11]. When comparing realistic profiles with non realistic profiles they found a difference of 2 percentage points in the solar fraction for the two patterns. 
The simplest draw profiles used involve a constant draw over an hour time interval follow by stagnation. These draw profiles are used to test conventional hot water tanks with internal heaters. Similar, but not identical, profiles are also used to evaluate the performance of solar hot water systems by the Solar Rating and Certification Corporation (SRCC). However, such profiles fail to capture the variability sought after by simulationists wishing to capture the season to season, day to day, and even hour to hour, variability observed in actual practice.

Early studies attempted to determine DHW draw rates through empirical evidence. In 1985, Perlman and Mills [12] collected measurements from 58 homes in the Toronto area. This information was recorded continuously at 15 minute intervals between 1981 and 1983. Not all homes were instrumented for the full two years. However, the minimum time for which measurements were taken was one year. The majority of homes involved in this study were composed of two adults and two children who owned a clothes washer and a dishwasher. The researchers used the data they collected to develop three temporal and magnitude based categories. These were high morning users, high evening users, and low users. They found the majority of users fell into the high morning category. Many factors were found to influence the draw profile in a particular home. Some of the greatest influencing factors were the number of occupants, the age of the occupants, and whether or not both adults were working outside the home. They found an average daily draw of $236 \mathrm{~L}$ per day and an average per capita use of $62 \mathrm{~L}$ per person per day. This information was adapted by the American Society of Heating Refrigeration and Air conditioning Engineers (ASHRAE) and has since been published in the ASHRAE HVAC Applications Handbook as their recommended draw pattern for evaluation of service water heating systems as recently as 2011 [13].

The work of Perlman and Mills was later integrated into a larger review of usage patterns completed by Becker and Stogsdill [14]. Collecting data from field studies performed by other researchers between 1979 and 1988 Becker and Stogsdill created a database with over 30 million data points. This data was collected in Ontario, Oregon, Florida, and various locations across the continental United States. All studies collected data at 15 minute time intervals for periods varying between one and two years. They were able to identify a trend of decreased usage during the summer months as compared to the winter months. Across all studies daily average summer draws were $13 \%$ less than daily average winter draws. The daily average 
draw for the entire year, $237 \mathrm{~L}$ per day, falls closely in line with that established by Perlman and Mills.

Field studies, such as those used in the development of the profiles described above, can be time consuming, costly, and invasive for residents. Recent investigations have attempted to overcome these challenges by developing probabilistic distributions which can be paired with a daily average draw. By pairing a daily average draw with a probability of a draw occurring within a particular time interval, an annual profile can be generated. Jordan and Vajen completed a study for the International Energy Agency's (IEA) Solar Heating and Cooling (SHC) Task 26 in which profiles, at up to 6 minute resolution, were generated using a methodology similar to that described above [15]. However, this research had a very euro-centric approach in which probabilities were extrapolated from research performed in Germany. The United States' National Renewable Energy Lab (NREL) generated profiles using a similar methodology with probabilities they generated using a German program called DHWcalc [16].

Regardless of the methodology used to generate the profiles all researchers agree on one thing: the occupant driven nature of DHW demand leads to tremendous variability in usage. This variability is observed between households, with some homes using less than $100 \mathrm{~L}$ per day on average and some using over $400 \mathrm{~L}$ per day on average, and even within a single home, where one home may use less than $50 \mathrm{~L}$ on a particular day and over $500 \mathrm{~L}$ on another day.

While empirically based profiles, such as those developed in the mid 1980s to early 1990s have the advantage of being grounded in evidence, they are, at this point, more than 20 years out of date. Energy efficiency policies and consumer awareness regarding energy use have shifted towards more conservative energy use and it is likely that, while temporal usage may have remained roughly constant, the magnitude of draws will likely have decreased over time. This trend has in fact been observed in recent studies such as that performed by Evarts and Swan [17]. Probabilistic draw patterns are advantageous in that they are low cost and easily generated based on daily average draw. However, the accuracy of the probabilistic distributions presented is a major point of uncertainty in these studies. While validated in small studies these distributions may not accurately reflect the conditions observed in Canada as none of the information used to generate these distributions was taken in North America. For this reason a new series of draw profiles was generated for this research using 
data collected by Hydro Québec between fall 2007 and spring 2008. The information detailing this process can be found in Chapter 4 .

\subsection{Solar Thermal Collectors and Design Princi- ples}

Whether or not a solar thermal system is designed for use in a cold climate, such as Canada, certain system components will always be included. These are a solar collector, which captures solar energy, a storage system, which allows for the use of solar energy during periods when solar radiation is not available, and an auxiliary heating system, to boost the temperature of the working fluid if it is not warm enough to meet the necessary loads.

If ambient temperatures fall below freezing during the year the liquid circulated through the collector array is an antifreeze solution. When antifreeze is used as the working fluid, heat is transferred to the storage tank via a heat exchanger. If freezing is not a concern then water may be used as the working fluid. When water is used as the working fluid, it is piped directly into the storage tank.

There are a number of commercially available collector types offered within Canada that are capable of harnessing solar energy for use in residential homes. Glazed flat plate collectors are the most commonly used of the commercially available systems in Canada. Flat plate collectors employ a glass cover to allow for the transmission of solar radiation while simultaneously reducing heat losses to the environment. Below this glass cover lies a thermal absorption plate. This plate is typically coated with a high absorptivity material to enhance collection of solar radiation. Finally, the back of the absorption plate is covered with an insulating material. This insulation assists in the reduction of heat losses. Liquid is passed through tubes embedded within the absorber plate. Heat is transferred from the absorber plate to the fluid which can then be circulated to a storage tank. Outlet fluid temperatures are typically in the range of $30-80{ }^{\circ} \mathrm{C}[18]$.

A simple flat plate collector in operation is shown in Figure 2.1. Solar radiation is transmitted, reflected, or absorbed by the glass cover. The large majority, between 89-94\% for a perpendicular beam, of radiation will be transmitted through the cover. When radiation hits the glass cover at a very oblique angle, in excess of 70 degrees, to the vertical, the transmitted portion of radiation drops rapidly from $74-81$ 


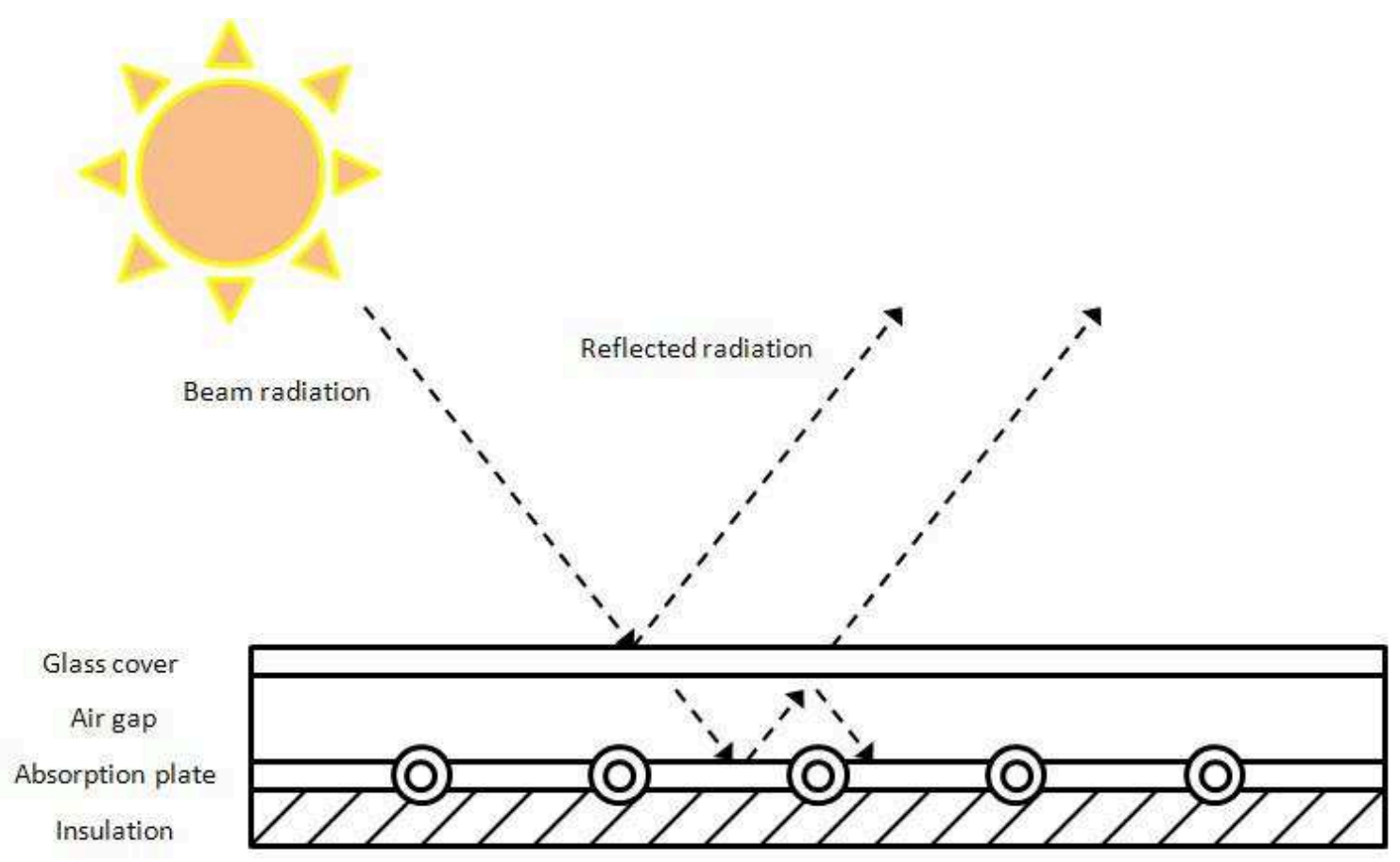

Figure 2.1: Cross section of a flat plate collector

$\%$, at an angle of 70 degrees, to $47-56 \%$, at an angle of 80 degrees [8]. In order to overcome this aspect of collector operation tracking mechanisms have sometimes been installed to optimize performance. These tracking mechanisms allow for collectors to follow incoming solar radiation and maintain the optimal angle of incidence for solar energy collection. However, these tracking mechanisms add additional capital and maintenance costs to the system.

The portion of radiation that is transmitted through the glass surface then strikes the absorber plate and is either absorbed or reflected. The heat generated by the radiation hitting the absorber surface is transmitted to the working fluid being pumped through the tubes embedded in the absorber plate. As stated previously these systems typically achieve temperatures no higher than $80^{\circ} \mathrm{C}$. This upper temperature limit is due to the balance between energy collection, via solar radiation, and energy losses, via heat losses to the ambient environment. As the temperature of the absorber plate increases so do the heat losses through the insulation backing and glass cover. If higher temperatures are required users must either increase the rate at which solar radiation is collected by the absorber plate or reduce heat losses to the ambient environment. 


\begin{tabular}{c|c} 
Collector type & Collector area $\mathrm{m}^{2}$ \\
\hline Unglazed & 71,510 \\
Glazed & 6,513 \\
Evacuated tube & 7,812
\end{tabular}

Table 2.1: Summary of domestic installations of solar thermal collectors, by collector area, in Canada in 2009 [5]

The two collectors typically used to improve performance are evacuated tube collectors and compound parabolic collectors. Evacuated tube collectors improve performance by reducing heat losses to the ambient environment. An absorber plate is placed within a clear tube. The air around the absorber plate is evacuated thus reducing convective heat losses to the ambient environment. This reduction in heat loss allows for higher collector outlet temperatures. These are typically in the range of $50-200{ }^{\circ} \mathrm{C}[18]$. While these systems do offer improved performance they typically have higher capital costs associated with their purchase and installation when compared to flat plate systems. In 2012 it was reported that the typical installation cost, per $\mathrm{m}^{2}$ of collector area, in Canada, for an evacuated tube system was 1073 CAD [5]. By comparison, flat plate systems were estimated to cost $730 \mathrm{CAD}$ per $\mathrm{m}^{2}$. Despite their higher capital cost there were more than $1,000 \mathrm{~m}^{2}$ of evacuated tube collectors installed in Canada in 2012 than flat plate collectors [5]. A comparison of sales for glazed liquid, unglazed liquid, and evacuated tube collectors can be seen in Table 2.1

The other option for improving performance is the use of compound parabolic collectors. These utilize parabolic shaped reflectors to concentrate the solar radiation on the collector tube. They improve performance by increasing the rate at which solar radiation hits the collector. These systems can operate at temperatures between 60$350{ }^{\circ} \mathrm{C}$ [18]. However, their performance is reliant on the efficacy of their reflectors. Obstructions, such as dirt or snow, severely impede the collection of solar radiation.

One of the main issues relating to the design of solar thermal systems in Canada is the mismatch between the consumption and generation of energy. Canadian winters last for months and during these times there are limited daylight hours when solar energy can be collected. Alternatively, Canadian summers, while short, have long days where solar energy can be collected for a significant portion of the day. This inconveniently leads to the peak generation of the year occurring in the months when 
demand, particularly for space heating, is at its lowest. This mismatch can be overcome by using a large seasonal thermal storage system, as simulated by Wills [19] and employed by Drake's Landing [20]. However, these systems, by design, require large storage tanks which may not always be practical. Alternatively, larger solar collector arrays may be used to generate more solar energy during winter days. Unfortunately both of these methods require more costly equipment and more space for installation.

Smaller changes can be made to the system to improve performance. While these changes will not be as effective as a seasonal storage tank they will be much less costly. During the winter months the sun is lower in the sky. By adjusting collector tilt angle the performance of the system can be improved for the winter months. Shariah et al. [21] conducted a series of simulations using the TRaNsient SYStem simulation tool (TRNSYS) to determine optimal tilt angles for thermosyphon systems for hot water preparation. They found that by adjusting collector tilt angle to latitude plus 10-20 degrees they were able to achieve optimal annual performance. Decreasing the collector tilt angle below latitude allowed for optimal solar energy collection. However, it was often the case that the energy collected was collected during the summer when enough solar energy was already collected to satisfy demand. Duffie and Beckman [8] reiterate this statement in their landmark text Solar Thermal Engineering of Thermal Processes suggesting a tilt angle of latitude $+10-20$.

Alternatively, matching the size of a solar collector array with the volume of a storage tank can result in improved system performance with limited increase in costs. Duffie and Beckman recommend sizing a storage tank to be 50-75 L in volume for every $\mathrm{m}^{2}$ of collector area when designing a system for space and hot water heating. Comakli et al. conducted an experimental and theoretical study on flat plate collectors for water heating systems and found the identical correlation was appropriate for use [22]. When conducting sensitivity studies on solar combisystems in Zurich, Switzerland many of the IEA SHC Task 26 researchers found different recommendations regarding storage volume to collector area ratios. Results ranged anywhere from 40 L per square metre to 200 L per square metre [23-29]. 


\subsection{Solar Combisystems}

Solar combisystems have been examined extensively over the past 20 years. However, much of the research has been done in Europe where climatic differences make it difficult to draw generalizations regarding the performance of such systems in Canada. The most recent Canadian based attempt at investigating the viability of combisystems was the EQuilibrium project presented by the CMHC as discussed in Section 1.2. However, this only included 12 homes and combisystem design was not necessarily their focus. Other large scale projects involving solar communities have been undertaken in Canada. However, these do not accurately reflect the small scale nature of the systems examined in this work. This section will provide an overview of residential size systems used in Europe and North America.

\subsubsection{General research on Combisystems}

A typical solar combisystem will include a solar collector, a storage tank, heat exchangers, an auxiliary heat source, and fluid pumps. A very simple system configuration can be seen in Figure 2.2. In this figure, and in future figures, valves are identified by colour as follows: a white triangle indicates an inlet and a black triangle indicates an outlet.

The largest international effort to develop a knowledge base around combisystems is likely the IEA SHC Task 26. Nineteen European countries and the United States collaborated to assess the state of the art in solar combisystems. This project was completed between the years 1998 and 2002. This culminated in the publication of the Solar Heating Systems for Houses: A Design Handbook for Solar Combisystems [30]. This involved the development of the draw profiles of Jordan and Vajen [15] described in Section 2.2 and a series of sensitivity analysis of various combisystem layouts. These sensitivity analysis were performed for three buildings in three different climates across Europe representing cold, average, and warm climates. These homes were located in Stockholm, Sweden; Zurich, Switzerland; and Carpentras, France; respectively. The 19 systems analysed in-depth were commercially available units from across Europe. Unfortunately, no North American systems were analysed.

Most studies discussed employed either a radiant floor or a radiator heating system. Radiators typically require a supply temperature between 30 and $50{ }^{\circ} \mathrm{Cabove}$ the 


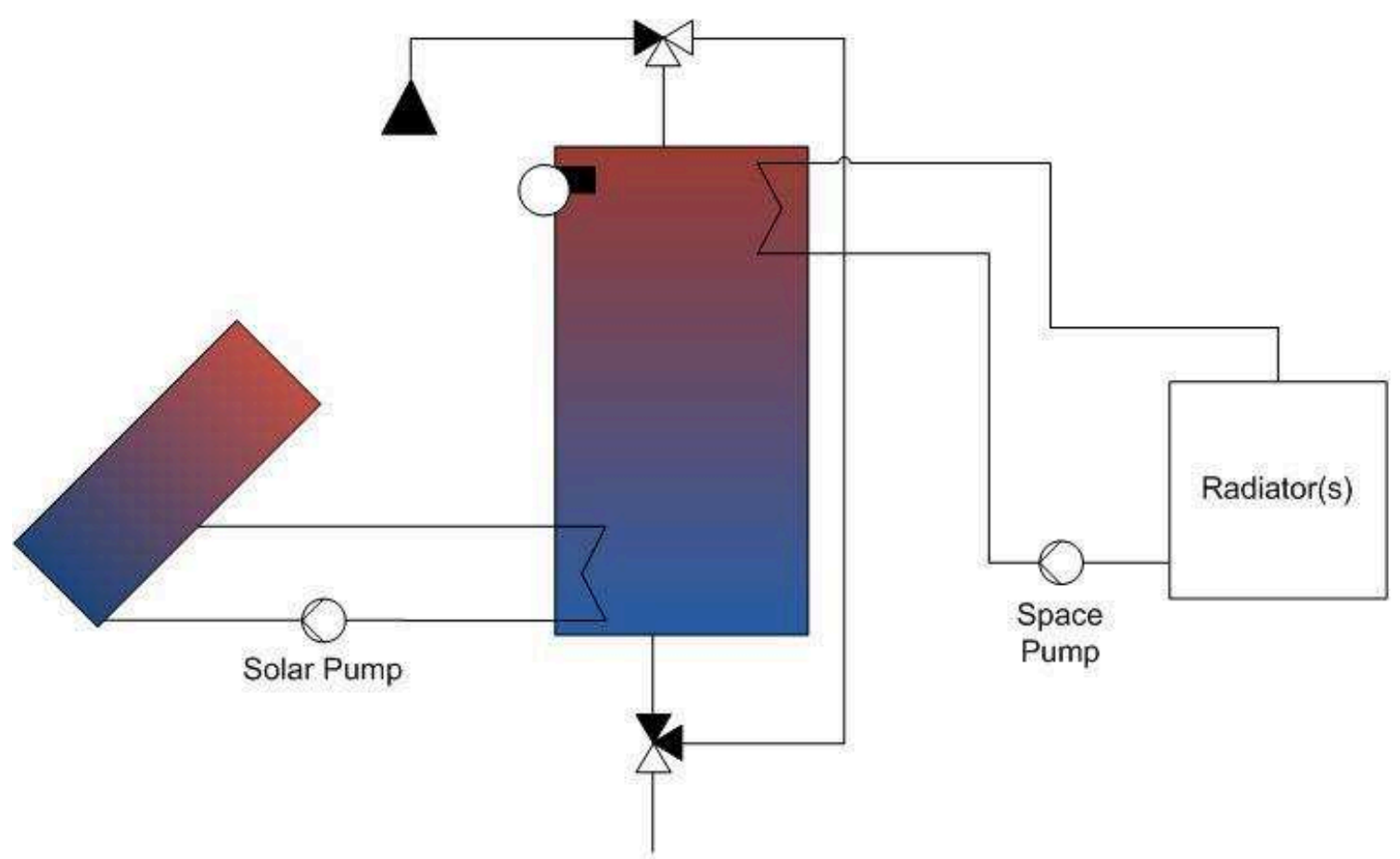

Figure 2.2: A simple solar combisystem with an internal auxiliary heater

desired room temperature. Alternatively, radiant floor heating systems only require a temperature between 5 and $7{ }^{\circ}$ Cabove the desired room temperature [31]. From this comparison of radiator supply temperatures, and the lowered required supply temperature of radiant floor systems, the casual observer may conclude that all systems which aim to supply space heating should employ radiant floor systems. However, this statement fails to account for the additional cost of installation of such a system. Leckner and Zmeureanu estimate the cost of installation of a radiant floor system, for a home in Montreal having a floor area of $210 \mathrm{~m}^{2}$, to be approximately 13,500 CAD [32]. While the radiant floor system does offer benefits in the form of a lower heat supply temperature requirement, it is costly and likely not installed in older homes. This may not be justifiable financially. Henden et al. found a limited improvement in system performance when comparing conventional radiator systems to radiant floors [31]. This improvement amounted to a 1-6\% increase in solar fraction between the two heating systems. Some researchers have questioned the assertion that radiant floor systems are required when using solar combisystems for space heating [33] . The homes modelled in this research are all constructed prior to 2000. It is likely that homes constructed in this time period are not equipped with radiant 
floor systems. For this reason radiator heating systems were the only heat delivery mechanism examined in simulations.

Lund [34] conducted an analytical study on the design of solar combisystems in order to provide others with the basics of sizing the various components within a combisystem. As a baseline he suggests between 8 and $30 \mathrm{~m}^{2}$ of collector area and a storage volume between 300 and 1500 L. By increasing the collector area substantially, over a conventional solar DHW system with between 4 and $8 \mathrm{~m}^{2}$, energy output from the collector can be increased by 20-30 \%. Due to the limited capacity of the storage tank, increasing the collector area has diminishing returns. The storage tank temperatures cannot be allowed to rise above an upper limit, commonly near $100{ }^{\circ} \mathrm{C}$. When this upper limit is reached the solar loop shuts off. Analysis on storage volumes determined that there is limited benefit in increasing the size of the storage tank to allow for energy storage of more than two days. In addition, by conducting simulations for six different locations across Europe, and for differing insulation properties, he was able to provide some general guidelines regarding the efficacy of combisystems for various climactic conditions. The central finding was that combisystems do not benefit homes which are already energy efficient or in relatively warm locations. Only low efficiency or average efficiency homes in northern climates could financially justify the integration of a combisystem.

The work of Wallin et al. [33] reiterated a similar message to that delivered by Lund. They investigated the performance of combisystems in cold climates; specifically Canada and Sweden. Using the TRNSYS simulation package they modelled four homes, all with a floor area of $126 \mathrm{~m}^{2}$, with different building constructions. The two different constructions were used to represent an older home, with a high heating load, and a new building, with a lower heating load. Two of the homes were located in Montreal while the other two were located in Stockholm. In their study they adopted the less conventional approach of using radiators for space heating as opposed to the floor heating systems adopted by others when assessing combisystem performance. Of particular interest is the result they obtained when adjusting the collector slope. While solar energy delivered to the DHW system was relatively insensitive to collector slope the solar energy delivered to the space heating was very sensitive to this parameter. The DHW draw profile is only marginally affected by seasonal variation. However, the space heating load changes drastically across the seasons. By adjusting the tilt angle the collector is oriented to optimally collect solar 
energy during the winter. For this reason they suggest setting a collector slope to an angle for higher solar energy collection during the winter months. Asaee et al. [35] built on this research by examining the viability of combisystems in four Canadian locations representing different climates. They found that a solar fraction of above 75 $\%$ was achievable in all areas when utilizing over $30 \mathrm{~m}^{2}$ of collector area. This high solar fraction can, in part, be attributed to the inclusion of a solar cooling system in addition to the combisystem used for space heating and DHW.

Most of the studies discussed thus far have focused solely on reducing the energy consumption of a particular home. As discussed by Lund [34], solar space heating systems are most viable in homes with average or above average heating loads. However, there are still researchers who look to integrate solar combisystems into high efficiency homes. Leckner and Zmeureanu [32] analysed just such a situation. They simulated a $210 \mathrm{~m}^{2}$ high efficiency home located in Montreal. The goal of the home design was to construct a net zero energy home by using solar thermal systems in conjunction with photovoltaic systems and a high efficiency building envelope. While they were able to attain the goal of a net zero energy home with a very large solar array, and a modest life cycle energy cost, they were unable to justify the installation financially. This is due to the exceedingly long payback period of 40 years for the system.

Hin and Zmeureanu [36] continued the project initially taken on by Leckner and Zmeureanu [32]. After Leckner and Zmeureanu [32] established a base case from which to begin work Hin and Zmeureanu attempted to optimize the system design through the use of hybrid particle swarm and Hooke-Jeeves optimization patterns. For details on these optimization tools the interested reader is directed to Hooke and Jeeves [37], for details on the Hooke-Jeeves algorithm, and Eberhart and Kennedy [38], for details on the hybrid particle swarm algorithm.

As was the case in the previous study the home under investigation was located in Montreal. After adjusting the number of collectors, the collector tilt, the collector flow rate per unit area, the volume of the various tanks in the system, and the auxiliary power units in the system, they were able to develop three optimized scenarios. Each of these scenarios represented a different optimization approach. The first reduced life cycle cost, the second reduced life cycle energy use, and the final reduced life cycle exergy destroyed. Substantial improvements were made to the system where life cycle cost was reduced by $19 \%$, life cycle energy use was reduced by $34 \%$ and life 
cycle exergy destroyed was reduced by $33 \%$. While these improvements did enhance system performance, no scenario allowed for a financially viable payback period. This was attributed to the high cost of solar technology and the low cost of electricity in Québec. When aiming to minimize life cycle energy use of the system a solar fraction of $74 \%$ was achieved. This amounted to a reduction in auxiliary energy use of 21.9 GJ or $70 \%$.

While the work of Lund [34] indicated that there is limited benefit to large storage volumes in combisystems not all researchers have agreed with this statement. There have been many researchers who have examined the effects of large diurnal storage systems $[30,39,40]$ and others who have examined seasonal storage systems $[19,20]$. However, their research is outside the scope of this work as they are focused on the seasonal storage aspects of combisystems.

\subsection{Conclusions}

The research on combisystems and the draw profiles necessary to accurately design them has been undergoing development over the last twenty years. The literature has helped to inform decisions regarding the selection of components involved in the simulations to be run for this research. By applying this information, to initial simulations run to determine viability, a baseline can be established for this work to springboard to a fully realized design for a combisystem for Canada. 


\section{Chapter 3}

\section{Simulation tools}

\subsection{Introduction}

This research employs two independent simulation tools and a coupling program which exchanges information between the two. The simulation tools used are Environmental Systems Performance Research software (ESP-r) and TRNSYS. The program which exchanges information between ESP-r and TRNSYS is referred to as the co-simulator. This co-simulation process allows for the use of ESP-r's strong building physics systems and the easily adaptable plant network of TRNSYS. Prior to discussing the two software tools the primary concerns, relating to the selection of simulation software, will be elaborated.

\subsubsection{Primary Concerns}

This section will describe the primary concerns regarding the selection of simulation tools. The treatment of building physics as it relates to the space heating load is of the utmost importance for this research. In a typical Canadian home the majority of energy will be used to heat the home. Typically, space heating will be three times the DHW energy demand [1]. In order to determine if a solar combisystem arrangement is capable of satisfying the space heating needs for a home it is necessary to first accurately determine the energy required for space heating. In order to provide an accurate estimate of space heating demand an energy balance must be performed on the building. Terms which must be considered when performing an energy balance include heat transfer across the building envelope, casual gains from occupants and appliances, solar gains through transparent surfaces, and infiltration to name a few. 
ESP-r is capable of assessing these energy flows in an accurate and stable manner. The methods it uses to do this will be explained in Section 3.2

An equally important aspect of this work is the modeling of the solar thermal plant components. Just as with the modeling of the building physics if the plant network is not accurately modelled the efficacy of a solar combisystem cannot be established. Due to the nature of this research, individual plant components are likely to be adjusted as simulations are run and performance is improved. For this reason it is necessary to select an accurate and adaptable simulation tool for the plant networks being modelled. TRNSYS offers a simulation tool capable of quickly creating and adjusting a plant network where necessary. The solution methodology it uses, and validation relating to this methodology, are discussed in Section 3.4. In particular, all systems studied here will include solar collectors, storage tanks, fluid pumps, and heat exchangers. TRNSYS offers capabilities for simulating all of these components. In particular, the storage tank and solar collectors are of particular interest for this research.

The final aspect of this research to be considered when selecting simulation tools is the availability of homes representative of the Canadian housing stock. As this research aims to present improved designs of solar combisystems for use in Canada, it was deemed important to have accurate house models which would represent the homes where these systems would be installed. The Canadian Hybrid Residential End-use Energy Model (CHREM) provides users with a sampling of homes from across Canada. The CHREM database was developed as part of the $\mathrm{PhD}$ dissertation of Lukas Swan [41]. An overview of the model can be found in Swan et al. [42]. The homes are prepared to be simulated using ESP-r with fully defined building envelopes and plant systems. Due to the availability of the CHREM models and their compatibility with ESP-r several homes were selected as representative homes for this research. These homes were selected based on size, vintage, and location. The CHREM database allows for more detailed selection, based on parameters such as window area and DHW heating type, however, these aspects of the building were determined extraneous to this research. Details on how the database was developed can be found in Section 3.3

Less concern is placed on aspects of the built environment such as electrical loads, lighting loads, and contaminant control. The systems modelled here are solely concerned with heat and do not provide electricity in any manner. For this reason the 
above mentioned aspects of the built environment were deemed extraneous to this research.

\subsubsection{Outline}

This chapter will first describe and discuss the two software packages the following aspects of the simulation tools used:

1. The ESP-r simulation environment

2. The CHREM database

3. The TRNSYS simulation environment

4. The co-simulator

\section{$3.2 \quad$ ESP-r}

The Environmental Systems Performance Research software package (ESP-r) is a powerful simulation suite capable of informing modellers on a number of issues relating to building design. Initially ESP-r was developed as part of Joe Clarke's PhD thesis in the late 1970s [43]. However, since then it has been under near continuous development. Some of the packages incorporated over the years allow for the simulation of lighting, acoustics, and Computational Fluid Dynamics (CFD) [44]. In addition to an ever expanding library of capabilities ESP-r has simultaneously been undergoing validation. Inter-program comparison, analytical verification, and empirical validation have all been used to ensure the results of simulations approximate reality to a high degree. Strachan et al. [45] detail over 30 individual studies conducted between 1977 and 2006 which attempted to validate aspects of the program.

ESP-r employs a partitioned solution methodology where separate domains, such as the thermal and the electrical domains, are individually solved. This segregation allows for each solver to be optimized to process the specific equations related to that domain. While each solver analyses a domain independently there is still a strong coupling between them. Information is exchanged at each time-step and used to check for convergence. For example airflow into the building, as caused by infiltration, is 
solved by the mass flow network solver. This mass flow of air into the zone from outside is passed to the thermal domain solver. Subsequently the heat transfer between the infiltrated air and the zone air is solved by the thermal domain solver.

The following sections provide details on the aspects of ESP-r most relevant to this research. These are:

1. The thermal domain

2. The plant domain

This research will not address in detail the air flow or electrical domains. For information on these aspects of ESP-r, Clarke provides further details [46] . While plant systems will be modelled in this research, the program TRNSYS will be used for this function. The section presented herein will provide a brief description of the strengths and shortcomings of the plant domain in ESP-r.

\subsubsection{The Thermal Domain}

The thermal domain of ESP-r handles the flow of thermal energy within the building being modelled. This includes, but is not limited to, conduction through construction materials, long wave radiation exchange between internal surfaces, and convection between internal surfaces and air nodes within zones. Analysis of the various energy flows is accomplished through the use of the finite-difference method. This varies from other Building Physics Simulations (BPS) packages, such as TRNSYS, which use a successive substitution method.

Beausoleil-Morrison identifies three key steps to the development of a finite difference solution for thermal analysis [47]. These are:

\section{Discretization}

2. Application of governing equations

3. Simultaneous solution

This chapter will provide a simplified explanation of these steps. For a more detailed description of the procedures involved in finite difference analysis the interested reader is directed to Beausoleil Morrison [47] and Clarke [46]. 


\subsubsection{Discretization}

Spatial discretization of the building to be modelled is the first step involved in ESPr's thermal analysis. Air within zones and solid construction materials are discretized into a series of nodes. These nodes are used to represent Control Volumes (CVs) within the system for which energy balances will be performed. The number of nodes utilized in an analysis may be customized to the level of detail required by the user.

In a typical analysis, a single set of thermal conditions are imposed on a building storey. However, if a more rigorous analysis is desired by the user, they may create several zones on a single floor. This is beneficial when dealing with systems which employ more complex heating and cooling devices. An example of such an arrangement would be a radiant floor heating and cooling system. The complexity involved in such analysis can increase the required computational time substantially. Additionally, if several rooms on a storey experience drastically different conditions, a separate zone is often created. An example of this would be an unheated garage on the first floor. The garage would experience thermal conditions far different from a conditioned space on the same storey.

Construction materials surrounding the air node are discretized into several nodes. Since ESP-r, by default, treats the heat transfer as a 1-D problem these nodes are placed within the construction material. Heat transfer is assumed to run perpendicular to the surface of the construction material. Default settings in ESP-r create three nodes per material. One of these nodes is placed at the center of the material while the remaining two are placed on either boundary. While all three modes of heat transfer may be present in a particular construction, it is typical to only address conduction heat transfer in building walls. However, if an air gap is placed in the construction all three modes of heat transfer will be considered.

\subsubsection{Application of Governing Equations}

The simplest CVs to analyse are those represented by internal nodes of opaque materials. While many forms of heat transfer may be present in these materials the problem is often treated as solely a conduction problem. Convection and radiation exchange are addressed by using an effective thermal conductivity. The energy balance is further simplified by assuming constant thermophysical properties. Finally, as mentioned above the analysis is restricted to one dimension. Air nodes, nodes which

contain transparent materials, and surface nodes, require more detailed analysis. The 
energy balance for any node in the system can be expressed as follows:

$$
\left(\begin{array}{c}
\text { Heat energy } \\
\text { stored in } C V
\end{array}\right)=\left(\begin{array}{c}
\text { Net heat } \\
\text { conducted into } C V
\end{array}\right)+\left(\begin{array}{c}
\text { Heat generation } \\
\text { within } C V
\end{array}\right)
$$

Using a finite volume approach the fully explicit, numerical solution to this can be stated as:

$\left(\rho c_{p} \Delta x \Delta y \Delta z\right) \frac{T_{I}^{t+\Delta t}-T_{I}^{t}}{\Delta t}=\frac{k_{I-1} \Delta y \Delta z}{\Delta x_{I-1}} \frac{T_{I-1}^{t}-T_{I}^{t}}{\Delta x_{I-1}}-\frac{k_{I+1} \Delta y \Delta z}{\Delta x_{I+1}} \frac{T_{I}^{t}-T_{I+1}^{t}}{\Delta x_{I+1}}+q_{p l a n t}^{t}$

If the temperatures used are instead the unknown temperatures of the time step currently being solved an implicit solution is created:

$$
\begin{aligned}
& \left(\rho c_{p} \Delta x \Delta y \Delta z\right) \frac{T_{I}^{t+\Delta t}-T_{I}^{t}}{\Delta t}= \\
& \frac{k_{I-1} \Delta y \Delta z}{\Delta x_{I-1}} \frac{T_{I-1}^{t+\Delta}-T_{I}^{t+\Delta} t}{\Delta x_{I-1}}-\frac{k_{I+1} \Delta y \Delta z}{\Delta x_{I+1}} \frac{T_{I}^{t+\Delta t}-T_{I+1}^{t+\Delta} t}{\Delta x_{I+1}}+q_{\text {plant }}^{t+\Delta t}
\end{aligned}
$$

The explicit solution is generally less computationally intense to solve than an implicit solution. However, stability becomes an issue when $\Delta \mathrm{x}$ and/or $\Delta \mathrm{t}$ become small. Should a mesh be too finely discretized, round off and truncation errors will be amplified and solutions will not be found. Alternatively, implicit solutions, while in theory unconditionally stable, are computationally intense. By default, ESP-r uses an equally weighted approach of both the explicit and implicit versions of the solution. This is conventionally known as the Crank-Nicolson approach. This method is unconditionally stable and less computationally intense than the purely implicit version. The Crank-Nicholson formulation of the heat balance is given as: 


$$
\begin{aligned}
& {\left[\frac{2\left(\rho c_{p}\right)_{I}}{\Delta t}+\frac{k_{I-1}}{\Delta x \Delta x_{I-1}}+\frac{k_{I+1}}{\Delta x \Delta x_{I+1}}\right] T_{I}^{t+\Delta t}-\left[\frac{k_{I-1}}{\Delta x \Delta x_{I-1}}\right] T_{I-1}^{t+\Delta t}-\left[\frac{k_{I+1}}{\Delta x \Delta x_{I+1}}\right] T_{I+1}^{t+\Delta t}} \\
& -\frac{q_{\text {plant }}^{t+\Delta t}}{\Delta x \Delta y \Delta z}=\left[\frac{2\left(\rho c_{p}\right)_{I}}{\Delta t}-\frac{k_{I-1}}{\Delta x \Delta x_{I-1}}-\frac{k_{I+1}}{\Delta x \Delta x_{I+1}}\right] T_{I}^{t}+\left[\frac{k_{I-1}}{\Delta x \Delta x_{I-1}}\right] T_{I-1}^{t} \\
& +\left[\frac{k_{I+1}}{\Delta x \Delta x_{I+1}}\right] T_{I+1}^{t}+\frac{q_{\text {plant }}^{t}}{\Delta x \Delta y \Delta z}
\end{aligned}
$$

When addressing surface nodes convection and radiation terms must also be considered. Long wave radiation between surfaces must be addressed. Radiation coefficients are calculated on a time step basis using a grey-body exchange approach. Convection between the surface and any air nodes it is exposed to is also addressed. A well-mixed air condition is assumed. The convection coefficient associated with each surface is individually calculated based on buoyancy driven flow. External surface heat transfer is addressed in a similar manner. However, short-wave radiation and convection based on wind conditions, based on the climate file used, are also considered. ESP-r includes a facility for including obstructions if a more detailed consideration of external radiation and convection is desired. For a more detailed, mathematical description of the heat transfer calculations used within ESP-r the interested reader is directed to Clarke [46].

Heat transfer for an air node within a zone is analysed in a similar manner using buoyancy driven convection coefficients between the air node and each surface in the zone. Casual gains and plant components which act as heat generators inject heat directly into the air node. These heat injections can be considered as a mix of convection and radiation if so desired. Detailed analysis of heat transfer can be accomplished through the use of the air flow network.

\subsubsection{Simultaneous Solution}

For the simple inter construction node heat balance presented, no further manipulation is necessary for a solution. The linearized equations can be placed into a set of matrices of the form:

$$
A \theta^{t+\Delta t}=B \theta^{t}+C=Z
$$


Nodal temperatures and flux components are held in the $\theta$ term while coefficients for future and present time steps are held in the A and B terms, respectively. Boundary conditions are held in the $\mathrm{C}$ term. Since $\theta^{t}$ and $\mathrm{C}$ are known they can be collected into a single term $\mathrm{Z}$. The future nodal temperatures and flux components can be solved for by multiplying both sides of the equation by the inverse matrix of A and employing a Gaussian elimination approach.

\subsubsection{The Plant Domain}

As mentioned previously in Section 3.2.1.3 ESP-r employs a partitioned solution technique with specialized solvers for each domain. When creating an explicit plant network in ESP-r the basic technique, of finite-difference control volumes, is essentially the same. The plant components are subdivided into discrete control volumes and heat balance equations are created for each node. Just as in the thermal domain a Crank-Nicolson approach is used to allow for stability and efficient simulations.

The shortcomings of the ESP-r plant domain have been detailed in BeausoleilMorrison et al. [48].

\subsection{CHREM models}

The CHREM consists of 17,000 house models representative of the Canadian housing stock of single detached and double row homes. These models were derived from a larger sample of 200,000 homes from across Canada available in the Canadian Single-Detached and Double Row Housing Database (CSDDRD). This database was established based on energy audits of homes between 1997 and 2006 completed by NRCan. These audits presented a high level of detail including building geometry, location, construction materials, and heating systems. The CHREM narrowed the number of homes in this database by selecting homes based on region, vintage, stories, heated floor area, and heating system. Homes were selected in such a way as to include a cross-section representative of homes in the Canadian housing stock.

The homes selected for this research were chosen primarily based on vintages and floor areas. Three of the homes selected represent typical midsize homes of the 1950s, 1970s, and 1990s. A single large home of the 1990s was also selected to examine the viability of solar combisystems for larger floor areas. In order to ascertain what 
the floor area of a midsize home was the Canadian Energy User's Handbook was consulted [1].

Appliance, lighting, and DHW loads used in the CHREM model were created using statistical inputs and a neural network technique. Casual gains from appliances and lighting were taken from the CHREM.

\subsection{TRNSYS}

TRNSYS, the TRaNsient SYStem simulation program, is a commercial software tool originally developed in 1975. Its purpose at the time was to simulate the transient performance of solar thermal systems. It completes this through the use of an executive program and a series of subroutines. Each subroutine is representative of a particular component in the plant network simulated. Types can be used to represent controls, plant components, and weather files, among other aspects of the simulation. Each type is, in turn, attached to a particular proforma containing the details of inputs, parameters, and outputs of that type.

The simulation studio, a graphical user interface, is used to develop a representation of the physical system being modelled. In the simulation studio, connections are created between different types and the outputs of one type are connected to the inputs of another type. Parameters, which do not change during simulation, are attributed in the proforma. The customization of TRNSYS types allows for the representation of a wide variety of physical systems.

The executive program controls the information exchange between the various subroutines employed by the component types. During simulation the executive program will call information from the various subroutines and offer the outputs from one type to the inputs of another. This process will be repeated until the executive is satisfied that convergence has been achieved to within user specified error limits. The order in which subroutines are called is optimized by the executive in order to avoid convergence issues. However, convergence issues can still arise in spite of the executives efforts.

The two TRNSYS plant components described in detail within this section are the solar collector and storage tank models. The remainder of this section will detail the equations and methodology used to solve for the outputs of these two components. 


\subsubsection{Storage Tank Models}

There are a variety of TRNSYS storage tank models to choose from. However, there are consistencies between all the available models. All tank models are analysed as 1 dimensional, vertically stratified tanks. This stratification of the tank can be seen in Figure 3.1. Each node represents a single temperature. The number of tank nodes can be controlled by the user as an input. The number of nodes used to assess the tank's performance has a significant effect on the level of stratification as well as the computational time required. A tank composed of a single node, no matter the total volume of the tank, would be represented as a single temperature. This would unrealistically simplify the tank model. A tank with 50 nodes would represent tank stratification very well. However, increasing the number of tank nodes to an arbitrarily high value would slow computation time. A balance is required in order to accurately describe the conditions experienced by the tank yet produce results within a reasonable amount of time.

There are a number of TRNSYS types which can be used to model storage tanks. The standard library offers a detailed 1-D stratified storage tank model, Type 60, a simplified 1-D stratified storage tank, Type 4, and a plug flow model, Type 38. Type 60 and Type 4 offer similar models. The difference lies in the reduced complexity of Type 4.

Allard et al. [49] conducted an inter-model comparison of various tank models used in TRNSYS. They studied not only the tank models available in the standard TRNSYS libraries, but also a model available in the Thermal Energy Systems Specialists (TESS) libraries. Experimental data was collected for a simple tank configuration and this was, in turn, compared to results from a series of TRNSYS simulations using four different tank models. The tank models studied were Type 4, Type 38, Type 60, Type 534, and a non-standard component available from Transsolar. Type 534 is a tank model available from the TESS libraries and, similarly to Type 60 and Type 4, is a 1-D stratified tank model. Just like Type 4 and Type 60, each node is assumed to be isothermal and increasing the number of nodes, while improving accuracy, will also increase computation time. Allard et al. [49] determined that, while no one model can accurately determine tank stratification with absolute accuracy, Type 534 is the best option currently offered. The major shortcoming of the current models is the inability to represent the vertical temperature profile during mixing. Based on the 


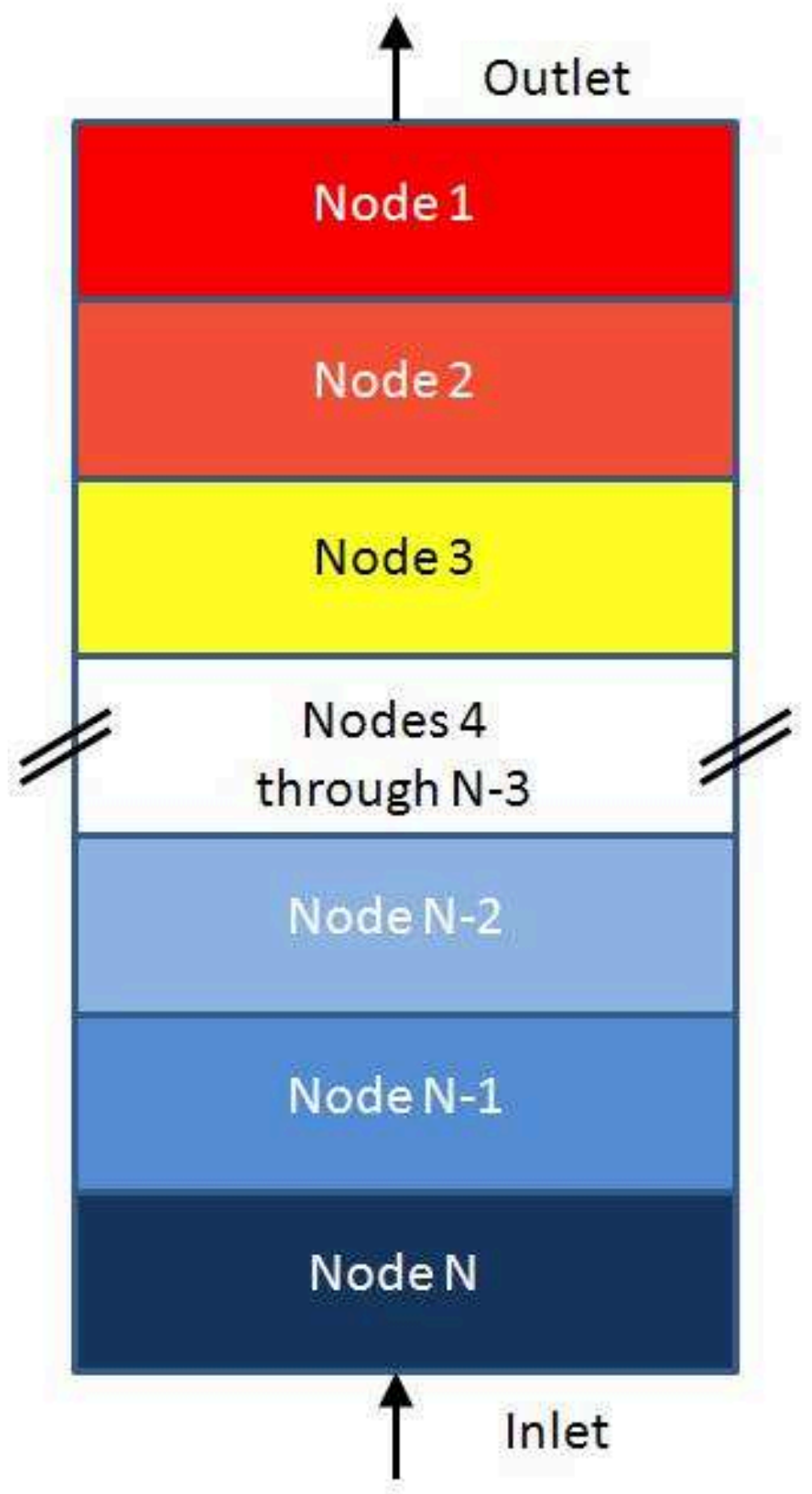

Figure 3.1: Discretization of storage tank in TRNSYS 
results they presented Type 534 was selected as the tank model used in this research.

Type 534 solves for the following heat transfer paths that allow for heat transfer between internal nodes, the ambient environment, and any heat exchangers which may be used:

1. Thermal losses to the ambient environment

2. Thermal losses to the environment through a gas flue passing through the tank

3. Heat exchange with flowing and stagnant fluid in the heat exchanger

4. Conduction between tank nodes

5. Mixing between tank nodes to eliminate thermal instabilities

6. Mixing between tank nodes due to flow through the tank

7. Auxiliary heat input

8. Miscellaneous heat flows

A simple schematic detailing three nodes within a tank is given in Figure 3.2. Losses through the sides of the tank are the $Q_{1 S}, Q_{2 S}$, and $Q_{3 S}$ terms. This heat transfer is based on the internal convection coefficient, between the fluid inside the tank and the inner wall of the tank; conduction across the tank wall, and the external convection coefficient, between the air surrounding the tank and the outer tank wall. Mixing due to thermal instabilities, defined as $Q_{m i x, i}$ and fluid flow through the tank is handled using Equation 3.6. In this equation the $\dot{m}_{\mathrm{i}}$ term refers to the rate of mixing between node $\mathrm{i}$ and the node below it. Similarly, the term $C p_{i}$ represent the average specific heat of fluid of node $i$ and the node below it. The $i$ - 1 terms represent the mixing rate and specific heats of node $i$ and the node above it. In addition to the flow paths illustrated in Figure 3.2, heat may be transferred between nodes through conduction. Besides the conduction between the fluid nodes in the tank this also takes into consideration the conduction effects along the wall of the tank.

$$
\begin{aligned}
Q_{m i x, i}= & \dot{m}_{i} \times C p_{i} \times\left(T_{i}-T_{i+1}\right)+ \\
& \dot{m}_{i-1} \times C p_{i-1} \times\left(T_{i}-T_{i-1}\right)
\end{aligned}
$$




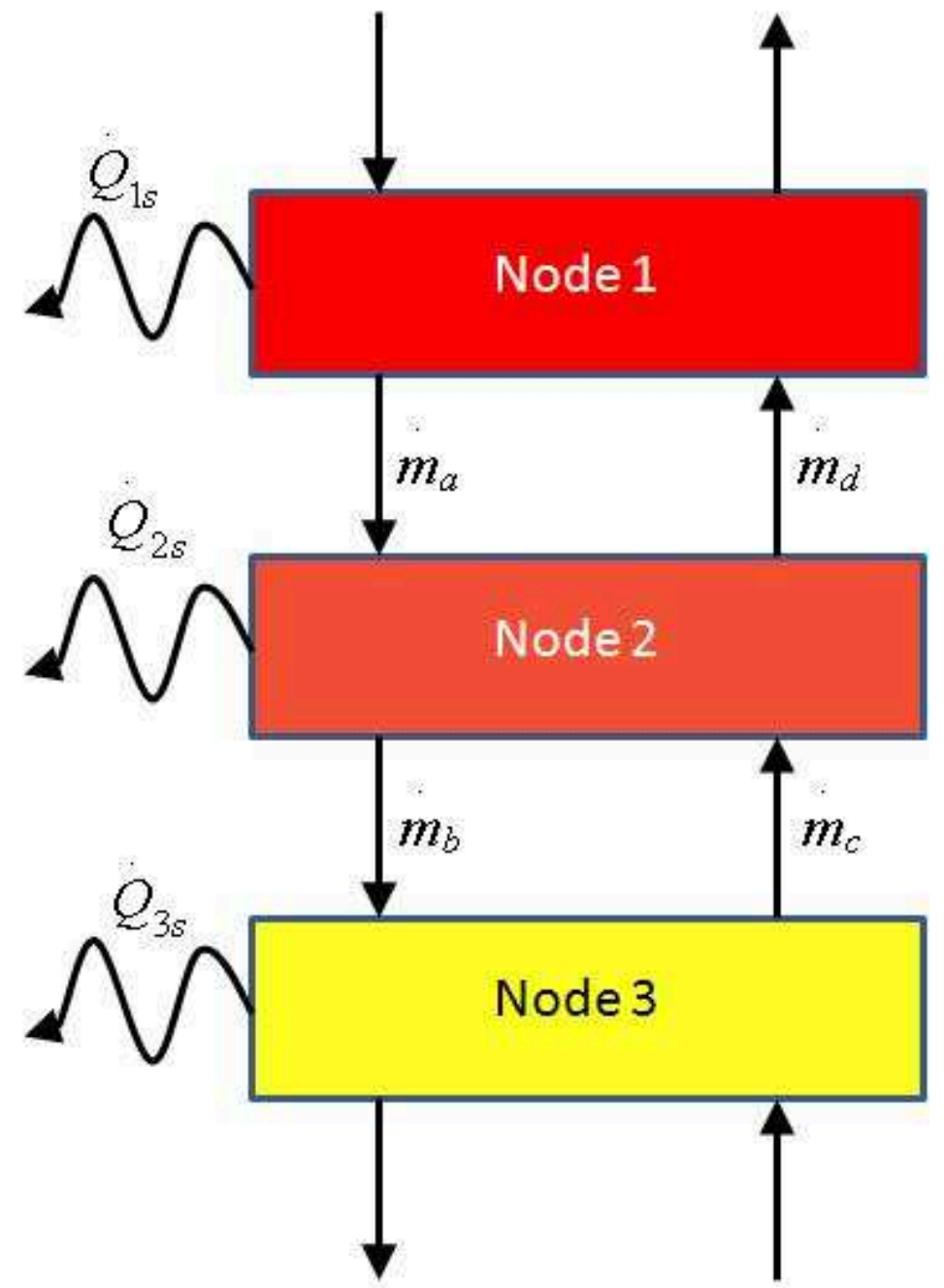

Figure 3.2: Simplified schematic of a three tank nodes 
When assessing mixing due to thermal instability in this model TRNSYS uses a simplifying assumption. If, at the end of the time step, any adjacent nodes are in a thermally unstable position, they are instantaneously perfectly mixed based on the average temperature of the two nodes. This situation commonly arises in solar thermal systems. If solar energy is injected in the lower portion of the tank an inverted temperature profile can be created where the warmest fluid is at the base of the tank. TRNSYS solves this issue by instantaneously mixing the nodes in the tank to produce a thermally stable system. Losses and bulk flow energy transfer are calculated prior to this mixing. Therefore, this can lead to errors in the tank energy balance. The effects of such errors have been determined to be minimal [50].

The systems described in this research do use heat exchangers and, upon first glance it would seem prudent to provide background on their solution methodology. However, the internal heat exchanger models offered by Type 534 were not used. These internal heat exchanger models used esoteric inputs which were not widely available in the literature. As an alternative, external heat exchangers were used for the systems described in this research.

Allard et al. [49] performed simulations to determine the significance of instantaneous mixing versus a gradual mixing. They found that only during the time step when cold water is added to the tank are there any discrepancies between an instantaneous mixing and gradual mixing process. With relatively small time steps they assert that there is no noticeable effect on overall system performance.

Auxiliary and miscellaneous heat inputs are provided by the user as inputs and are simply added into TRNSYS' final calculation as seen in Equation 3.7. A simplified representation of this equation is given in Equation 3.8. Here the term $\mathrm{C}_{\text {tank,i }}$ represents the capacitance of the fluid in the tanks' .

$$
\begin{gathered}
\frac{d T_{\text {tank }, i}}{d t}=\frac{Q_{\text {losses }}-Q_{h x, i \rightarrow k}-Q_{a u x}-Q_{\text {conduction }, i}-Q_{\text {mix }, i}-Q_{\text {flow }, i, j}-Q_{\text {misc }}-Q_{\text {flow }, i, j}}{C_{\text {tank }, i}} \\
\frac{d T_{\text {tank }, i}}{d t}=\frac{\left(Q_{\text {in }, \text { tank }, i}-Q_{\text {out }, \text { tank }, i}\right)}{C_{\text {tank }, i}}
\end{gathered}
$$

Equation 3.7 can then be placed into the form:

$$
\frac{d T}{d t}=a T+b
$$


In this equation $a$ refers to a constant and $b$ is a function of the temperatures of other nodes within the tank and heat exchanger. TRNSYS assumes that the value of $b$ is constant over the time step. The constant value it attributes to $b$ is based on the average value of $b$ over the time step. While this may lead to some inaccuracies in calculation the effects are said to be limited when using small time steps less than an hour [50]. Equation 3.9 can then be solved to produce the following result:

$$
T_{\text {final }}=\left(T_{\text {initial }}+b_{\text {ave }}\right) \times e^{a \Delta t}-\frac{b_{\text {ave }}}{a}
$$

Since $b$ is a function of temperature, the average value of $b$ can be said to be a function of the average temperature. Solving for the average temperature yields:

$$
T_{\text {ave }}=\frac{1}{a \Delta t} \times\left(T_{\text {initial }}+\frac{b_{\text {ave }}}{a}\right) \times\left(e^{a \Delta t}-1\right)-\frac{b_{\text {ave }}}{a}
$$

$T_{\text {final }}$ and $T_{\text {ave }}$ can then be solved for iteratively as described earlier.

\subsubsection{Solar Collector Models}

TRNSYS offers a variety of solar collector models. In the basic TRNSYS package there are six solar collector types offered. These types offer users the option to model flat plate, evacuated tube, and concentrating parabolic collectors. Additionally, more specific models, varying the number of covers or the equations used for solving, are available in the TESS packages. While concentrating collectors and evacuated tube systems generally produce a higher temperature fluid they are considerably more expensive than flat plate collector systems.

Type 539 was selected to model solar collectors in this research. This takes into consideration the effects of the collector's mass on thermal performance. This ther-

mal capacitance will have an effect on collector performance. The collector itself is discretized into a series of nodes in order to reflect conditions across the collector. This process is very similar to that described for the storage tank model described in Section 3.4.1. This approach creates a more realistic temperature distribution across a collector and accounts for time-lag effects on performance.

Heat transfer between the collector fluid and the ambient environment can be expressed as follows:

$$
C \frac{d T}{d t}=F^{\prime}\left(S-U_{L} \times\left(T-T_{a}\right)\right)-\dot{m} C_{p}\left(T-T_{i n}\right)
$$


For flat plate collectors which employ tubes embedded in an absorber plate, such as those described in Figure 2.1, the efficiency of heat transfer between the absorber plate and the fluid in the tubes must be characterized. This is done in the above equation through the use of the fin efficiency factor $F$ '. This describes the ratio of actual energy absorbed by the fluid to the energy that could be absorbed if the collector plate had been at the fluid temperature. $S$ represents the solar energy input to the system.

TRNSYS breaks this differential equation into the following form to solve:

$$
\frac{d T_{i}}{d t}=a T_{i}^{2}+b T_{i}+c
$$

In the above equation the $a$ and $b$ terms are constant over the time step and $c$ is a time dependent variable. The terms $a$ and $b$ are characterized based on the user inputs described below. Once a user has inputted the information necessary to characterize collector performance TRNSYS iteratively solves this equation as described earlier.

In order to solve for this equation TRNSYS requires a series of user inputs which are based on manufacturer data. The information required is based on the collector's efficiency, the incidence angle modifier (IAM), tested collector flow rate, and tested fluid specific heat.

The collector efficiency TRNSYS uses is based on the work of Duffie and Beckman [8]. This can be expressed as:

$$
\eta=F_{R}(\tau \alpha)_{n}-F_{R} U_{L} \frac{\left(T_{i}-T_{a}\right)}{I_{T}}-F_{R} U_{L} \frac{\left(T_{i}-T_{a}\right)\left|T_{i}-T_{a}\right|}{I_{T}}
$$

The collector heat removal factor $\left(F_{\mathrm{R}}\right)$, transmittance-absorptance product $(\tau \alpha)_{n}$, and the overall loss coefficient $\left(U A_{\mathrm{L}}\right)$ are constant. These terms can be collected to produce an equation of the form:

$$
\eta=a_{0}-a_{1} \frac{\left(T_{i}-T_{a}\right)}{I_{T}}-a_{2} \frac{\left(T_{i}-T_{a}\right)\left|T_{i}-T_{a}\right|}{I_{T}}
$$

Manufacturers provide the coefficients $a_{0}, a_{1}$, and $a_{2}$ in order to characterize performance. TRNSYS takes this information as parameters for use with Type 539 and uses this in the calculation of collector outlet temperature when beam radiation is at normal incidence.

However, unless tracking mechanisms are used, beam radiation occurring at normal incidence is very rare. In order to compensate for times when beam radiation hits 
the absorber plate at non-normal incidence the IAM is used. This is characterized as follows:

$$
I A M=1-b_{0}\left(\frac{1}{\cos \theta}-1\right)-b_{1}\left(\frac{1}{\cos \theta}-1\right)^{2}
$$

The terms $b_{0}$ and $b_{1}$ can be established based on performance data provided by manufacturers. The establishment of the IAM for the collectors used in this research can be found in Section 5.2.1.

Using the IAM and efficiency curves provided by manufacturers, along with the tested flow rates and tested fluid specific heat, the collectors used can be fully characterized by TRNSYS. With this information, the TRNSYS executive can use the user provided information to determine the required outputs, such as collector outlet temperature, that other TRNSYS types use.

\subsection{Co-Simulation}

The co-simulator tool allows for co-simulation of ESP-r and TRNSYS using the strengths of each software package. Both simulation tools are run in parallel and exchange information at each time step. The co-simulator has access to both the ESP-r and TRNSYS Dynamic-Link Library (DLL) libraries and uses these to share information between the two packages. Boundary conditions are passed back and forth between the two packages until convergence is achieved. However, there is no direct interaction between the two programs. All information is passed to the cosimulator which, in turn, passes this information back to the required program. Once convergence is achieved by both programs, the co-simulator moves the simulation forward to the next time step.

The co-simulator passes fluid streams, casual gains, and zone conditions between ESP-r and TRNSYS. Zone temperatures, from ESP-r, can be used to control components within TRNSYS. Heat losses, from plant components within TRNSYS, can pass these heat losses to ESP-r zones.

The development and verification of the co-simulator is documented by BeausoleilMorrison et al. [48]. The functionality of the co-simulator, as it applies to solar thermal systems, has been demonstrated by Wills [19] and Beausoleil-Morrison et al. [48]. 


\section{Chapter 4}

\section{Development of Hot Water Draw Profiles}

\subsection{Measured Hot Water Draws}

This chapter describes the measurement methods employed in the development of the DHW draw profiles used in this thesis. It provides details on the instrumentation used, the physical placement of this instrumentation, and the sources of uncertainty in the measurements. It then presents the measured data and contrasts them to previous hot water consumption data.

\subsubsection{Measurement Methods}

The raw data utilized in this research was collected by Hydro Québec. They installed instrumentation on the hot water heaters of 73 homes in Southern Québec. The owners of all but five of these homes provided information on occupancy levels; this information is summarized in Table 4.1. The hot water consumption patterns were measured continuously for 60 to 165 days in each house during the autumn, winter, and early spring seasons between early November 2006 and mid-April 2007.

All 73 houses were supplied with hot water from tanks with immersed electricresistance heaters. Positive displacement flow meters of the oscillating piston type were installed on the cold-water make-up lines upstream of each water heater. Since the volume of hot water supplied by a tank is replaced by cold make-up water, in this way these meters measured the volume of hot water supplied to each house.

The flow meters produced a pulse signal each time $1 \mathrm{~L}$ of water had been consumed. Every five minutes the pulse signals produced by the meter were counted and recorded

by a data acquisition system (DAQ). With this configuration it was possible to resolve 
Table 4.1: Occupancy levels of houses measured in study

\begin{tabular}{c|c} 
Number of occupants & Number of homes \\
\hline 1 & 2 \\
2 & 23 \\
3 & 13 \\
4 & 21 \\
5 & 9
\end{tabular}

water consumptions between $2.5 \mathrm{~L}$ and $370 \mathrm{~L}$ over a 5-minute logging interval.

There was measurement uncertainty associated with both the flow meter and the DAQ. In the case of the former, the bias error in resolving flows was greatest (in relative terms) at the lower end of the measurement range. The DAQ's bias error was \pm 1 pulse per 5-minute logging interval. When these individual bias errors are propagated using the methods suggested by [51], it is found that the hot water consumption could be resolved to \pm 1 L over the 5-minute logging interval at the lowest consumption levels (zero consumption, which was recorded for $90 \%$ of the more than 3 million measurement points). And the combined uncertainty at the highest consumption level observed in the study (125 L for a 5-minute logging interval) was found to be \pm 2 L over the 5-minute logging interval.

\subsubsection{Analysis of Measured Data}

The daily averaged hot water consumption of each of the 73 houses was first calculated. This revealed a wide range of consumption levels: from 70 to $438 \mathrm{~L} /$ day. The distribution of the consumption levels is illustrated in Figure 4.1, while the mean, median, standard deviation, and the $20^{\text {th }}$ and $80^{\text {th }}$ percentiles of the consumption level of the 73 houses is summarized in Table 4.2 .

It is interesting to compare the mean of the daily averaged hot water consumption of $189 \mathrm{~L} /$ day of this sample of 73 houses to some of the earlier published data. Burch and Salasovich [52] report data gathered in 12 houses in the USA. The average daily hot water draw from this sampling of 12 houses was 280 L/day. In their study which 


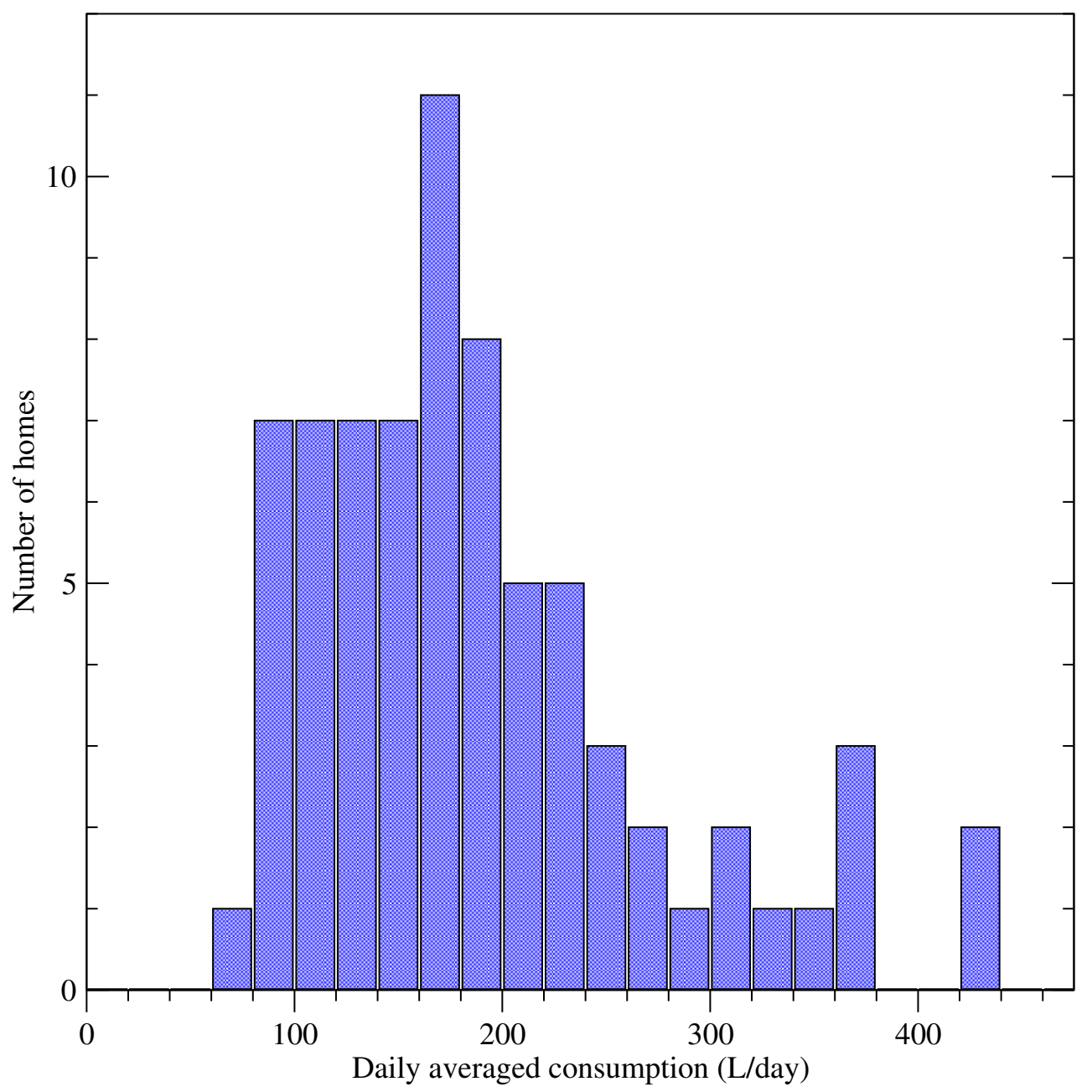

Figure 4.1: Distribution of daily averaged hot water consumption of the 73 houses. 
Table 4.2: Statistical summary of measured data from 73 houses

\begin{tabular}{c|c} 
Statistic & Value (L/day) \\
\hline Mean & 189 \\
Median & 173 \\
$20^{\text {th }}$ percentile & 119 \\
$80^{\text {th }}$ percentile & 245 \\
Standard deviation & 83 \\
Minimum & 70 \\
Maximum & 438
\end{tabular}

measured the hot water consumption of 58 houses in Ontario, Canada during the early 1980s, Perlman and Mills [12] found the mean daily hot water consumption to be $236 \mathrm{~L} /$ day. Becker and Stogsdill [14] conducted a review of previous field studies on hot water consumption and constructed a database of measurements from five studies conducted in Canada and the USA from the late 1970s to the mid-1980s, including the measurements of [12]. They found that the daily averaged hot water consumption of the several hundred houses and apartments included in their database to be 238 L/day.

Examining the homes' daily DHW usage based on the number of occupants reveals the expected trend of increased usage with increased occupancy. The four highest users, who filled out the survey, had five occupants. However, a trend relating to per capita usage is more difficult to determine. Very few homes in this study had more than four occupants. For this reason it is difficult to make any kind of generalization regarding per capita usage for high occupancy homes based on this data. The results of per capita analysis are displayed in Table 4.3.

These numbers for per capita use did not compare well with previous studies by Evarts and Swan [17] and Burch and Salasovich [16]. However, the work by Perlman and Mills study showed reasonable agreement [12]. A possible explanation for this disparity is the limited number of homes in this sample set, and the difference in times the data was recorded. Some of the studies had much larger sample sets and some of the data was recorded much earlier than this study. Some selected results 
Table 4.3: Per capita usage

\begin{tabular}{c|ccc}
$\begin{array}{c}\text { Number of } \\
\text { Occupants }\end{array}$ & $\begin{array}{c}\text { Average daily } \\
\text { use (L/day) }\end{array}$ & $\begin{array}{c}\text { Per capita average } \\
\text { daily use (L/person/day) }\end{array}$ & $\begin{array}{c}\text { Number of } \\
\text { homes in study }\end{array}$ \\
\hline 1 & 183 & 183 & 2 \\
2 & 142 & 71 & 23 \\
3 & 171 & 57 & 14 \\
4 & 201 & 50 & 22 \\
5 & 281 & 56 & 9
\end{tabular}

Table 4.4: Per capita usage observed in other studies $[12,17,52]$

\begin{tabular}{c|cc|cc|cc}
$\begin{array}{c}\text { Number of } \\
\text { Occupants }\end{array}$ & $\begin{array}{c}\text { Evarts } \\
\text { and Swan }\end{array}$ & $\begin{array}{c}\text { Number } \\
\text { of homes }\end{array}$ & $\begin{array}{c}\text { Perlman } \\
\text { and Mills }\end{array}$ & $\begin{array}{c}\text { Number } \\
\text { of homes }\end{array}$ & $\begin{array}{c}\text { Burch } \\
\text { and Salasovich }\end{array}$ & $\begin{array}{c}\text { Number } \\
\text { of homes }\end{array}$ \\
\hline 2 & 84 & 341 & 69 & 6 & 80 & 4 \\
3 & 67 & 231 & 86 & 18 & 97 & 1 \\
4 & 60 & 272 & 63 & 19 & 71 & 4 \\
5 & 59 & 89 & 46 & 15 & 50 & 1
\end{tabular}

from previous studies can be seen below in Table 4.4.

Differences in the temporal distribution of the consumption patterns were also observed between houses. This is illustrated in Figure 4.2, which contrasts the consumption patterns of four of the measured houses. Each quadrant of this figure was produced by integrating a given house's measured hot water consumption over each hour of the day, and then averaging these hourly integrated quantities over each day of the monitoring period. This reveals, for example, that the house represented by Figure 4.2a experienced significantly more hot water draws from $7 \mathrm{~h} 00$ to $8 \mathrm{~h} 00$ than at any other time of the day over the course of the monitoring period.

In their study, Perlman and Mills, [12], observed that most houses experience their peak hot water demands either in the morning or in the evening. An analysis of the 
data revealed that about a quarter of the measured houses in the current study could best be characterized as predominantly morning consumers (such as in Figure 4.2a) while about a third could best be characterized as predominantly evening consumers (such as in Figure 4.2b). But the remaining houses (approximately $40 \%$ ) fit neither of these consumption patterns. Figures $4.2 \mathrm{c}$ and $4.2 \mathrm{~d}$ illustrate the consumption patterns of two of these houses: the former experiences peaks in consumption late at night with smaller peaks midday, whereas the latter has consumption dispersed throughout the day, with smaller peaks in the morning and evening.

\subsection{Annual Hot water Draw Profiles}

The previous section presented the newly measured data. This section describes how these data were used to construct annual hot water draw profiles.

As previously stated, the goal of the research was to develop representative DHW draw profiles that could be used in annual simulations. As both the magnitude and the temporal distribution of hot water consumption is significant, it was decided that 12 profiles would be created to provide researchers with data that span a broad cross-section of occupancy behavior: 4 consumption levels with 3 distinct temporal consumption patterns. The following consumption levels were selected:

- houses that consume close to the average of the measured sample;

- houses that consume close to the median;

- houses with sparing consumers, defined to be close to the $20^{\text {th }}$ percentile;

- houses with profligate consumers, defined to be close to the $80^{\text {th }}$ percentile.

For each of the above-mentioned consumption levels, it was decided that profiles should be created with the following temporal consumption patterns:

- predominantly morning consumption, similar to Figure 4.2a;

- predominately evening consumption, similar to Figure 4.2b;

- dispersed consumption, similar to Figure 4.2d. 


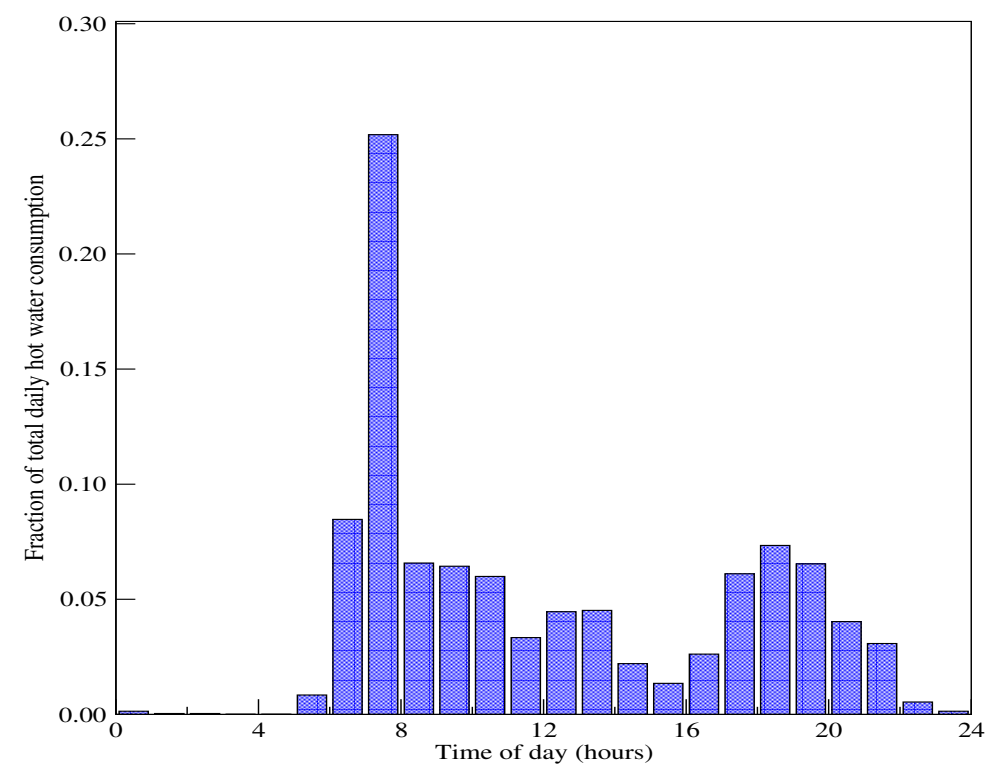

(a) Predominantly morning

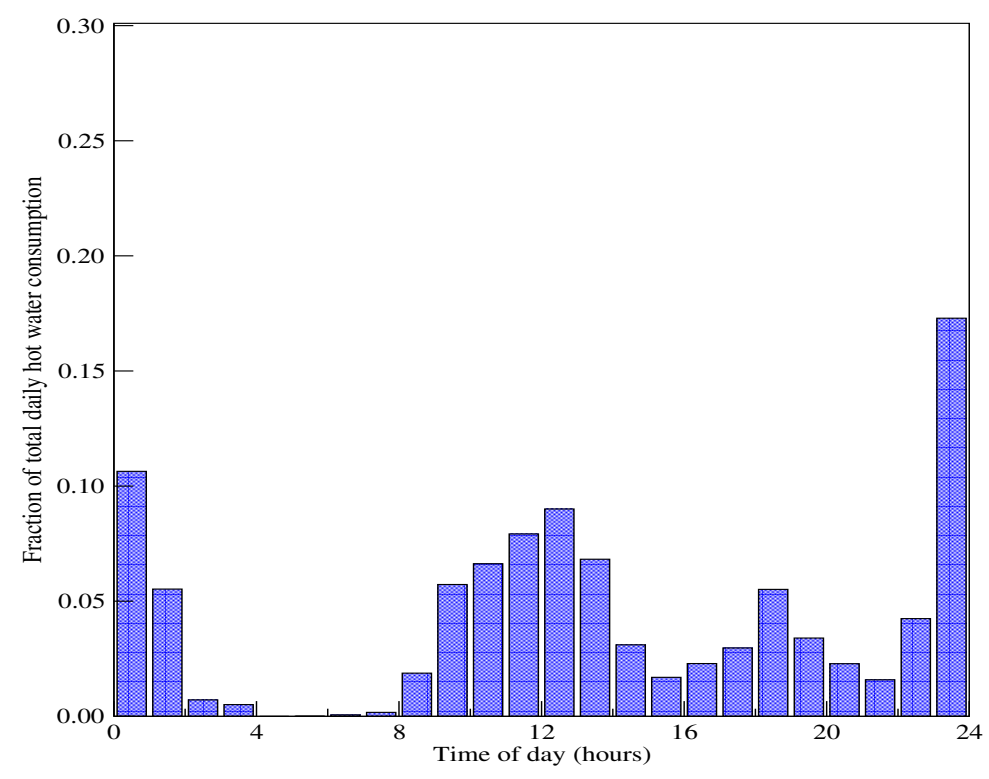

(c) Predominantly late night

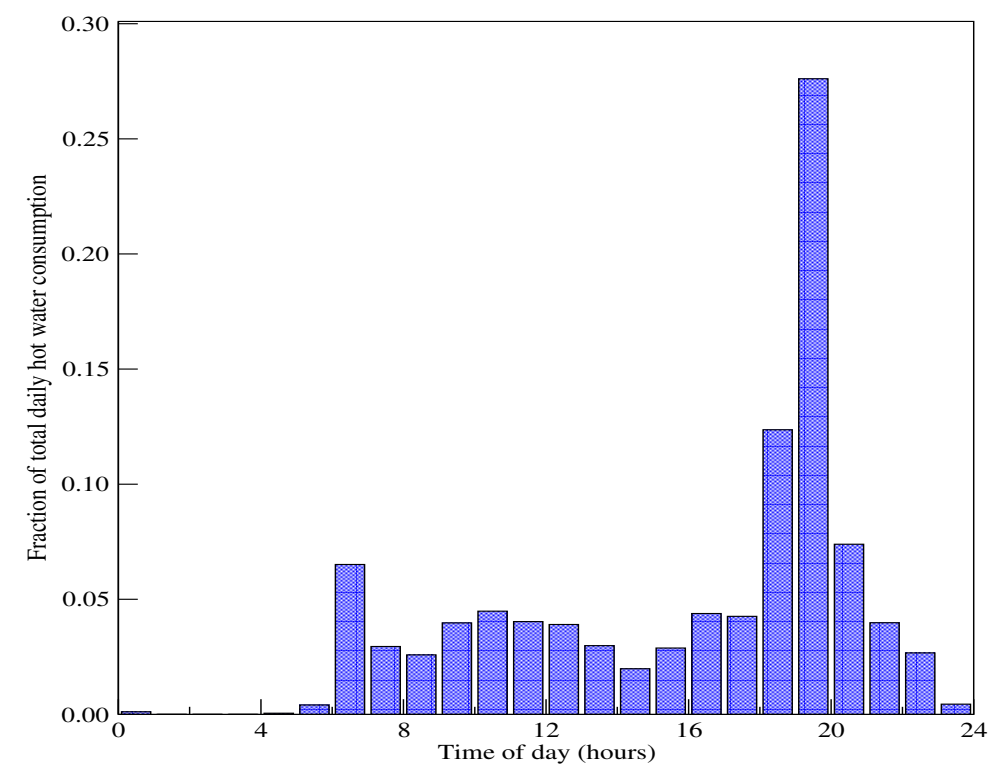

(b) Predominantly evening

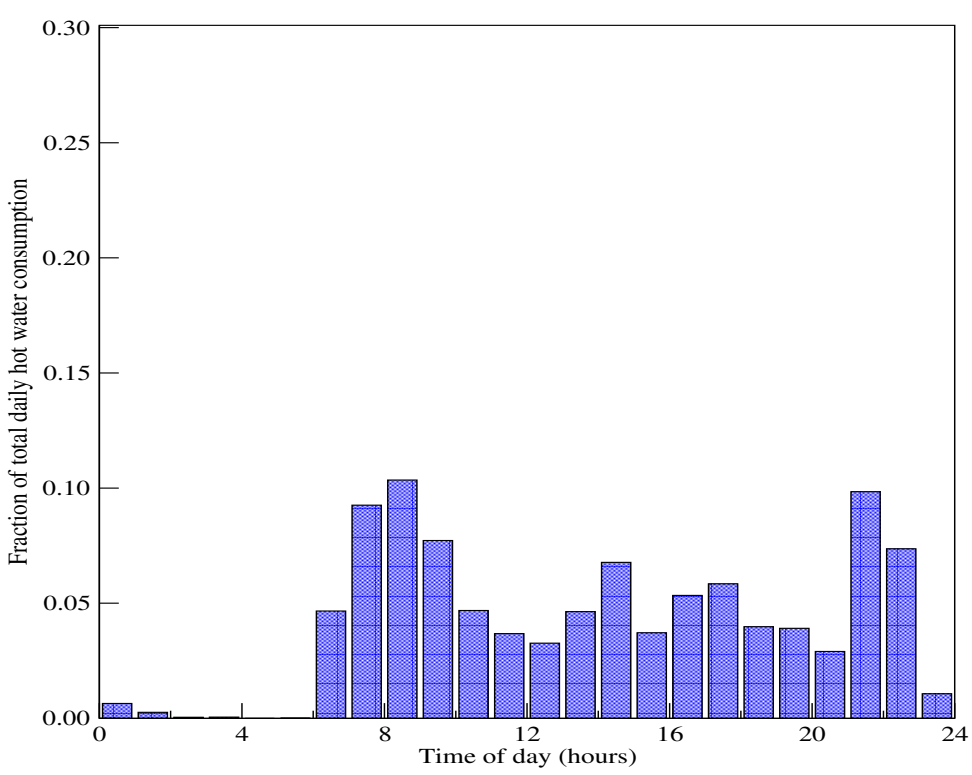

(d) Dispersed throughout day

Figure 4.2: Temporal consumption patterns of four of the houses. (The hourly integrated consumptions have been averaged over each day of the monitoring period.) 
As previously mentioned, data were collected for 73 houses and the measurements were taken for 60 to 165 days, depending upon when the equipment could be installed and the houses accessed. The data from each of the 73 houses were examined and those most closely matching the target consumption levels and temporal distribution patterns listed above were selected for developing the annual profiles. Preference was given to houses with the longest measurement periods.

Each of the 12 selected houses had a complete set of data for the winter season (December 21 to March 21). However, the monitoring period spanned only one quarter to one half (depending the house) of the autumn (September 21 to December 21) and only about one quarter of the spring (March 21 to June 21) seasons. A datafilling procedure was employed to populate these missing periods in order to produce annual DHW usage profiles. For the autumn, measured data from November and December were used to estimate the DHW usage profiles for the unmonitored days in September and October. Data from sequential November and December days were taken to fill the missing records, taking care to equivalence days of the week (e.g. Saturday data from November were used to fill Saturdays in September). No adjustments were made to the magnitude or temporal distributions of these data. Similar methods were employed for the spring.

The original study did not require information on summer use. For this reason no data was recorded for this period. Given that previous research has shown that DHW consumption levels can vary significantly with season $[12,14,16,53]$, a method was required to synthesize summer data for the annual profiles.

The findings of [14] was chosen for creating the summer DHW draw patterns. Although they found limited variation in the temporal demand patterns between seasons, [14] observed a marked reduction in the average daily DHW use during the summer; daily consumption was found to be, on average, $13 \%$ lower in the summer compared to winter.

The measured data from the winter period were used to synthesize summer data. The entire winter period was copied to the summer period, taking care to match days of the week. The DHW consumption at each 5-minute interval were then reduced by $13 \%$ according to the findings mentioned above.

The resulting 12 annual DHW profiles are summarized in Table 4.5. As can be seen, there is one profile for each combination of the four consumption levels (mean, 
median, sparing, and profligate) and the three temporal demand patterns (predominantly morning consumption, predominantly evening consumption, and dispersed consumption). The table indicates the number of occupants in each of the houses. It also records the average and standard deviation of the daily DHW consumption of each house over the year.

Inspection of Table 4.5 reveals that magnitude of the standard deviation of the daily DHW consumption is large compared to the average for most of the houses. This indicates that there are substantial day-to-day variations in the magnitude of the consumption, thus justifying the need for annual profiles rather than typical daily profiles.

Figure 4.4 focuses on one house (H14) to examine the range of day-to-day variations in DHW consumption that is captured in the representative profiles. This histogram shows that while the majority of daily consumption is centered around the average for this home, of $189 \mathrm{~L} /$ day, there are many days above this average daily usage and many days below this daily average. For 10 days there is approximately zero DHW consumed. The highest consumption, of approximately $600 \mathrm{~L} /$ day, occurs only once. However, this variability of high usage is captured in the draw profiles used here.

Further evidence of the significant day-to-day variations in the DHW demand profiles is seen in Figure 4.4, which examines the daily DHW consumption of the three average houses for a two-week period in January. The daily DHW consumption of each house is plotted relative to its average consumption: $176 \mathrm{~L} /$ day for H38, 189 $\mathrm{L} /$ day for H14, and $182 \mathrm{~L} /$ day for H73. This figure shows, for example, that the DHW consumption in house H73 on January 1 is more than average, but this is followed by two days with no consumption, and then very low consumption on January 4. During this particular two-week period the DHW consumption in house H14 is substantially greater than average; in fact on January 13 consumption is seen to be $575 \mathrm{~L}$, three times the average value for that house. These important temporal variations would not be seen in simulation analyses conducted with average-day profiles.

The twelve profiles described here capture a variety of users. The per capita usage rates presented here are generally lower than those seen in previous studies. The dissimilarities between the results presented here and earlier studies is likely 
Table 4.5: 12 representative annual DHW load profiles

\begin{tabular}{|c|c|c|c|c|c|}
\hline $\begin{array}{l}\text { Consumption } \\
\text { level }\end{array}$ & $\begin{array}{l}\text { Consumption } \\
\text { pattern }\end{array}$ & $\begin{array}{l}\text { House } \\
\text { number }\end{array}$ & $\begin{array}{l}\text { Number of } \\
\text { occupants }\end{array}$ & $\begin{array}{c}\text { Annually averaged } \\
\text { daily consumption (L) }\end{array}$ & $\begin{array}{c}\text { Standard deviation } \\
\text { of daily consumption }(\mathrm{L})\end{array}$ \\
\hline \multirow{3}{*}{ Average } & Morning & H38 & 3 & 176 & 101 \\
\hline & Evening & H14 & 3 & 189 & 79 \\
\hline & Dispersed & $\mathrm{H} 73$ & 3 & 182 & 75 \\
\hline \multirow{3}{*}{ Median } & Morning & $\mathrm{H} 49$ & 3 & 169 & 71 \\
\hline & Evening & H69 & 3 & 170 & 39 \\
\hline & Dispersed & H5 & 2 & 166 & 97 \\
\hline \multirow{3}{*}{ Below Average } & Morning & H11 & 2 & 118 & 83 \\
\hline & Evening & $\mathrm{H} 43$ & 3 & 116 & 62 \\
\hline & Dispersed & $\mathrm{H} 16$ & $\mathrm{n} / \mathrm{a}$ & 124 & 52 \\
\hline \multirow{3}{*}{ Above Average } & Morning & H59 & 5 & 219 & 104 \\
\hline & Evening & H35 & 4 & 246 & 78 \\
\hline & Dispersed & $\mathrm{H} 52$ & 4 & 240 & 97 \\
\hline
\end{tabular}




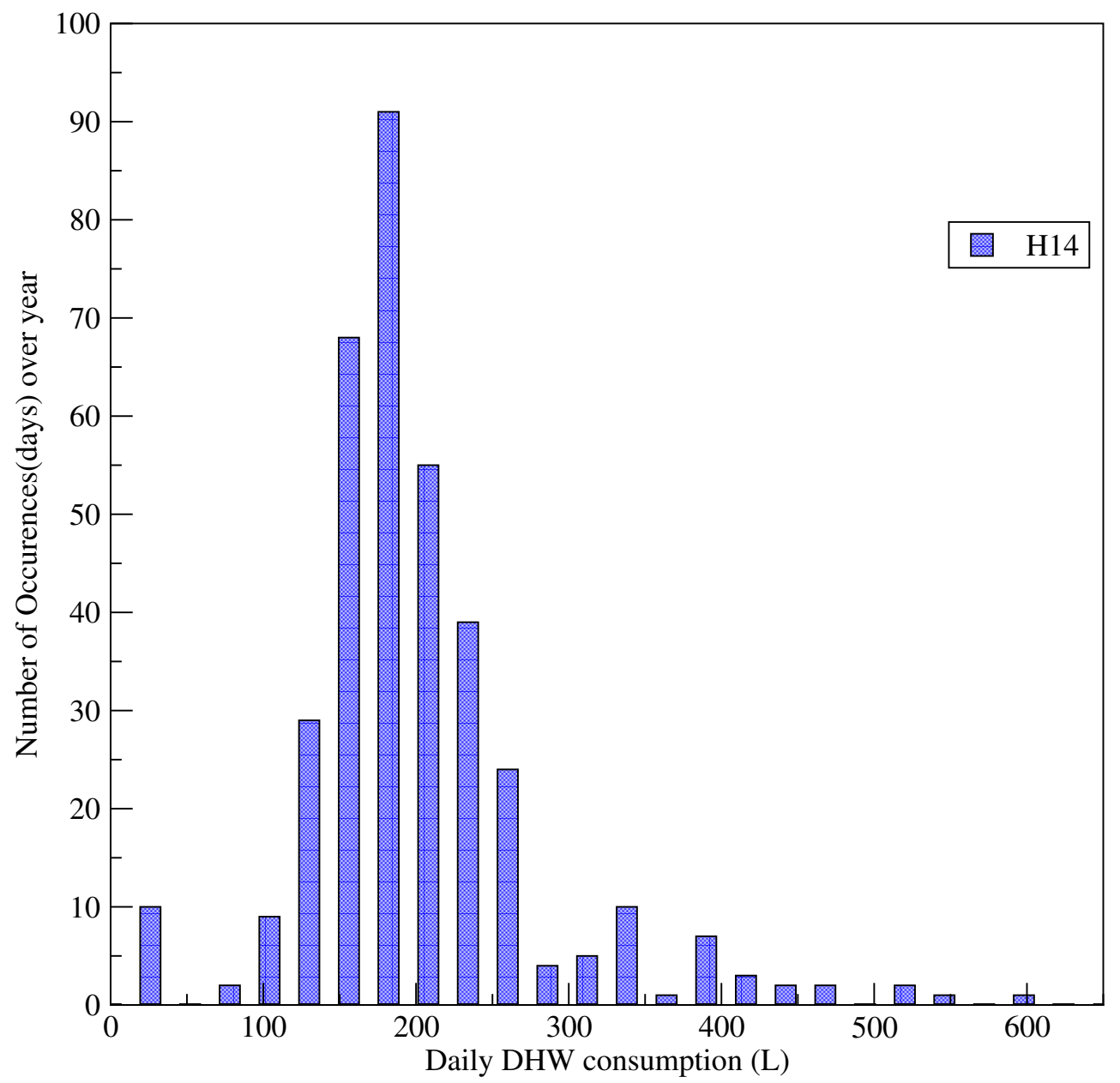

Figure 4.3: Histogram of daily DHW consumption for the average predominantly evening consuming house, H14 


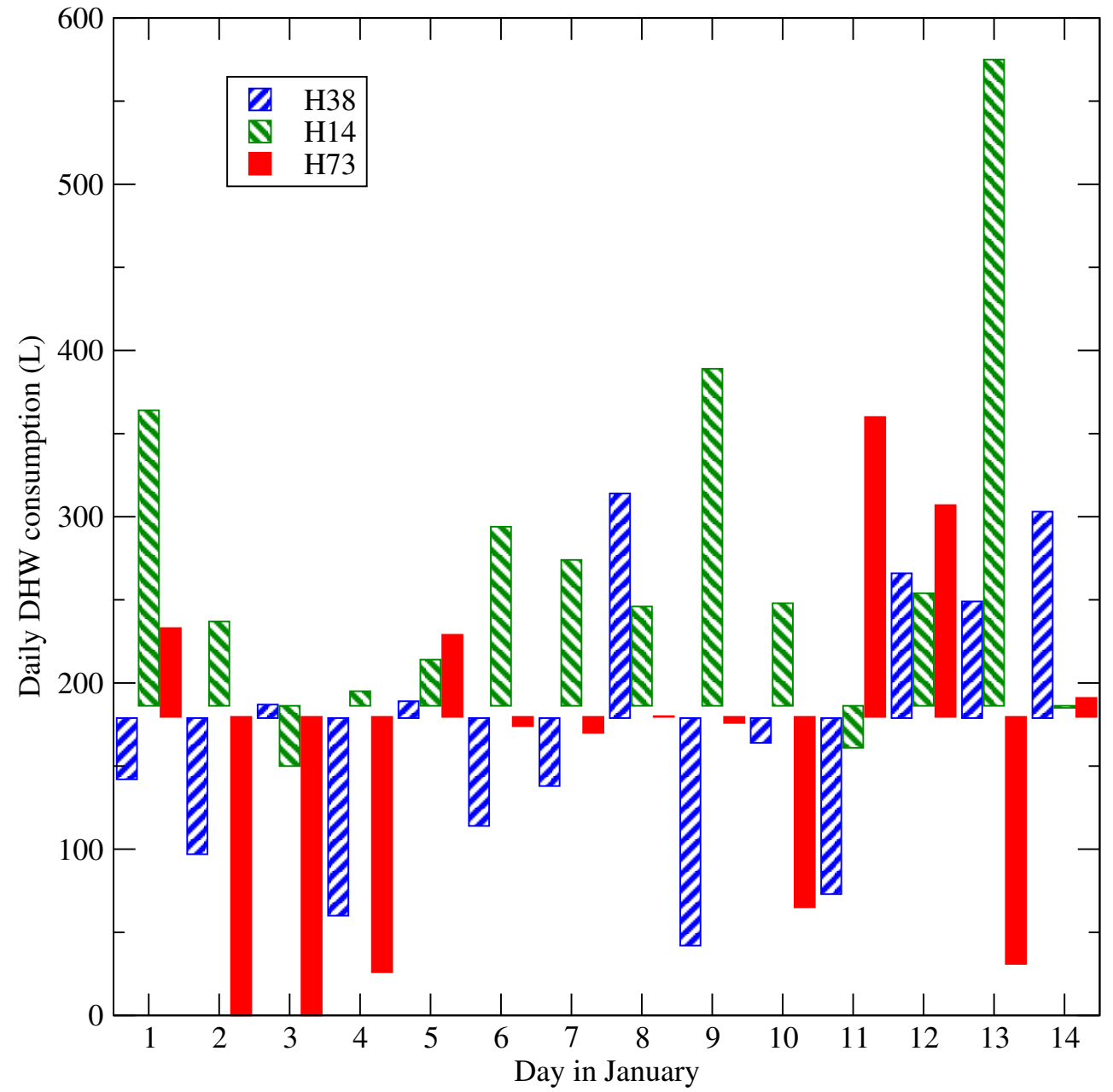

Figure 4.4: Daily DHW consumption of the three average houses for a two-week period in January 
due to the improved efficiency of hot water consuming devices such as dishwashers, washing machines, and showers. The dissimilarities between the more recent study by Evarts and Swan can be explained by the rather coarse method they for extrapolating DHW usage based on billing data.

This thesis will use four of the 12 draw profiles described above. Histograms, depicting the frequency of the daily draws for each of the draw profiles used can be seen in Figure 4.5. These figures show that, while there is a tendency towards a regular daily use, each home experiences a variety of daily draws with many days below the average daily draw and many days above the daily average draw. In addition the hourly use for each of the draw profiles used can be seen below in Figure 4.6. These figures show the variability the draw profiles experience not only in magnitude but also in time of use.

These draw profiles will be used in the co-simulations undertaken during this research. A variety of magnitudes, and times of use, are examined here in order to capture a broader understanding of these effects. 


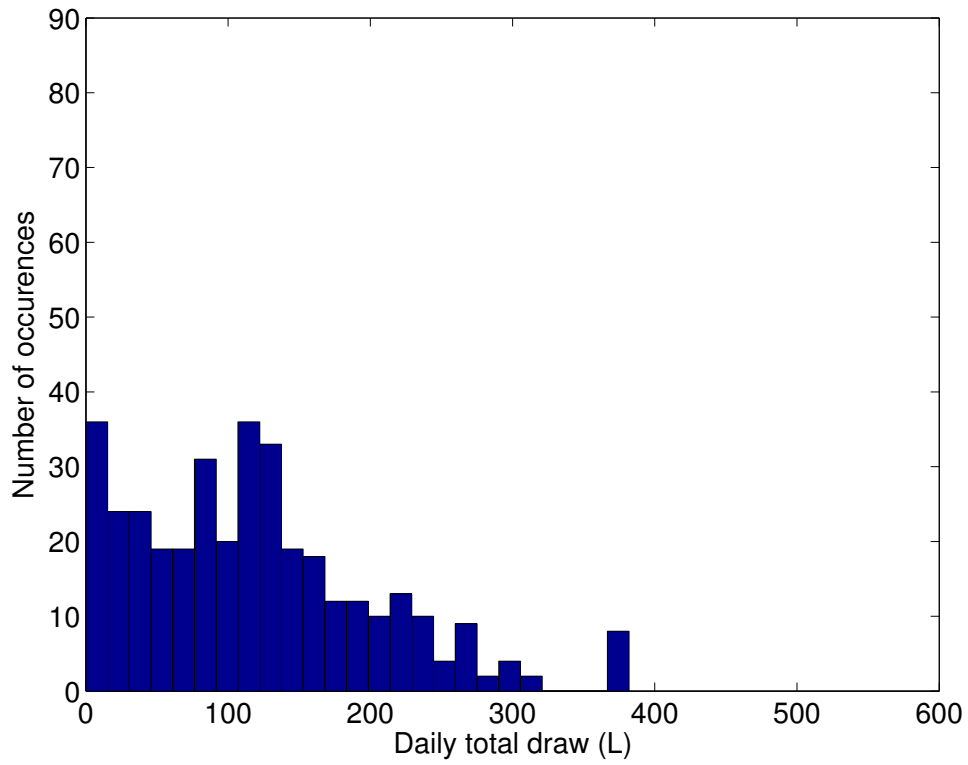

(a) Daily draws for below average consumer

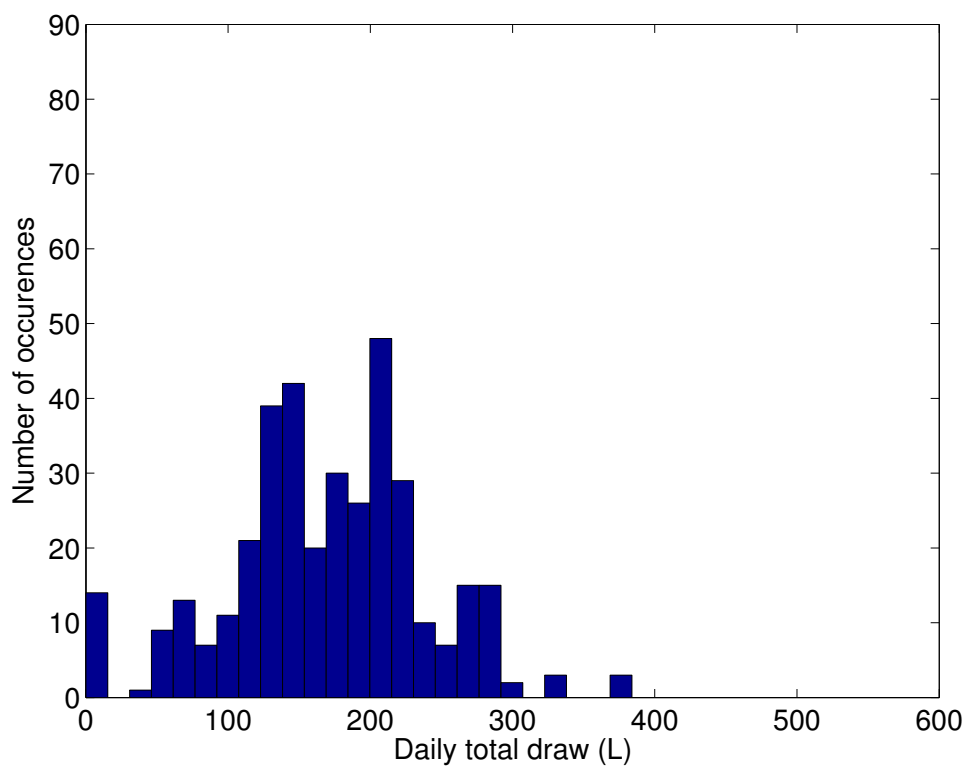

(c) Daily draws for median consumer

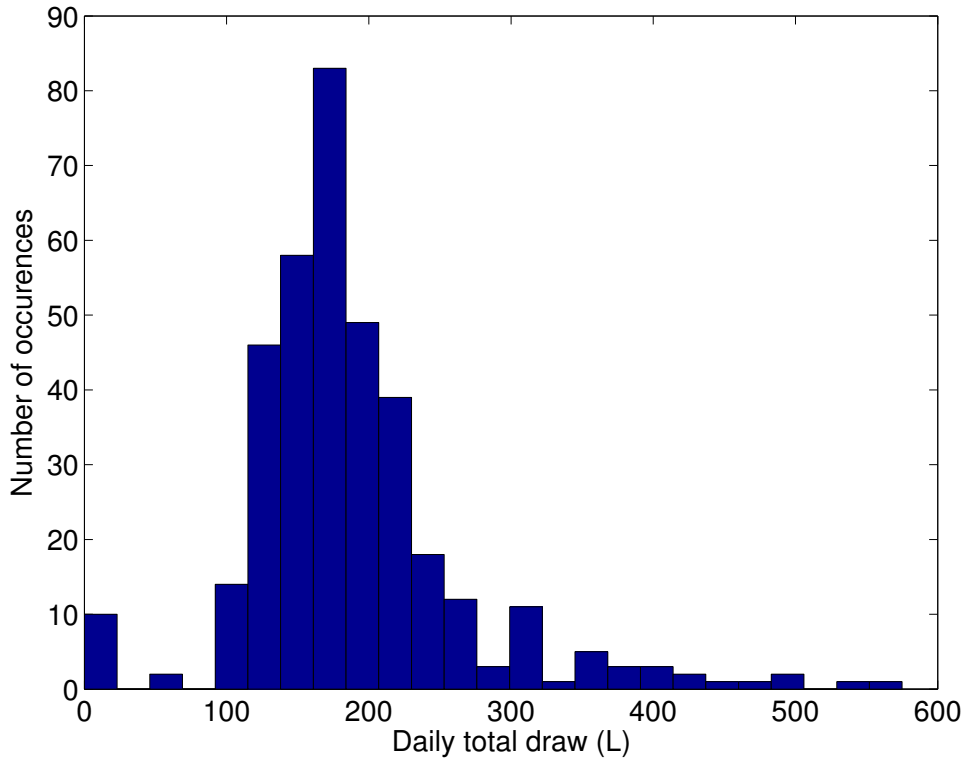

(b) Daily draws for average consumer

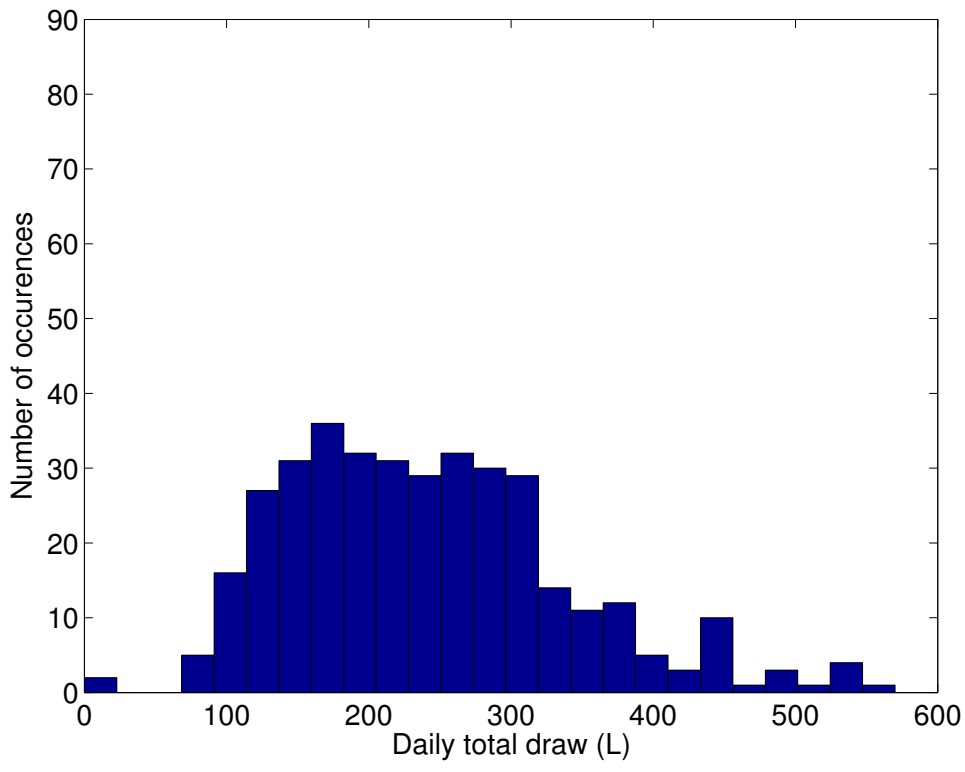

(d) Daily draws for above average consumer

Figure 4.5: Histograms showing the daily consumption patterns for the draw profiles used in this research 


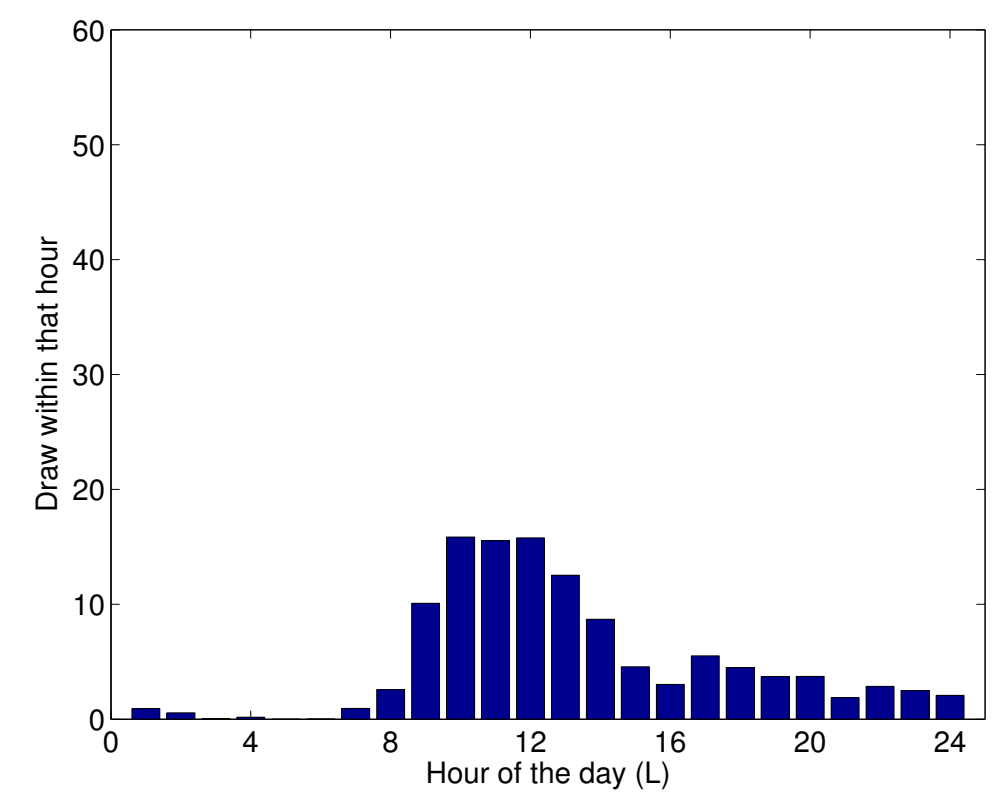

(a) Hourly consumption pattern for below average consumer

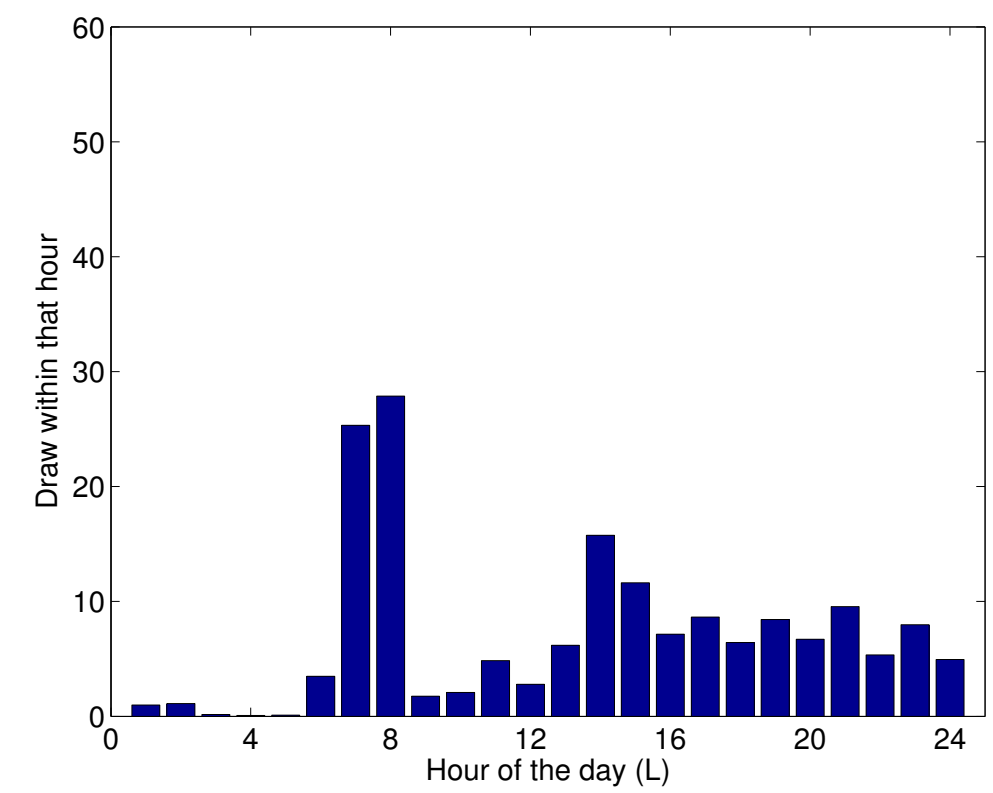

(c) Hourly consumption pattern for median consumer

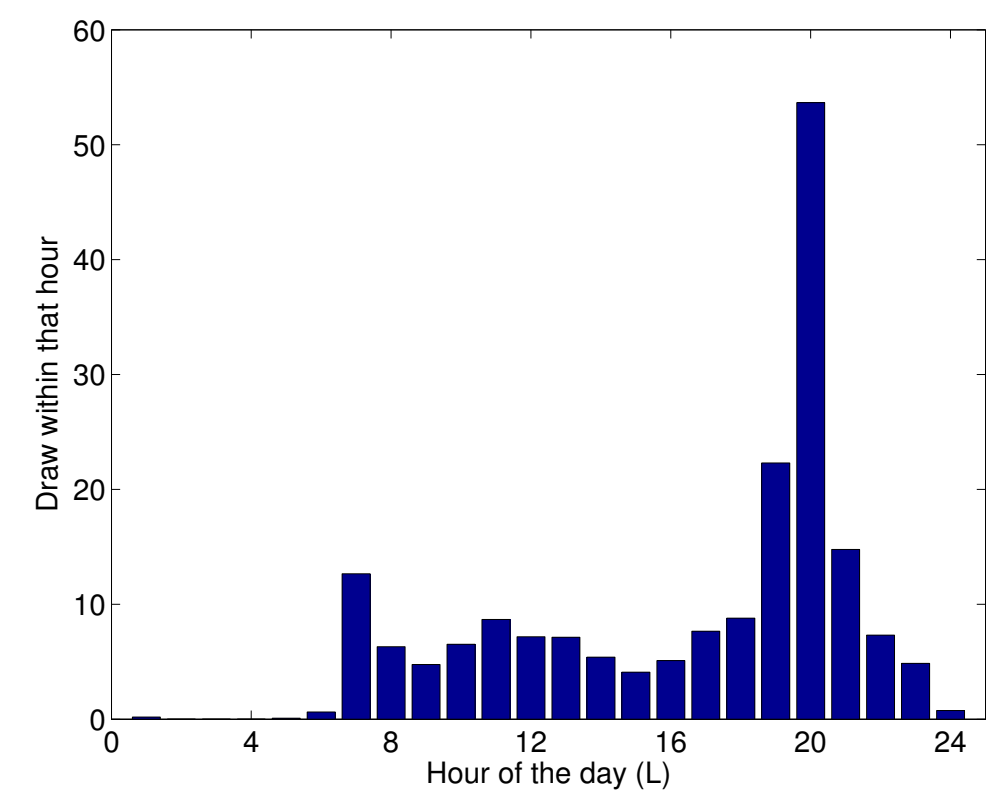

(b) Hourly consumption pattern for average consumer

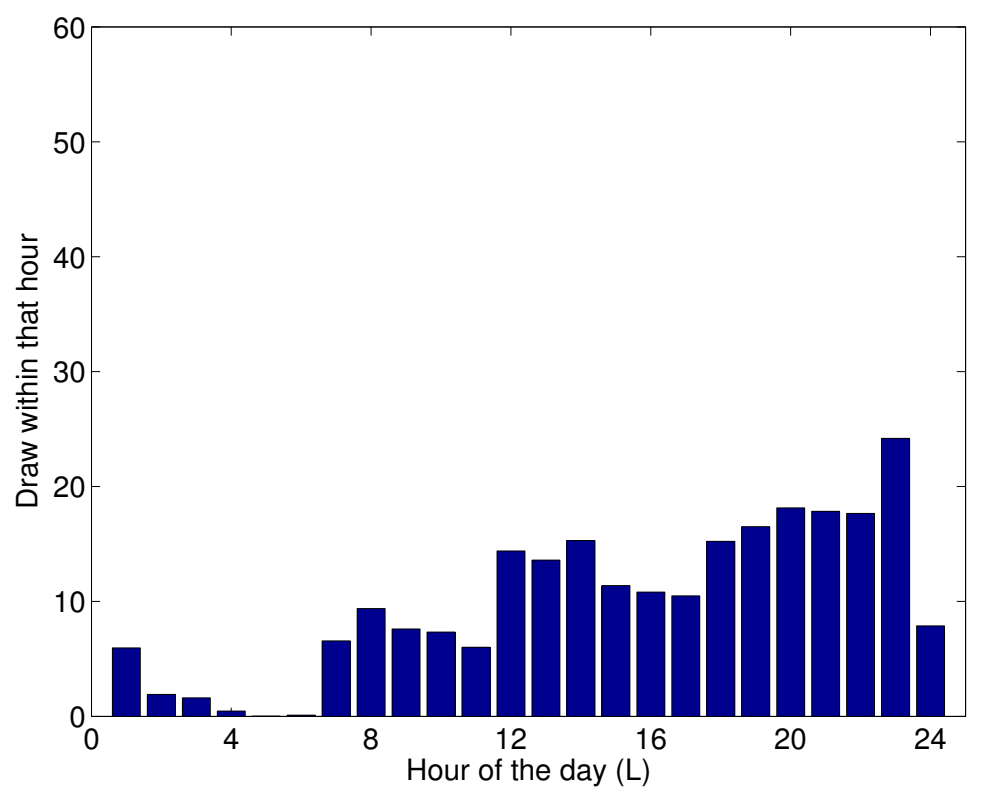

(d) Hourly consumption pattern for above average consumer

Figure 4.6: Hourly consumption patterns for the draw profiles used in this research 


\section{Chapter 5}

\section{Simulation Methodology}

\subsection{Introduction}

This chapter will lay out the basic structure used to determine the requirements for the various system components and homes used in this work. The baseline parameters used for solar collector and storage tank models will be elaborated upon. The house models will be discussed and the details regarding their locations, annual heating loads, peak heating loads, and available roof area will be given. Details regarding the systems modelled will be provided and the heat management systems will be described. A summary of the simulations run, and the parameters which will be varied, will be given. Finally the performance metrics which will be used for analysis will be outlined.

\subsection{Baseline Parameters}

Based on the available literature, and manufacturer specifications, the initial parameters relating to the various components in the systems analysed were assessed. The components of most interest were the solar collectors and the storage tanks. During the sensitivity analysis, discussed in Chapter 6, only collector area and storage tank volume were varied. However, in order to accurately model a system, knowledge of several other parameters was required. This section will describe how the initial values for collector area and storage tank volume were decided upon and how other parameters were varied based on these results. 


\subsubsection{Solar Collector Baseline Parameters}

The solar collectors modeled in this research were based on Enerworks flat plate collectors. While evacuated tube collectors reject less heat to the ambient environment, and by proxy operate at higher temperatures, this can become a problem in areas with heavy snow fall. The reduced heat losses can result in snow build up on the collector surface. This hampers, or completely eliminates any solar energy absorption by the collector surface [54].

The manufacturer documentation, offered by Enerworks, presents information on aperture area, collector efficiency, incidence angle modifier, and conditions under which the collector's performance was assessed by the manufacturer. This information was used to develop initial estimates of the required inputs for the co-simulation.

Each collector has an aperture area of $2.7 \mathrm{~m}^{2}$. In order to determine the appropriate number of collectors connected in series a brief set of exploratory tests were run. Three configurations, consisting of 2, 3, and 4, collectors connected in series, were evaluated based on annual simulations. Each collector arrangement was tested for a tank volume of $2000 \mathrm{~L}$. The total surface area for each of these configurations remained constant at $31.2 \mathrm{~m}^{2}$ throughout the simulations. This was accomplished by varying the number of parallel branches. For the 2 series arrangement 6 parallel branches were used, for the 3 and 4 series arrangements 4 and 3 parallel branches were used, respectively. All parameters of the system, besides collector arrangement were held constant.

Examples of 2, 3, and 4 series collector arrangements are given in Figures 5.1(a), 5.1(b), and 5.1(c), respectively. All figures shown represent 2 parallel branches, labeled A and B. When branches have the same number of collectors in series they should, theoretically, have the same outlet temperature.

The desired outlet temperature of the collectors was $55{ }^{\circ} \mathrm{Cor}$ above. This was selected as it is the required inlet temperature to the space heating loop. If water

entering the space heating loop was below $55{ }^{\circ} \mathrm{Cit}$ would have to be boosted by the auxiliary heater. The frequency for which outlet temperatures were above $55{ }^{\circ} \mathrm{Ccan}$ be seen in Table 5.1. This frequency is calculated as follows: 


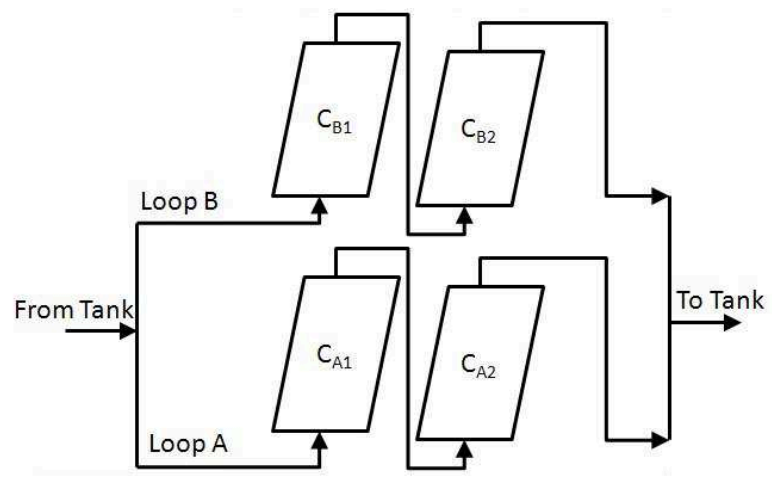

(a) 2 collectors in series

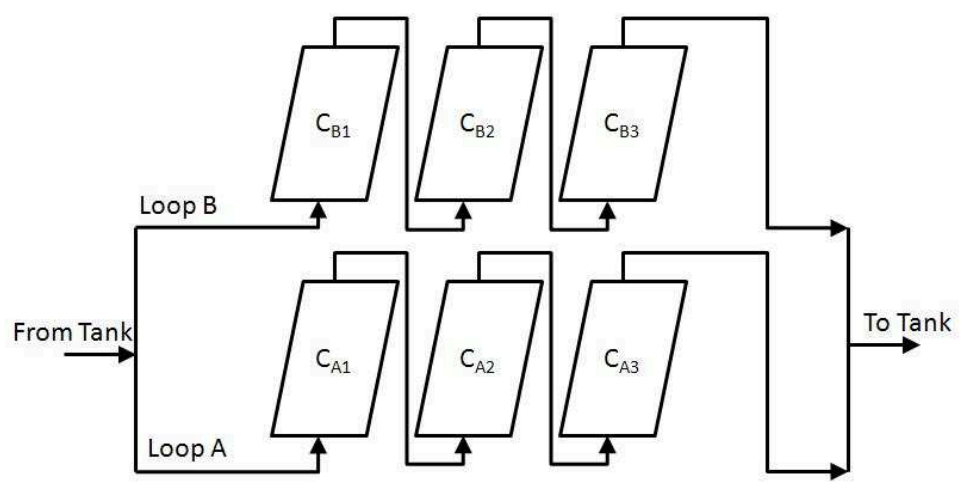

(b) 3 collectors in series

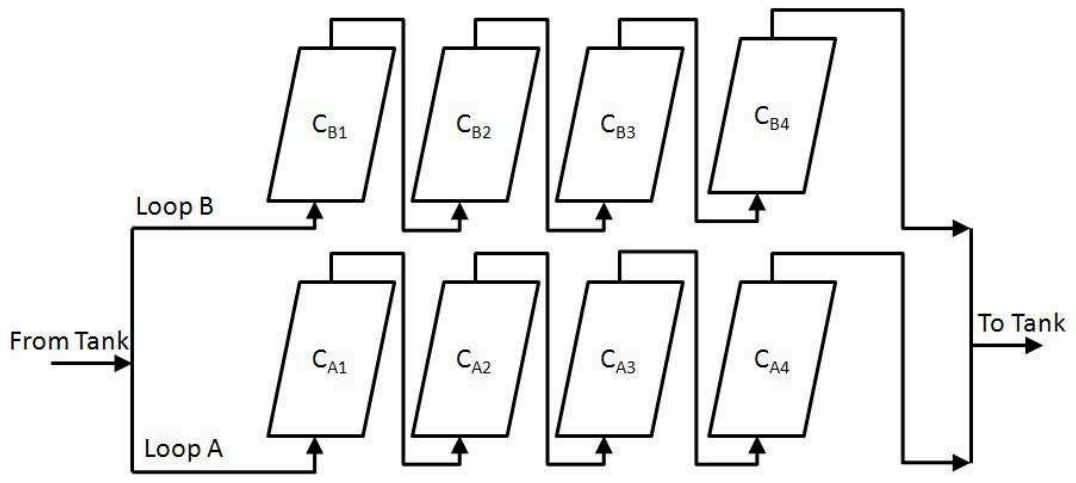

(c) 4 collectors in series

Figure 5.1: Examples of 2, 3, and 4 collectors connected in series in 2 parallel branches. 
Frequency $=\frac{\text { Number of time steps temperature at collector outlet is greater than } 55^{\circ} \mathrm{C}}{\text { Number of time steps solar collector pump is operating }}$

Table 5.1: Frequency outlet temperatures were above $55^{\circ} \mathrm{C}$

\begin{tabular}{c|c|c|c} 
Tank Volume (L) & 2 Series & 3 Series & 4 Series \\
2000 & $88.9 \%$ & $92.8 \%$ & $93.6 \%$
\end{tabular}

While the 4 series arrangement produces a consistently higher outlet temperature over the year, the three series arrangement is frequently above the minimum required temperature. Therefore, the three series arrangement was selected for this work. For all further simulations, three collectors were connected in series to form a total aperture area of $8.1 \mathrm{~m}^{2}$ in each parallel branch.

Based on the manufacturer's documentation [55] these collectors have an efficiency described by the following equation:

$$
\eta=0.7166-4.014 \frac{\left(T_{i}-T_{a}\right)}{I}-0.0187 \frac{\left(T_{i}-T_{a}\right)^{2}}{I}
$$

In this equation $T_{i}$ is the fluid inlet temperature, $T_{a}$ is the ambient temperature, and $I$ is the incoming solar radiation on the surface. This equation was used to extrapolate the intercept efficiency, the 1st order efficiency coefficient, and the 2nd order efficiency coefficient. In addition to the collector's efficiency equation TRNSYS also requires the user to input the IAM. Enerworks provides data concerning the IAM for a variety of incidence angles. This information is given in Table 5.2

In Table 5.2 the $\theta$ term represents the incidence angle of the incoming solar radiation and the IAM term represents the incidence angle modifier. This describes

Table 5.2: Incidence angle modifier provided by Enerworks

\begin{tabular}{c||c|c|c|c}
$\theta$ & 0 & 30 & 45 & 60 \\
\hline IAM & 1 & 0.980 & 0.946 & 0.839
\end{tabular}


the amount of solar radiation that is absorbed by the absorption plate relative to the amount of solar radiation that would be absorbed at normal incidence. Transmittance and absorptance of a surface are affected by the angle at which a beam of radiation hits the surface. This means that to accurately predict the radiation which is finally absorbed by the absorption plate this value must be continuously adjusted. TRNSYS requests that the user present information on the IAM in the following form:

$$
I A M=1-b_{0}\left(\frac{1}{\cos \theta}-1\right)-b_{1}\left(\frac{1}{\cos \theta}-1\right)^{2}
$$

In this equation the $b_{0}$ and $b_{1}$ terms are required TRNSYS inputs. A line of best fit was plotted for the data provided by Enerworks. A comparison between the manufacturer's specifications and the calculated IAM can be found in Figure 5.2. This lead to a correlation where $b_{(0)}$ and $b_{(1)}$ were found to be 0.129 and 0.031422 , respectively.

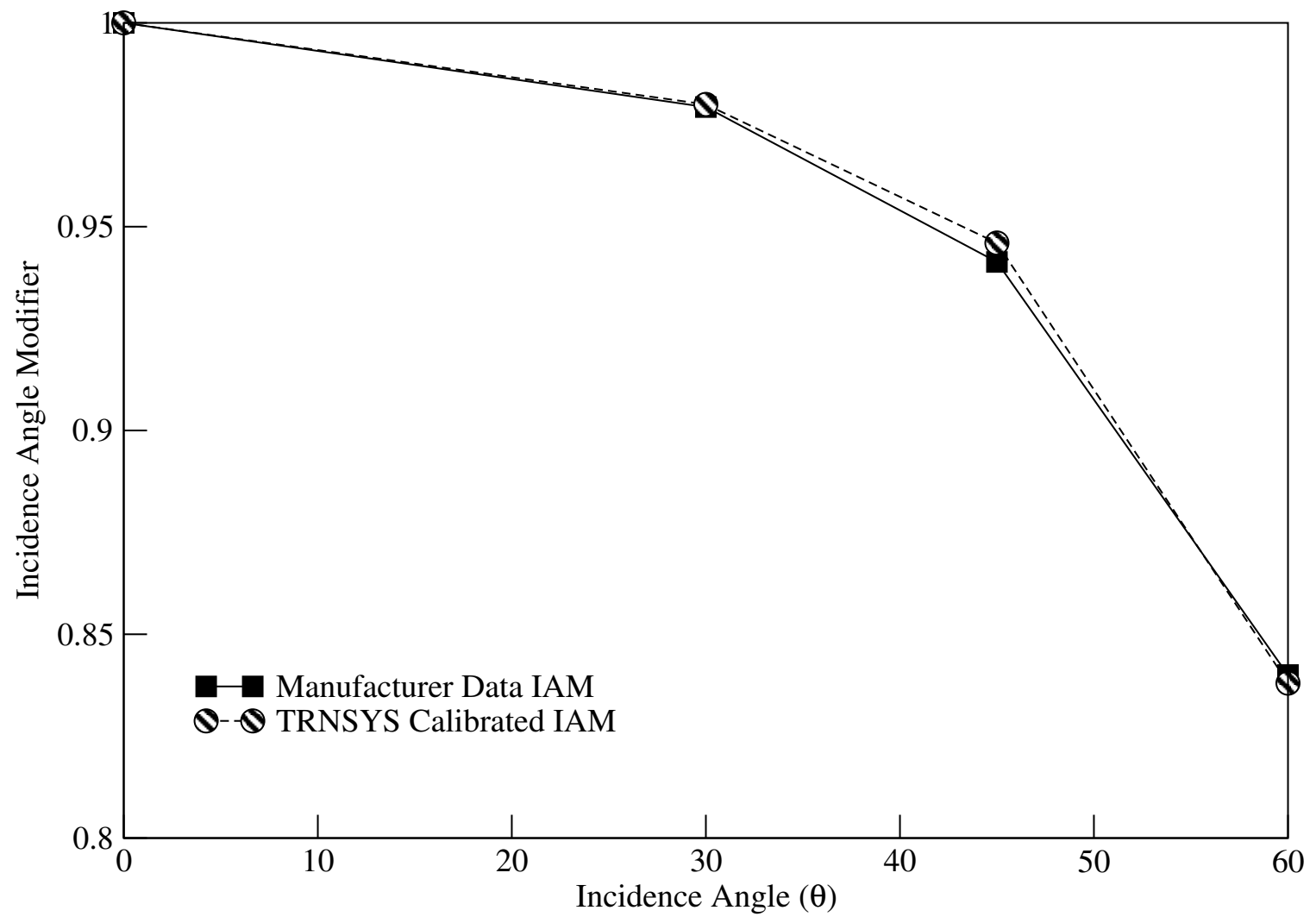

Figure 5.2: Calculated incidence angle modifier

Another important parameter for collector performance is specific mass flow rate 
through the collector. For similar systems Shah [26], Ellehauge [23], Cheze and Papillon [24], and Peter [27] recommend using a specific flow rate between 40 and 72 $\mathrm{kg} / \mathrm{m}^{2}-\mathrm{hr}$. Due to the fact that the system with arrangements most similar to those examined in this research recommend a flow rate on the high end of $72 \mathrm{~kg} / \mathrm{m}^{2}-\mathrm{hr}$ this was used for all simulations. Flow was split evenly between parallel branches in a collector array.

Initial tests were run to determine the optimal tilt angle in order to produce the highest solar fraction and the lowest required auxiliary energy use. Duffie and Beckman [8] recommend a tilt angle equal to latitude plus 10-20 degrees. For the Ontario locations latitudes ranged between 43 and 48 degrees north. London and Toronto are roughly at the same latitude. London is at a latitude of 43 degrees north and Toronto is at a latitude of 43.7 degrees north. Therefore, the same tilt angle was used for the two locations. A single series of simulations, wherein collector tilt was varied between 40 and 80 degrees in 5 degree increments, were run for one of the Toronto house models to determine, in a general sense, an appropriate tilt angle for this location. An arrangement of 3 collectors in series and 2 parallel arrays, with a $1500 \mathrm{~L}$ storage tank were run and it was found that a collector tilt of 55 degrees produced the highest solar fraction and the lowest required auxiliary energy use. Therefore, all future simulations for Toronto homes were run with this tilt angle. Both the required auxiliary energy and the solar fraction were found to be insensitive to tilt angle. Results of these simulations can be seen in Table 5.3. Auxiliary energy requirements only increased by 0.6 GJ, for the lowest tilt angle of 40 degrees, and 1.9 GJ, for the highest tilt angle of 80 degrees.

The simulations described above were performed a second time. However, this time the location was changed to Thunder Bay. This was done in order to determine if the optimal tilt angle would change when changing locations. The results of these simulations can be seen in Table 5.4. There is a minor deviation regarding auxiliary energy use and solar fraction. The minimum auxiliary energy use and the maximum solar fraction occur at a tilt angle of 60 degrees. However, just as was seen in the testing for the Toronto homes the results are insensitive to tilt angle. The discrepancy between the auxiliary energy use of the two locations can be explained by the significant difference between the space heating load for the two locations. The Toronto location has a space heating load of 63.0 GJ while the Thunder Bay location has a 
Table 5.3: Annual auxiliary energy use for various tilt angles for Toronto

\begin{tabular}{c|cc} 
Tilt Angle & Auxiliary Energy Added (GJ) & Solar Fraction (\%) \\
\hline 40 & 37.1 & 39.0 \\
45 & 36.8 & 39.4 \\
50 & 36.7 & 39.6 \\
55 & 36.5 & 39.7 \\
60 & 36.6 & 39.4 \\
65 & 36.9 & 38.9 \\
70 & 37.2 & 38.0 \\
75 & 37.7 & 36.7 \\
80 & 38.4 & 35.1
\end{tabular}

Table 5.4: Annual auxiliary energy use for various tilt angles for Thunder Bay

\begin{tabular}{c|cc} 
Tilt Angle & Auxiliary Energy Added (GJ) & Solar Fraction (\%) \\
\hline 40 & 65.6 & 28.2 \\
45 & 65.0 & 28.8 \\
50 & 64.6 & 29.2 \\
55 & 64.4 & 29.4 \\
60 & 64.2 & 29.4 \\
65 & 64.5 & 29.0 \\
70 & 64.9 & 28.4 \\
75 & 65.6 & 27.4 \\
80 & 66.6 & 26.2
\end{tabular}


space heating load of 103.0 GJ.

The most important parameter relating to solar collectors which was varied was the number of collectors in parallel. Assuming the number of collectors in series remained constant each increase in the number of parallel collector arrays increased the total surface area available for solar energy collection by $8.07 \mathrm{~m}^{2}$. In turn, by increasing the surface area, the flow rate from the collectors to the heat exchangers connected to the storage tank was also increased. An initial study, where a variety of storage volumes and collector areas were assessed for a midsize home built in 1955, revealed that solar fractions exceeding $50 \%$ were only achievable with a total collector area in excess of $32.3 \mathrm{~m}^{2}$. This was set as the minimum total collector area for further simulations. The upper limit was set as $48.4 \mathrm{~m}^{2}$, or 6 parallel arrays with 3 collectors in series. This was established based on the limited gains made by further increasing the total collector area. For a $2000 \mathrm{~L}$ tank, the upper limit for storage volume as described in Section 5.2.2, auxiliary energy use would drop by less than 2.0 GJ when increasing the total collector area above $48.4 \mathrm{~m}^{2}$. For smaller tank volumes auxiliary energy use would decrease by a smaller margin when increasing total collector area.

\subsubsection{Storage Tank Baseline Parameters}

Initial estimates regarding the parameters of the storage tanks used in the simulations presented were based on commercially available tanks from Viessmann and Austria Email. There was very limited variation regarding insulation levels for the tanks examined. All tanks had close to ten centimetres of insulation and height to diameter ratios ranging from $2-3$. The smallest tanks that were available from these companies were $130 \mathrm{~L}$ tanks while the largest were $5000 \mathrm{~L}$ tanks.

The height to diameter ratio runs contrary to what researchers have suggested in the literature. Ismail et al. [56] and Nelson et al. [57] suggest a height to diameter ratio between 3 and 4 . These increased height to diameter ratios allow for increased stratification and improved system performance. However, practical limitations on tank height may impede the commercial release of such tanks. The tanks for this research were modeled as though they were placed in the homes' basements. Therefore, the basement height was determined to be the limiting factor as far as tank height was concerned. Simulations kept a constant height to diameter ratio of 2. Above this height to diameter ratio the tank height would become too large for many of the homes and the tanks could not physically be placed in the basements. Some 
researchers have found that larger tank volumes are insensitive to height to diameter ratios [39].

During the IEA SHC Task 26 project researchers examined non-seasonal storage tank volumes ranging in volume from 180-2000 L [30]. Other researchers have examined larger volumes up to $4000 \mathrm{~L}$ [39]. However, above $2000 \mathrm{~L}$ the storage tank is typically employed as a seasonal storage system. One example of a large tank not employed as a means of seasonal storage is the tank used by Saskatchewan Research Council's Factor 9 home. They utilized a $2350 \mathrm{~L}$ tank [9]. They found that this volume was reasonable for their space heating and DHW needs. However, they recommended having a high level of insulation on such a large tank as they experienced unusually high heat losses. For this research initial tests were conducted for tank volumes, ranging from 500 to $4000 \mathrm{~L}$. These tests revealed that, while increasing the storage volume to large sizes did result in improved performance, in most cases, it was not necessarily optimal. Increasing the storage volume increased the amount of solar energy delivered to the tank but also increased tank losses. In order to determine what volumes would be tested in further simulations the reduction in auxiliary energy use was compared to the increase in tank losses for a set of initial simulations. These simulations were set for 500, 750, 1000, 1250, 1500, 2000, 2500, 3000, 4000 L storage tanks and 3 collectors in series in 4, 5, and 6 parallel branches.

Limited benefits were observed when increasing the tank volume above $2000 \mathrm{~L}$. The increase in standby losses, caused by the increase in volume, are greater than the benefits accrued by the reduction in auxiliary energy use that accompanies increasing the tank volume. For small collector arrays, which are not able to fully heat the storage tank, any increase in storage volume will actually increase the required auxiliary energy use. This is the case if the ratio of tank volume to collector area ever gets too large. For all tested cases it appears that above a $\mathrm{L} / \mathrm{m}^{2}$ ratio of 128 auxiliary energy use increases as tank volume increases. This was true for collector arrays as large as $46.8 \mathrm{~m}^{2}$. Larger arrays were not tested. If tank volumes were less than 1000 $\mathrm{L}$ it was found that the high temperature cutoff for the solar loop would frequently be reached. This lead to the collector remaining idle for long periods of time. The collector outlet temperature would be high enough to provide energy to the tank but the tank simply could not accommodate any more high temperature fluid. Based on the information regarding reduced benefits of tanks larger than $2000 \mathrm{~L}$, and the poor performance of tanks smaller than $1000 \mathrm{~L}$, further tests were confined to tank 
volumes between 1000 and $2000 \mathrm{~L}$.

While increasing tank volume does increase the capacity of the system, a major limiting factor, which cannot be adjusted in practice, is the narrow temperature band required in DHW systems. Tanks must regularly be heated to $60{ }^{\circ} \mathrm{Cin}$ order to prevent concerns regarding bacterial growth. However, tanks cannot be held at so high a temperature where boiling becomes a concern. This restricts the operating range of theses systems to between 60 and $90{ }^{\circ} \mathrm{C}$. In this research minimum allowable tank temperatures were set to $50^{\circ} \mathrm{Cwhen}$ there was no hot water demand.

Insulation thickness for storage tanks is also an important parameter to examine. While all the tanks commercially available had roughly $10 \mathrm{~cm}$ of insulation this is not what is recommended by the literature. Lundh et al. [39] suggest using $30 \mathrm{~cm}$ thick insulation while Asaee et al. [35] suggests employing an insulation thickness of $15 \mathrm{~cm}$. Lundh states that adding more insulation than the $30 \mathrm{~cm}$ they recommend is wasteful as there is limited benefit. A brief sensitivity study was done for a single home and plant configuration. Insulation thickness levels were initially set to $10 \mathrm{~cm}$ and gradually increased to determine the effects of increased insulation on performance. Auxiliary energy required and energy losses were used as performance metrics for this simulation.

Initial testing, done on $750 \mathrm{~L}$ and $2000 \mathrm{~L}$ tanks, respectively, revealed that there was very limited change in the tank losses, and the auxiliary energy required, when increasing insulation levels above $15 \mathrm{~cm}$. These tests were run for a year for system A described in Section 5.4. Both the $750 \mathrm{~L}$ tank and the $2000 \mathrm{~L}$ tank were connected to a $23.4 \mathrm{~m}^{2}$ collector array. The house selected for testing was the midsize 1955 home. Results from these tests can be seen in Table 5.5. Insulation levels were raised to unrealistic levels of $50 \mathrm{~cm}$ in order to determine the extent to which high insulation levels affect performance. As can be seen in Table 5.5 when increasing insulation levels from 15 to $20 \mathrm{~cm}$ auxiliary energy requirements were only reduced by 0.1 GJ for the $750 \mathrm{~L}$ tank system and by 0.2 GJ for the $2000 \mathrm{~L}$ tank system. When comparing performance at $15 \mathrm{~cm}$ of insulation to performance at $50 \mathrm{~cm}$ of insulation there is only an observable reduction of auxiliary energy requirements of 0.3 GJ for the 750 L tank system and 0.7 GJ for the $2000 \mathrm{~L}$ tank system. While the tank losses do continue to drop there is limited benefit in increasing insulation levels above $15 \mathrm{~cm}$ as the auxiliary energy use does not significantly change.

Tank losses, and by proxy, insulation levels should be affected by the DHW draw 
Table 5.5: Comparison of insulation levels in $750 \mathrm{~L}$ and $2000 \mathrm{~L}$ tank

\begin{tabular}{c|cc|cc} 
& \multicolumn{2}{|c|}{$750 \mathrm{~L}$ Tank } & \multicolumn{2}{c}{2000 L Tank } \\
\hline Insulation & Auxiliary Energy & Tank & Auxiliary Energy & Tank \\
thickness (cm) & Required (GJ) & Losses (GJ) & Required (GJ) & Losses (GJ) \\
\hline 5 & 31.2 & 6.5 & 32.8 & 12.41 \\
10 & 30.5 & 3.7 & 31.6 & 7.2 \\
15 & 30.3 & 2.5 & 31.1 & 5.0 \\
20 & 30.2 & 1.9 & 31.0 & 3.8 \\
25 & 30.2 & 1.5 & 30.7 & 3.1 \\
30 & 30.1 & 1.2 & 30.7 & 2.6 \\
35 & 30.1 & 1.1 & 30.6 & 2.2 \\
40 & 30.0 & 0.9 & 30.5 & 1.9 \\
45 & 30.0 & 0.8 & 30.5 & 1.7 \\
50 & 30.0 & 0.7 & 30.4 & 1.5
\end{tabular}

profile used. A user who primarily uses DHW in the morning would experience greater tank losses throughout the night and much of the solar energy which was stored would be lost over the night. However, this trend was not observed in simulations. The magnitude of the daily draw was seen to have a much greater effect on system performance than time of use. This was observed in annual simulations which were run using only a solar hot water system.

\subsection{House Models}

The house models selected for this research were chosen based on average floor areas for Canadian homes, housing vintages, and location. The floor areas selected for this research represent the average for Canadian homes. Data on heated floor areas of Canadian homes was taken from the Energy Use Handbook. Homes were selected to represent homes constructed in the $50 \mathrm{~s}, 70 \mathrm{~s}$, and $90 \mathrm{~s}$. These years were chosen to allow examination of older homes, which are likely to have building envelopes composed of materials which do not insulate well, and newer homes, which are likely to have higher performing building envelopes. 
Table 5.6: Summary of information on homes used

\begin{tabular}{|c|c|c|c|c|c|c|c|}
\hline $\begin{array}{l}\text { Vintage and } \\
\text { size category }\end{array}$ & Location & $\begin{array}{l}\text { Annual heating } \\
\text { load (GJ) }\end{array}$ & $\begin{array}{l}\text { Heated floor } \\
\text { area } \mathrm{m}^{2}\end{array}$ & Orientation & $\begin{array}{l}\text { Roof incline } \\
\text { (degrees) }\end{array}$ & $\begin{array}{c}\text { Roof } \\
\text { area } \mathrm{m}^{2}\end{array}$ & $\begin{array}{l}\text { Radiator } \\
\text { size }(\mathrm{kW})\end{array}$ \\
\hline Midsize 1955 & Toronto & 57.7 & 145.0 & Due south & 22.8 & 77.8 & 8.9 \\
\hline Midsize 1974 & London & 69.5 & 143.0 & 45 degrees west of south & 36.0 & 89.0 & 10.5 \\
\hline Midsize 1990 & Thunder Bay & 98.9 & 132 & Due east & 22.8 & 70.5 & 11.3 \\
\hline Large 1990 & Toronto & 51.6 & 222.0 & 45 degrees west of south & 30.8 & 88.3 & 9.3 \\
\hline
\end{tabular}


Information on heating loads was gathered using an ideal heating system which injected heat to zones to achieve a zone temperature of $20{ }^{\circ} \mathrm{C}$. Radiators were sized to accommodate the $99 \%$ of the heating loads which occurred throughout the year. The homes experienced maximum heating loads throughout the year that would necessitate the installation of a radiator 3 to $4 \mathrm{~kW}$ larger than the radiator sizes given in Table 5.6. However, these high heating loads occurred for only a few five minute time intervals throughout the year. Sizing the radiators to accommodate $99 \%$ of the heating loads was deemed a good balance between occupant comfort and equipment size.

When characterizing the radiator in ESP-r, parameters, such as weight and specific heat, were established based on information provided by manufacturers documentation from Stelrad. In addition to information on radiator specifications ESP-r also required information regarding the performance of the radiator in terms of convective versus radiative output. According to Beck et al. [58] radiators typically output heat at a ratio of $45 \%$ radiative and $55 \%$ convective. This information was used to characterize performance in simulations.

The higher heating load observed in Table 5.6 for the midsize 1990 home can be attributed to its location. Thunder Bay lies at a latitude of 48.4 degrees north in comparison to 43.7 degrees north for Toronto and 42.9 degrees north for London. This harsher climate leads to lower ambient temperatures throughout the year and a higher heating load. A graph showing the average monthly temperatures for the three locations can be seen in Figure 5.3.

All of the homes, with the exception of the Large 1990 home, were one story with an unheated basement and unheated attic. These homes were all modelled as having a single heated zone on the main floor. The plant equipment was modeled as being in the unheated basement. For this reason all heat losses from the storage tanks were injected into the basement. The basement temperature was used in the energy balance for the storage tanks to determine heat losses from the tanks. All remaining information regarding casual gains, including casual gains due to appliances, lighting and occupant behaviour, were established based on information provided within CHREM boundary condition files. In addition, information regarding the building envelope was taken from the CHREM database.

Zones were controlled to be maintained at $20 \pm 0.5^{\circ} \mathrm{Cby}$ the radiators during the daytime. A nighttime setback was implemented to reduce the overall heating load. 


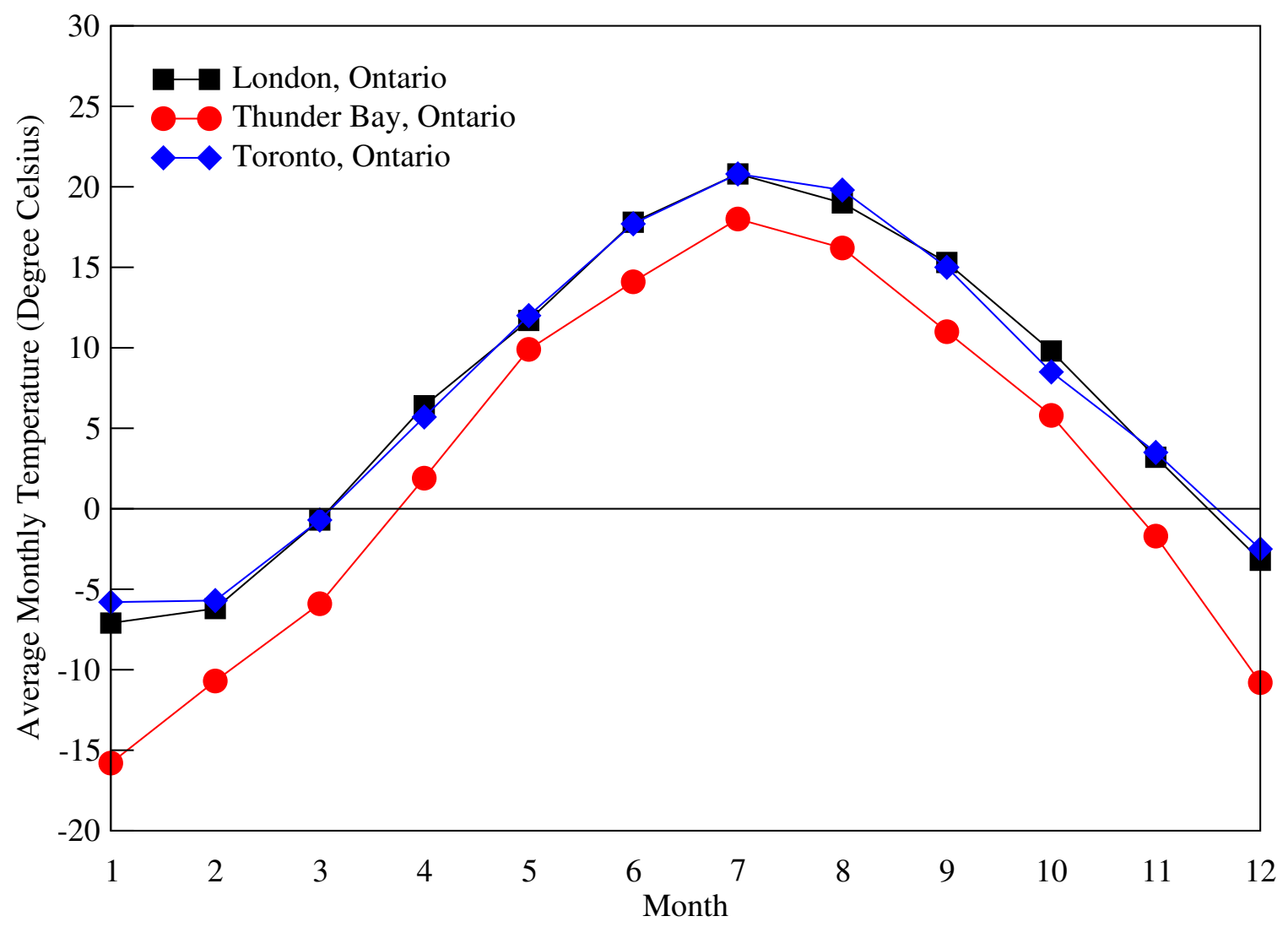

Figure 5.3: Average monthly ambient temperatures for the homes simulated. 
This reduced the heating set point to $18{ }^{\circ}$ Cbetween 2300 and 0600 hours.

The effects of a cooling system were not modeled in this research as they were deemed extraneous to the performance of a combisystem which did not integrate an absorption or adsorption cooling system. However, windows were modeled to open when zone temperatures reached $26^{\circ} \mathrm{Cand}$ ambient temperatures were greater than 18 degrees. This ensured that windows would not open during the heating season.

\subsection{General System Setup}

This research investigates two possible solar combisystem plant configurations in detail. The plant systems were selected using the 19 systems studied in the IEA SHC Task 26 as a baseline. While it may seem redundant to attempt to improve upon a system that has already been tested, it should be noted that the testing and optimization undertaken as part of IEA SHC Task 26 was done for three European climates. Simulations were run for Zurich, Switzerland; Carpentras, France; and Stockholm, Sweden. These three locations have different climates than Canada and, therefore, the results of task 26 could not be applied arbitrarily to Canadian homes.

The remainder of this section will detail the system setup and control strategies employed. System A, adapted from IEA SHC Task 26 system 4, represents an unusual system which is not commonly seen in Canada. Three internal heat exchangers are used within a single tank to provide space heating and DHW. This system was selected as it is not commonly seen in Canada. By studying a system not used before in Canada the efficacy for this climate can be determined. Limited adjustments were made to the plant. The internal heat exchangers described by Task 26 were replaced with external heat exchangers. System B, adapted from IEA SHC Task 26 system 6, represents a more traditional solar thermal system in Canada. This was tested alongside System A to determine if this more traditional system offered superior performance to a more novel plant configuration. A small DHW tank is connected to a larger preheat tank which is used as the store for solar thermal energy. The outlet of the preheat tank is connected to the inlet of the DHW tank. The original plant from IEA SHC Task 26 included internal heat exchangers. These were replaced with external heat exchangers. In addition, a heat exchanger was originally used to transfer heat between the two tanks. This heat exchanger was removed for this research and, instead, the outlet from the preheat tank was linked directly to the inlet of the DHW tank. 


\subsubsection{System A}

The plant layout for system A can be seen in Figure 5.4. In this diagram, and the plant diagram for system $\mathrm{B}$, the white triangles represent inlets and the black triangles represent outlets. It involves a single tank with three external heat exchangers. The first heat exchanger is used for heat transfer between the solar loop and the DHW tank. It is connected to the lower third of the DHW tank. The second heat exchanger is used to transfer heat from the auxiliary heater and the DHW tank. It is connected to the middle third of the tank. The final heat exchanger is used to extract heat from the DHW tank for space heating. It is connected to the upper third of the tank. Three diverter valves are used to control the flow of water throughout the system.

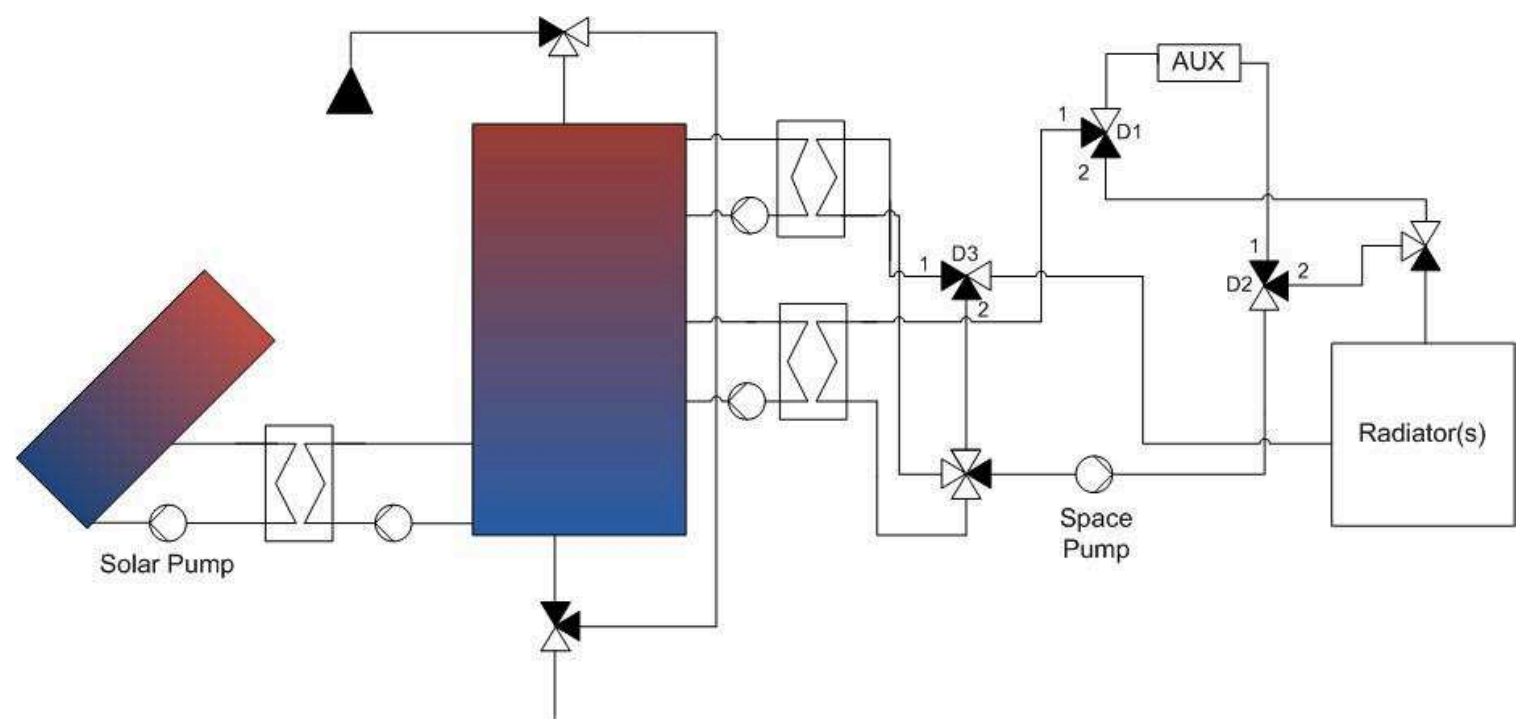

Figure 5.4: System A configuration

Diverter 1 (D1), as labeled in Figure 5.4, controls whether auxiliary heat is supplied to the hot water tank or the radiators. If there is flow out of the DHW tank, and the top of the tank is at a temperature below $60{ }^{\circ} \mathrm{C}$, then flow is put through the first outlet. This ensures that the water that exits the tank is maintained at $60{ }^{\circ} \mathrm{C}$. If there is no demand for hot water, and the top node in the tank is below $50^{\circ} \mathrm{C}$, flow is still directed out the first outlet. This is done to ensure that tank temperatures never fall low enough to cause concerns regarding bacterial growth. When either of the two conditions described above are met, the path the working fluid takes the green path indicated in Figure 5.5. If neither of the above conditions is met then flow is directed 


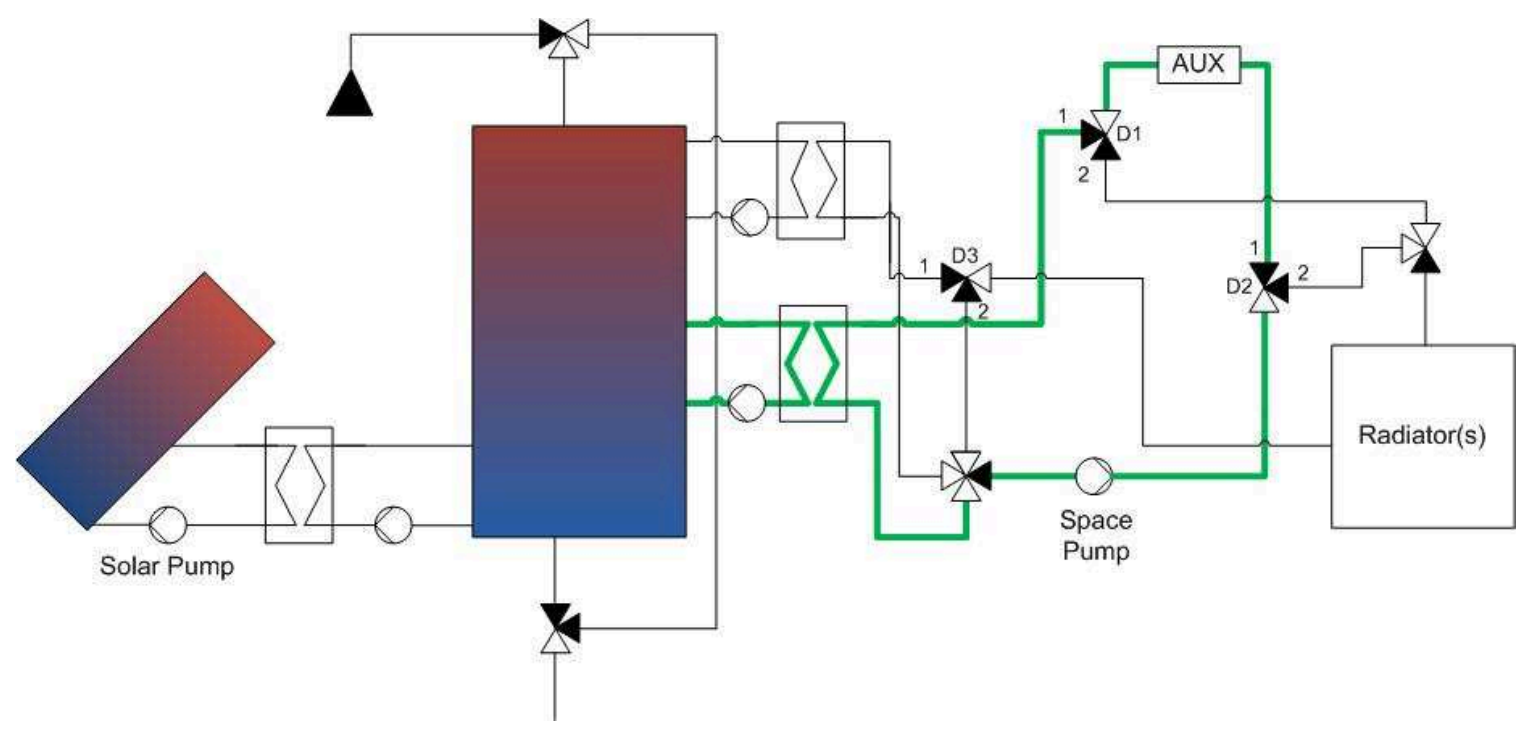

Figure 5.5: System A configuration when DHW heating is required

out of the second outlet to provide space heating.

Diverter 2 (D2) is used to control whether additional heating of the fluid is required for the radiators. If DHW heating is not required, and the temperature of fluid exiting the space heating pump is below $55^{\circ} \mathrm{C}$, flow is directed through the first outlet. This is done to ensure that the temperature entering the radiator system is maintained at a minimum of $55{ }^{\circ} \mathrm{C}$ which the system was designed to operate under. This is 35 ${ }^{\circ}$ Cabove the desired room temperature. This condition is illustrated by the green path in Figure 5.6.

The final diverter valve (D3) is used to control the reheat loop of the system. If the temperature of fluid leaving the radiator is below the temperature of the DHW tank where the heat exchanger is placed, flow is directed through the first outlet. This allows the fluid stream to uptake heat from the tank and places less demand on the auxiliary heating system. This condition is illustrated by the green path in Figure 5.7.

\subsubsection{System B}

The plant layout for System B can be seen in Figure 5.8. A preheat tank is connected to the solar loop. Mains water enters the base of the preheat tank and water, which is heated by the solar loop, leaves the top of the preheat tank to enter the base of a 


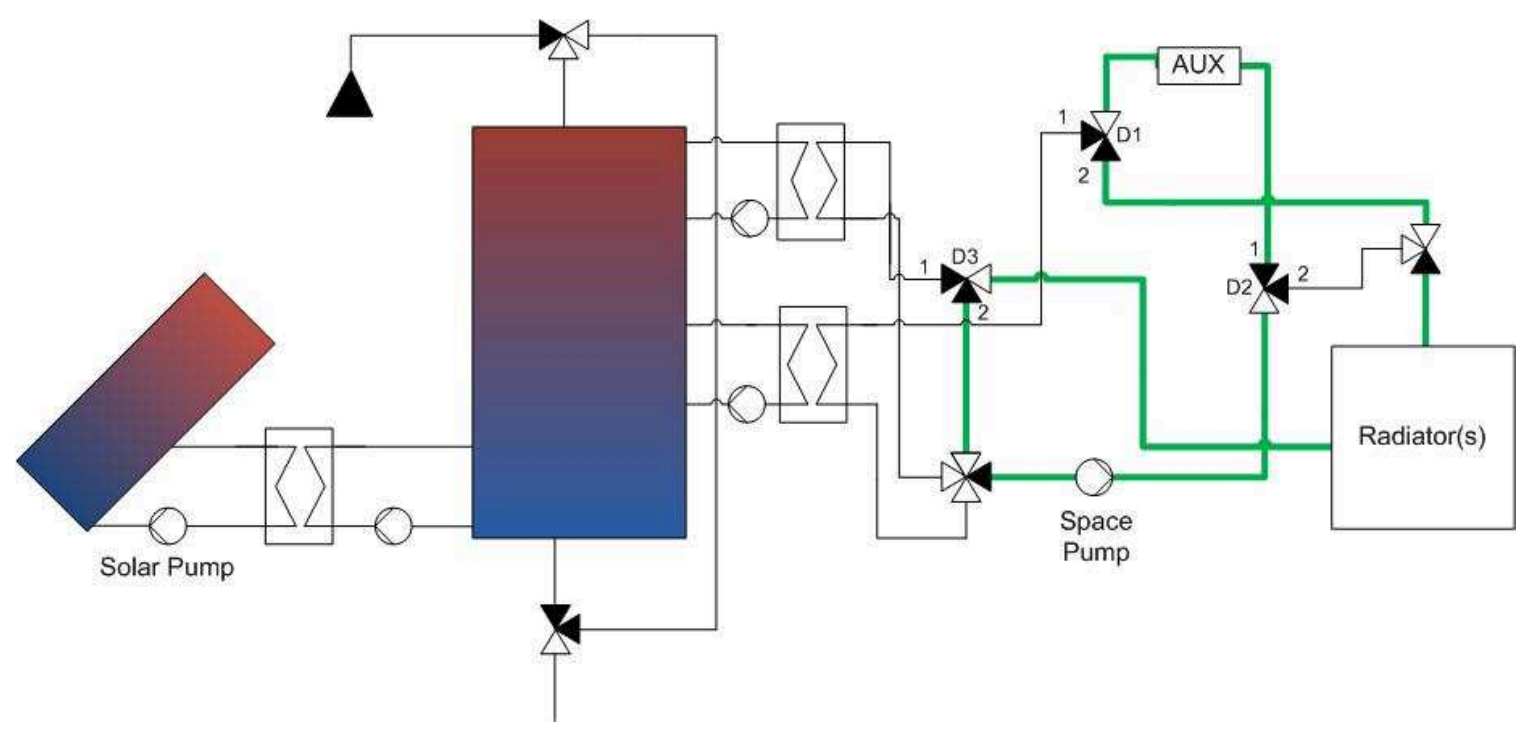

Figure 5.6: System A configuration when additional heating is required for the radiators

small DHW tank. Fluid exiting the DHW tank is controlled to be at a temperature of $60{ }^{\circ} \mathrm{C}$. Auxiliary heat is added to the DHW tank via an external heat exchanger. A inline heater is included in the space heating loop to allow for additional heating of the radiator fluid if necessary. The solar loop is connected to the preheat tank via an external heat exchanger placed in the lower third of the tank. The reheat heat exchanger, for the preheat tank is connected to the top third of the preheat tank. The reheat heat exchanger for the DHW tank is placed in the top third of the DHW tank.

Flow throughout the system is controlled via 2 diverter valves. Diverter 1 (D1), as labeled in Figure 5.8, checks the temperature of the fluid exiting the radiator against the temperature of reheat heat exchanger in the preheat tank. If the temperature of fluid exiting the radiator is below the temperature of the lower portion of the heat exchanger then flow is passed through the second outlet. This condition is illustrated by the green path in Figure 5.9.

If the preheat tank is not at a high enough temperature to provide additional heating then flow is directed through outlet 1. Diverter 2 (D2) operates under a similar principle. However, instead of extracting heat from the preheat tank it is extracted from the DHW tank. When temperature entering the second diverter valve 


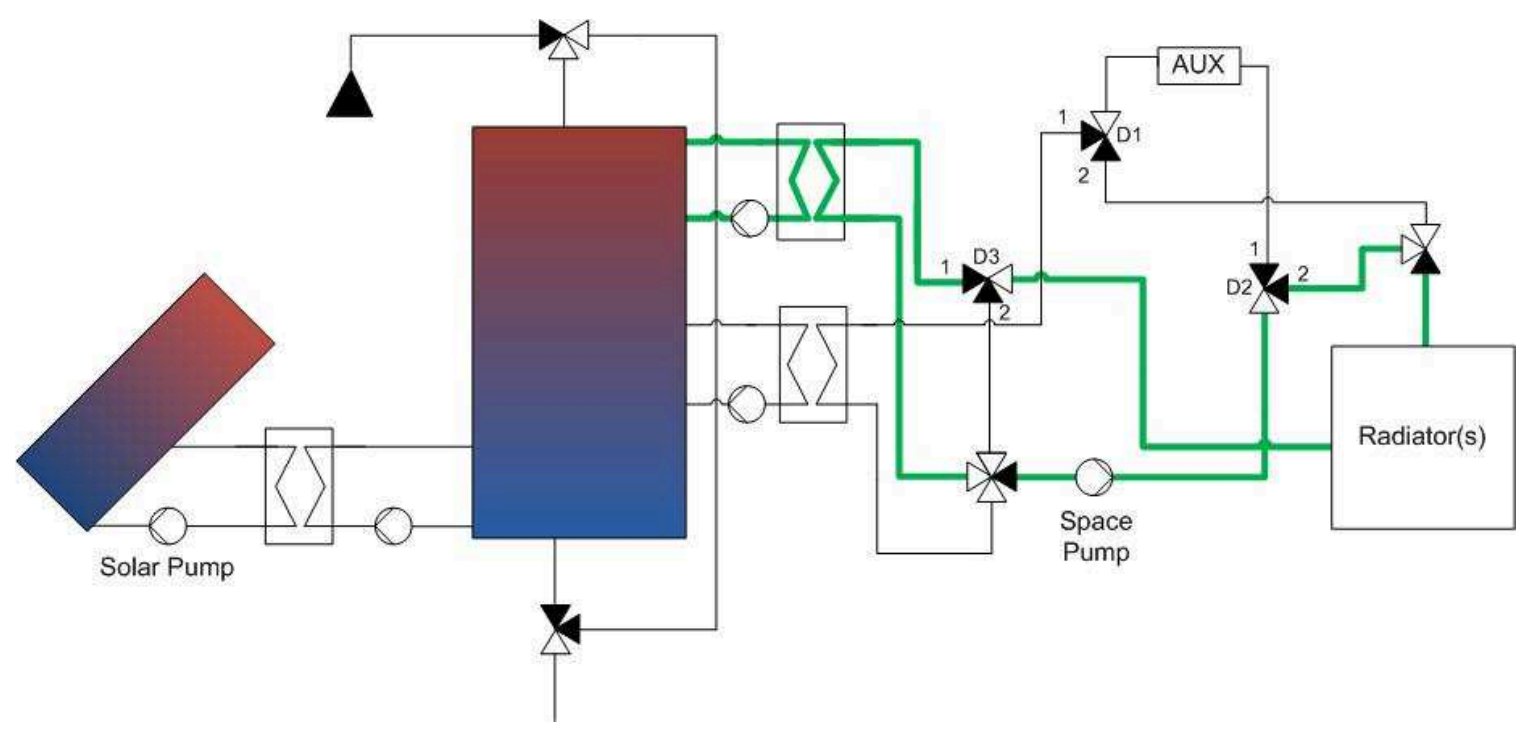

Figure 5.7: System A configuration when no additional heating is required for the radiators

(D2) is below the temperature of the heat exchanger in the DHW tank then flow is directed through the first outlet. This condition is illustrated by the green path in Figure 5.10.

The internal auxiliary heater for the DHW tank was controlled in a similar fashion to System A. If the temperature at the top of the tank falls below $60{ }^{\circ}$ Cand there was a draw from the tank then the auxiliary heater was turned on. Alternatively, if there is no draw, and the temperature at the top of the tank drops below $50{ }^{\circ} \mathrm{C}$, the auxiliary heater was turned on. Similarly, the external auxiliary heater, used for heating the space heating fluid, is turned on when fluid entering the heater is below $55^{\circ} \mathrm{C}$.

\subsection{Summary of Simulations Run}

For each of the plant systems 144 different simulations were run. This allowed for testing each of the 4 homes with the 2 systems, 4 draw profiles, 3 tank configurations, and 3 collector areas. The 4 draw profiles represent 4 different daily average draws. These are a below average consumer of $116 \mathrm{~L} /$ day, an average consumer of $186 \mathrm{~L} /$ day, a median consumer of $167 \mathrm{~L} /$ day, and an above average user of $236 \mathrm{~L} /$ day. In addition to testing a variety of draw magnitudes these profiles also represent a variety of 


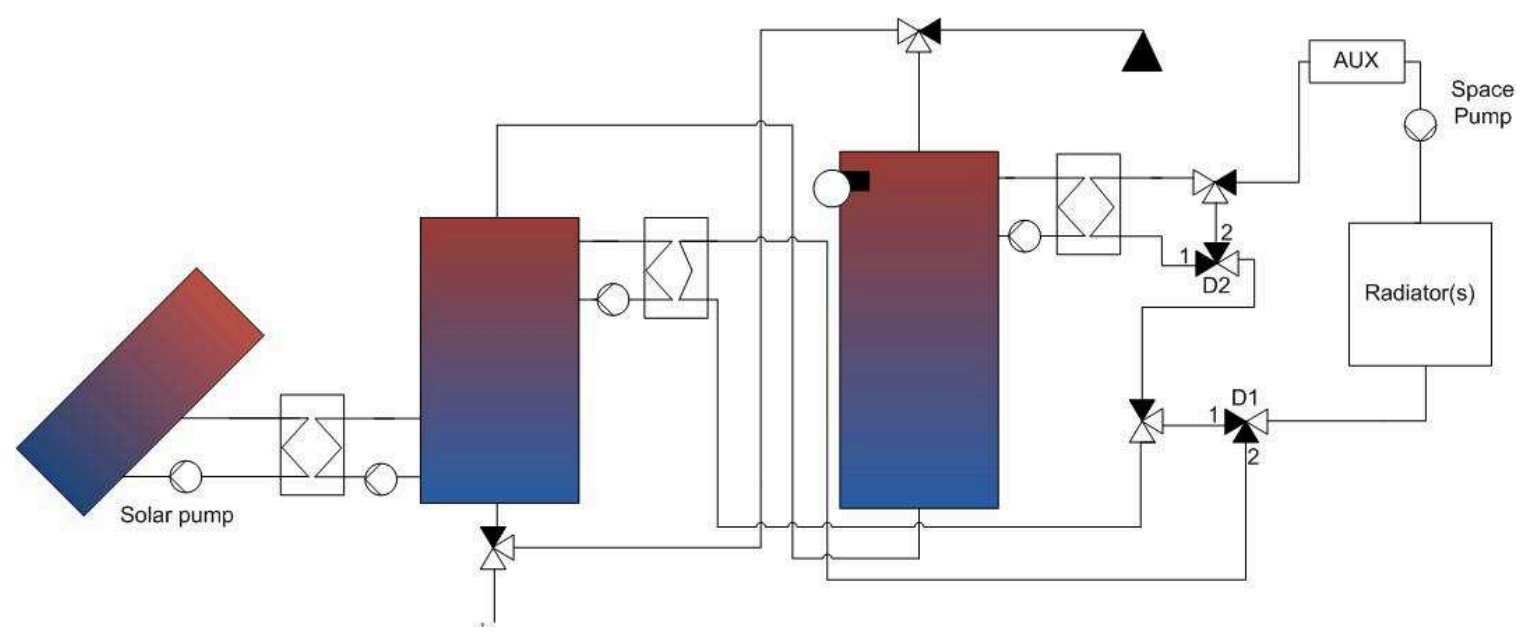

Figure 5.8: System B configuration

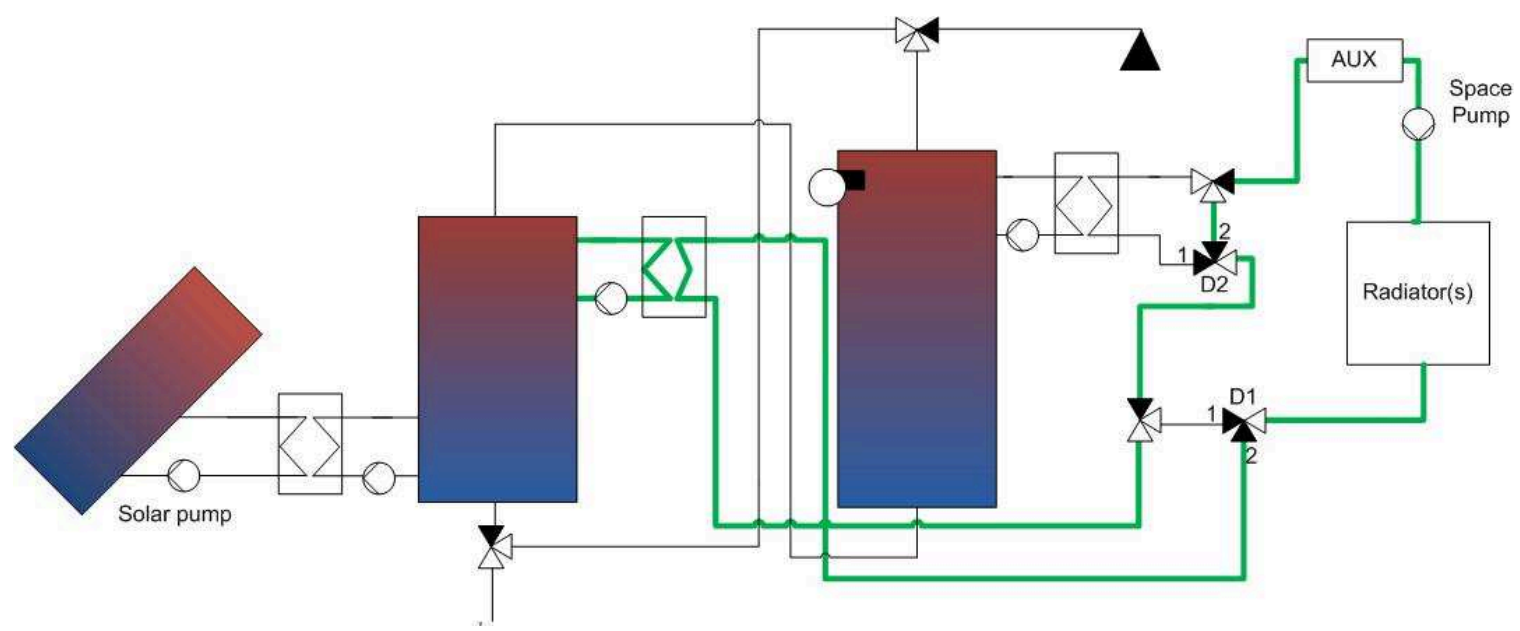

Figure 5.9: System B configuration with heat extraction from the preheat tank

times of use. The below average consumer uses the majority of their hot water in the morning, the average consumer uses the majority of their hot water in the evening, the median consumer uses the majority of their hot water in the morning, and the above average users demonstrates no preference for time of use. The three tank configurations include a $1000 \mathrm{~L}$ tank, a $1500 \mathrm{~L}$ tank, and a $2000 \mathrm{~L}$ tank. For system B, which employ two tanks, the DHW tank is kept at a fixed volume while the preheat tank volume is adjusted as described. These sizes were selected based on initial simulations described in Section 5.2.2. The solar collector configurations tested represent $31.2 \mathrm{~m}^{2}, 39 \mathrm{~m}^{2}$, and $46.8 \mathrm{~m}^{2}$. These represent a variety of parallel configurations. All tested configurations utilize 3 collectors connected in series. These 


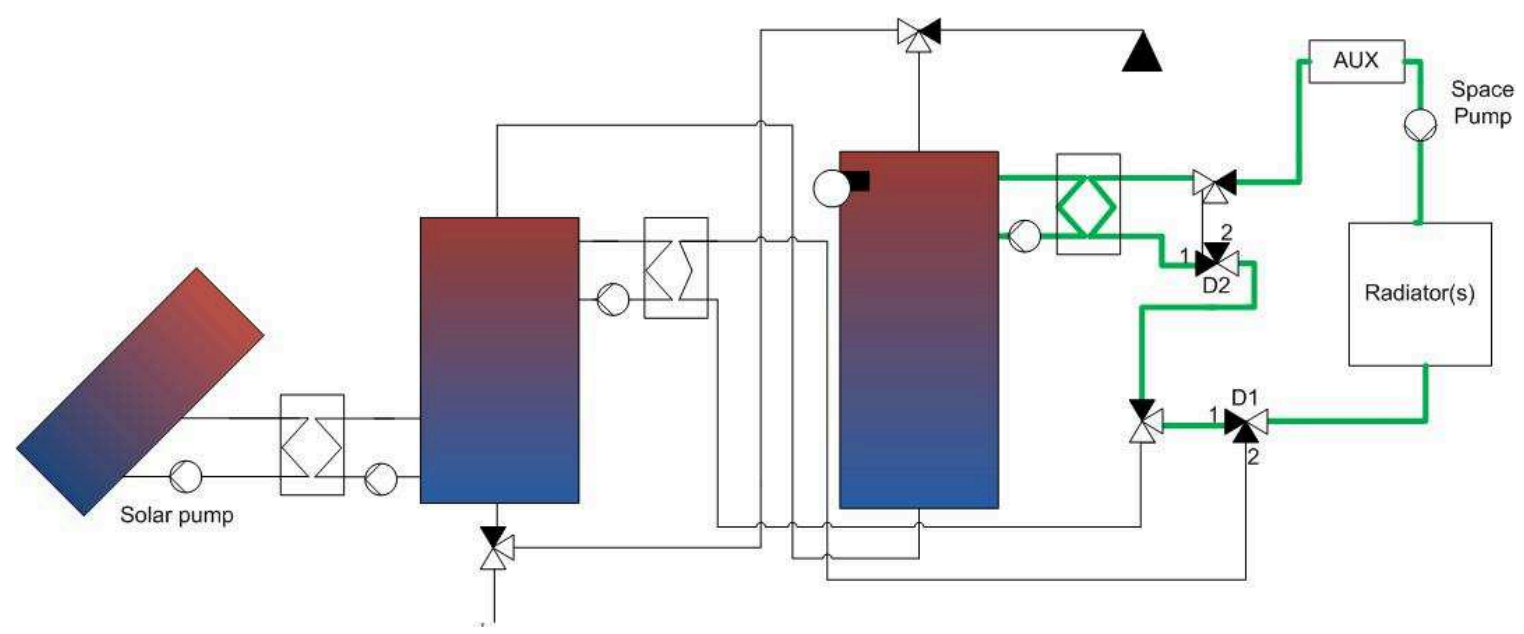

Figure 5.10: System B configuration with heat extraction from the DHW tank

configurations were selected based on initial simulations described in Section5.2.1.

All simulations were run using Canadian Weather for Energy Calculation (CWEC) files. These are artificial weather files created using hourly weather data collected between 1935 and 1995 .

\subsection{Performance Metrics}

The simulation runs described above were examined from a variety of perspectives. The interaction of tank losses and solar energy delivered to the tank were examined. As tank volume is increased, the tank losses increase. However, the amount of solar energy which can be delivered to the tank also increases. At a certain point the increase in tank losses will exceed the increase in solar energy collected. For each of the collector configurations the difference in solar energy collected between the 1500 $\mathrm{L}$ and $1000 \mathrm{~L}$ tanks and the $2000 \mathrm{~L}$ and $1500 \mathrm{~L}$ tanks was determined. These values were compared to the change in tank losses. This calculation is shown in simplified form in Equation 5.4. When the result of this calculation drops below zero there is no benefit in increasing the tank volume. That is to say, the increase in tank losses, due to increasing surface area with increasing tank volume, is greater than the increase in solar energy collected by increasing tank volume and, by proxy, increasing the capacity of the tank. 
(Total Solar Energy Collected with 1500 L tank - Total Solar Energy Collected with 1000 L tank) - (Tank Losses with 1500 L tank - Tank Losses with 1000 L tank)

Solar collector performance was assessed based on the difference between energy collected for different collector arrangements. As collector area is increased there are diminishing returns due to the overheating and the subsequent pump safety cutoff.

In addition to this energy based metric, the frequency at which the high limit cutoff for the solar pump was reached was also examined. When the temperature of the DHW tank, where the solar heat exchanger fluid enters the tank (node 16), reaches $90^{\circ} \mathrm{Cthe}$ solar pump is shut off to prevent the water in the storage tank from boiling. This value was only calculated using data from the fall, winter and spring. The reason for neglecting the summer is that even for small systems overheating may occur frequently. This high limit cutoff is less frequently achieved with larger tank volumes and more frequently achieved with large collector arrays. By presenting this value it can be determined whether or not the collector array is too large for the tank volume. The calculation used to determine this value is given in Equation 5.5

Number of occurrences of node 16

$$
\text { Solar pump cutoff frequency }=\frac{\text { being above } 90{ }^{\circ} \mathrm{C}}{\begin{array}{l}
\text { Number of occurrences of collector } \\
\text { outlet being warmer than node } 16
\end{array}}
$$

In addition to these isolated performance metrics other metrics, such as solar fraction and total auxiliary energy use, were investigated to determine overall system performance. The goal of this research is to size these systems to achieve a solar fraction of $50 \%$ and reduction in auxiliary energy use by $50 \%$ of the baseline for a home without a solar combisystem.

Solar fraction in this work is defined as follows:

$$
1-\frac{\text { Auxiliary Energy Use }+ \text { Solar Pump Energy }}{\text { DHW Load }+ \text { Space Heating Load }+ \text { DHW Tank Losses }}
$$


The solar pump energy is evaluated here based on data provided by IEA SHC Task 26. The equation they provide is as follows:

$$
\text { Solar Pump Energy }=44.6 \times e^{0.0181 \text { Collector Area }}
$$

The space heating pump energy use is ignored in this definition as solar fraction is being used to determine efficacy of a solar combisystem in comparison to a baseline system without a combisystem. The space heating pump energy use would be similar in both cases and therefore is not included.

Finally, the total auxiliary energy offset through the use of the solar combisystem will be examined. The total auxiliary energy requirement for the each home is given in Table 5.7. The values given in the table were established based on the base case space heating load, given in Section 5.3, and the average annual DHW loads, given in Section 4.2. 
Table 5.7: Average annual DHW and space heating energy usage of the homes and DHW load profiles used in this research (GJ)

\begin{tabular}{c|cccc} 
Draw Pattern & Mid-size 1955 home & Mid-size 1974 home & Mid-size 1990 home & Large 1990 home \\
\hline Below average DHW user & 66.0 & 77.8 & 107.2 & 59.9 \\
Average DHW user & 71.1 & 82.9 & 112.3 & 65.0 \\
Median DHW user & 69.6 & 81.4 & 110.8 & 63.5 \\
Above average DHW user & 74.9 & 86.7 & 116.1 & 68.8
\end{tabular}




\section{Chapter 6}

\section{Results and Discussion}

\subsection{Introduction}

This section will describe the results of the tests described in Chapter 5. This section will be divided based on the systems examined. The first section will present results for System A. The second section will present results for System B. The final section will provide an overview and comparison of the results for the various homes.

\subsection{System A}

This section will be divided into four subsections. These subsections will be segregated based on the parameters of interest described in Section 5.6. Graphical results will be provided for the mid-size 1955 home. In the interest of space the results for the mid-size 1974, mid-size 1990, and large 1990 home can be found in Appendix A. The results for the other homes will still be discussed within this section in order to determine the effects of space heating loads on system performance. Once all the parameters have been discussed in detail a general system recommendation will be made.

\subsubsection{Interaction of Energy Collection and Tank Losses for System A}

The interaction of tank losses and solar energy collected, for the mid-size 1955 home, is shown graphically in Figure 6.1. For all cases, excluding the case of an unusually high consumer using a $2000 \mathrm{~L}$ tank and a $48 \mathrm{~m}^{2}$ area collector array, there is a net 
benefit in increasing tank volume. For all other configurations, and draw profiles, the increase in solar energy collection is greater than the increase in tank losses.

When examining draw profile there is no observable effect due to temporal use. Both the median and average users, who use similar total volumes of water, experience the same benefits when increasing tank volumes. The increase in solar energy collection minus the increase in tank losses is very similar for both of them.

A summary of the range of values seen in the remainder of the homes studied can be found below in Table 6.1. The results of the mid-size 1974 and large 1990 home mirror the results observed for the mid-size 1955 to a reasonable degree. However, there was an aberration in the observed results for the mid-size 1990 home.

The trend observed for the 1955 home, where increasing tank volume will generally provide a benefit for all but the largest tank volume and smallest collector area, did not hold true for all homes studied. In fact, in nearly all cases for the mid-size 1990 home there was no benefit in increasing tank volume above $1500 \mathrm{~L}$. The increase in tank losses were almost always greater than the increase in solar energy collected for this home. The only situation in which a benefit was seen for increasing tank volume beyond $1500 \mathrm{~L}$ for this home was for the below average and average users each with 48 $\mathrm{m}^{2}$ collector area. The results suggest that this is due to lower ambient temperature which would lead to a lower temperature in the unheated basement area where the tanks were held. This would increase heat losses from the tank more rapidly.

In addition to the generally limited benefits observed for increasing tank volume for the mid-size 1990 home there was also a much larger effect due to draw profile observed for this home. The median DHW user was observed to have the least benefit from increasing tank volume from 1500 to $2000 \mathrm{~L}$ for all collector areas. There was a significant increase in standby losses from the tank when increasing from 1500 to 2000 L. The increase in solar energy collection could not match the increase in tank losses. Their predominantly morning based use leads to the tank remaining idle for a majority of the day. While solar energy is collected throughout the day in a similar manner to the other draw profiles it is not used and therefore, standby losses increase for this user.

The results presented here, while technically confirming that there is a benefit to increasing tank volume, suggest that there is limited benefit in increasing storage tank volumes beyond $1000 \mathrm{~L}$. When comparing the increase in solar energy collection and tank losses, the net benefit of increasing tank volumes provides less than 1 GJ of 


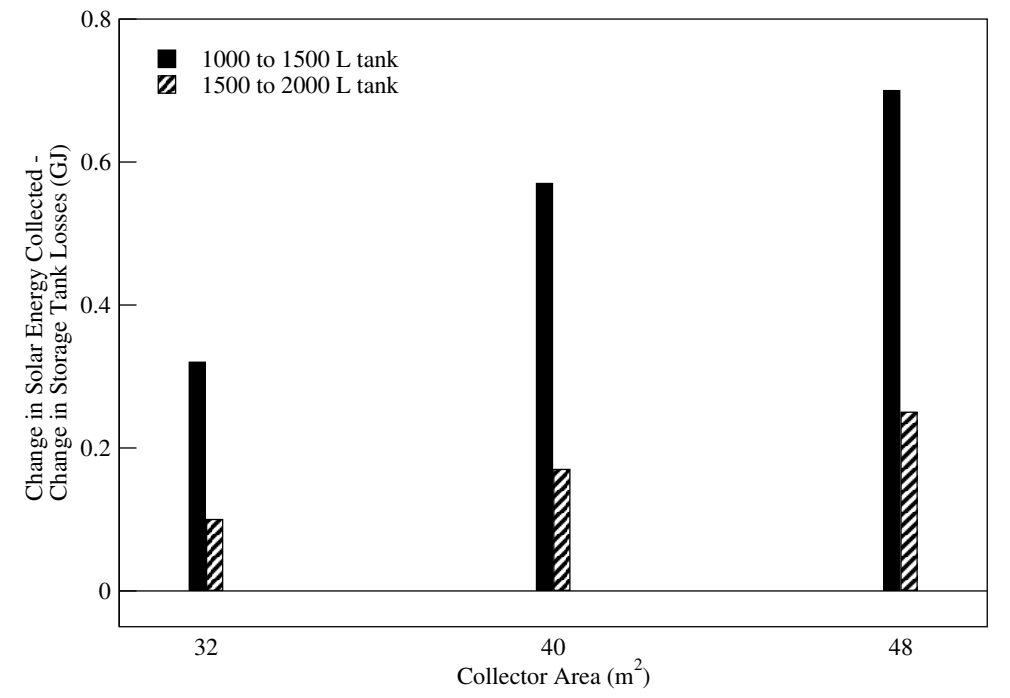

(a) Below average DHW consumer system A

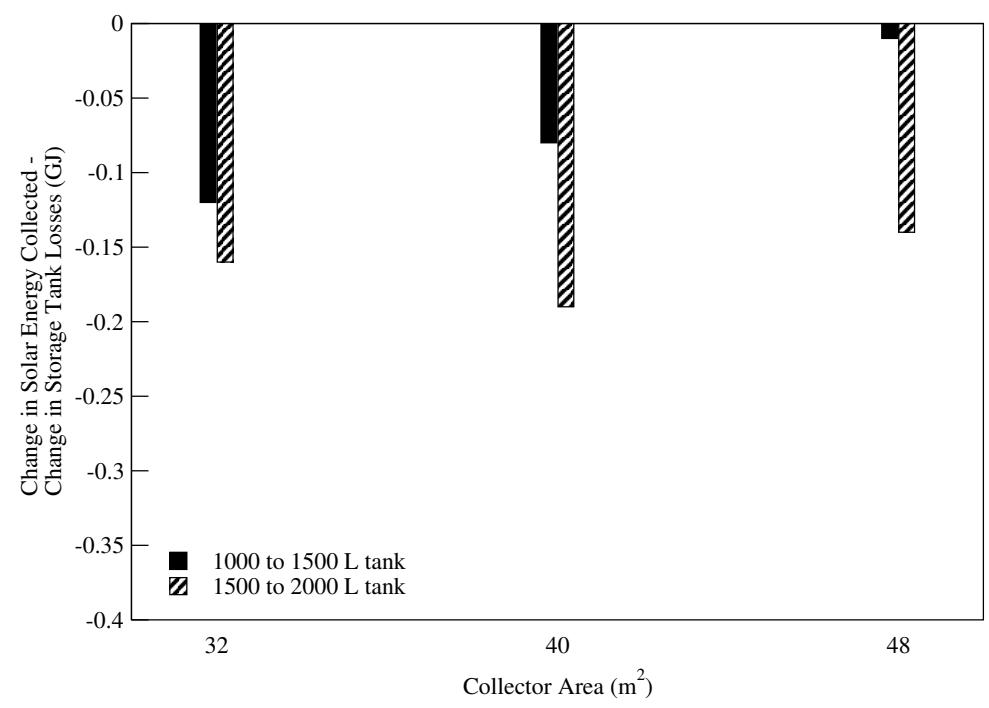

(c) Below average DHW consumer system B

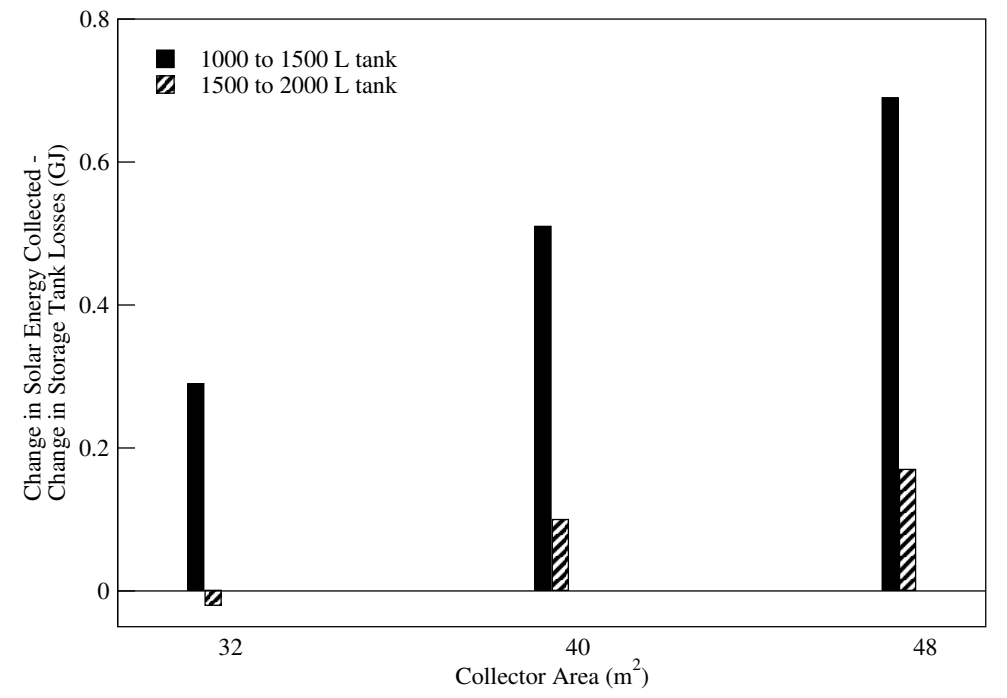

(b) Above Average DHW consumer system A

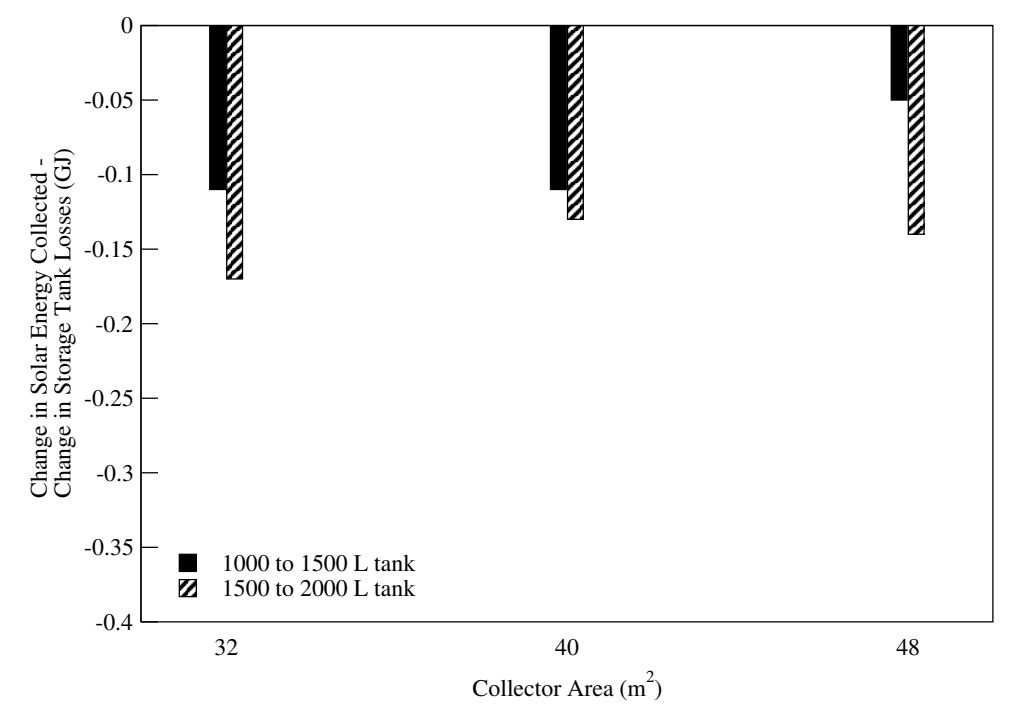

(d) Above Average DHW consumer system B

Figure 6.1: Difference in solar energy collected and DHW tank Losses when varying collector area and storage volume for mid-size 1955 home. 
energy to the home owners.

\subsubsection{Energy Collection for System A}

The increase in solar energy collection for the mid-size 1955 home can be seen in Figure 6.2. Draw profiles are not seen to have a significant effect on the increase in solar energy collection. Increasing tank volumes from 1000 to $1500 \mathrm{~L}$ always resulted in an increase in solar energy collection between 1.5 and $1.6 \mathrm{GJ}$, for the $32 \mathrm{~m}^{2}$ arrangement, and between 1.9 and $2.0 \mathrm{GJ}$, for the $48 \mathrm{~m}^{2}$ arrangement. Increasing tank volumes from 1500 to $2000 \mathrm{~L}$ proved to be less beneficial with increases in solar energy collection varying between 1.0 and 1.2, for the $32 \mathrm{~m}^{2}$ arrangement, and between 1.2 and 1.3 , for the $48 \mathrm{~m}^{2}$ arrangement.

This being said, it is pertinent to point out that the total solar energy collection for each of the draw profiles was quite different with the below average user only collecting, on average, across all storage volumes and collector arrangements, 24.3 GJ of solar energy and the above average user collecting, on average, across all storage volumes and collector arrangements, 28.9 GJ of solar energy.

A summary of the range of values seen in the remainder of the homes studied can be found in Table 6.2. Details of simulation results can be found in Appendix A. Results on increase in solar energy collection remain constant for all homes studied and the trends described above hold true for all cases. This result suggests that loads, both DHW and space heating related, have no significant effect on increases in solar energy collection. However, as was the case with the total solar energy collected, the homes with higher heating loads were able to collect more solar energy throughout the year.

\subsubsection{Solar Fraction for System A}

The solar fractions observed for the various draw profiles can be seen in Figure 6.3. The general trend is towards higher solar fractions for larger collector areas and storage tank volumes. However, for all cases studied for the mid-size 1955 home, increasing tank volume from $1000 \mathrm{~L}$ to $2000 \mathrm{~L}$ results in only a marginal increase in solar fraction. This is represents an increase in solar fraction of 3 percentage points 
Table 6.1: Range of results for differences in solar energy collected and storage tank losses when varying collector area and storage volume for remainder of homes studied

\begin{tabular}{c|cc|cc} 
House & $\begin{array}{c}1000-1500 \mathrm{~L} \\
\text { Minimum (GJ) }\end{array}$ & $\begin{array}{c}\text { 1000-1500 L } \\
\text { Maximum (GJ) }\end{array}$ & $\begin{array}{c}\text { 1500-2000 L } \\
\text { Minimum (GJ) }\end{array}$ & $\begin{array}{c}\text { 1500-2000 L } \\
\text { Maximum (GJ) }\end{array}$ \\
\hline Mid-size 1974 & 0.3 & 1.0 & -0.1 & 0.3 \\
Mid-size 1990 & 0.2 & 0.8 & -0.3 & 0.1 \\
Large 1990 & 0.3 & 0.7 & 0.0 & 0.3
\end{tabular}




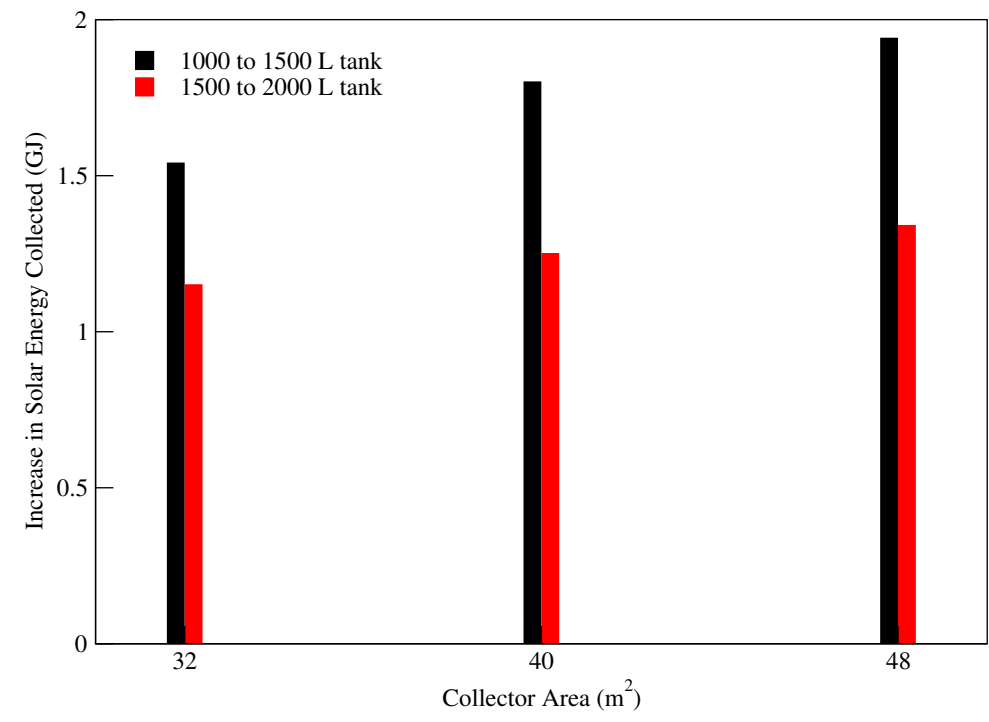

(a) Below average DHW consumer

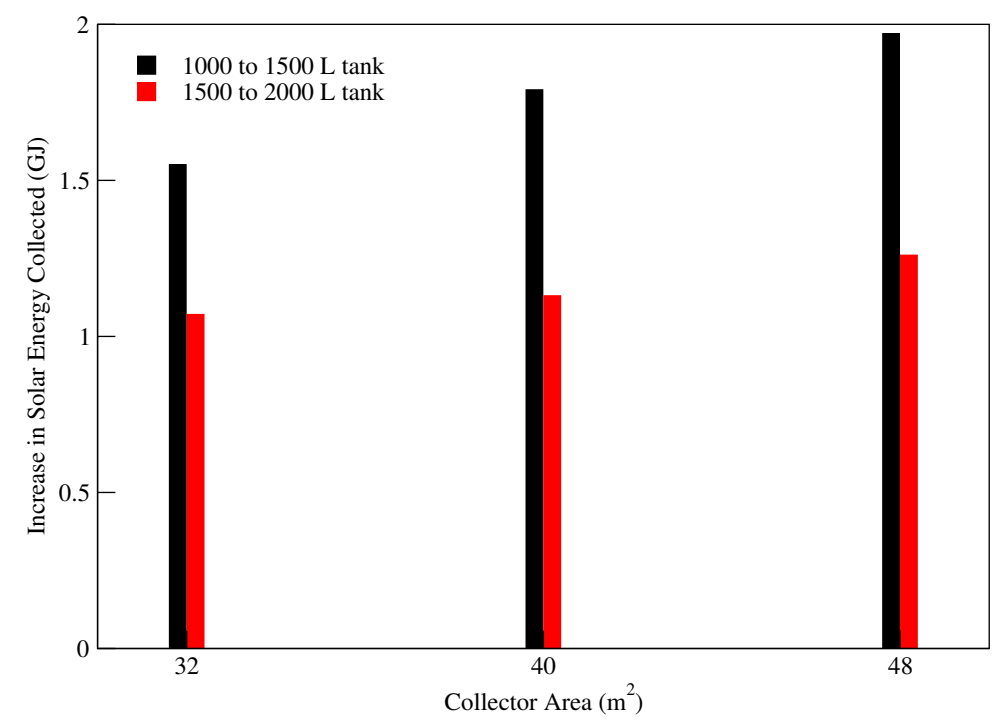

(c) Median DHW consumer

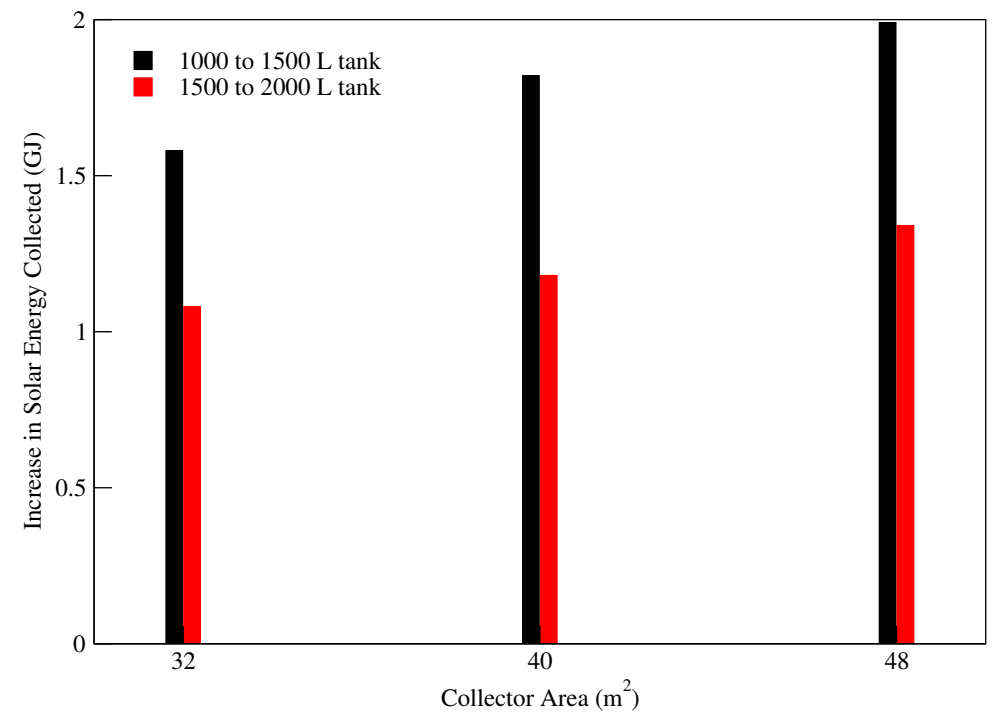

(b) Average DHW consumer

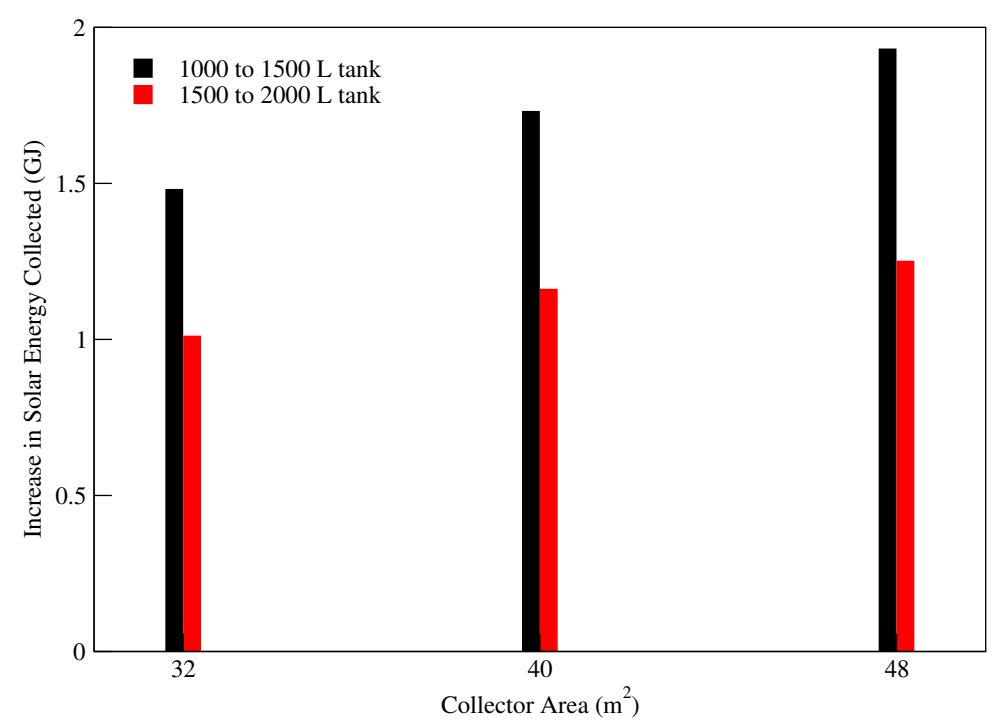

(d) Above average DHW consumer

Figure 6.2: Difference in solar energy collected when varying collector area and storage volume for mid-size 1955 home. 
Table 6.2: Range of results for differences in solar energy collected when varying collector area and storage volume for remainder of homes studied

\begin{tabular}{c|cc|cc} 
House & $\begin{array}{c}1000-1500 \mathrm{~L} \\
\text { Minimum (GJ) }\end{array}$ & $\begin{array}{c}\text { 1000-1500 L } \\
\text { Maximum (GJ) }\end{array}$ & $\begin{array}{c}\text { 1500-2000 L } \\
\text { Minimum (GJ) }\end{array}$ & $\begin{array}{c}1500-2000 \mathrm{~L} \\
\text { Maximum (GJ) }\end{array}$ \\
\hline Mid-size 1974 & 1.5 & 2.3 & 1.0 & 1.5 \\
Mid-size 1990 & 1.6 & 2.2 & 1.0 & 1.4 \\
Large 1990 & 1.5 & 2.0 & 1.1 & 1.4
\end{tabular}


for all collector areas and draw profiles. Increasing the total collector area from $32 \mathrm{~m}^{2}$ to $48 \mathrm{~m}^{2}$ only results in a marginal increase in solar fraction of roughly 4 percentage points for all tank volumes and draw profiles. Neither the magnitude, nor the time of use, of a draw profile appears to have a significant effect on the solar fraction.

One of the goals of this research, as stated in Section 1.3, was to determine a possible plant configuration for which a $50 \%$ solar fraction could be achieved. Unfortunately, none of the draw profiles or plant configurations for the mid-size 1955 home yielded this result. In order to produce a $50 \%$ solar fraction, tank volumes and/or solar collector areas would need to be increased. However, based on the information given in Figure 6.1 there would be limited benefit in increasing the storage volume unless collector area was also increased. The increase in tank losses would not justify the increase in energy collected resultant from increasing tank volume.

A summary of the range of values seen in the remainder of the homes studied can be found below in Table 6.3. For the mid-size 1955 home described in Figure 6.3 the largest storage volume and the largest collector area arrangement reach high solar fractions nearing $50 \%$. However, they never are able to achieve this goal. The only home which was able to do so was the Large 1990 home, the home with the lowest space heating load. The homes with the lowest heating loads, the mid-size 1955 home and the large 1990 home both had solar fractions significantly higher than the other homes studied. This runs contrary to the results presented by previous researchers who suggested that high solar fractions could only be achieved for homes with high space heating loads $[33,34]$.

\subsubsection{Solar Loop Safety Cutoff for System A}

The frequency with which the solar loop pump turns off during the fall through spring months can be seen in Figure 6.4. There is a trend toward less frequent cutoffs with higher DHW loads. This is to be expected as the higher DHW loads will result in lower average tank temperatures throughout the year and, therefore, less frequent occurrences of tank temperatures reaching 90 degrees Celsius. In addition larger collector arrays generally result in a higher frequency of cutoffs and larger storage volumes lead to less frequent cutoffs. Draw profile is seen to have a significant effect on pump cutoff. There is a 10 percentage point difference in the frequency of pump 


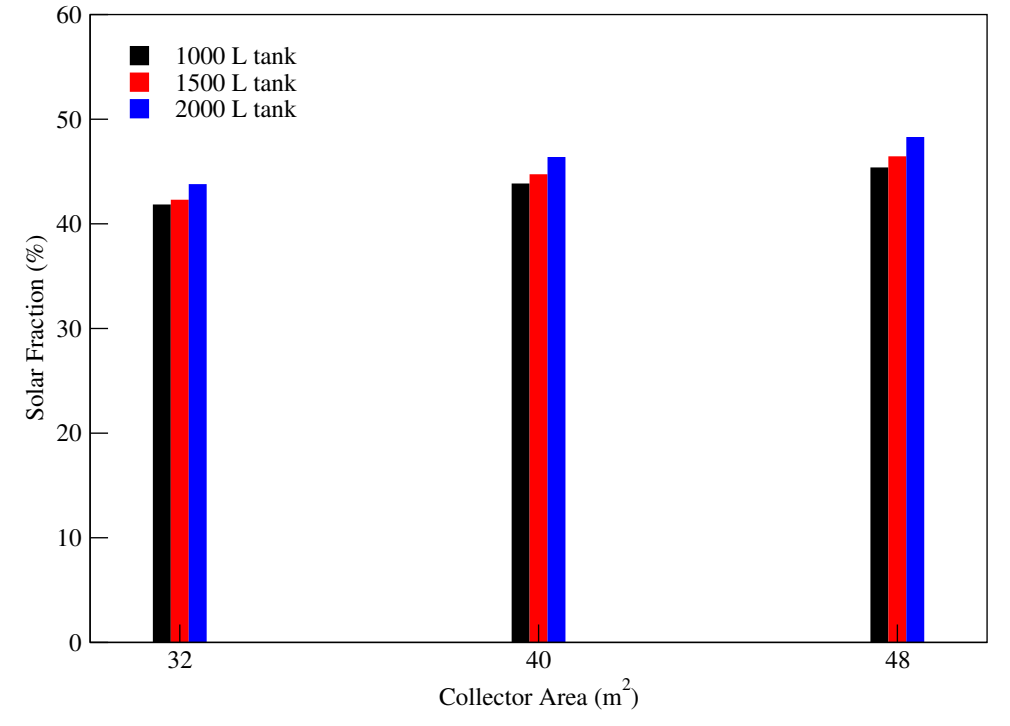

(a) Below average DHW consumer for system A

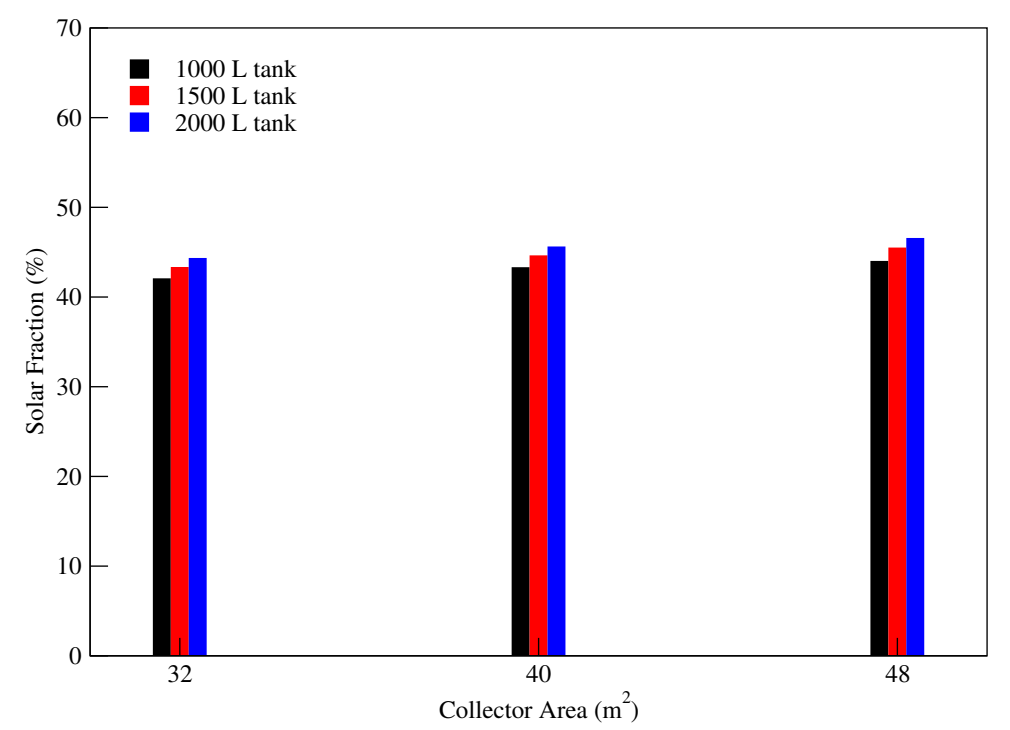

(c) Below average DHW consumer for system B

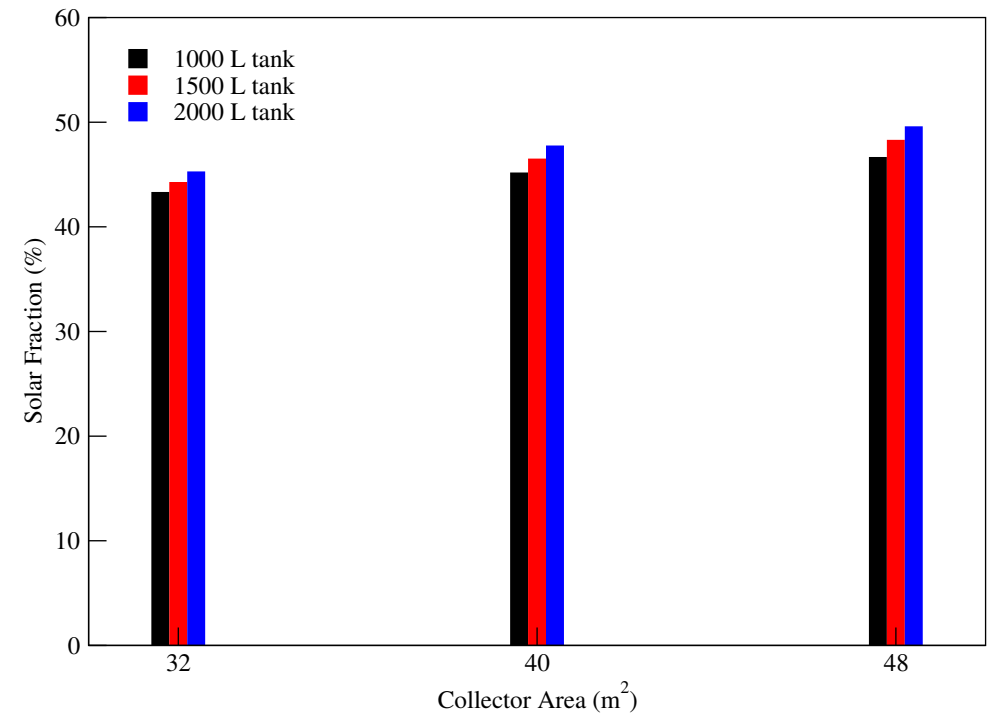

(b) Above Average DHW consumer for system A

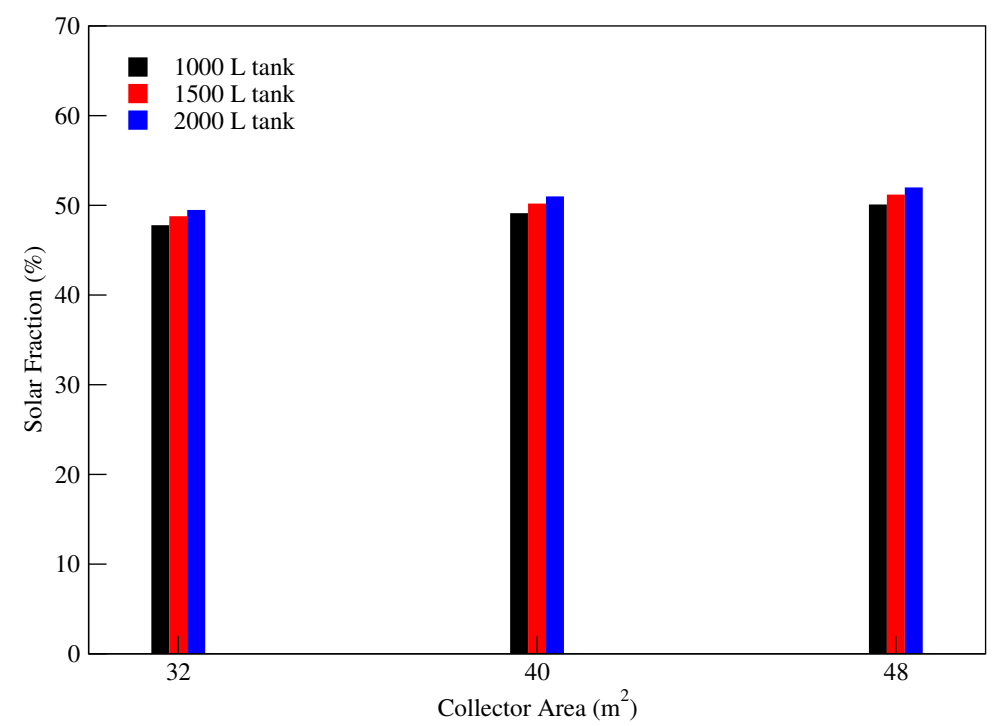

(d) Above average DHW consumer for system B

Figure 6.3: Difference in solar fractions when varying collector area and storage volume for mid-size 1955 home. 
Table 6.3: Range of results for solar fraction when varying collector area and storage volume for remainder of homes studied

\begin{tabular}{c|cc|cc|cc} 
House & $\begin{array}{c}1000 \mathrm{~L} \\
\text { Minimum (\%) }\end{array}$ & $\begin{array}{c}1000 \mathrm{~L} \\
\text { Maximum (\%) }\end{array}$ & $\begin{array}{c}1500 \mathrm{~L} \\
\text { Minimum (\%) }\end{array}$ & $\begin{array}{c}1500 \mathrm{~L} \\
\text { Maximum (\%) }\end{array}$ & $\begin{array}{c}2000 \mathrm{~L} \\
\text { Minimum (\%) }\end{array}$ & $\begin{array}{c}2000 \mathrm{~L} \\
\text { Maximum (\%) }\end{array}$ \\
\hline Mid-size 1974 & 37.0 & 41.9 & 37.1 & 42.7 & 38.0 & 43.9 \\
Mid-size 1990 & 39.5 & 44.4 & 39.2 & 44.5 & 39.5 & 45.0 \\
Large 1990 & 44.1 & 48.7 & 45.1 & 50.1 & 46.2 & 51.5
\end{tabular}


cutoffs for above average consumer and the frequency of pump cutoffs for the below

average consumer. The average and median user lie roughly halfway between the above and below average users.

The remainder of the homes produced results similar to those described above. Table 6.4 shows that the least cutoffs were experienced by the home with the highest heating load. An abnormality can be observed here though. The mid-size 1974 home, which has the second highest heating load, experiences the fewest pump cutoffs of all homes examined. A more in-depth analysis was conducted to determine the reasons behind this result. It was seen that the temperature of the fluid exiting the radiator system was frequently higher than the tank temperature where the reheat heat exchanger was placed. This resulted in less frequent extraction of heat from the tank and more frequently use of the auxiliary heater for space heating. This lead to more frequent cutoffs from the solar loop pump.

\subsubsection{Auxiliary Energy Use for System A}

As can be seen below in Figure 6.5 auxiliary energy use is sensitive to DHW load. Variation between the above average user and the below average user, who have a difference in average daily draw of approximately $100 \mathrm{~L} /$ day, results in a difference in auxiliary energy use of approximately 4 GJs for all plant arrangements. The mild variation between the median and average users can be attributed to the small variation, of approximately $20 \mathrm{~L} /$ day, in the magnitude of their average daily draw. While it was observed that solar fractions tended to increase with increasing storage volume, as seen in Figure 6.3, if the goal is to reduce overall auxiliary energy use it would be unjustifiable to increase storage volume beyond $1000 \mathrm{~L}$ for all but the users with the above average draw or the median DHW load. While there is a mild decline in auxiliary energy use when increasing from a $1500 \mathrm{~L}$ tank to a $2000 \mathrm{~L}$ tank the amount of auxiliary energy used by the $2000 \mathrm{~L}$ tank is similar, and sometimes higher than that of the $1000 \mathrm{~L}$ tank. 


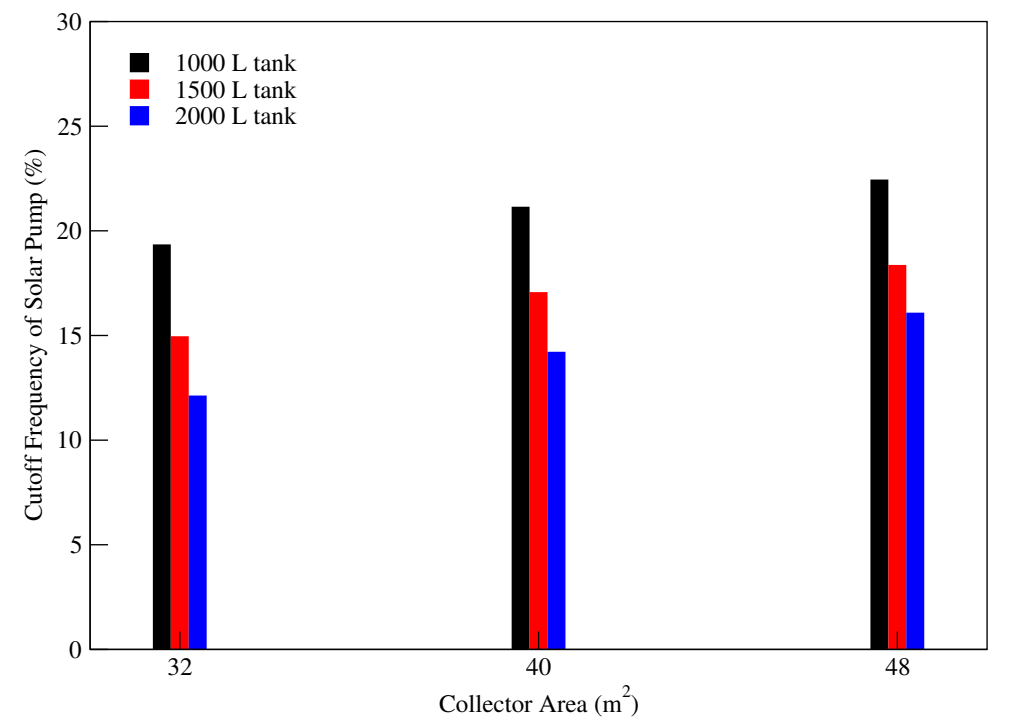

(a) Below average DHW consumer

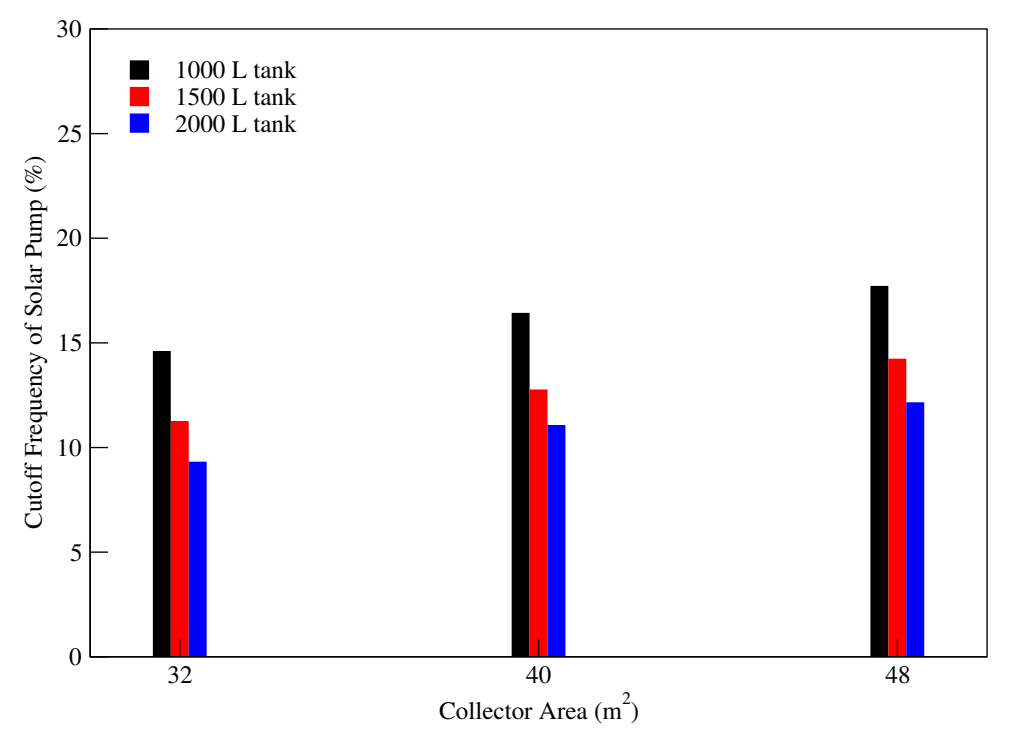

(c) Median DHW consumer

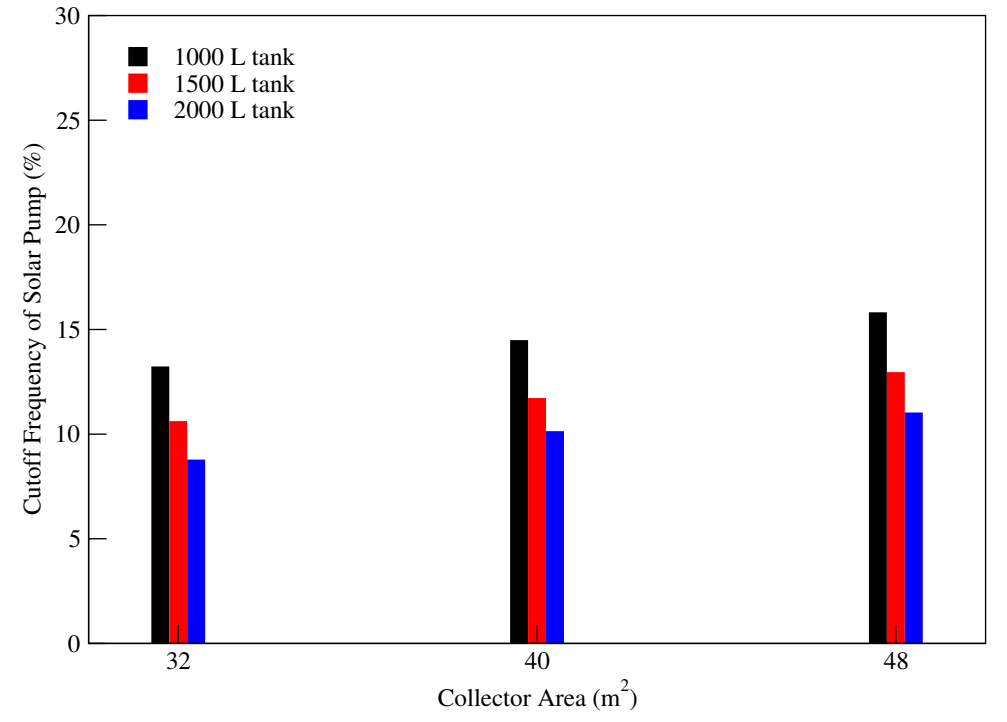

(b) Average DHW consumer

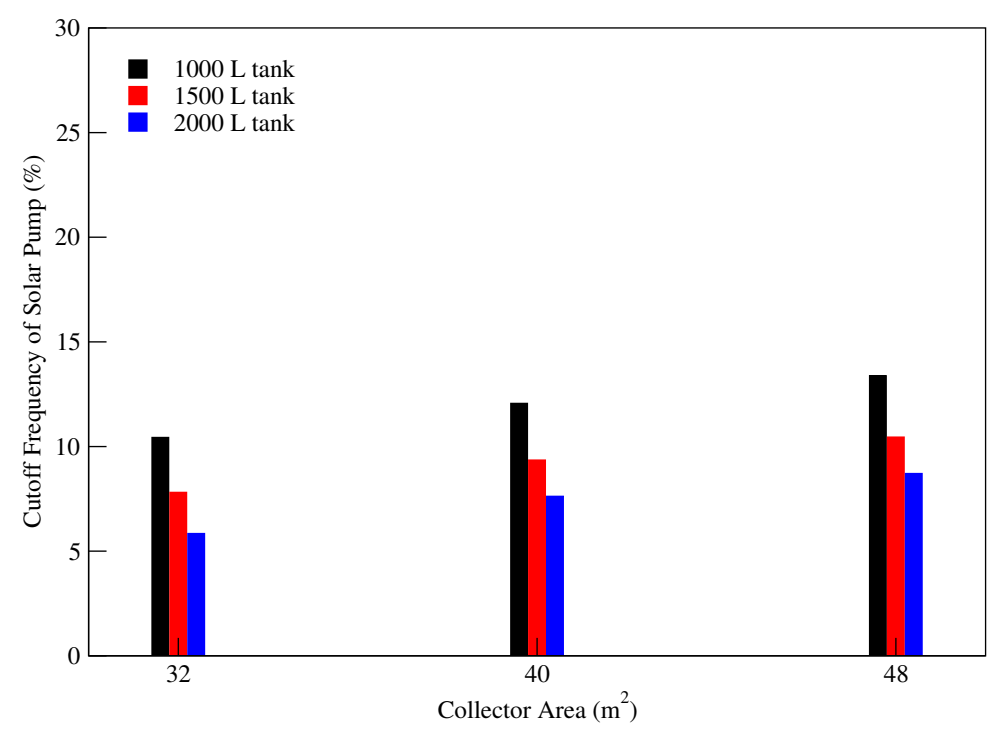

(d) Above average DHW consumer

Figure 6.4: Difference in solar pump cutoffs when varying collector area and storage volume for mid-size 1955 home. 
Table 6.4: Range of results for solar loop cutoff when varying collector area and storage volume for remainder of homes studied

\begin{tabular}{|c|c|c|c|c|c|c|}
\hline House & $\begin{array}{c}1000 \mathrm{~L} \\
\text { Minimum (\%) }\end{array}$ & $\begin{array}{c}1000 \mathrm{~L} \\
\text { Maximum (\%) }\end{array}$ & $\begin{array}{c}1500 \mathrm{~L} \\
\text { Minimum (\%) }\end{array}$ & $\begin{array}{c}1500 \mathrm{~L} \\
\text { Maximum (\%) }\end{array}$ & $\begin{array}{c}2000 \mathrm{~L} \\
\text { Minimum (\%) }\end{array}$ & $\begin{array}{c}2000 \mathrm{~L} \\
\text { Maximum (\%) }\end{array}$ \\
\hline Mid-size 1974 & 17.3 & 34.9 & 15.3 & 32.2 & 14.4 & 30.2 \\
\hline Mid-size 1990 & 3.8 & 9.2 & 1.9 & 7.1 & 1.3 & 5.9 \\
\hline Large 1990 & 17.1 & 30.1 & 13.8 & 25.5 & 11.2 & 22.5 \\
\hline
\end{tabular}




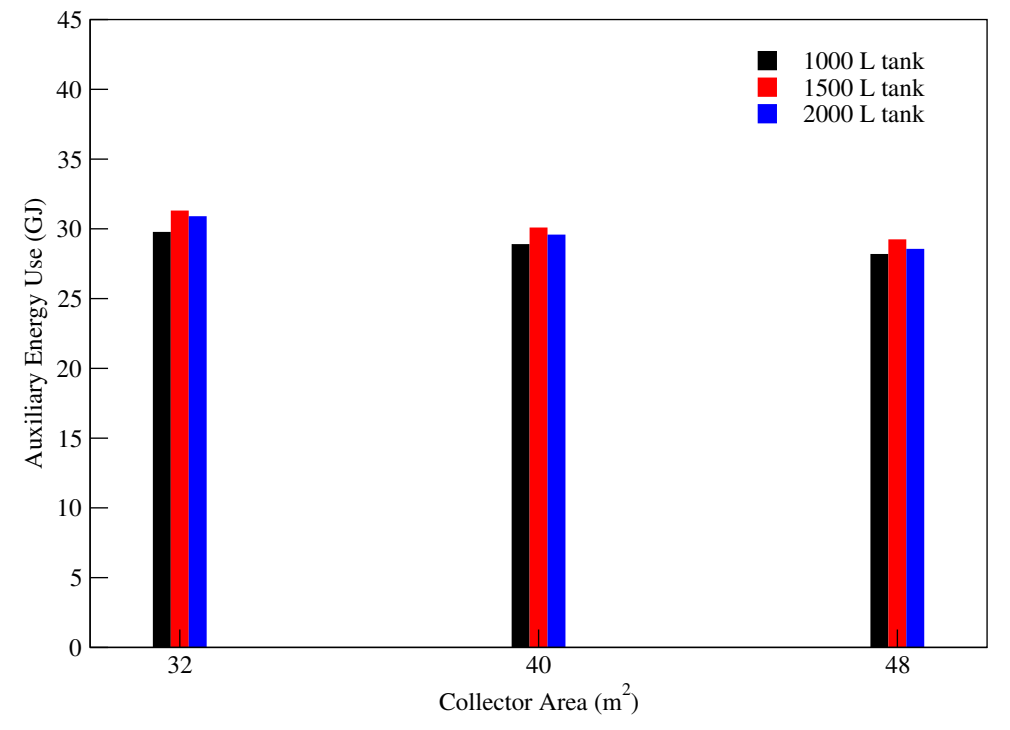

(a) Below average DHW consumer for system A

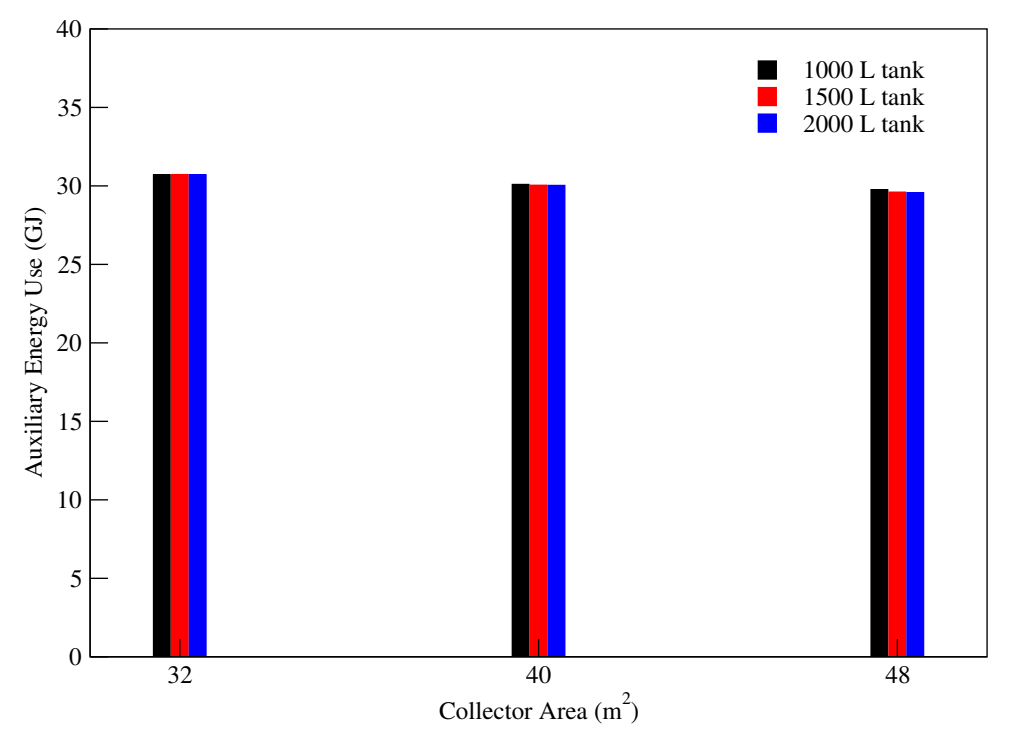

(c) Below average DHW consumer for system B

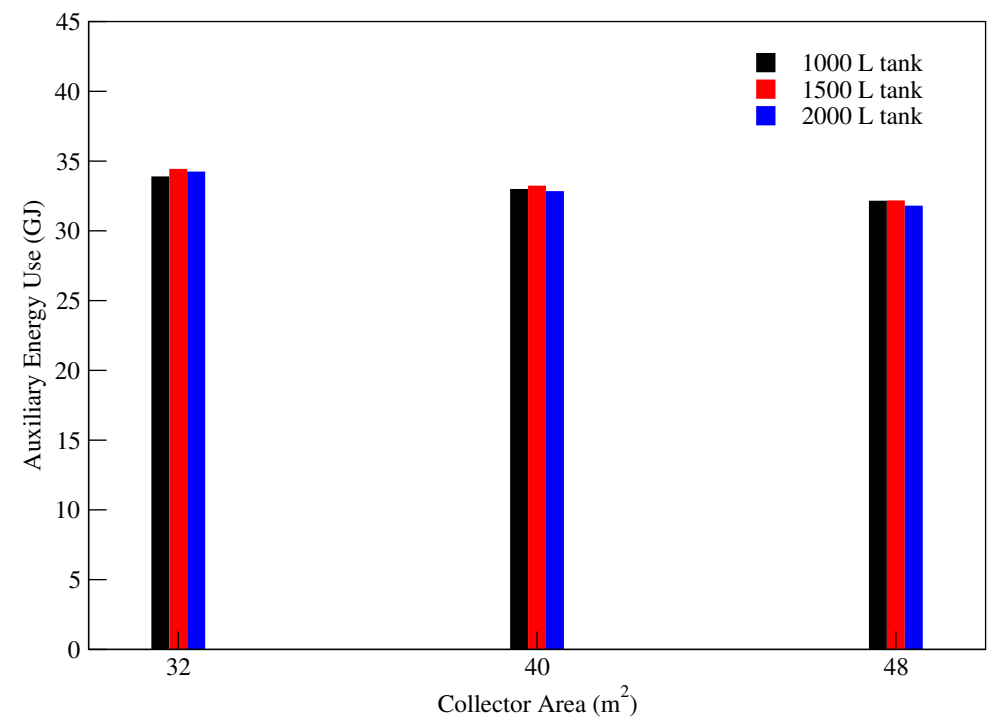

(b) Above Average DHW consumer for system A

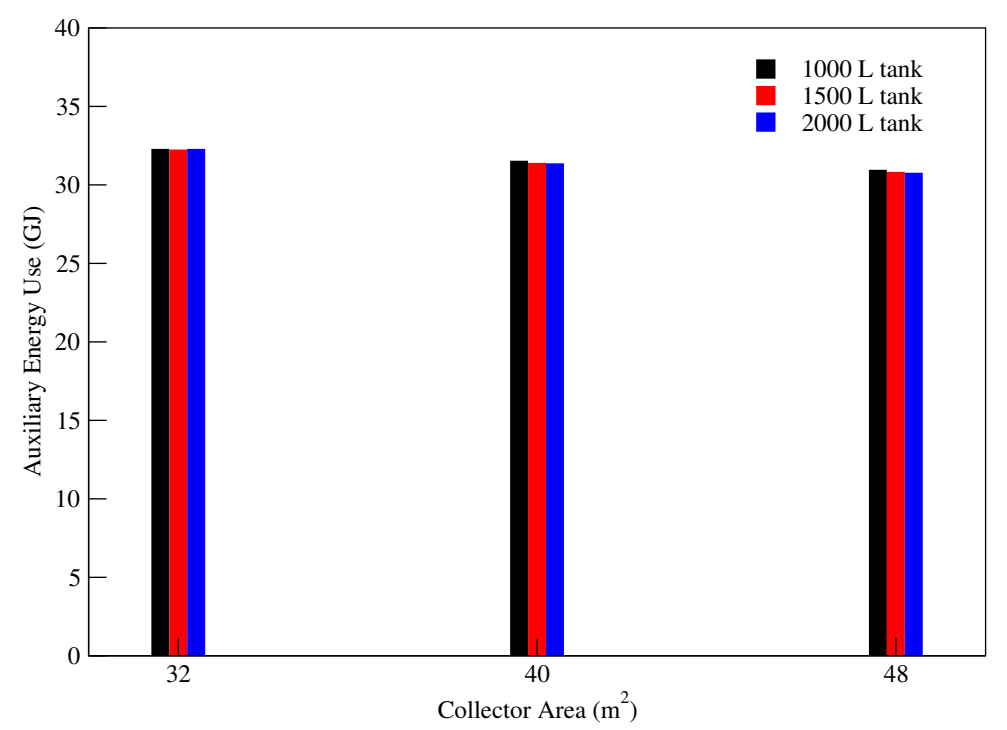

(d) Above average DHW consumer for system B

Figure 6.5: Difference in auxiliary energy use when varying collector area and storage volume for mid-size 1955 home. 
As was stated in Section 5.6 the auxiliary energy usage of a base case, in which heat was injected to the zone to maintain a steady temperature of 20 degrees Celsius, and a simple electric auxiliary system was used for DHW heating, was compared to the output of the solar combisystem described here. Between 50 and $60 \%$ of total auxiliary energy use was offset through the use of this system for the mid-size 1955 home. While this system failed to reach the goal of a $50 \%$ solar fraction it was able to reduce auxiliary energy use beyond the goal of $50 \%$.

The findings described above for the mid-size 1955 home, relating to the effects of DHW draw profile, hold true for the remaining homes. However, for the homes with higher space heating loads, the mid-size 1974 and the mid-size 1990 homes, auxiliary energy use always increased with increasing tank volume. This is attributable to the cooler ambient temperatures experienced in the unheated basements where the DHW tanks are placed. In all cases a significant reduction in total auxiliary energy use was observed. For the homes with high space heating loads the greatest reduction in auxiliary energy use was observed for the $1000 \mathrm{~L}$ tank. For the homes with lower space heating loads the greatest reduction in auxiliary energy use was observed for the $2000 \mathrm{~L}$ tank.

\subsubsection{Summary, General Comments, and Recommendations on System A}

While the system was not able to reach a solar fraction of $50 \%$ in the cases studied a significant reduction in total auxiliary energy use was achieved. Based on the parameters investigated here it can be concluded that the system is most sensitive to space heating load rather than collector area, storage tank volume, or DHW draw profile. The time of use of DHW was not found to have a significant effect on any of the parameters investigated. Due to the increase in overall auxiliary energy use observed when increasing tank volume across these simulations, the $1000 \mathrm{~L}$ tank is sufficient, and in many ways superior, to the larger tanks. Limited benefit was observed for increasing collector area above $32 \mathrm{~m}^{2}$. While the total solar energy delivered to the tank did increase, the increase was relatively small and resulted in an increase in the frequency that the tank reached the upper temperature limit for the solar loop pump cutoff. For this reason a system involving $32 \mathrm{~m}^{2}$ and a $1000 \mathrm{~L}$ tank can be deemed sufficient for the locations studied. 
Table 6.5: Range of results for auxiliary energy use when varying collector area and storage volume for remainder of homes studied

\begin{tabular}{c|cc|cc|cc} 
House & $\begin{array}{c}1000 \mathrm{~L} \\
\text { Minimum (GJ) }\end{array}$ & $\begin{array}{c}1000 \mathrm{~L} \\
\text { Maximum (GJ) }\end{array}$ & $\begin{array}{c}1500 \mathrm{~L} \\
\text { Minimum (GJ) }\end{array}$ & $\begin{array}{c}1500 \mathrm{~L} \\
\text { Maximum (GJ) }\end{array}$ & $\begin{array}{c}2000 \mathrm{~L} \\
\text { Minimum (GJ) }\end{array}$ & $\begin{array}{c}2000 \mathrm{~L} \\
\text { Maximum(GJ) }\end{array}$ \\
\hline Mid-size 1974 & 39.3 & 45.7 & 41.5 & 47.5 & 41.3 & 47.5 \\
Mid-size 1990 & 47.3 & 56.2 & 50.0 & 58.8 & 50.7 & 28.5 \\
Large 1990 & 28.5 & 33.6 & 29.0 & 34.1 & 33.9
\end{tabular}




\subsection{System B}

This section will be segregated into sections in a similar manner to Section 6.2. Graphical results will only be presented for the mid-size 1955 home. The remainder of graphical results can be found in Appendix A. However, a summary of the results from the remaining simulations will be discussed within the parameter specific subsections. A general system design for system B will be presented once all results have been discussed.

\subsubsection{Interaction of Energy Collection and Tank Losses for System B}

The interaction of solar energy collection and tank losses for the mid-size 1955 home is presented in Figure 6.6. The magnitude of draw profile is seen to have limited effect on the interaction of tank losses and solar energy collection for this home. The below average, average, and above average users all show a trend where no benefit is achieved from increasing tank volume. In all cases the benefits, in the form of additional solar energy collection, are less pronounced than the downsides, in the form of additional tank losses, for increasing tank volumes. The results for one of the draw profiles, the median user, shows different results than the others. For a small collector array it is beneficial to increase tank volume from 1000 to $1500 \mathrm{~L}$. The increase in solar energy collected is greater than the increase in tank losses for this case. For the remainder of the tests performed on the median draw profile, there is no benefit in increasing tank volume. The increase in collector energy does not outweigh the increase in tank losses for large collector areas and large tank volumes.

A summary of results for the remaining homes can be found in Table 6.6. For all homes studied, and in nearly every situation studied, when increasing tank volume, the increase in tank losses is greater than the increase in solar energy collected. This effect is most pronounced in the homes with high space heating loads. This suggests that the unheated basements in these homes have a lower temperature and, therefore, a greater rate of heat loss from the tanks was experienced. The below average DHW user always experienced the greatest benefit from increasing tank volumes. The difference in the increase in solar energy and the increase in tank losses is the least for this user. However, in all but the most extreme circumstance, with a very large 


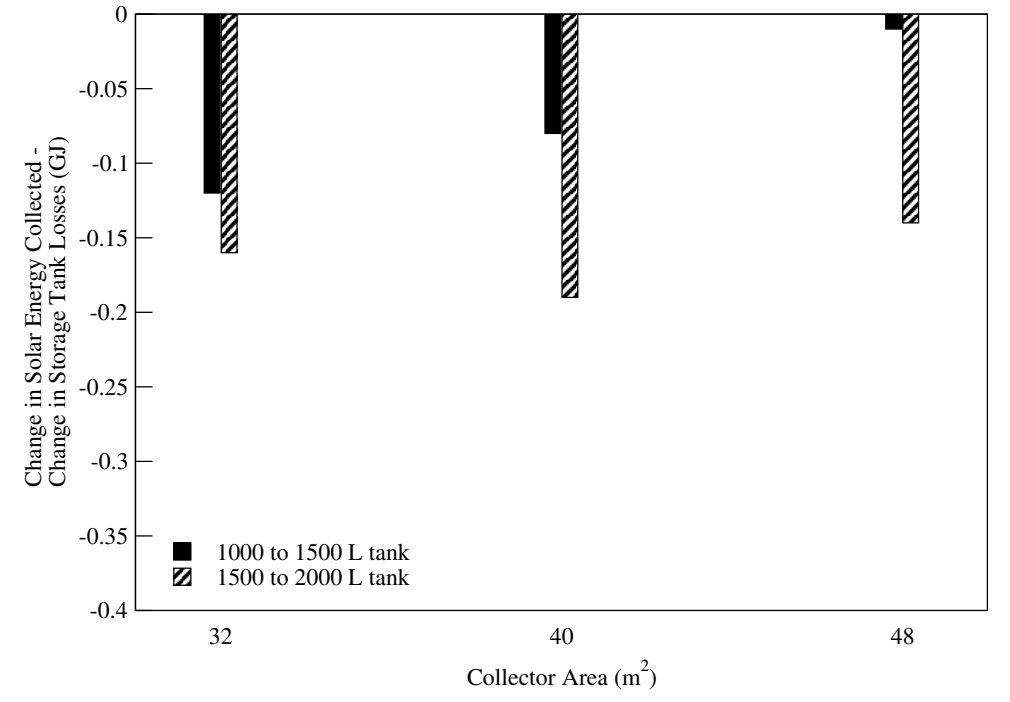

(a) Below average DHW consumer

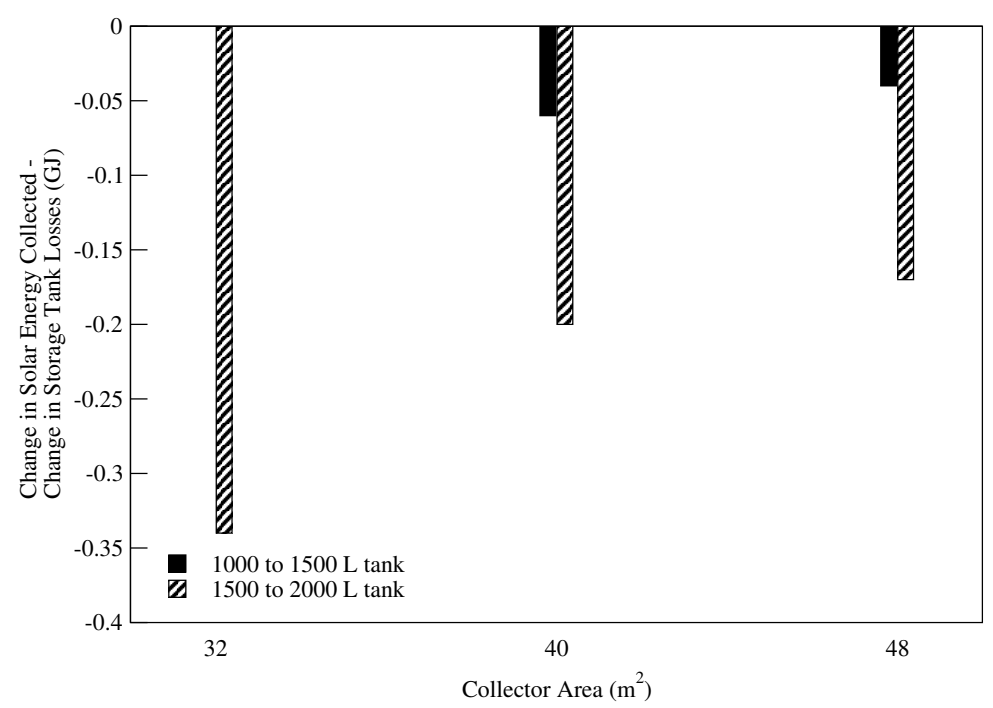

(c) Median DHW consumer

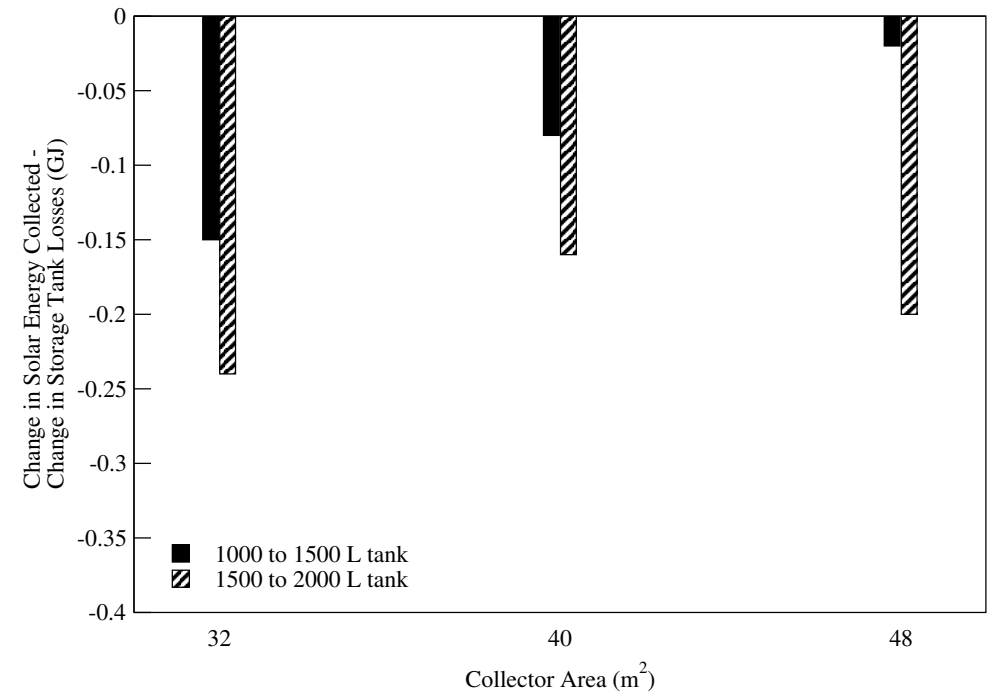

(b) Average DHW consumer

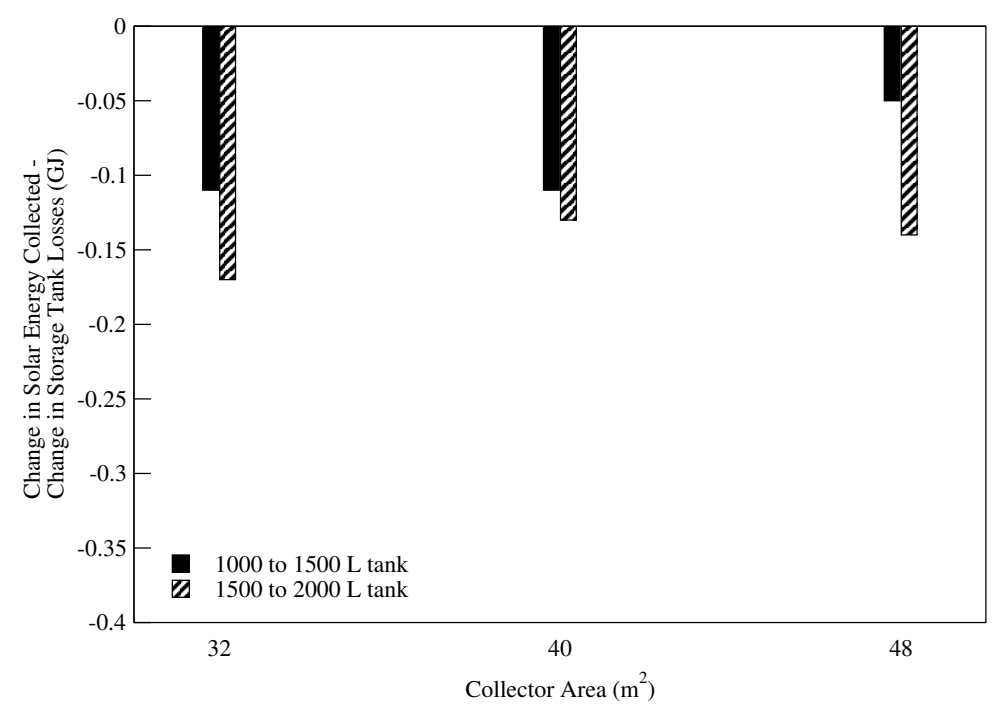

(d) Above average DHW consumer

Figure 6.6: Difference in solar energy collected and DHW tank losses when varying collector area and storage volume for mid-size 1955 home. 
collector array, the increase in tank losses was always greater than the increase in solar energy collected.

In most homes studied the above average user saw the least benefit from increasing tank volume. When increasing tank volume for this user, the increase in solar energy collected was less than the increase in tank losses. This change was greater for the above average user than for all other users except for one of the homes studied. The one home which showed a trend dissimilar to the other homes was the mid-size 1990 home. For this home the median and average users suffered the most from increasing tank volumes. The difference in solar energy collected and tank losses was less for these users than it was for the above average user.

\subsubsection{Energy Collection for System B}

Results regarding annual solar energy collected for the mid-size 1955 home are presented in Figure 6.7. The draw profiles used have similar trends. For the below average, average, and above average users all show nearly identical increases in solar energy collection for all volumes and areas tested. The median user shows a slightly greater increase in energy collected for a small collector area when increasing tank volume from 1000 to 1500 L. However, over a year the difference is negligible.

For all volumes tested, when increasing collector area from 32 to $48 \mathrm{~m}^{2}$ the increase in solar energy collected is approximately 0.2 GJ. This does not present a significant increase in annual energy consumption and, therefore, does not justify increasing the collector area. Increasing tank volume offers more benefits than increasing collector area for this system. Increasing tank volume from 1000 to $1500 \mathrm{~L}$ increases solar energy collection by approximately 1.2 GJ for all configurations. Increasing the tank volume another $500 \mathrm{~L}$, from 1500 to $2000 \mathrm{~L}$, increases solar energy collection by approximately 1 GJ for all configurations. Annual solar energy collection, for this plant system, is insensitive to collector area. If solar energy collection is to be improved then increasing tank volume is recommended.

Results for increases in solar energy collected for the remainder of homes is given in Table 6.7. The DHW draw profile does not appear to have any real effect on the performance of the large 1990 home. However, for the mid-size 1974 and mid-size 1990 homes, a trend different to the one observed for the mid-size 1955 home can 
Table 6.6: Range of results for differences in solar energy collected and DHW tank Losses when varying collector area and storage volume for remainder of homes studied

\begin{tabular}{c|cc|cc} 
House & $\begin{array}{c}1000-1500 \\
\text { L Minimum (GJ) }\end{array}$ & $\begin{array}{c}\text { Maximum (GJ) } \\
\text { Mid-size 1974 }\end{array}$ & $\begin{array}{c}\text { Minimum (GJ) } \\
\text { Maxim }\end{array}$ & $\begin{array}{c}\text { Maximum (GJ) } \\
\text { Mid-s000 L }\end{array}$ \\
Mid-size 1990 & -0.2 & -0.1 & -0.3 & -0.1 \\
Large 1990 & -0.2 & 0.00 & -0.6 & -0.3 \\
& & 0.0 & -0.2 & -0.1
\end{tabular}




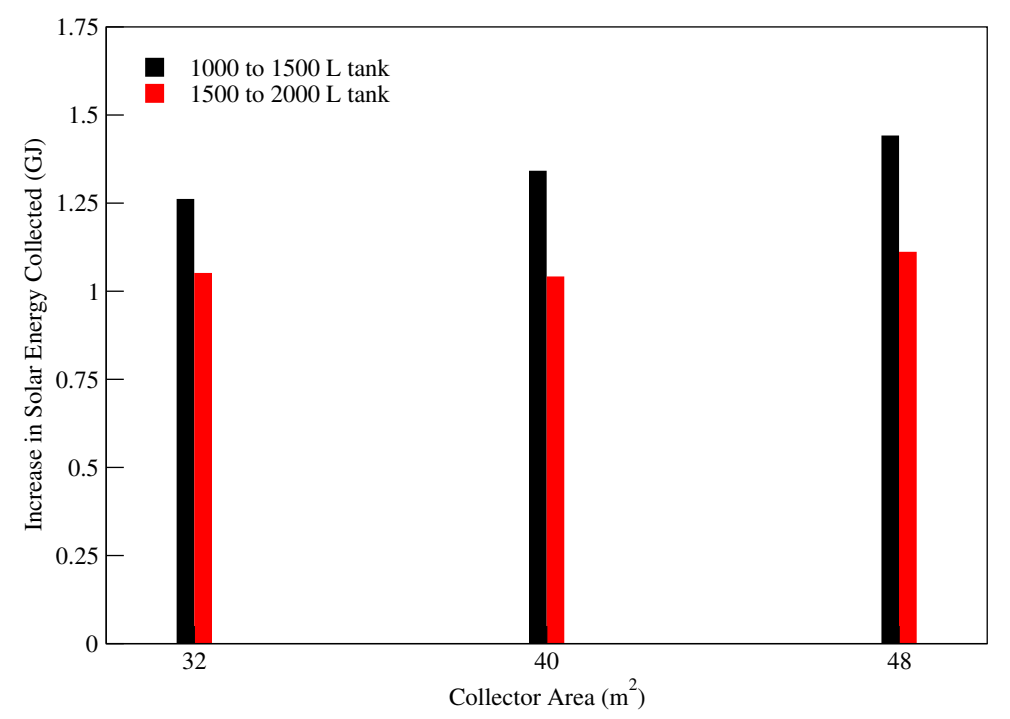

(a) Below average DHW consumer

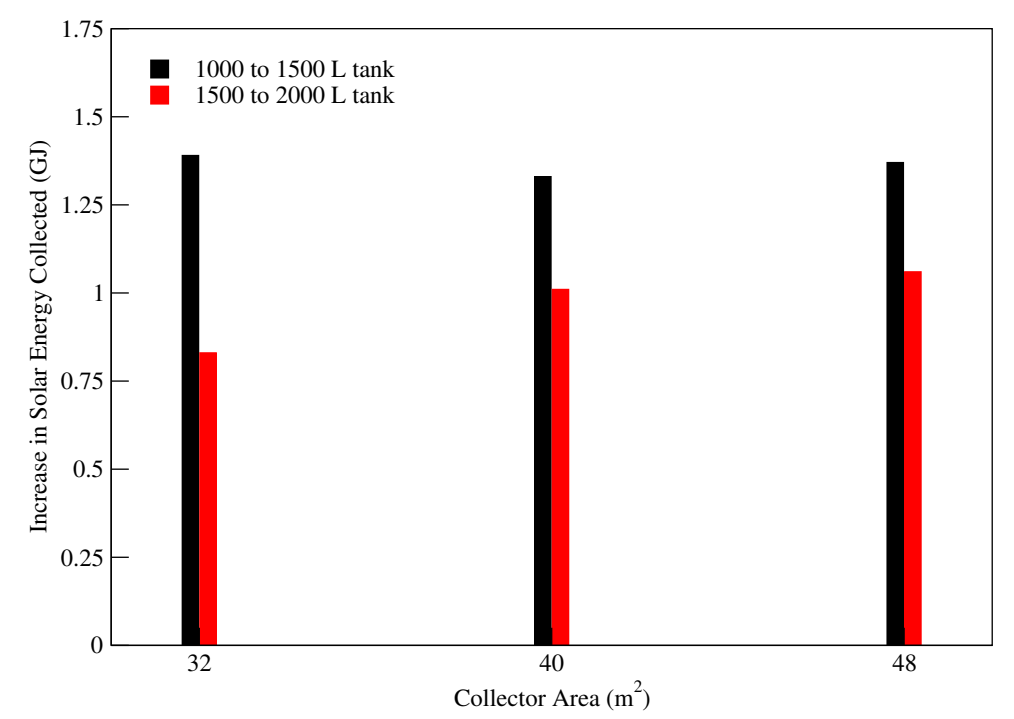

(c) Median DHW consumer

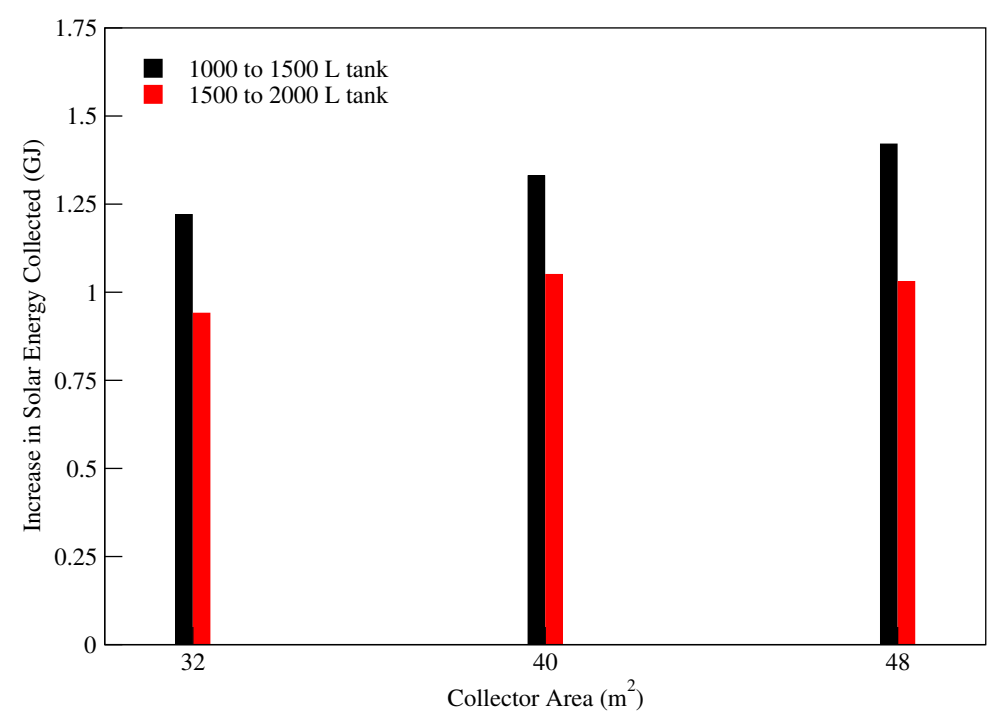

(b) Average DHW consumer

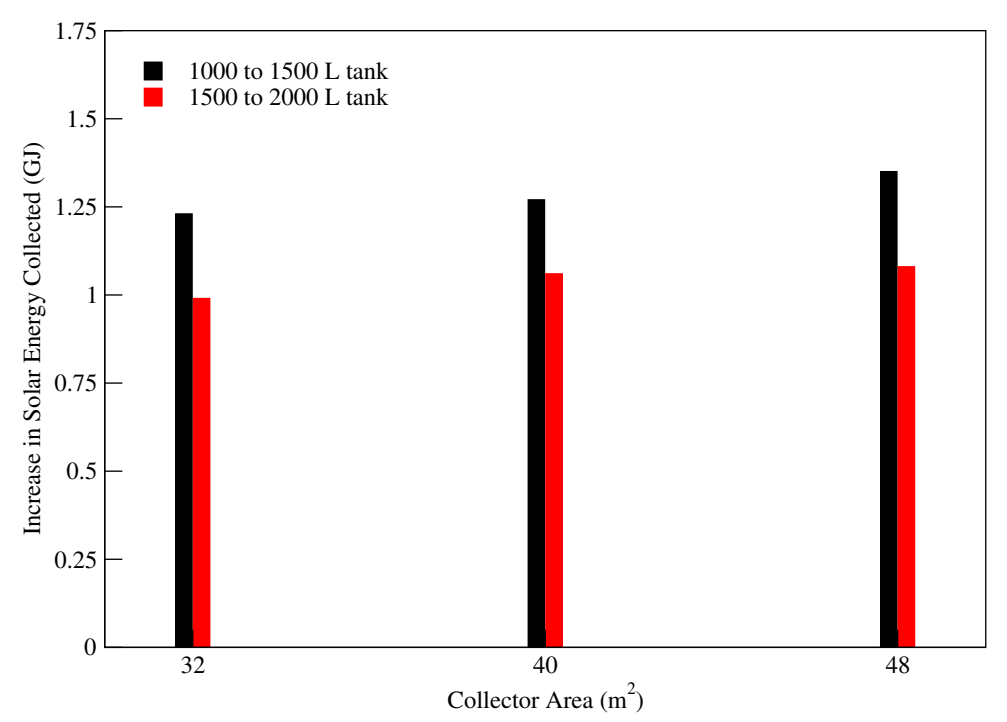

(d) Above average DHW consumer

Figure 6.7: Difference in solar energy collected when varying collector area and storage volume for mid-size 1955 home. 
be seen. In these cases the below average user showed the greatest increase in solar energy collected when increasing tank volume. This increase, in the mid-size 1990 home was 0.3 GJ greater than it was for the above average user in most cases.

When increasing collector area the benefit, seen in increased solar energy collection is marginal for all homes. While increasing tank volume can be seen in increased total energy collected of 1.0 to 1.6 GJ, increasing collector area, from 32 to $48 \mathrm{~m}^{2}$, an increase in solar energy collected of less than 0.4 GJ can be observed.

\subsubsection{Solar Fraction for System B}

Solar fractions for the mid-size 1955 home ranged between 40 and $50 \%$ as can be seen in Figure 6.8. The magnitude of DHW load profile was seen to have a relatively significant effect on this variable. When holding tank volume and collector area constant, the above average DHW consumer was seen to have a solar fraction approximately 5 percentage points than the below average user. When examining the effects of time of use on solar fraction no discernible effect could be detected. The average and median users, who had similar annual loads but different preferred times of use, have nearly identical solar fractions over the year. The goal of a $50 \%$ solar fraction cannot be achieved for this home for any DHW profile but the highest consumer. At the very minimum, a $50 \%$ solar fraction would require a $1000 \mathrm{~L}$ storage with a $48 \mathrm{~m}^{2}$ collector array.

Neither collector area nor tank volume were observed to have a significant effect on solar fraction. When holding draw profile and collector area constant, a doubling of the tank volume only showed a 2 percentage point increase in solar fraction in most situations. Similarly, when holding draw profile and tank volume constant, increasing collector area from 32 to $48 \mathrm{~m}^{2}$ resulted in an increase of only 1 to 2 percentage points. The greatest benefits observed for increasing collector area were found with large tank volumes.

A summary of results for the remainder of the homes studied can be found in Table 6.8. For none of the remaining homes studied could a solar fraction of $50 \%$ be achieved. The highest observed solar fraction for these homes was $43.9 \%$. This was seen in the large 1990 home. Homes with a higher space heating load had similar

results. As was seen with the mid-size 1955 home the draw profile used was found to 
Table 6.7: Range of results for differences in solar energy collected when varying collector area and storage volume for remainder of homes studied

\begin{tabular}{c|cc|cc} 
House & $\begin{array}{c}1000-1500 \mathrm{~L} \\
\text { L Minimum (GJ) }\end{array}$ & $\begin{array}{c}\text { Maximum (GJ) } \\
\text { Mand }\end{array}$ & $\begin{array}{c}\text { 1500-2000 L } \\
\text { Minimum (GJ) }\end{array}$ & $\begin{array}{c}1500-2000 \mathrm{~L} \\
\text { Maximum (GJ) }\end{array}$ \\
\hline Mid-size 1974 & 1.2 & 0.9 & 1.5 & \\
Mid-size 1990 & 1.1 & 1.8 & 0.9 & 1.3 \\
Large 1990 & 1.2 & 1.4 & 0.9 & 1.1
\end{tabular}




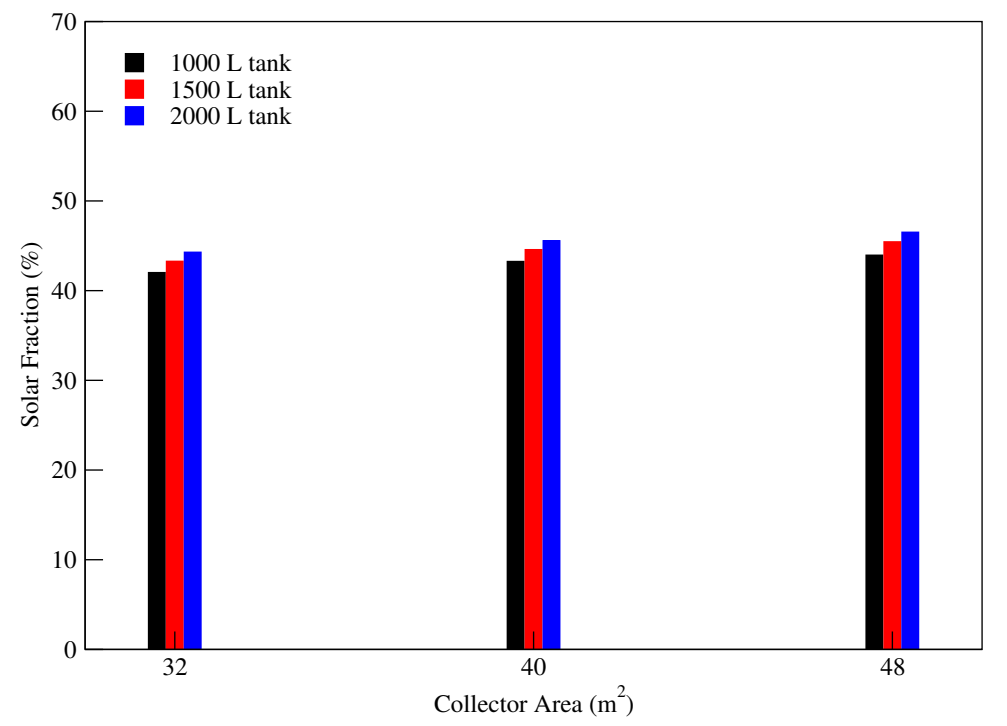

(a) Below average DHW consumer

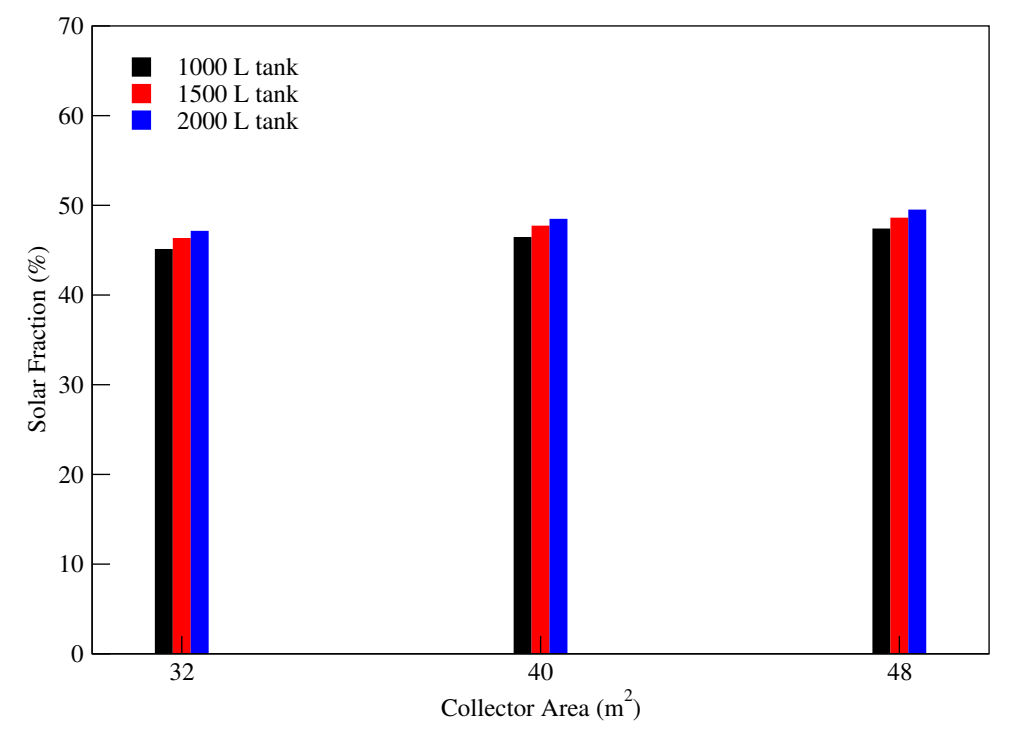

(c) Median DHW consumer

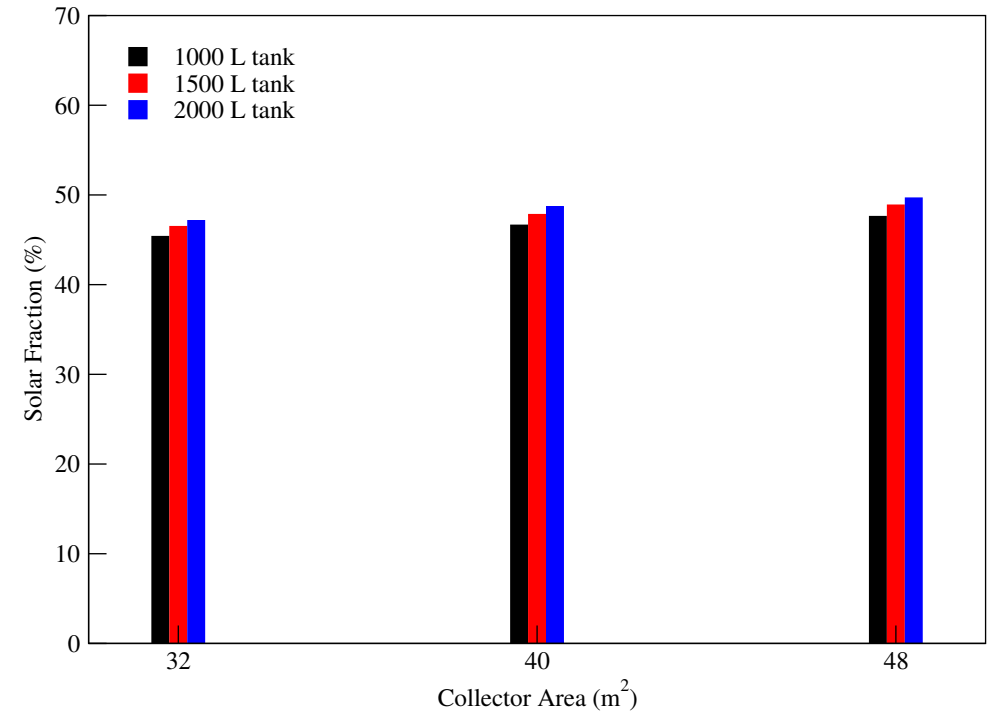

(b) Average DHW consumer

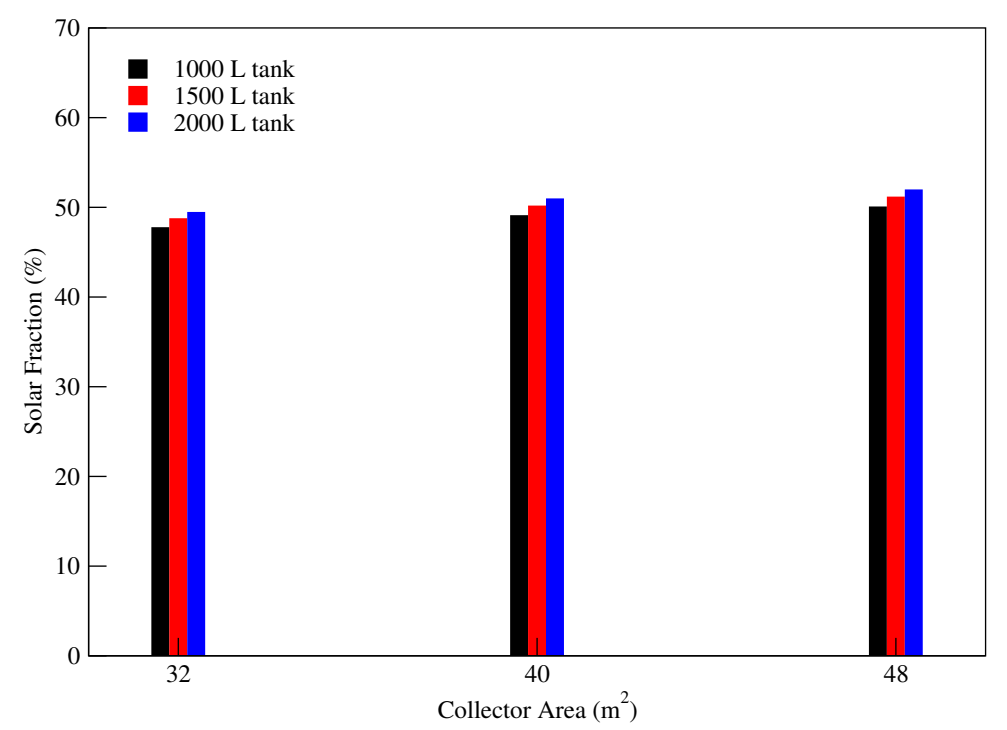

(d) Above average DHW consumer

Figure 6.8: Difference in solar fractions when varying collector area and storage volume for mid-size 1955 home. 
have a relatively significant effect. The above average user always had the greatest solar fraction and the below average user always had the lowest solar fraction.

Doubling the tank volume, from 1000 to 2000 L, increased solar fraction for homes by approximately $2 \%$ in all cases. Increasing collector area, from 32 to $48 \mathrm{~m}^{2}$, saw a similar increase of approximately 2 percentage points in all cases studied. A solar fraction of $50 \%$ does not appear to be achievable for this system configuration except when paired with a very specific space heating and DHW load.

\subsubsection{Solar Loop Safety Cutoff for System B}

As can be seen in Figure 6.9 the draw profile selected for simulation can have a significant effect on the frequency with which the safety limit temperature is reached. When holding collector area and tank volume constant, there is a difference of nearly 15 percentage points between the below average and above average users. The time of use does not appear to have any significant effect as the median and average users both show similar results.

The tank volume can be seen to affect the frequency with which the high limit temperature is reached. When doubling the tank volume the frequency with which the high limit temperature is reached drops by approximately 10 percentage points. The collector area can also be seen to affect the frequency with which the high limit temperature is reached. When increasing the collector area from 32 to $48 \mathrm{~m}^{2}$ the frequency with which the safety limit temperature was reached increased by 4 to 6 percentage points.

A summary of the results for the remaining homes can be found in Table 6.9. As was observed for the mid-size 1955 home the greatest factor in the frequency with which the safety temperature limit is reached, resulting in the cessation of useful energy collection, is the DHW profile used. When holding tank volume and collector area constant, a difference of approximately 15 percentage points can be observed between the below average and above average user. This trend is less pronounced for large tank volumes and small collector areas. In addition, space heating loads can be seen to have a relatively significant effect as well. The home with the least occurrences of the safety limit temperature being reached is the mid-size 1990 home. This is the home with the largest space heating load. 
Table 6.8: Range of results for solar fraction when varying collector area and storage volume for remainder of homes studied

\begin{tabular}{c|cc|cc|cc} 
House & $\begin{array}{c}1000 \mathrm{~L} \\
\text { Minimum (\%) }\end{array}$ & $\begin{array}{c}1000 \mathrm{~L} \\
\text { Maximum (\%) }\end{array}$ & $\begin{array}{c}1500 \mathrm{~L} \\
\text { Minimum (\%) }\end{array}$ & $\begin{array}{c}1500 \mathrm{~L} \\
\text { Maximum (\%) }\end{array}$ & $\begin{array}{c}2000 \mathrm{~L} \\
\text { Minimum (\%) }\end{array}$ & $\begin{array}{c}2000 \mathrm{~L} \\
\text { Maximum (\%) }\end{array}$ \\
\hline Mid-size 1974 & 33.3 & 41.3 & 34.6 & 42.9 & 35.5 & 43.0 \\
Mid-size 1990 & 33.3 & 40.2 & 34.4 & 40.9 & 35.0 & 41.4 \\
Large 1990 & 35.5 & 42.6 & 36.6 & 43.1 & 37.5 & 43.9
\end{tabular}




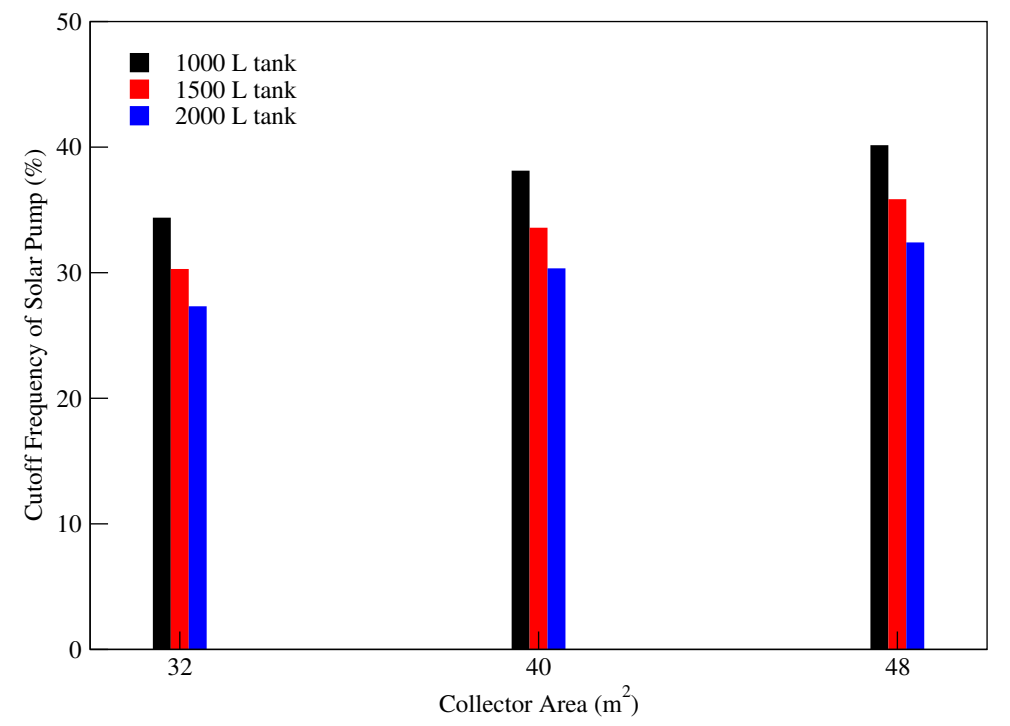

(a) Below average DHW consumer

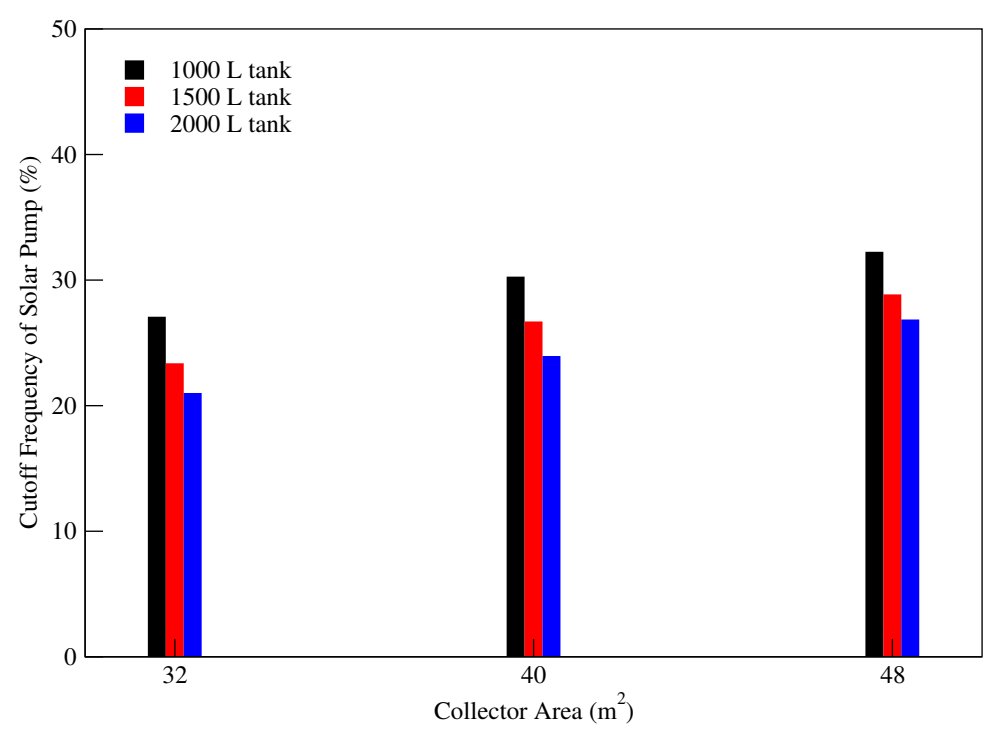

(c) Median DHW consumer

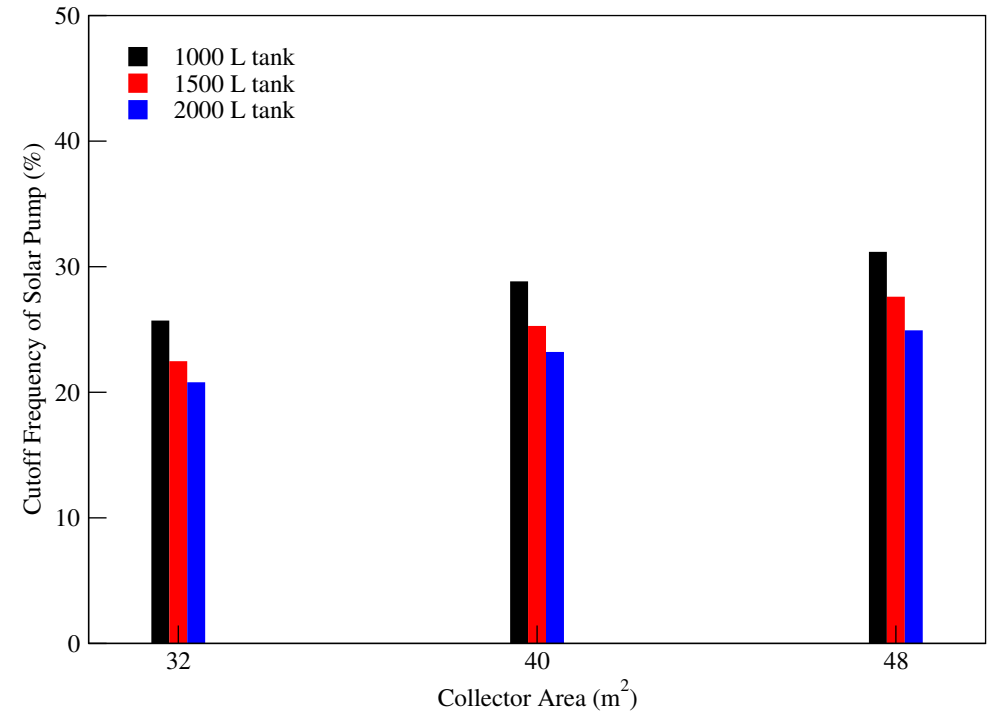

(b) Average DHW consumer

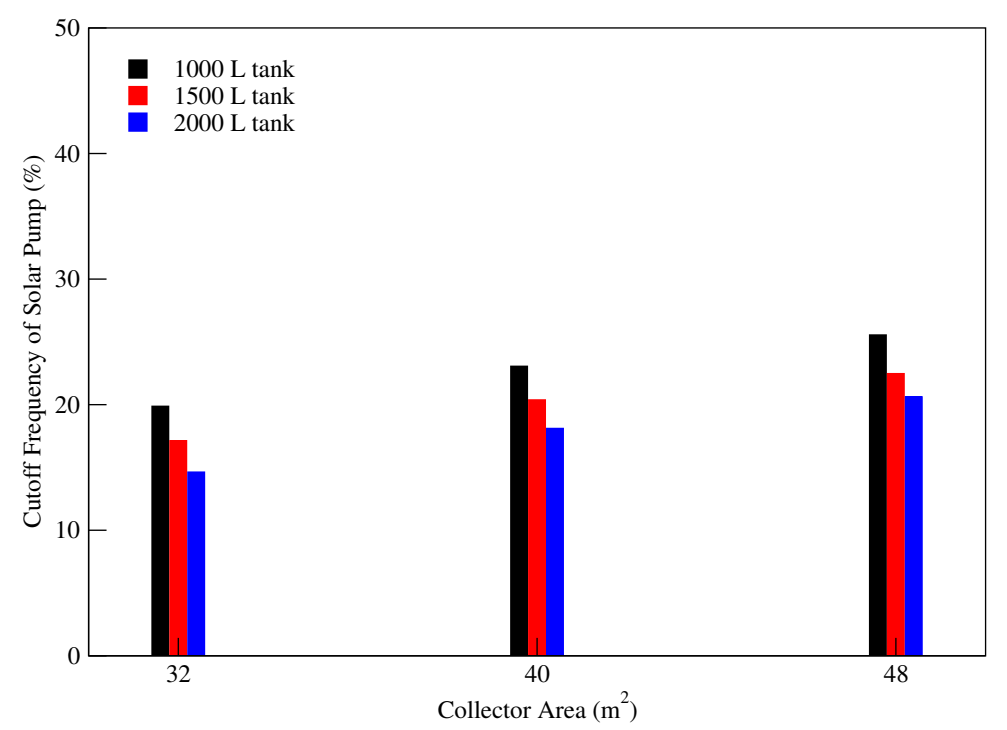

(d) Above average DHW consumer

Figure 6.9: Difference in solar pump cutoffs when varying collector area and storage volume for mid-size 1955 home. 
When doubling the tank volume, and keeping draw profile and collector area constant, a decrease of approximately 5 percentage points can be observed for all cases. When increasing collector area from 32 to $48 \mathrm{~m}^{2}$, and holding draw profile and tank volume constant, an increase of approximately 5 percentage points can be observed for all cases. For homes with low space heating loads, such as the large 1990 home, small tank volumes and large collector areas provide little benefit. During the fall through spring the safety limit temperature is reached $42 \%$ of the time when the system could be providing useful energy.

\subsubsection{Auxiliary Energy Use for System B}

The auxiliary energy use for system B is shown in Figure 6.10. There is limited to no variation shown for auxiliary energy use when adjusting collector area and/or tank volume. The only parameter that was varied, and can be seen to have an effect on auxiliary energy use, is the draw profile used. A difference of approximately 2.5 GJ was observed between the above average and below average DHW users for all combinations of collector area and tank volume.

When comparing the auxiliary energy usage for this home with the auxiliary energy consumed in the baseline scenario a reduction of 55 to $62 \%$ can be found. While the $50 \%$ solar fraction target was found to be unachievable a significant reduction in auxiliary energy consumption can be made by adopting this system. 
Table 6.9: Range of results for solar loop cutoff when varying collector area and storage volume for remainder of homes studied

\begin{tabular}{c|cc|cc|cc} 
House & $\begin{array}{c}1000 \mathrm{~L} \\
\text { Minimum (\%) }\end{array}$ & $\begin{array}{c}1000 \mathrm{~L} \\
\text { Maximum (\%) }\end{array}$ & $\begin{array}{c}1500 \mathrm{~L} \\
\text { Minimum (\%) }\end{array}$ & $\begin{array}{c}1500 \mathrm{~L} \\
\text { Maximum (\%) }\end{array}$ & $\begin{array}{c}2000 \mathrm{~L} \\
\text { Minimum (\%) }\end{array}$ & $\begin{array}{c}\text { Maximum (\%) } \\
\text { Mid-size 1974 }\end{array}$ \\
\hline 14.8 & 32.0 & 11.8 & 28.3 & 9.2 & 25.9 \\
Mid-size 1990 & 9.5 & 29.5 & 7.1 & 24.6 & 5.6 & 20.2 \\
Large 1990 & 20.0 & 42.1 & 17.9 & 38.3 & 14.4 & 34.2
\end{tabular}




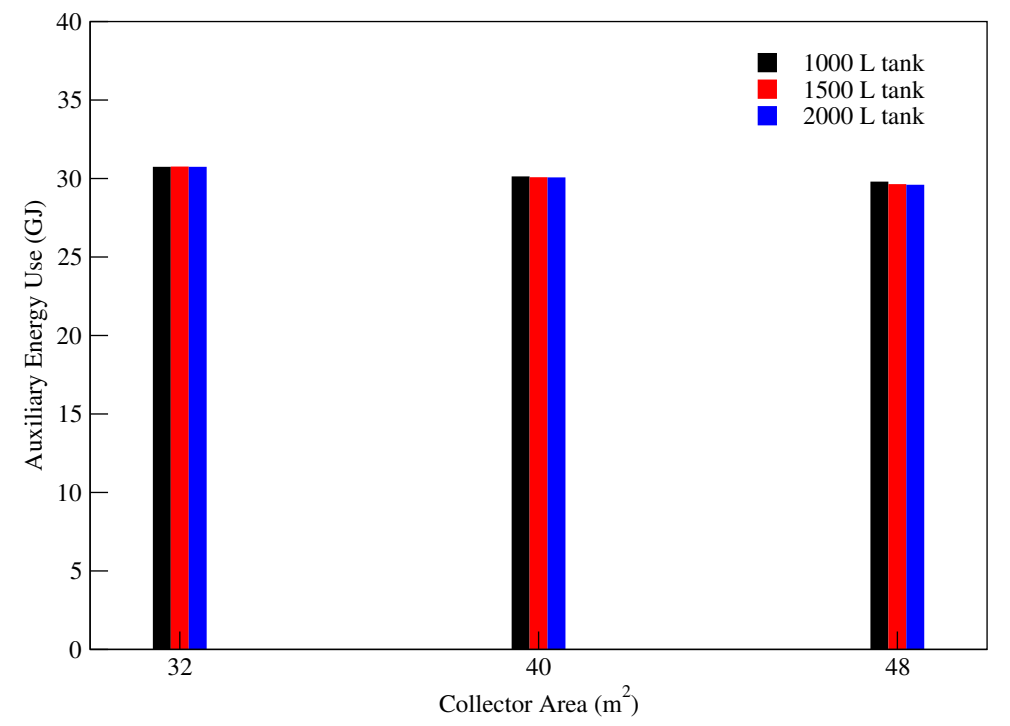

(a) Below average DHW consumer

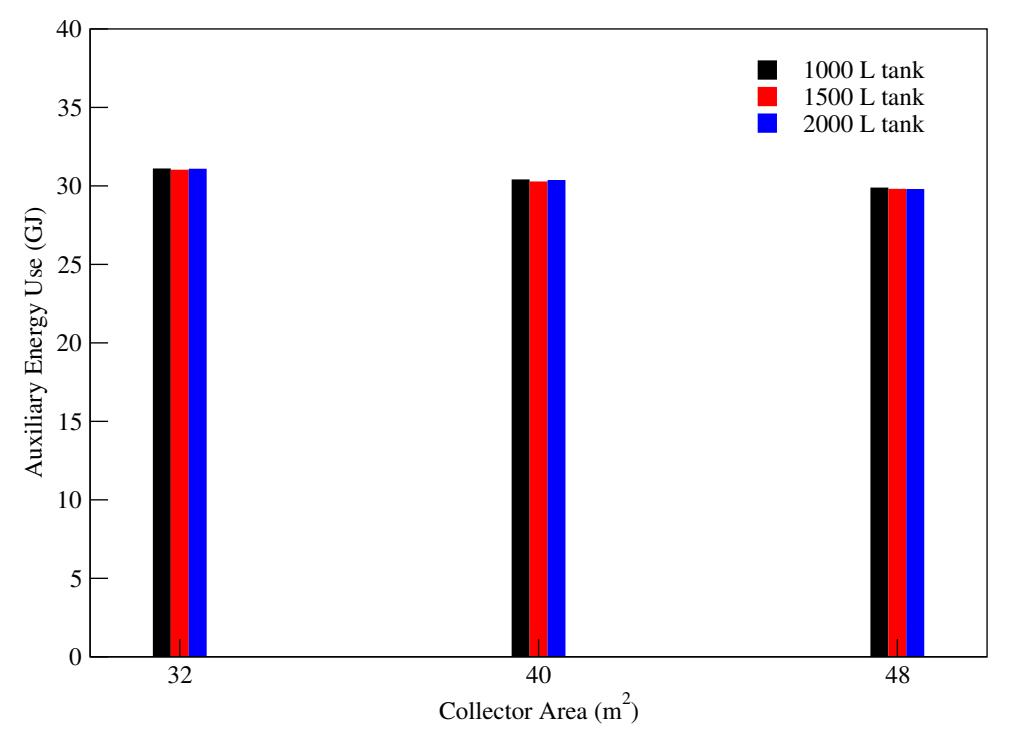

(c) Median DHW consumer

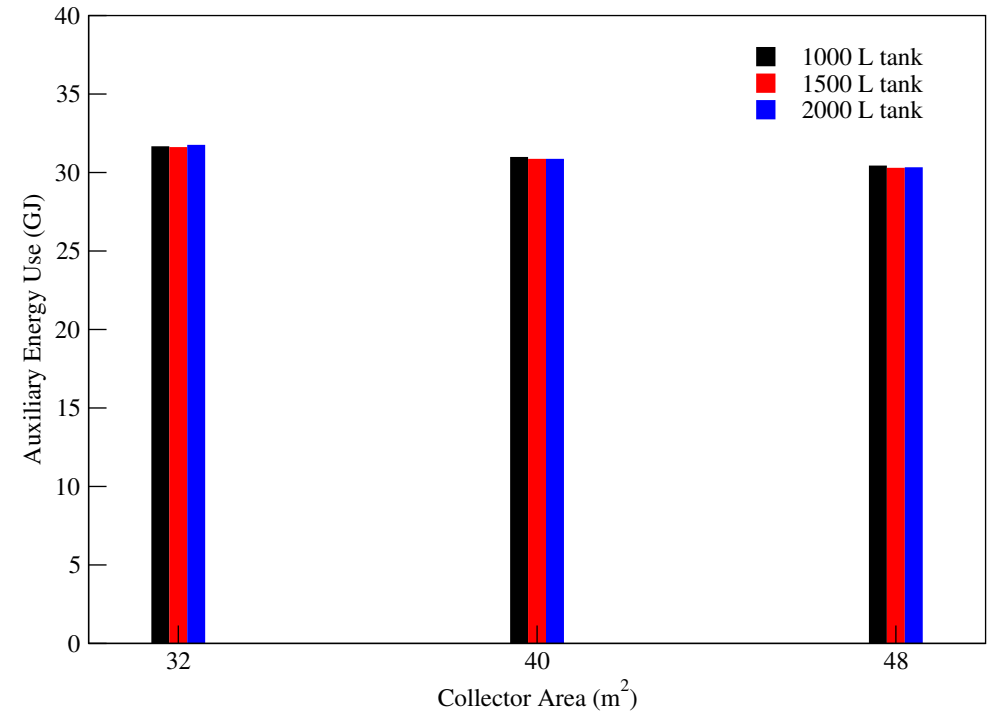

(b) Average DHW consumer

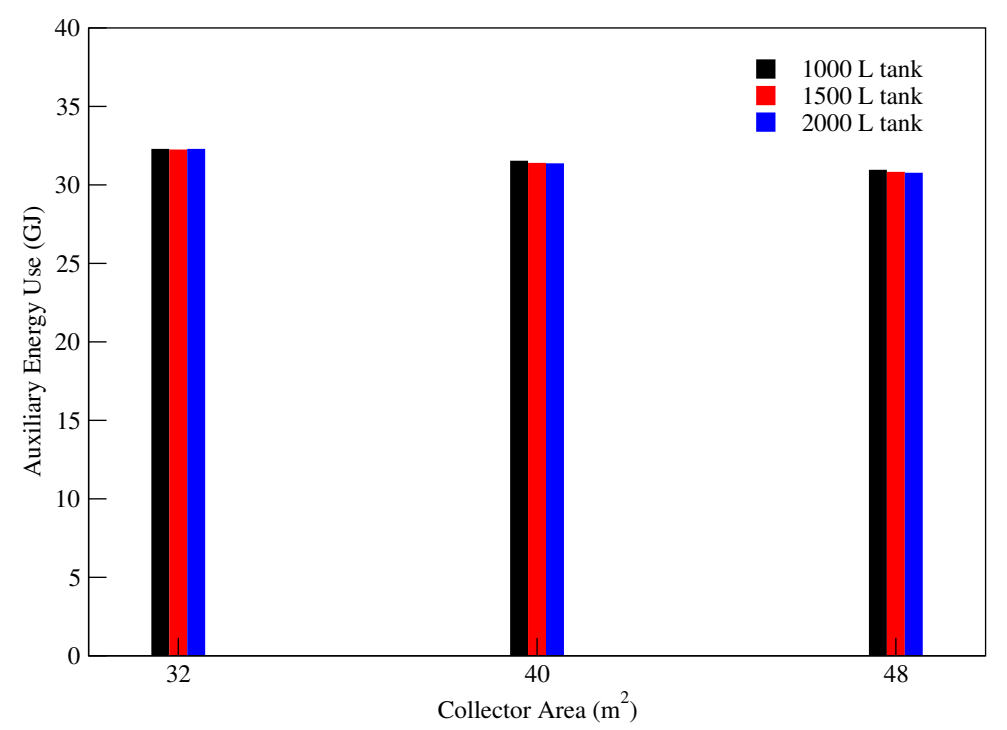

(d) Above average DHW consumer

Figure 6.10: Difference in auxiliary energy use when varying collector area and storage volume for mid-size 1955 home. 
A summary of the remaining results for auxiliary energy use can be found in Table 6.10. Very limited effect was observed when adjusting tank volume and collector area. This mirrors the result observed for the mid-size 1955 home. When varying draw profile the difference between the above average and below average user was seen to be less than 2 GJ for all homes studied. The only variable seen to significantly effect the auxiliary energy use was the space heating load. This resulted in a difference of roughly 20 GJ between the mid-size 1990 home and the large 1990 home.

When looking at the percentage of auxiliary energy use offset through the installation of a solar combisystem a reduction of 30 to $50 \%$ can be observed. The greatest reduction in use is observed for the mid-size 1990 home and the lowest reduction in use is observed for the large 1990 home. The greatest reduction in auxiliary energy can be seen for the high collector areas and mid-size tank volumes.

\subsubsection{Summary, General Comments, and Recommendations on System B}

Increasing the preheat tank volume above $1000 \mathrm{~L}$ was not seen to have a significant benefit for the system in any way. In fact, when comparing the increase in solar energy collected and tank losses, increasing tank volume was found to be detrimental to performance. While a marginal increase in solar energy collected was observed when increasing tank volumes to $1500 \mathrm{~L}$ this increase was marginal and, based on the increase in tank losses, could not be justified. Only the mid-size 1955 home was capable of achieving a solar fraction of $50 \%$ for this system. Even then, this required a high DHW load, the remainder of the systems had solar fractions in the $40 \%$ range. While goals of a $50 \%$ solar fraction proved to be unattainable, many of the homes were able to offset a significant portion of their auxiliary energy use when compared to the base case of a home not using a solar combisystem. Only the mid-size 1990 and mid-size 1955 home were capable of offsetting $50 \%$ auxiliary energy use for this system.

Based on these results it is recommended that, for this system, a relatively small configuration be used. Increasing tank volume beyond $1000 \mathrm{~L}$ and collector area beyond $32 \mathrm{~m}^{2}$ were found to provide limited benefit for all parameters investigated. Further study may be required in order to completely optimise this system. Parameters were varied as described in Section 5.6 in order to provide a comparison 
Table 6.10: Range of results for auxiliary energy use when varying collector area and storage volume for remainder of homes studied

\begin{tabular}{|c|c|c|c|c|c|c|}
\hline House & $\begin{array}{c}1000 \mathrm{~L} \\
\text { Minimum (GJ) }\end{array}$ & $\begin{array}{c}1000 \mathrm{~L} \\
\text { Maximum (GJ) }\end{array}$ & $\begin{array}{c}1500 \mathrm{~L} \\
\text { Minimum (GJ) }\end{array}$ & $\begin{array}{c}1500 \mathrm{~L} \\
\text { Maximum (GJ) }\end{array}$ & $\begin{array}{c}2000 \mathrm{~L} \\
\text { Minimum (GJ) }\end{array}$ & $\begin{array}{c}2000 \mathrm{~L} \\
\text { Maximum (GJ) }\end{array}$ \\
\hline Mid-size 1974 & 45.5 & 48.0 & 45.3 & 47.9 & 45.3 & 48.1 \\
\hline Mid-size 1990 & 57.4 & 60.5 & 57.6 & 60.9 & 57.9 & 61.3 \\
\hline Large 1990 & 44.8 & 47.0 & 44.4 & 47.1 & 44.8 & 47.3 \\
\hline
\end{tabular}


between the two systems discussed here. It is possible that a smaller configuration may perform in a superior manner for this particular system.

\subsection{Comparison of System A and System B per- formance}

Observing trends across the two systems is beneficial as it assists in determining if one particular system configuration is more appropriate for a location and/or draw profile.

When examining the difference in the increase of solar energy collection and the increase in storage tank losses it becomes clear that system B is inferior to system $\mathrm{A}$. The increase in solar energy collected for system A was almost always greater than the increase in storage tank losses when increasing tank volume. However, system B rarely ever saw a benefit when increasing tank volume beyond $1000 \mathrm{~L}$.

No major difference was observed when comparing the annual solar energy collected by the two systems. System A showed a minor increase when compared with system B. However, this amounted to less than half 1 GJ in all situations. One aspect of interest was the limited benefit seen in System B when increasing collector area. In nearly all homes, and plant configurations, System A showed a regular increase of approximately 0.5 GJ when increasing collector area from 32 to $48 \mathrm{~m}^{2}$. This was true across all true draw profiles and homes studied. When increasing collector area from 32 to $48 \mathrm{~m}^{2}$ for System B there was rarely an increase greater than 0.2 GJ. System A was insensitive to draw profile. All homes and draw profiles showed a 0.5 GJ increase when increasing from 32 to $48 \mathrm{~m}^{2}$. System B was more sensitive to draw profile. The above average user showed the greatest increase in solar energy collected when increasing collector area from 32 to $48 \mathrm{~m}^{2}$.

Examining solar fraction reveals that, in general, System B has a lower solar fraction than System A. It also becomes apparent that solar fractions are more sensitive to draw profiles when using System B. For System A, solar fractions, for each home, when holding collector area and storage volume constant, were consistently within 2 $\%$ of one another. However, for System B variation of $5 \%$ was regularly observed between the below average and above average users. Additionally, in the mid-size 1990 and large 1990 homes, the solar fractions for System B were approximately $5 \%$ lower than those observed in System A. 
The frequency with which the solar loop's safety temperature was reached was generally higher in System B than in System A. In general the high limit temperature was reached $5 \%$ more frequently in System B than in System A. This result suggests that energy is not being harvested from the preheat tank regularly enough in System B. Heat is only transferred to the DHW tank in this system when there is a DHW draw. Performance could be improved by either eliminating the DHW tank and placing an internal heat exchanger in the preheat tank, or by implementing a heat exchanger loop between the two tanks.

In general, the auxiliary energy use for the two systems was very similar. However, when looking to draw profiles it was observed that, in general, the below average user had lower auxiliary energy use in System A. This can be attributed to the nature of System B, wherein, as stated above, heat can only be transferred when there is a DHW draw. With less frequent draws the auxiliary heater for System B was required more regularly than in System A. The only major discrepancy between system auxiliary energy use was observed for the large 1990 home. On average 10 to 15 GJ more energy was used in System B than in System A. This was true for all draw profiles, storage tank volume, and collector area. This suggests that, for a house with a very low heating load, such as the large 1990 home, System B, there is limited benefit using the System B configuration studied here.

In general, it would appear that System A has superior performance to System B. Solar fractions were generally higher with System A than with System B and auxiliary energy use was generally lower for System A than for System B. In addition, System B experienced more instances of the high limit safety temperature being reached in the spring, winter, and fall months. This lead to situations in which solar energy could not be supplied to the plant due to safety concerns. If a larger tank was used this high limit safety temperature would be achieved less often. However, as was discussed in Section 6.3.1 there was limited benefit observed in increasing tank volume above even the lowest threshold of $1000 \mathrm{~L}$. 


\section{Chapter 7}

\section{Conclusions and Recommendations}

\subsection{Conclusions and Contributions}

As discussed in Chapter 1 this research aimed to compare the performance of two solar combisystems for four Canadian homes and a variety of newly developed DHW draw profiles with two specific goals: A solar fraction of $50 \%$ and a reduction in auxiliary energy use of $50 \%$ from a baseline system without a solar thermal plant. A sensitivity analysis was performed on the two plant configurations through the manipulation of storage tank volume and collector area. It was determined that a solar fraction of 50 $\%$ could not readily be achieved for any of the plant configurations studied. However, for select homes, plant configurations, and draw profiles, a reduction in total auxiliary energy use of $50 \%$ could be achieved.

System performance was assessed through the use of building simulation software packages. Specifically, TRNSYS, ESP-r, and the co-simulator were used to determine system performance. The building model, including the radiator system, was simulated in ESP-r. The building model was linked to the plant network, which was simulated in TRNSYS. The interaction of these two simulation tools was moderated through the use of the co-simulator. This took advantage of ESP-r's strong building

physics suite, and TRNSYS' easily adaptable plant network. Initial simulations were run to determine the effect that storage tank insulation thickness and collector tilt angle had on system performance. Above a insulation thickness of $15 \mathrm{~cm}$ there was limited variation observed in tank losses and auxiliary energy use. Similarly there was very limited effect on solar energy collection when adjusting collector tilt. Both of these parameters were set to constant values for the remaining simulations.

After initial simulations determined general system size, several parameters were 
varied in order to hone in on a system which could satisfy the objectives described above. The total collector area along with storage tank volume were the main parameters which were varied. In addition, the effects of newly developed draw profiles were studied and analysed with respect to system performance.

ESP-r house models were taken from the CHREM, originally developed by Lukas Swan [41], and used as representative examples of homes in Canada. These house models represented homes from across Ontario with a variety of space heating loads and heated floor areas. These house models were, in turn, linked to plant networks, developed in TRNSYS, based on systems reported on in IEA SHC Task 26.

New DHW draw profiles, based on data collected by Hydro Québec were developed and used in this research. This study showed that there is a great deal of variability in both the magnitude of draw and the time of use across homes. Large variations were also observed between individual homes in terms of the magnitude of daily draws. While 12 profiles were developed 4 of these were selected for detailed analysis in this work. The profiles used were selected based on daily magnitude and time of use. The development of the profiles is detailed in Chapter 5. The effects of magnitude and time of use of the draw profiles were investigated in detail in Chapter 6 . These profiles represent some of the most recent empirically based draw profiles in recent years. Most draw profiles currently in use are created using probabilistic distributions.

The two different plant configurations were assessed from a number of perspectives. One of the performance metrics selected for analysis was based on the interaction of solar energy collection and tank losses as storage tank volume was increased. It was found that System A, a one tank plant configuration with three internal heat exchangers, generally benefited from increasing tank volume as the increase in solar energy collected was greater than the increase in tank losses. However, System B was not able to take advantage of the increased capacity of the larger tank. System B, a two tank system with an isolated preheat tank, was found to regularly fail to make use of the available solar energy as the safety limit temperature was reached much more frequently with this configuration than for System A. During the fall through spring months System B was forced to shut down the loop connected to the solar collector $10 \%$ more often than System A.

System A achieved high solar fractions and significant reductions in overall auxiliary energy use. While it was found that solar fractions rarely hit $50 \%$ for any home, 
except under conditions with very large collector areas and storage tank volumes, reductions in auxiliary energy use of $50 \%$ could easily be achieved with modest system sizes. System B had less impressive performance than System A. The solar fractions were generally lower and the overall reduction in auxiliary energy use did not hit 50 $\%$ in many of the configurations studied. Results suggest that System A has superior performance in most circumstances.

Little effect was observed on system performance with respect to DHW profiles. Solar fractions were seen to rise with users who consumed more hot water. The magnitude of draw was found to have a more significant effect than time of use on solar fraction and auxiliary energy use. Comparing auxiliary energy use for the above average user and below average user revealed a difference of approximately 5.0 GJ for System A. System B was seen to be much less sensitive to draw profile when considering auxiliary energy use.

The factor which was seen to have the greatest effect on system performance was the house model selected. The space heating load, which comprised approximately 3 times the total energy use of the DHW load, created the greatest discrepancy across homes. While changing domestic hot waters loads was seen to affect a home's auxiliary energy use by up to 5.0 GJ, increasing the space heating load would result in an increase in auxiliary energy use of up to 20.0 GJ.

This research has created a series of DHW draw profiles which can be used by other simulationists. A thorough description of these draw profiles is given in a paper which is currently being written. In addition, this research has demonstrated the viability of the co-simulation tool.

It should be noted that not all the conclusions drawn regarding this research can be generalized. The results described here regarding performance were specific to the plant systems, homes, and locations studied.

\subsection{Recommendations for Future Work}

This research examined several solar combisystems with newly developed DHW draw profiles. The results presented demonstrate the viability of a solar combisystem for Ontario. However, there is further research which can be completed to expand the knowledge on this topic and the systems described.

Further work is required in order to determine the efficacy of these plant systems in 
Canadian climates besides Ontario. The performance of these systems in the prairies, the Maritimes, Québec, and British Columbia (BC) may vary substantially from the systems described here due to their different climates. The milder climates of the Maritimes and $\mathrm{BC}$ could allow for smaller systems, whereas the harsher climates of Québec and the prairies may require larger systems.

The performance of System B was generally found to be poor. During this research the DHW tank was held at a constant volume. Adjusting DHW tank volumes could yield improved performance. In addition, a heat exchanger could be placed between the DHW tank and the preheat tank to improve heat transfer between the the two tanks. Further refinement of System B is recommended to improve solar fraction and auxiliary energy usage.

This study only investigated four of the DHW draw profiles that were discussed in Chapter 4. The application of these draw profiles is not confined to use with solar thermal systems. These draw profiles could be used with standard electric water heaters, fuel cells, or natural gas boilers to determine if draw profiles affect the performance of these systems. If time of use rates, where users pay more for energy during select periods of the day, are implemented in a particular district it would be beneficial to have these newly developed draw profiles. The temporal aspect of these draw profiles could be beneficial for the assessment of time of use rates.

This study only assessed performance in terms of energy use and did not take into consideration any economic aspects associated with the systems studied. It could be beneficial to assess the system under a variety of conditions and determine its economic viability. The collector area and storage tank volume are relatively large when compared to typical systems. Incorporating an economic analysis into performance could provide a more realistic eye to system design.

While evacuated tube collectors were not studied here, due to possibilities regarding snow cover, it would be interesting to observe the effects of these collectors on system performance. It is likely that using evacuated tube collectors would reduce the required collector area. However, the interaction with storage volume is uncertain. The increased outlet temperatures from the evacuated tubes may necessitate large storage volumes.

Finally, studying these systems with a radiant floor system could yield improved performance. By utilizing a radiant floor, lower inlet temperatures would be required and, therefore, less energy required from the solar combisystem. This could be used 
as an alternative to the radiators used here and result in higher solar fractions and reduced auxiliary energy use. 


\section{List of References}

[1] Natural Resources Canada, Energy Use Data Handbook, 1990 to 2010 - February 2013, February 2013.

[2] J. Prentice, "Federal sustainable development strategy," tech. rep., Environment Canada, 2010.

[3] T. Weis and M. Bramley, "United states to invest over six times more per capita in renewable energy and energy efficiency than canada," tech. rep., The Pembina Institute, February 2009.

[4] "Solar thermal," Novemeber 2013. http://www.nrcan.gc.ca/energy/renewableelectricity/solar-thermal/7301.

[5] R. Djebbar, "Survey of active solar thermal collectors, industry and markets in canada (2009)," Tech. Rep. CM002387, Natural Resources Canada, August 2010.

[6] B. McLaren and S. Parker, "Transpired collectors for outdoor ventilation air," Tech. Rep. DOE/GO-10098-528, United States Department of Energy, April 1998.

[7] T. Paul, "Innovative buildings: Southfield solar model home-guelph, ont.," tech. rep., Canada Mortgage and Housing Corporation, July 2007.

[8] J. Duffie and W. Beckman, Solar Engineering of Thermal Processes. John Wiley and Sons Inc., 2006.

[9] R. Dumont, "The factor 9 home: A new prairie approach monitoring final report," Tech. Rep. 12155-2C08, Saskatchewan Research Council, December 2008.

[10] S. Haight, "Project profile: Urban ecology - winnipeg, manitoba," tech. rep., Canada Mortgage and Housing Corporation, November 2012.

[11] U. Jordan and K. Vajen, "Influence of dhw load profile on the fractional energy savings: A case study of a solar combisystem with trnsys simulation," Solar Energy, vol. 69, pp. 197-208, 2000.

[12] M. Perlman and B. Mills, "Development of residential hot water use patterns," ASHRAE Transactions, vol. 91, pp. 657-679, 1985.

[13] ASHRAE, HVAC Applications Handbook, 2011. 
[14] B. Becker and K. Stogsdill, "Development of a hot water use data base," ASHRAE Transactions, vol. 96, pp. 422-427, 1990.

[15] U. Jordan and K. Vajen, "Realistic domestic hot water profiles in different time scales," tech. rep., International Energy Agency, 2001.

[16] R. Hendron and J. Burch, "Development of standardized domestic hot water event schedules for residential buildings," Tech. Rep. NREL/CP-550-40874, National Renewable Energy Laboratory, June 2007.

[17] J. Evarts and L. Swan, "Domestic hot water consumption estimates for solar thermal system sizing," Energy and Buildings, vol. 58, pp. 58-65, 2013.

[18] S. Kalogirou, "Solar thermal collectors and applications," Progress in Energy and Combustion Science, vol. 30, pp. 231-295, 2004.

[19] A. Wills, "Design and co-simulation of a seasonal solar thermal system for a canadian single-family detached house," Master's thesis, Carleton University, May 2013.

[20] R. Quail, "Drake landing: Solar community," September 2007.

[21] A. Shariah, M. Al-Akhras, and I. Al-Omari, "Optimizing the tilt angle of solar collectors," Renewable Energy, vol. 26, pp. 813-819, 2002.

[22] K. Comakli, U. Cakir, M. Kaya, and K. Bakirci, "The relation of collector and storage tank size in solar heating systems," Energy Conversion and Management, vol. 63, pp. 112-117, 2012.

[23] K. Ellehuage, "Appendix 1: Generic system 2: A solar combisystem based on a heat exchanger between the collector loop and space-heating loop," tech. rep., International Energy Agency, July 2002.

[24] D. Cheze and P. Papillon, "Appendix 2: Generic system 3a: Advanced direct solar floor," tech. rep., International Energy Agency, July 2002.

[25] J. Bony and T. Pittet, "Appendix 4: Generic system 8: Space heating store with double load-side heat exchanger for dhw," tech. rep., International Energy Agency, July 2002.

[26] L. Shah, "Appendix 3: Generic system 4: Dhw tank as a space-heating storage device," tech. rep., International Energy Agency, July 2002.

[27] M. Peter, "Appendix 5: Generic system 9b: Space heating store with immeresed dhw tank and external dhw store with auxiliary," tech. rep., International Energy Agency, July 2003.

[28] C. Bales, "Appendix 7: Generic system 12: Space heating store with dhw load side heat exchanger(s) and external auxiliary boiler (advanced version)," tech. rep., International Energy Agency, July 2002. 
[29] C. Bales, "Appendix 6: Generic system 11: Space heating store with dhw load side heat exchanger(s) and external auxiliary boiler," tech. rep., International Energy Agency, July 2002a.

[30] W. Weiss, ed., Solar Heating Systems for Houses: A Design Handbook for Solar Combisystems. James and James (Science Publishers), 2003.

[31] L. Henden, J. Rekstad, and M. Meir, "Thermal performance of combined solar systems with different collector efficiencies," Solar Energy, vol. 72, pp. 299-305, 2002.

[32] M. Leckner and Zmeureanu, "Life cycle cost and energy analysis of a net zero energy house with solar combisystem," Applied Energy, vol. 88, pp. 232-241, 2011.

[33] J. Wallin, D. Bastien, and J. Claesson, "The influence of energy conservation on the performance of solar thermal systems - a cold country case study," Energy Procedia, vol. 30, pp. 1069-1078, 2012.

[34] P. Lund, "Sizing and applicability considerations of solar combisystems," Solar Energy, vol. 78, pp. 59-71, 2005.

[35] S. Asaee, V. Ugursal, I. Beausoleil-Morrison, and N. Ben-Abdallah, "Preliminary study for solar combisystem potential in canadian houses," Applied Energy, 2014. In press.

[36] J. Hin and R. Zmeureanu, "Optimization of residential solar combisystem for minimum life cycle cost, energy use and exergy destroyed," Solar Energy, vol. 100, pp. 102-113, 2014.

[37] T. Jeeves and R. Hooke, "'direct search' solution of numerical and statistical problems," Journal of the ACM, vol. 8, pp. 212-229, 1961.

[38] R. Eberhart and J. Kennedy, "Particle swarm optimization," tech. rep., IEEE, December 1995.

[39] M. Lundh, K. Zass, C. Wilhelms, K. Vajen, and U. Jordan, "Influence of store dimensions and auxiliary volume configuration on the performance of mediumsized solar combisystems," Solar Energy, vol. 84, pp. 1095-1102, 2010.

[40] R. Bornatico, M. Pfeiffer, A. Witzig, and L. Guzzella, "Optimal sizing of a solar thermal building installation using particle swarm optimization," Energy, vol. 41, pp. 31-37, 2012.

[41] L. Swan, Residential Sector Energy and GHG Emissions Model for the Assessment of New Technologies. PhD thesis, Dalhousie University, August 2010.

[42] L. Swan, V. Ugursal, and I. Beausoleil-Morrison, "Hybrid residential end-use energy and greenhouse gas emissions model - development and verification for canada," Journal of Building Performance Simulation, vol. 6, pp. 1-23, 2013.

[43] J. Clarke, Environmental Systems Performance. PhD thesis, University of Strathclyde, 1977. 
[44] "Esp-r," 2014. http://www.esru.strath.ac.uk/Programs/ESP-r.htm.

[45] P. Strachan, G. Kokogiannakis, and I. Macdonald, "History and development of validation with the esp-r simulation program," Building and Environment, vol. 43, pp. 601-609, 2008.

[46] J. Clarke, Energy Simulation in Building Design. Woburn, Massachusets: Butterworth-Heinemann, 2001.

[47] I. Beausoleil-Morrison, The Adaptive Coupling of Heat and Air Flow Modelling Within Dyanmic Whole-Building Simulation. PhD thesis, University of Strathclyde, 2000.

[48] I. Beausoleil-Morrison, F. Macdonald, M. Kummert, T. McDowell, and R. Jost, "Co-simulation between esp-r and trnsys," Journal of Building Performance Simulation, vol. 7, pp. 133-151, 2014.

[49] Intermodel Comparison and Experimental Validation of Electrical Water Heater Mdoels in TRNSYS, 2011.

[50] TRNSYS 17, TRNSYS 17 Documentation, 17.01.0000 ed., March 2012.

[51] R. Abernethy, R. Benedict, and R. Dowdell, "Asme measurement uncertainty," Journal of Fluids Engineering, vol. 107, pp. 161-164, 1985.

[52] J. Burch and J. R. Salasovich, "Flow rates and draw variability in solar domestic hot water usage," in Proceedings of the American Solar Energy Society Solar 2002 Conference, (Reno, Nevada, USA), pp. 287-292, 2002.

[53] F. Goldner, "Energy use and domestic hot water consumption," Tech. Rep. 1647EEED-BES-91, Energy Management and Research Associates, November 1994.

[54] Performance of vacuum tube and flat plate collectors concerning domestic hot water preparation and room heting, 2005.

[55] F. Plavosin, "Solar collector test report," tech. rep., EnerWorks Inc., 2006.

[56] K. Ismail, J. Leal, and M. Zanardi, "Models of liquid storage tanks," Energy, vol. 22, pp. 805-815, 1997.

[57] J. Nelson, A. Balakrishnan, and S. Murthy, "Parametric studies on thermally stratified chilled water storage systems," Applied Thermal Engineering, vol. 19, pp. 89-115, 1999.

[58] S. Beck, S. Grinsted, S. Blakey, and K. Worden, "A novel design of panel radiators," Applied Thermal Engineering, vol. 24, pp. 1291-1300, 2004. 
Appendix A

Results of System A plant configuration for all Homes Aside from Mid-size 1955 


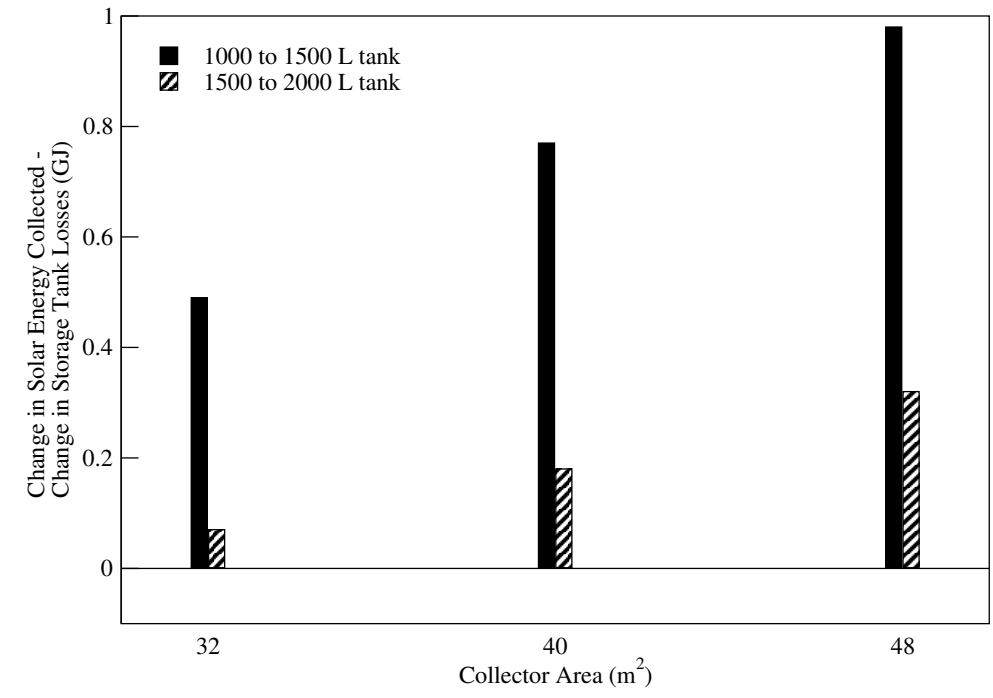

(a) Below average DHW consumer

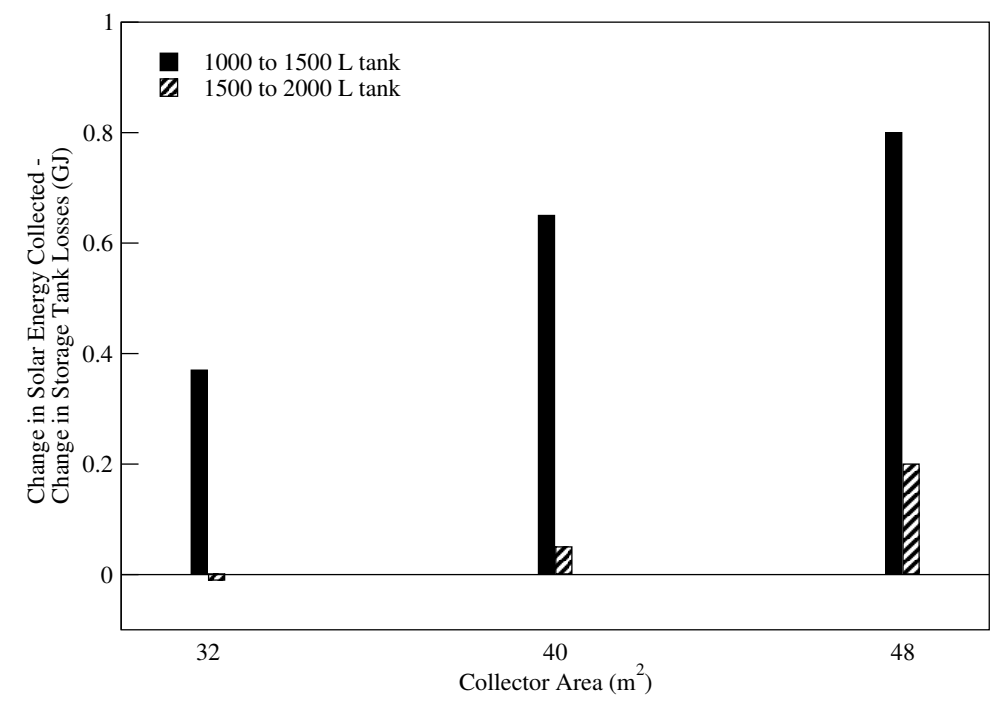

(c) Median DHW consumer

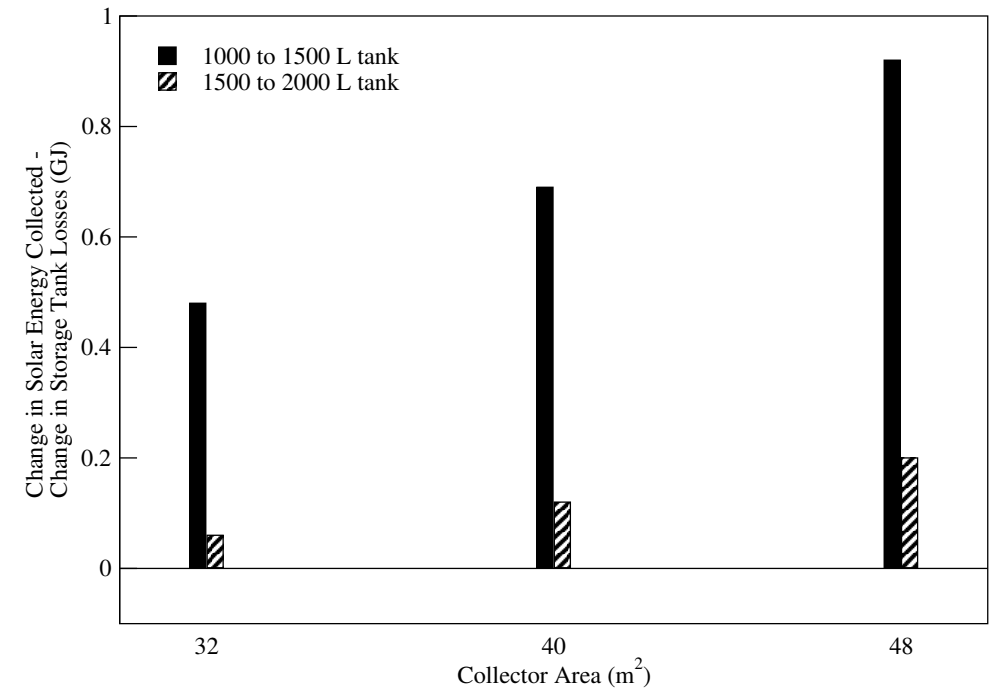

(b) Average DHW consumer

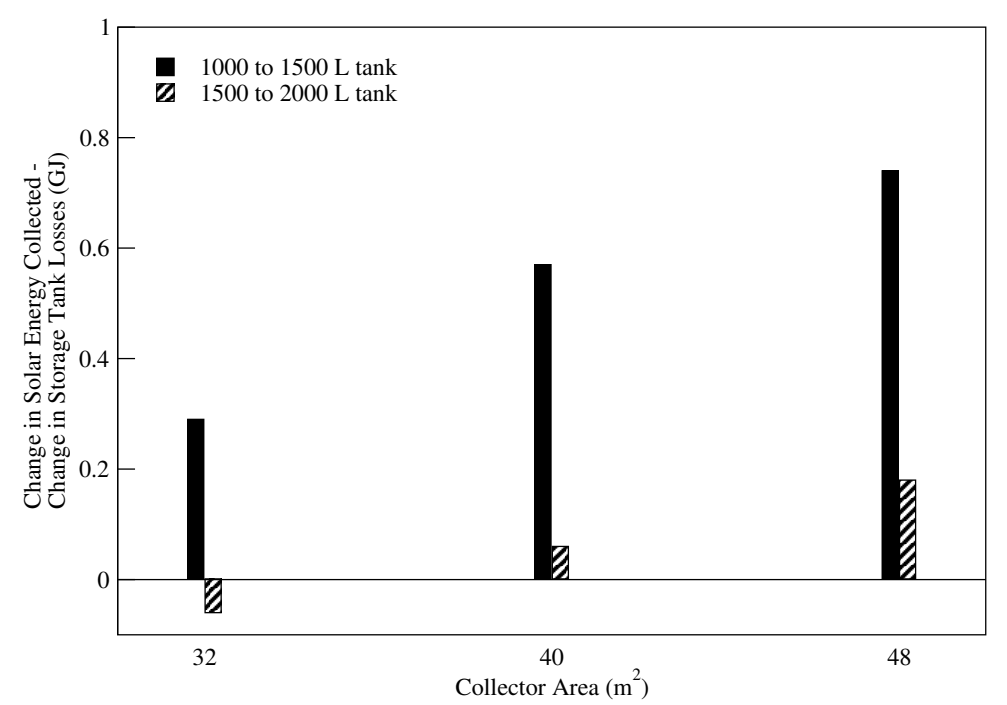

(d) Above average DHW consumer

Figure A.1: Difference in solar energy collected when varying collector area and storage volume for mid-size 1974 home. 


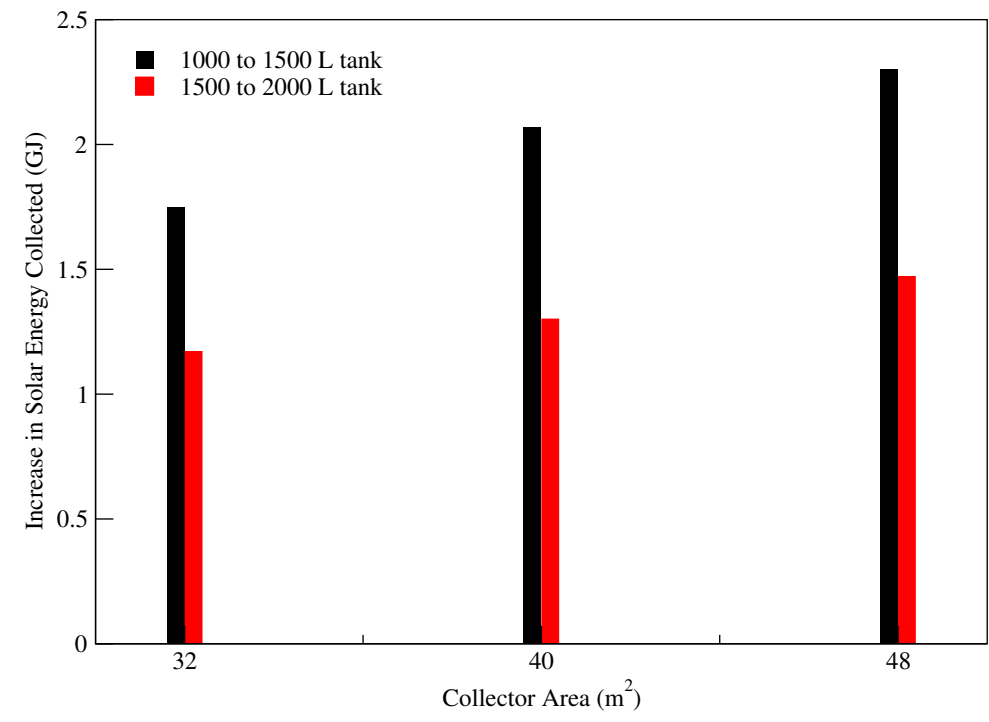

(a) Below average DHW consumer

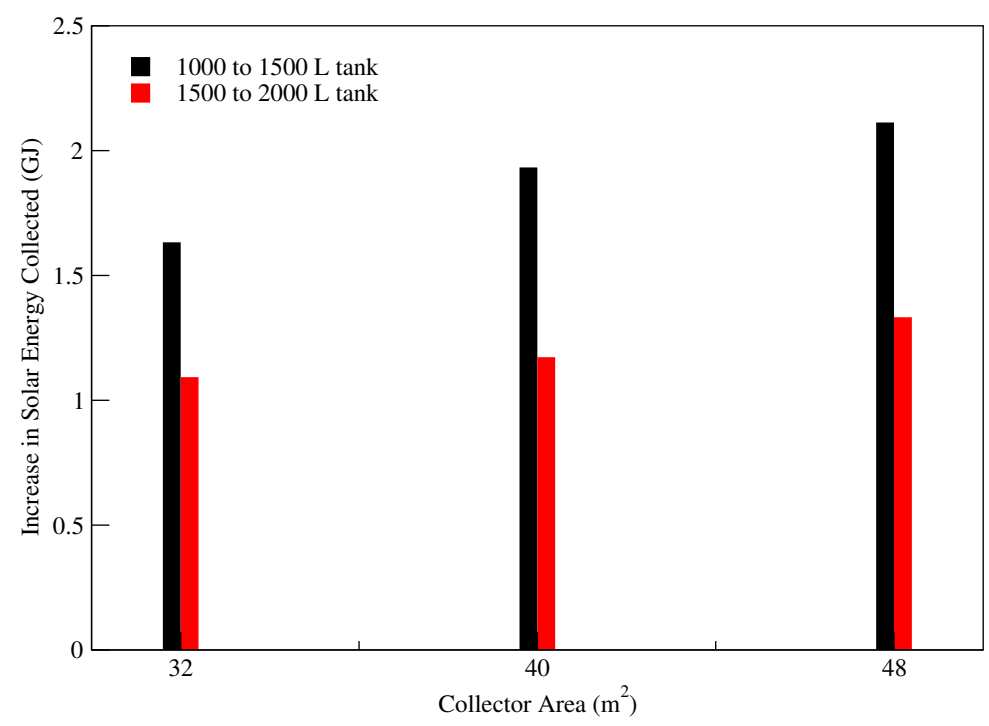

(c) Median DHW consumer

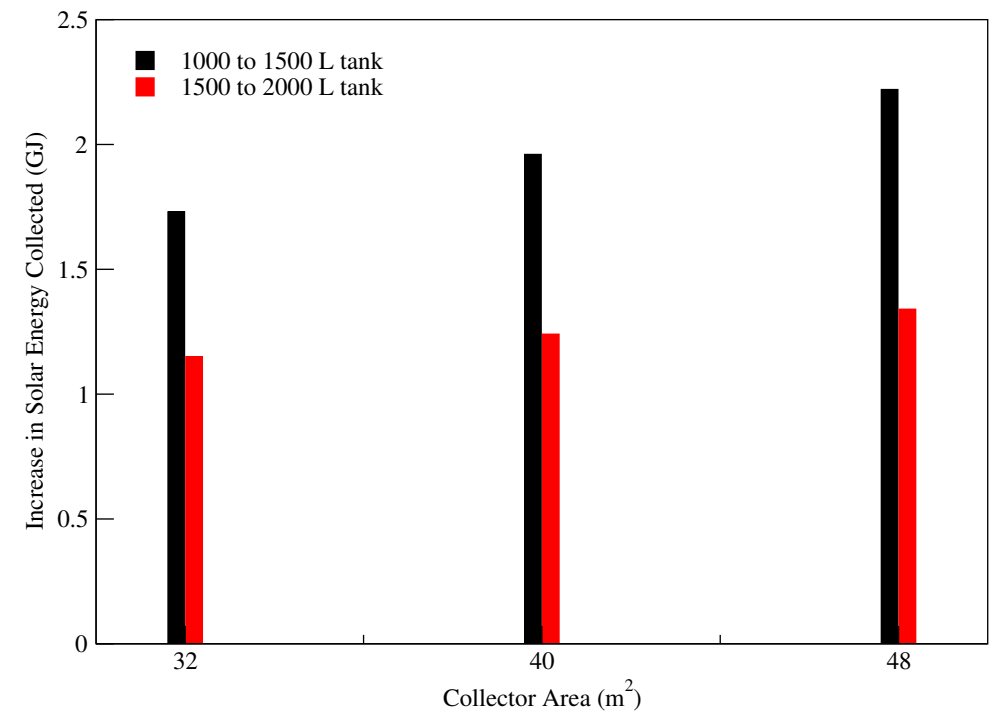

(b) Average DHW consumer

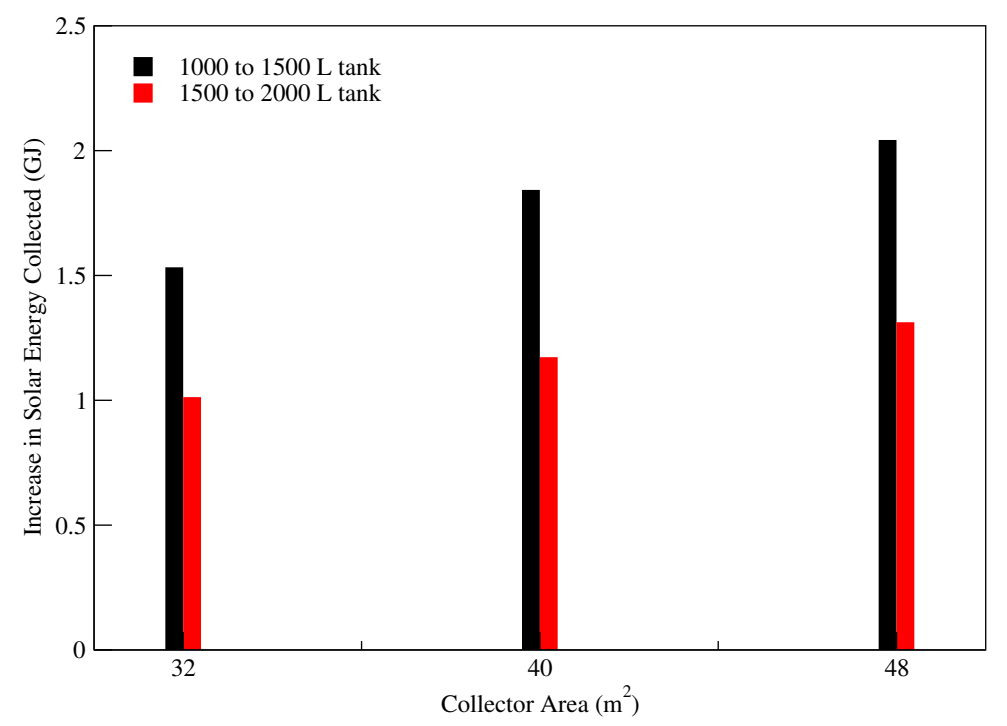

(d) Above average DHW consumer

Figure A.2: Difference in solar energy collected when varying collector area and storage volume for mid-size 1974 home. 


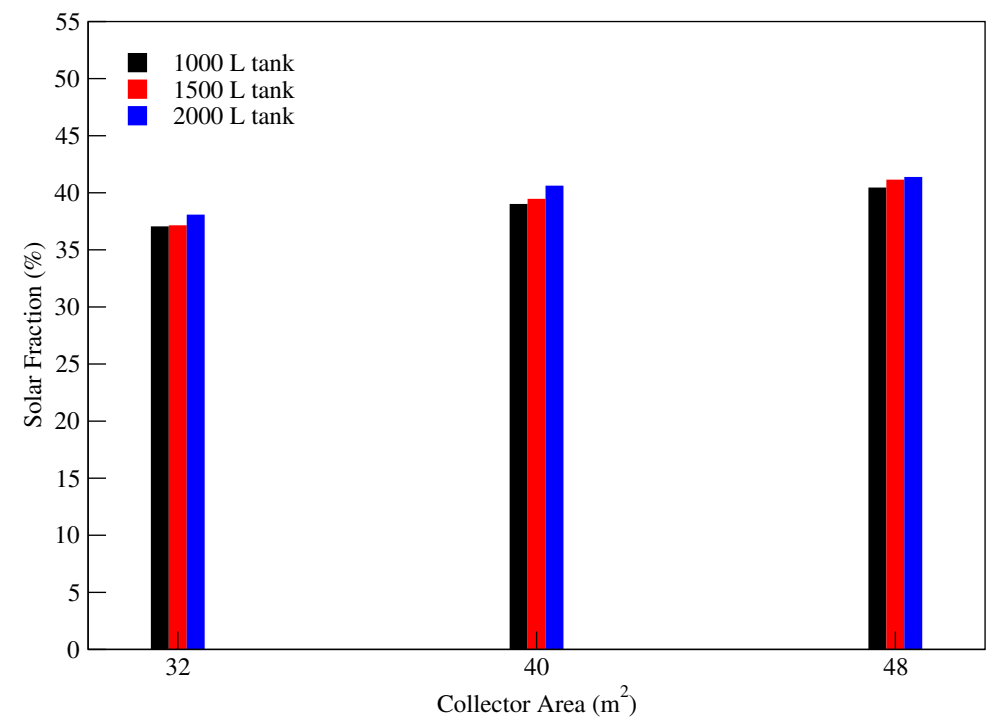

(a) Below average DHW consumer

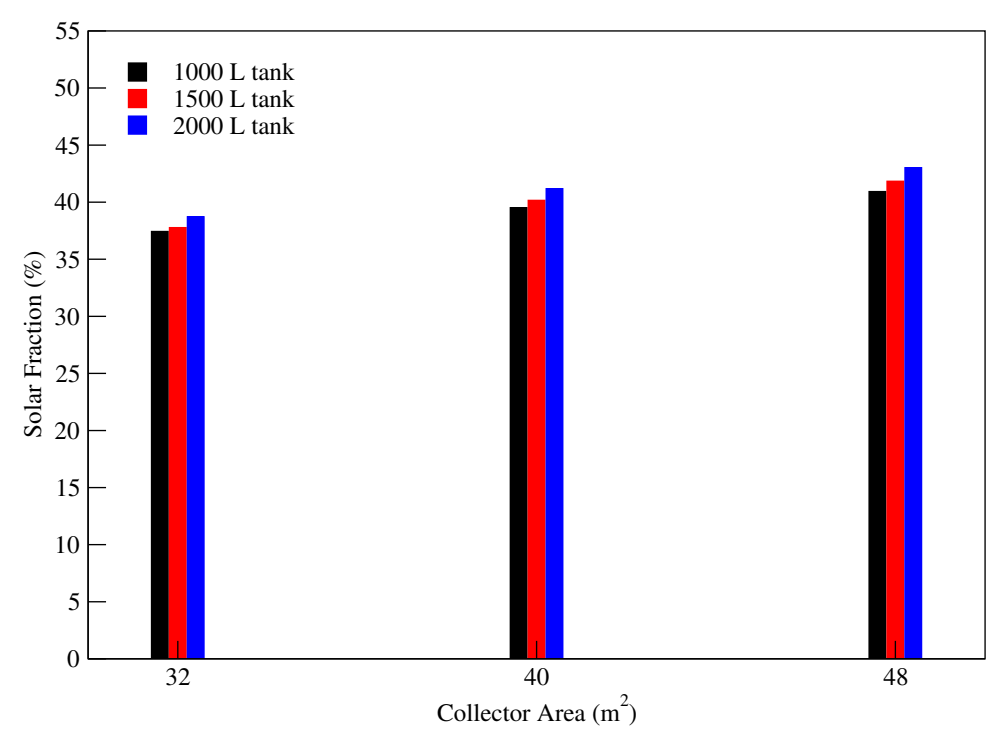

(c) Median DHW consumer

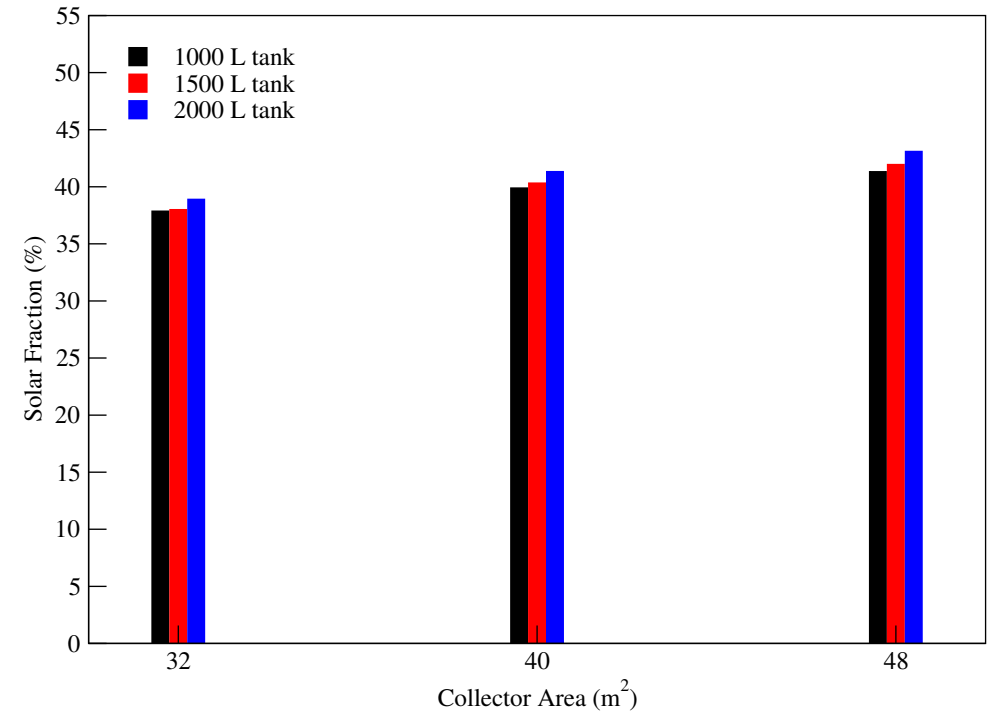

(b) Average DHW consumer

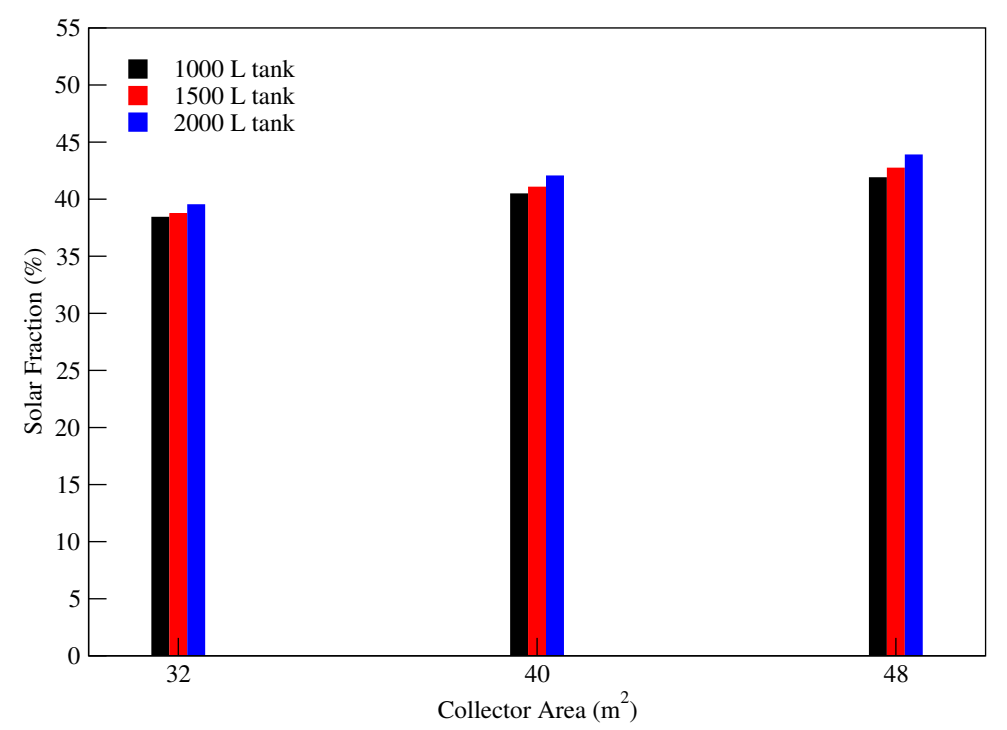

(d) Above average DHW consumer

Figure A.3: Difference in solar fractions when varying collector area and storage volume for mid-size 1974 home. 


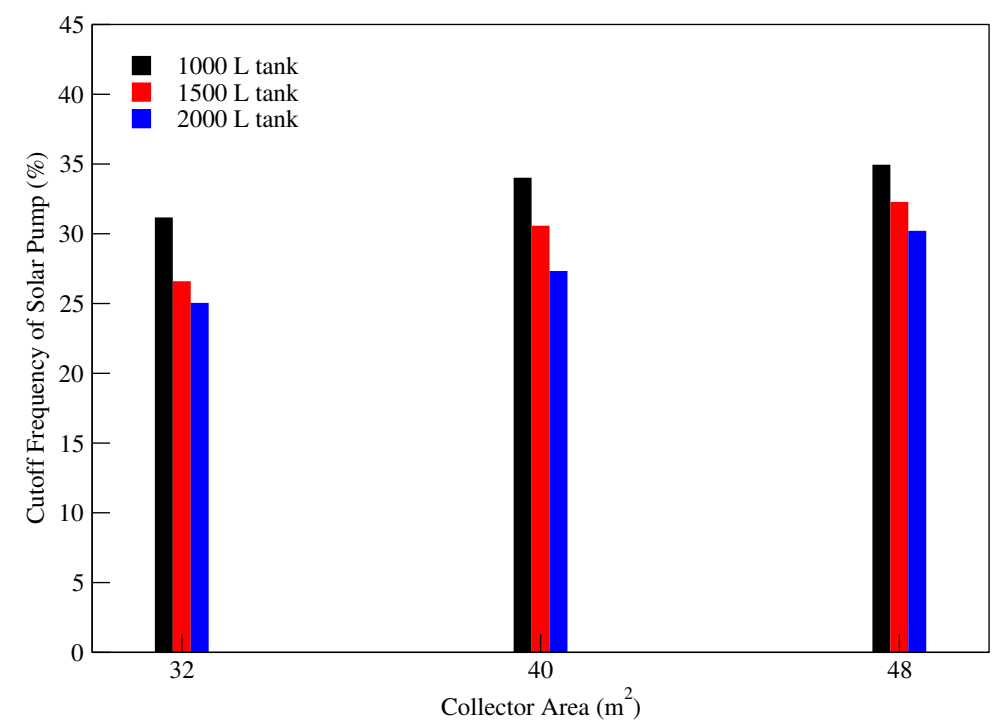

(a) Below average DHW consumer

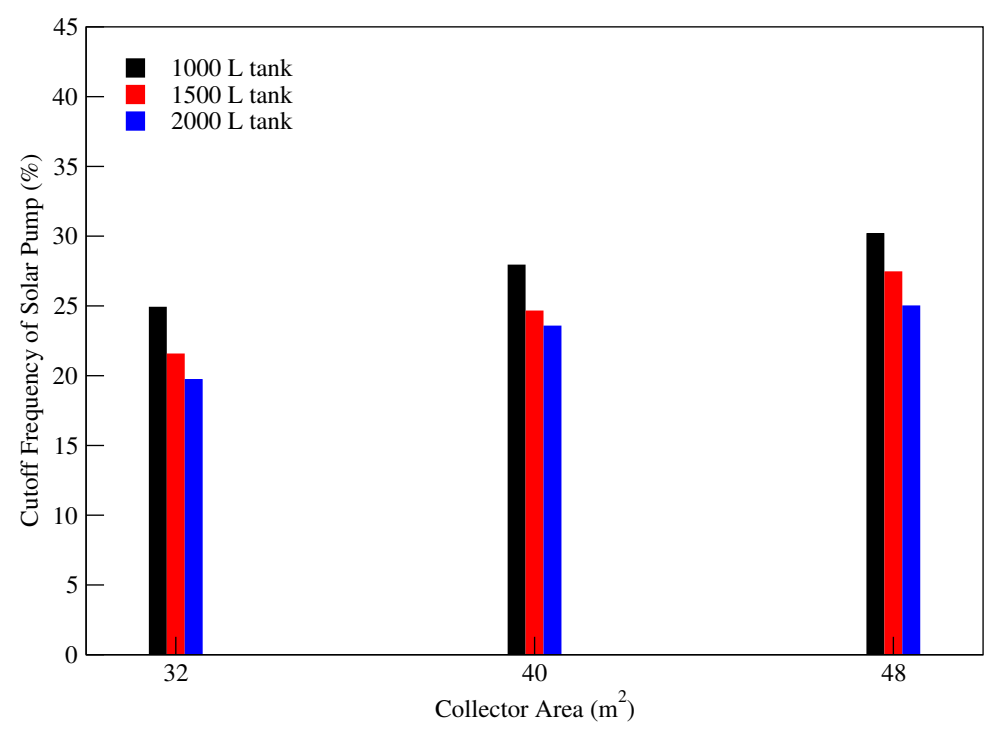

(c) Median DHW consumer

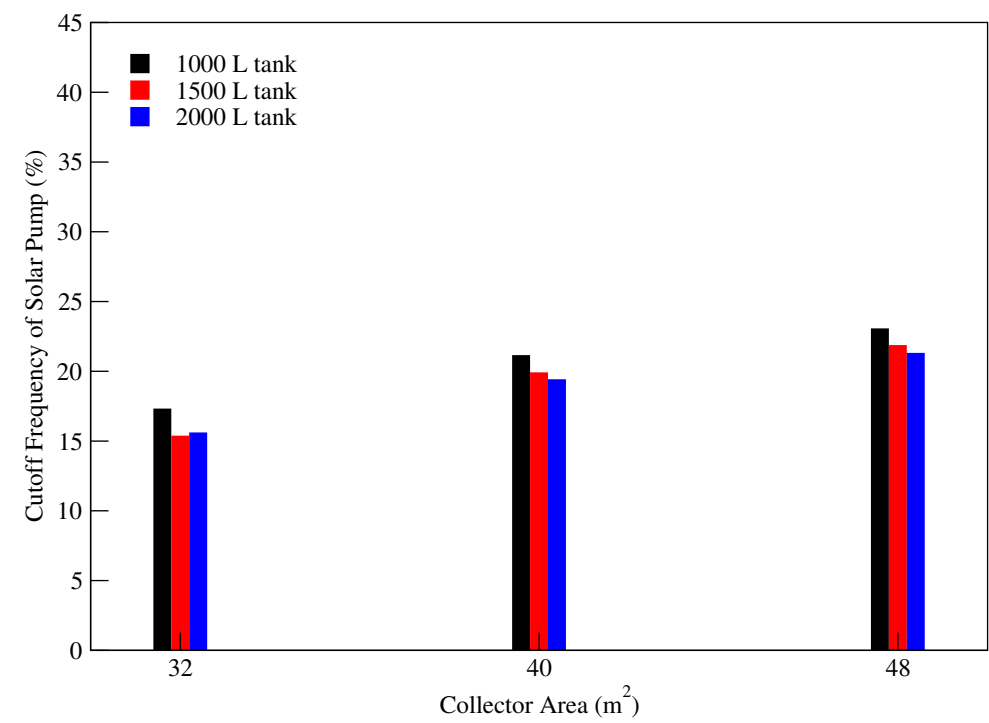

(b) Average DHW consumer

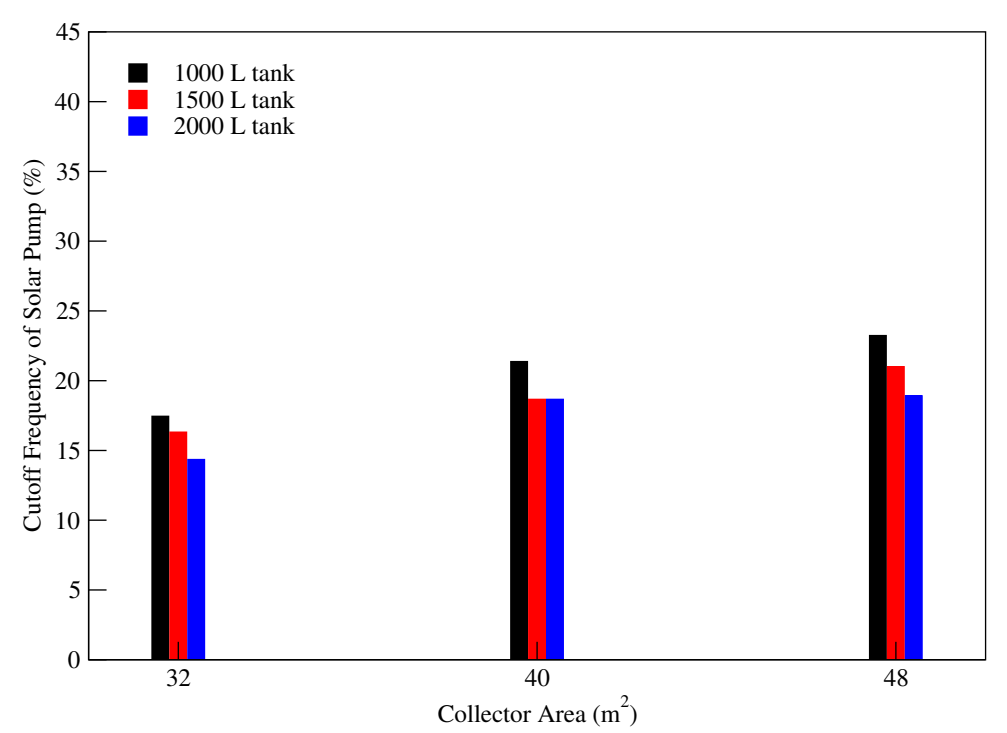

(d) Above average DHW consumer

Figure A.4: Difference in solar pump cutoff times when varying collector area and storage volume for mid-size 1974 home. 


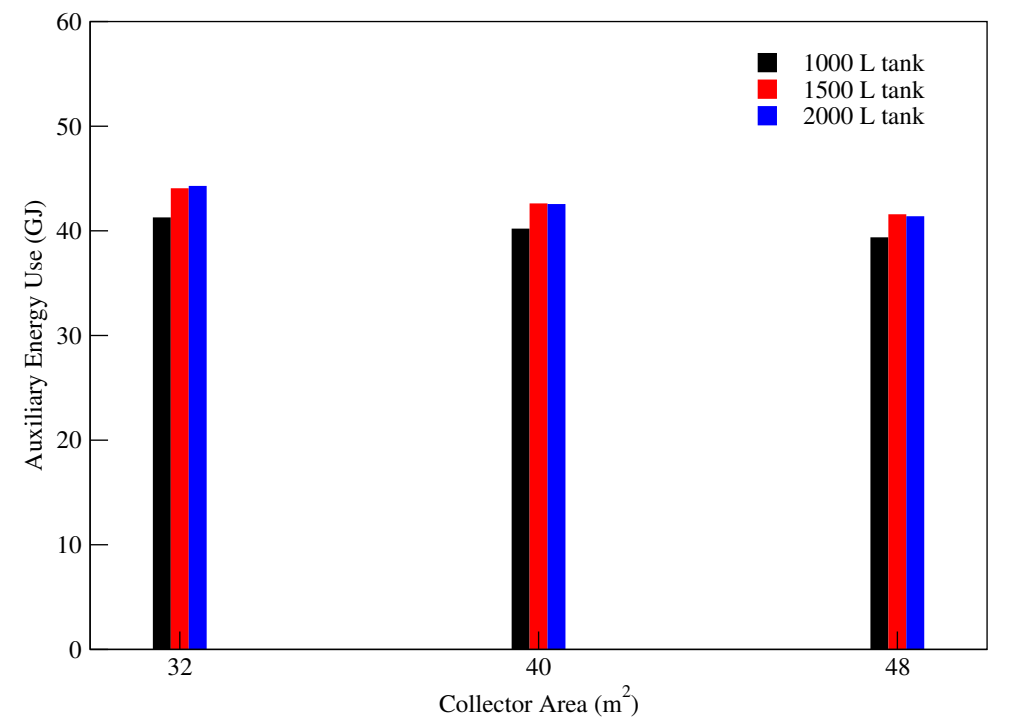

(a) Below average DHW consumer

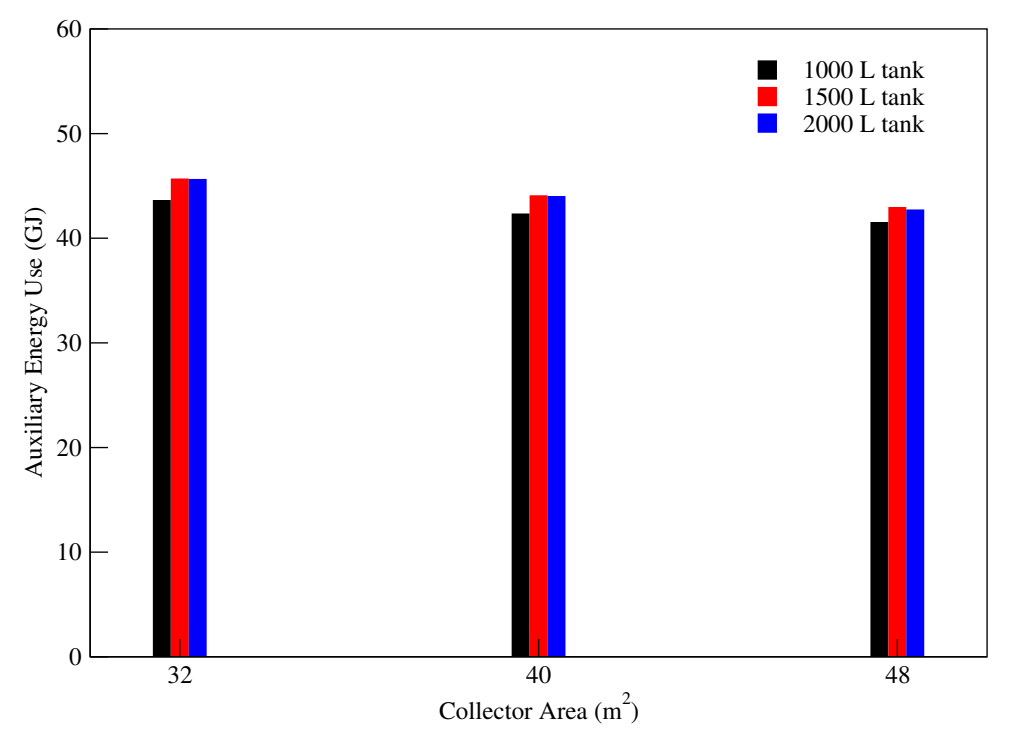

(c) Median DHW consumer

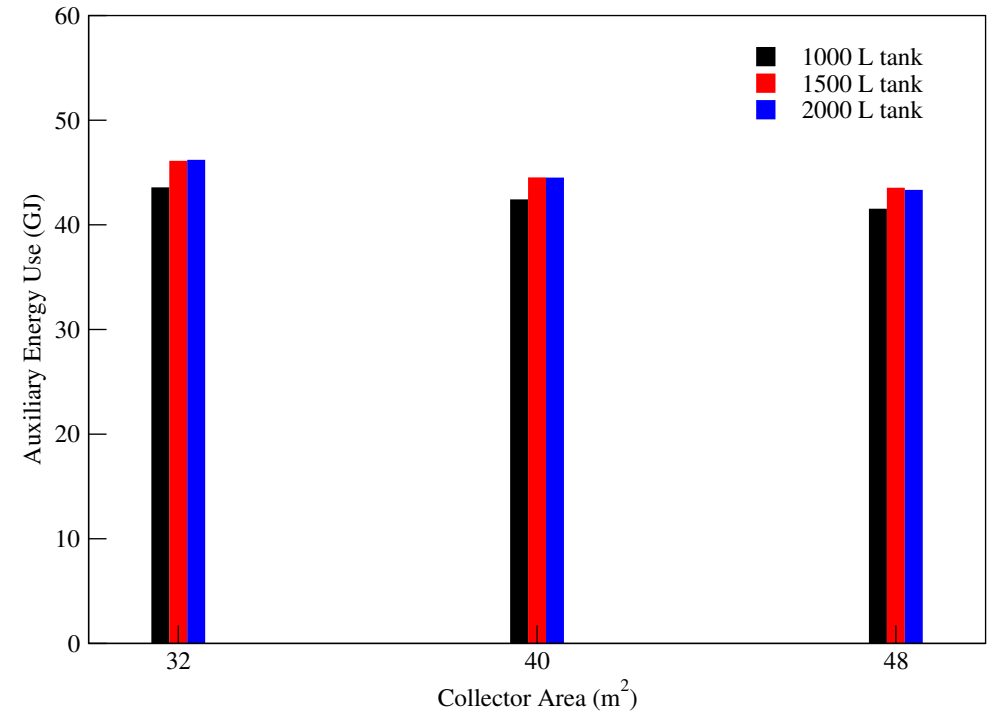

(b) Average DHW consumer

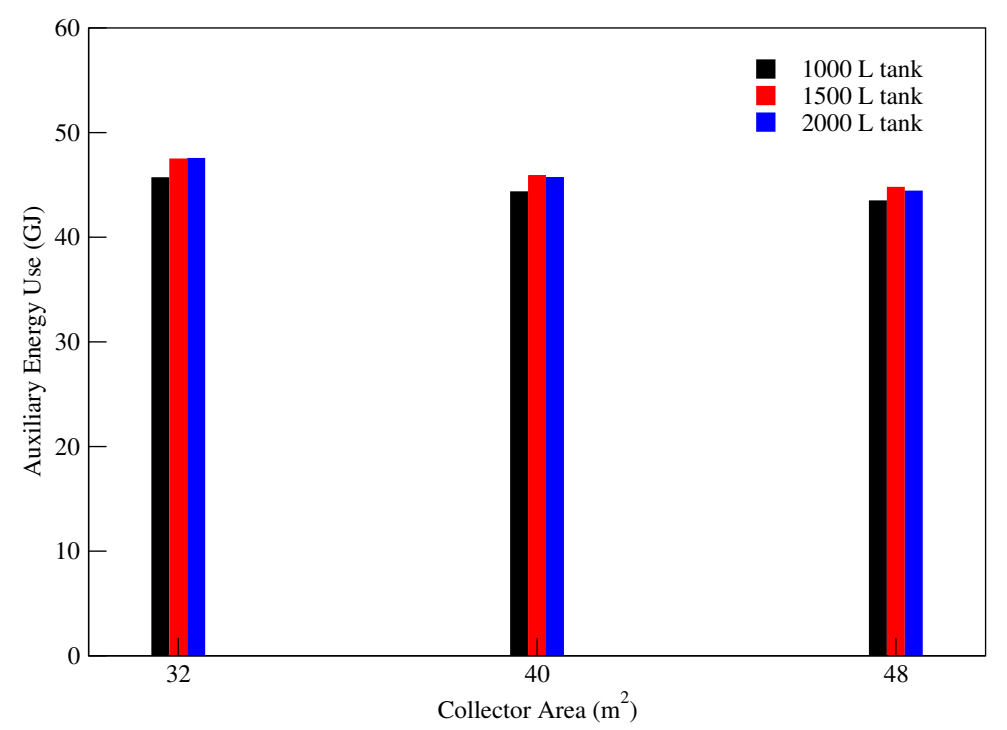

(d) Above average DHW consumer

Figure A.5: Difference in auxiliary energy use when varying collector area and storage volume for mid-size 1974 home. 


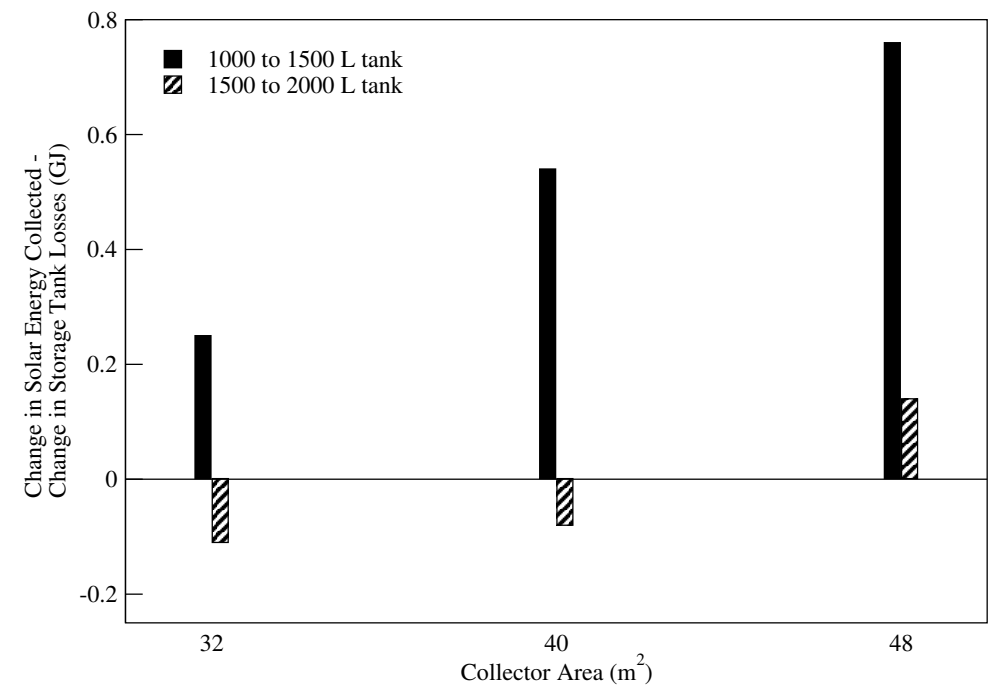

(a) Below average DHW consumer

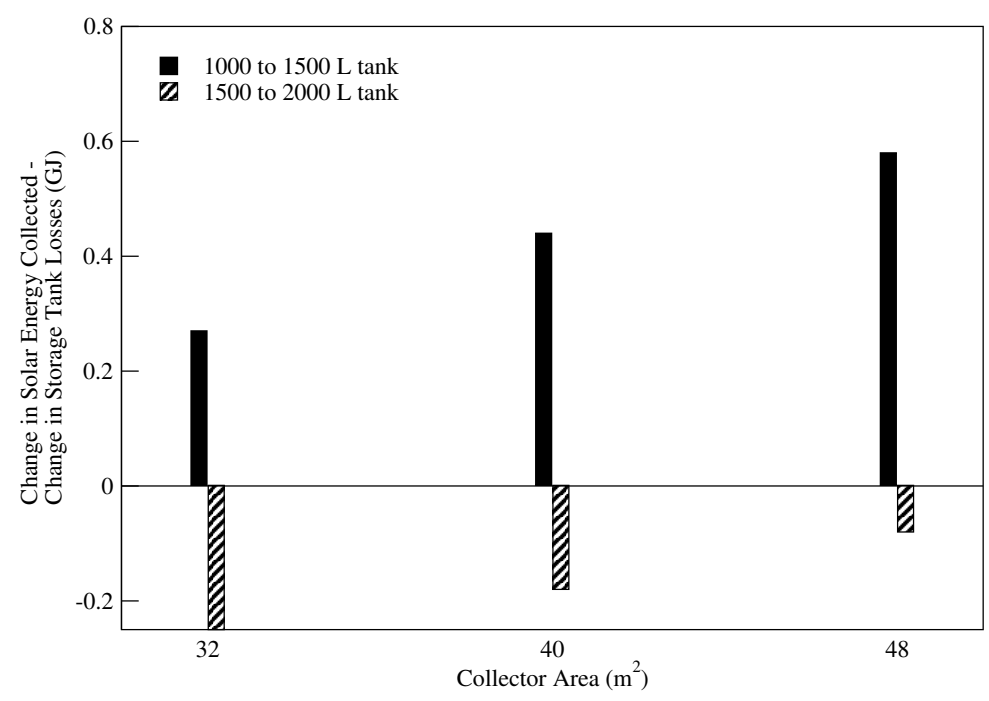

(c) Median DHW consumer

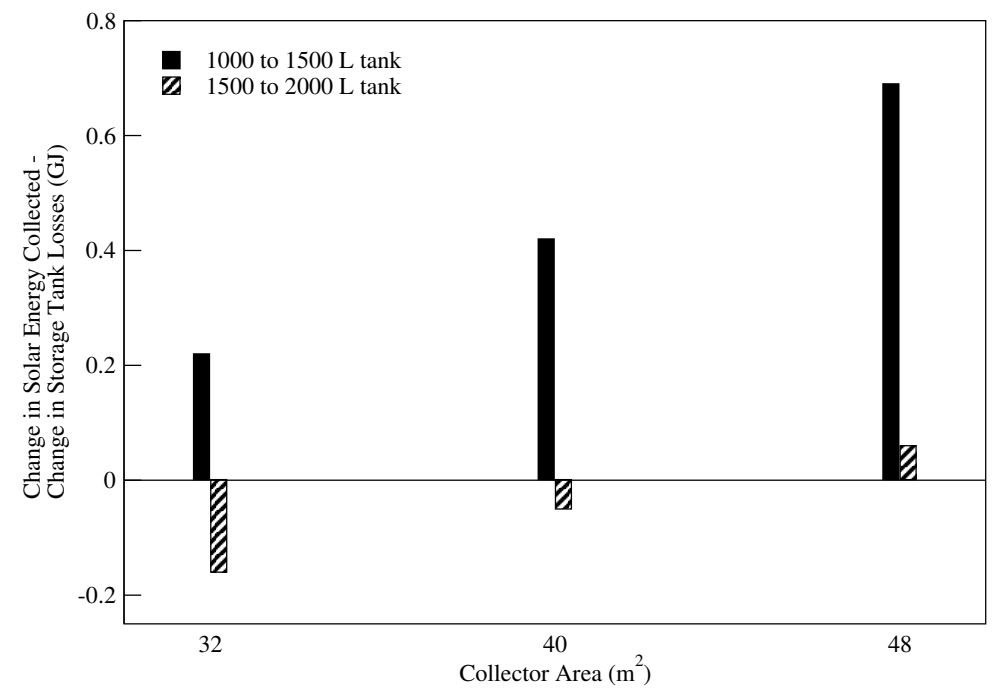

(b) Average DHW consumer

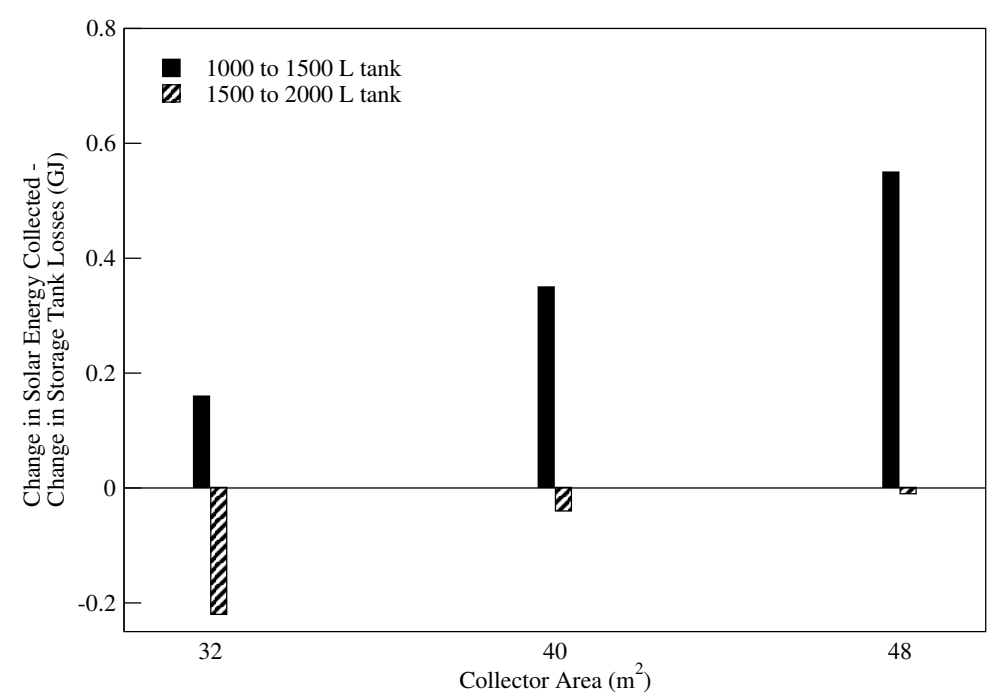

(d) Above average DHW consumer

Figure A.6: Difference in solar energy collected and DHW tank Losses when varying collector area and storage volume for for mid-size 1990 home. 


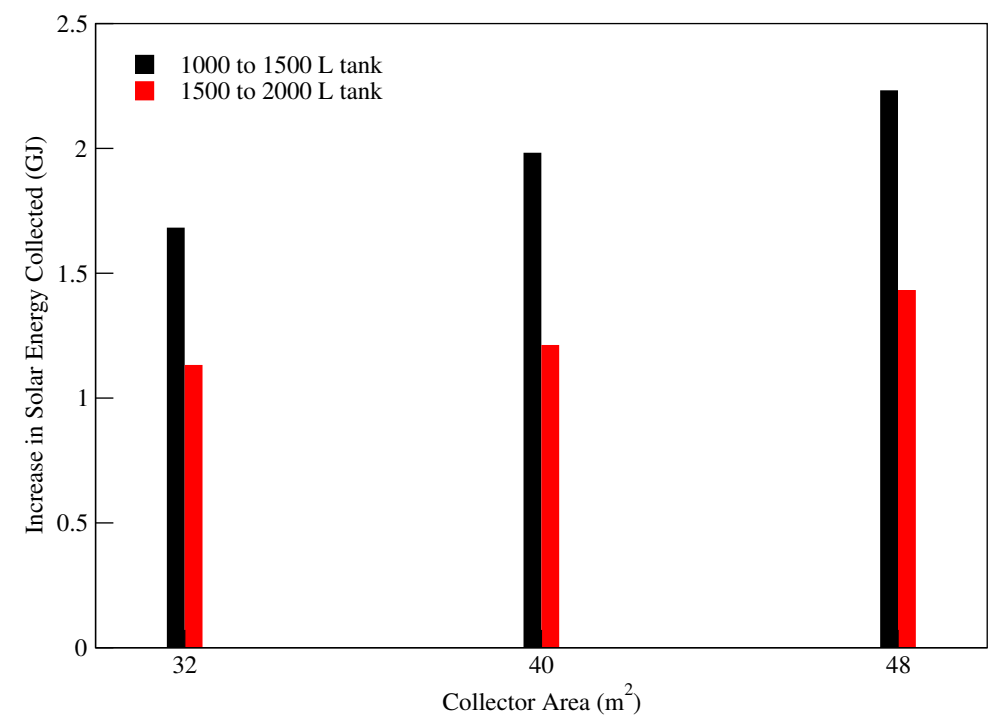

(a) Below average DHW consumer

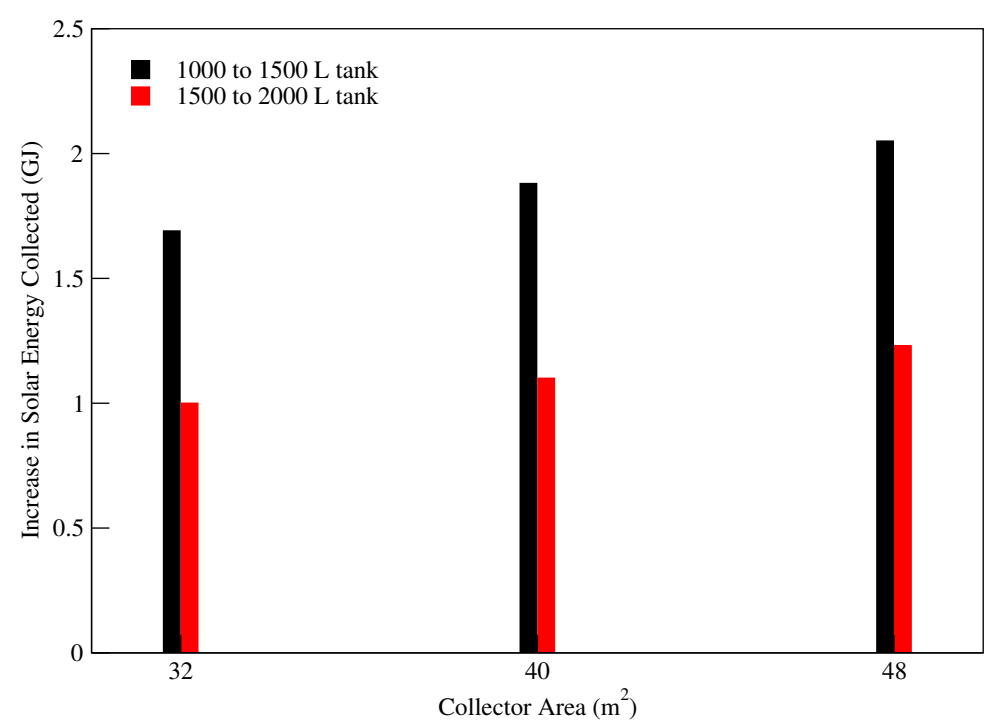

(c) Median DHW consumer

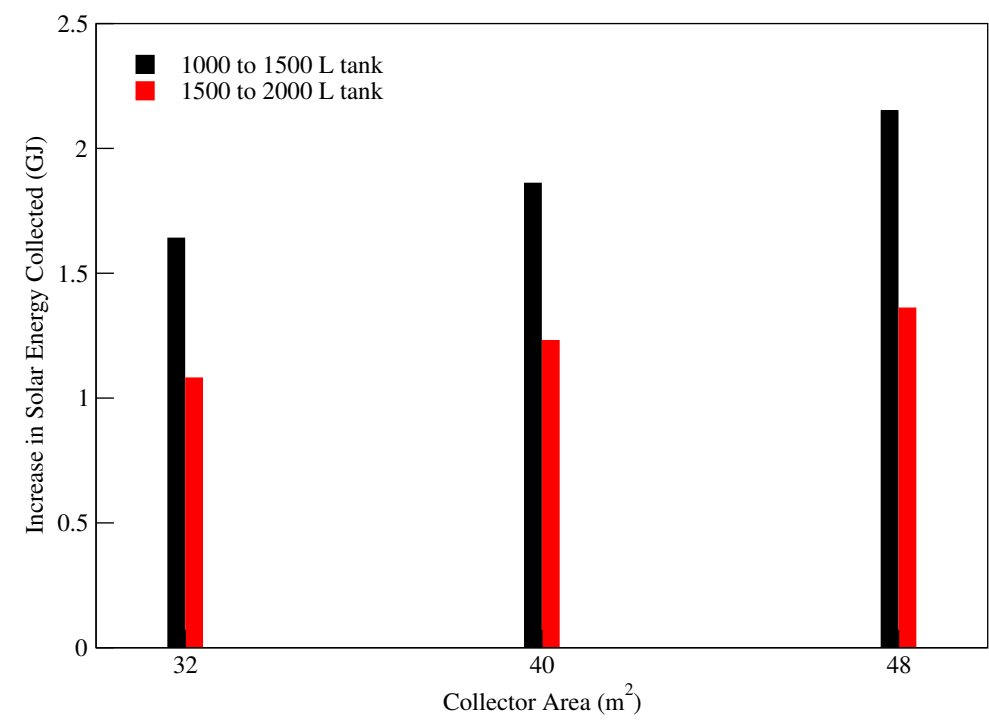

(b) Average DHW consumer

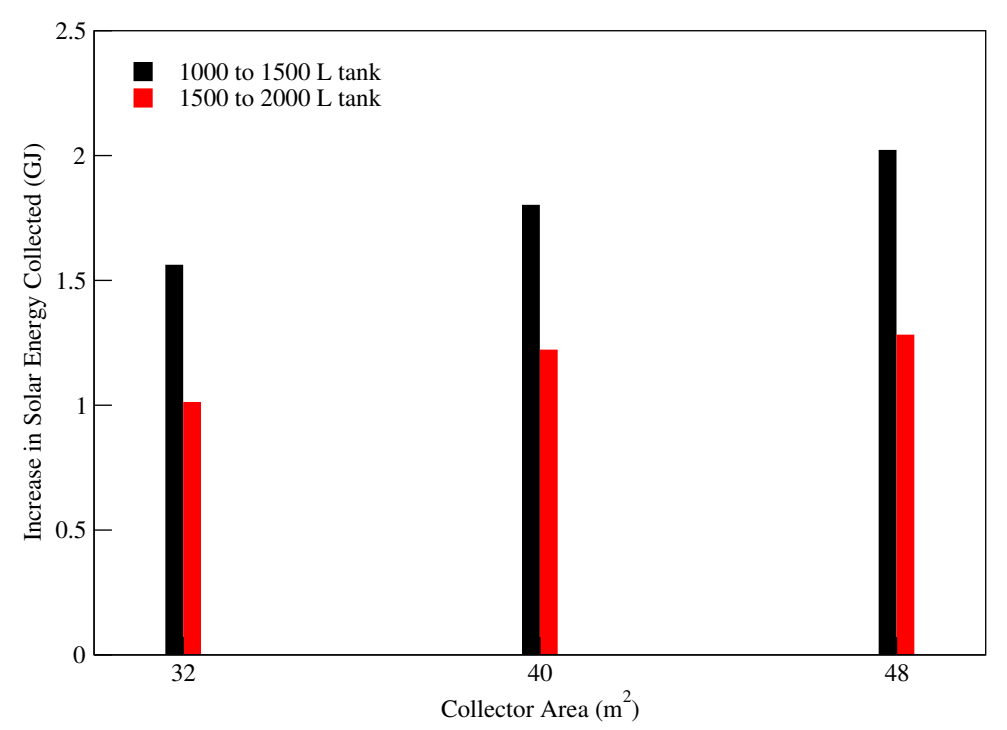

(d) Above average DHW consumer

Figure A.7: Difference in solar energy collected when varying collector area and storage volume for for mid-size 1990 home. 


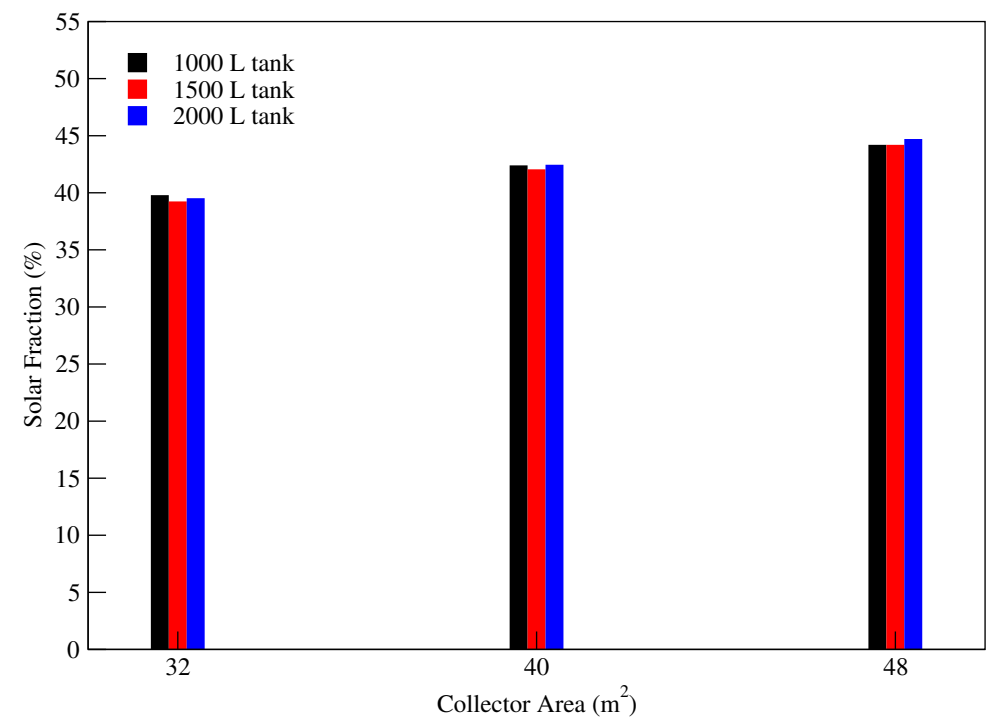

(a) Below average DHW consumer

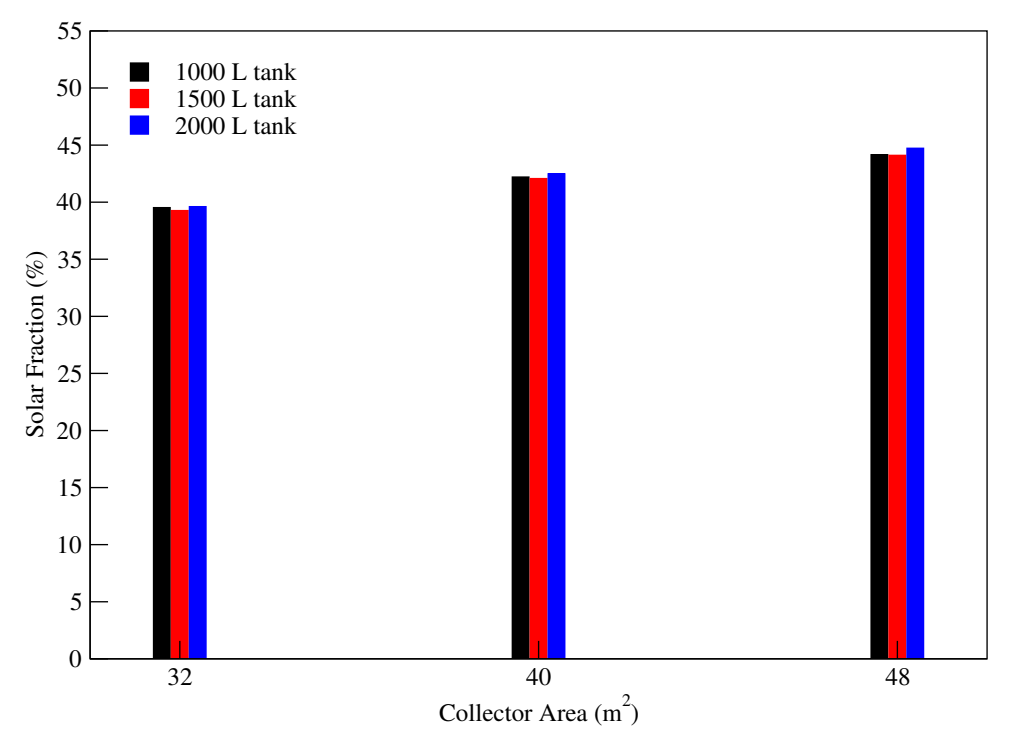

(c) Median DHW consumer

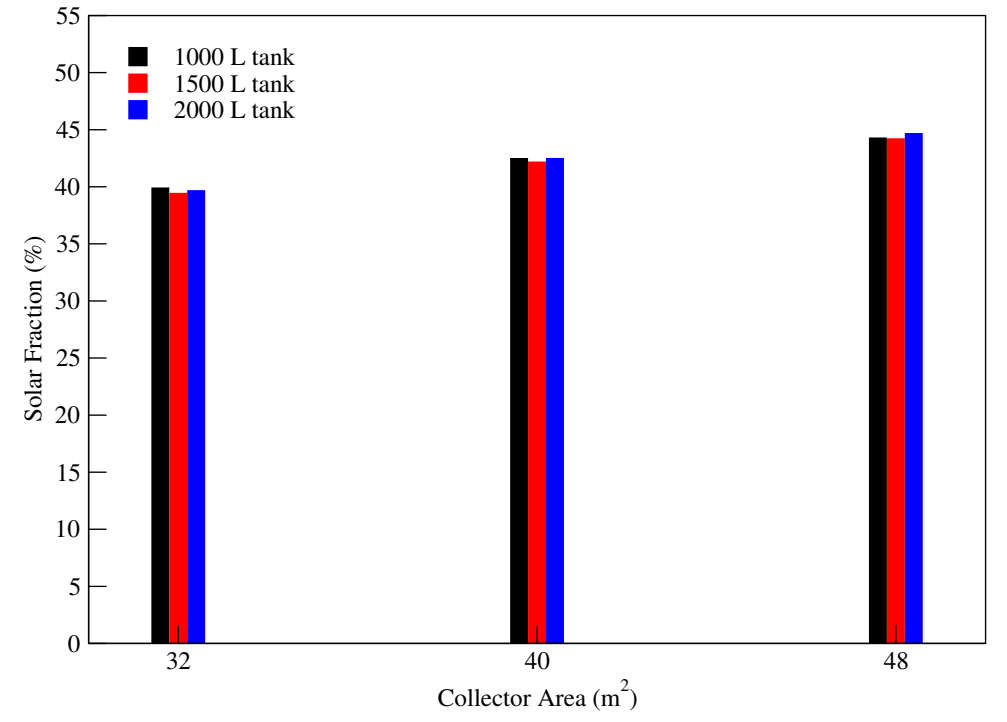

(b) Average DHW consumer

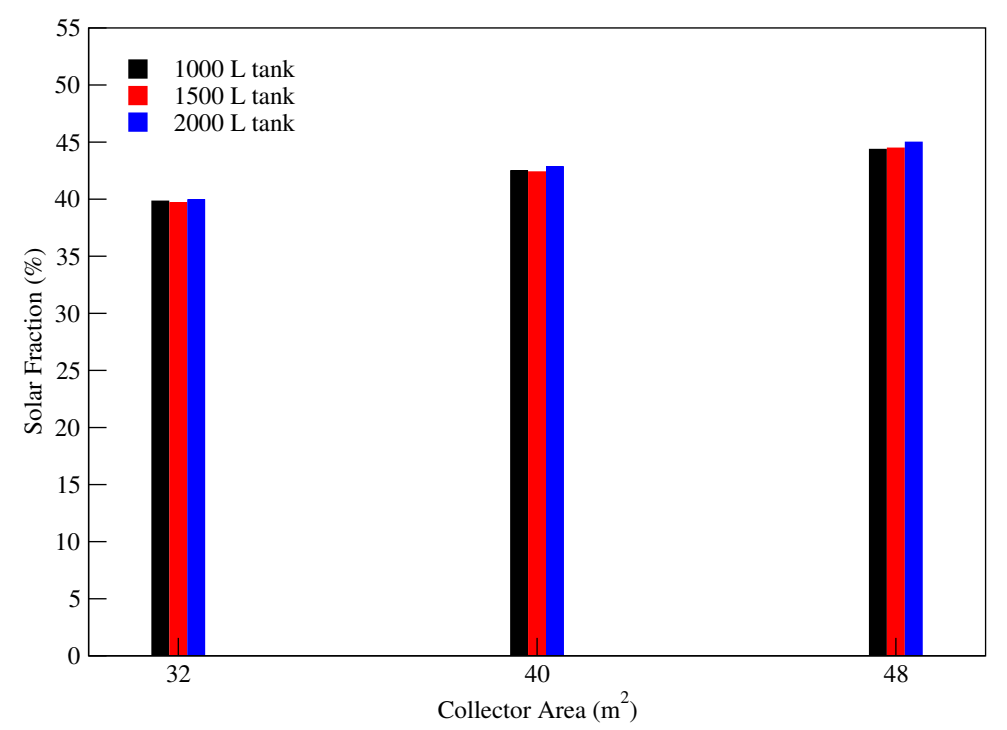

(d) Above average DHW consumer

Figure A.8: Difference in solar fractions when varying collector area and storage volume for for mid-size 1990 home. 


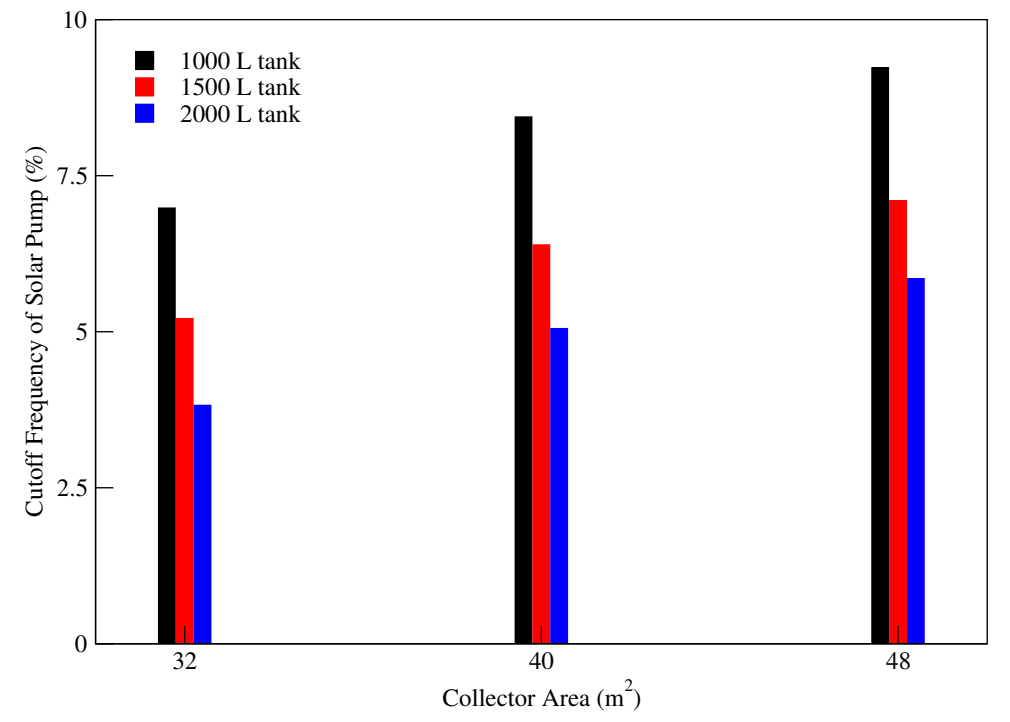

(a) Below average DHW consumer

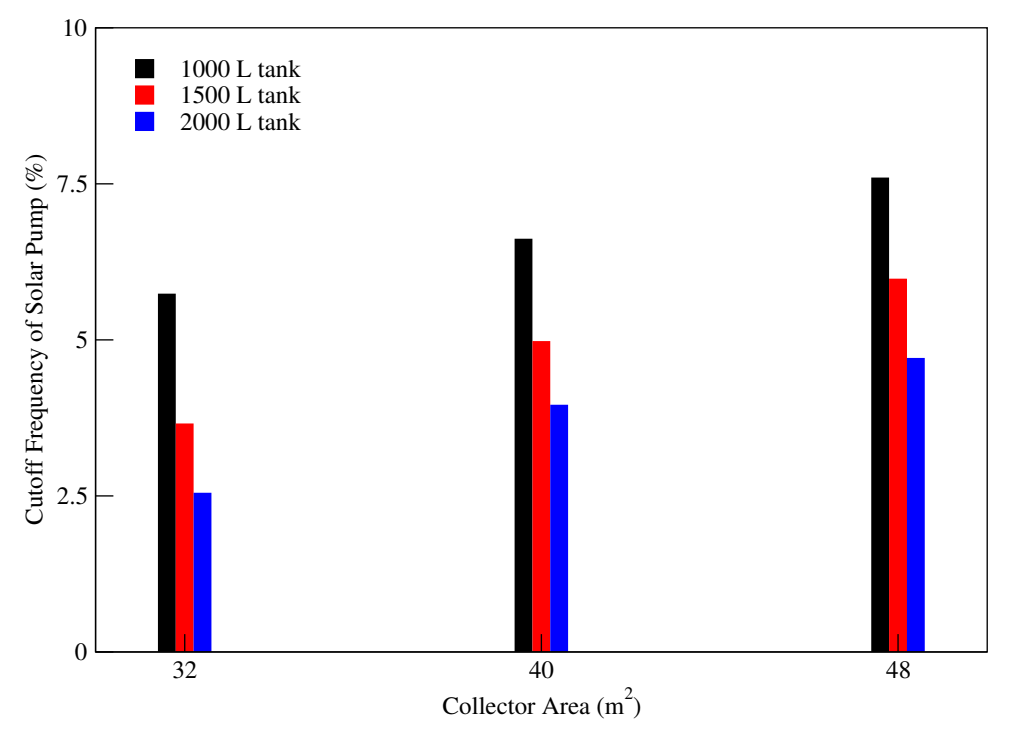

(c) Median DHW consumer

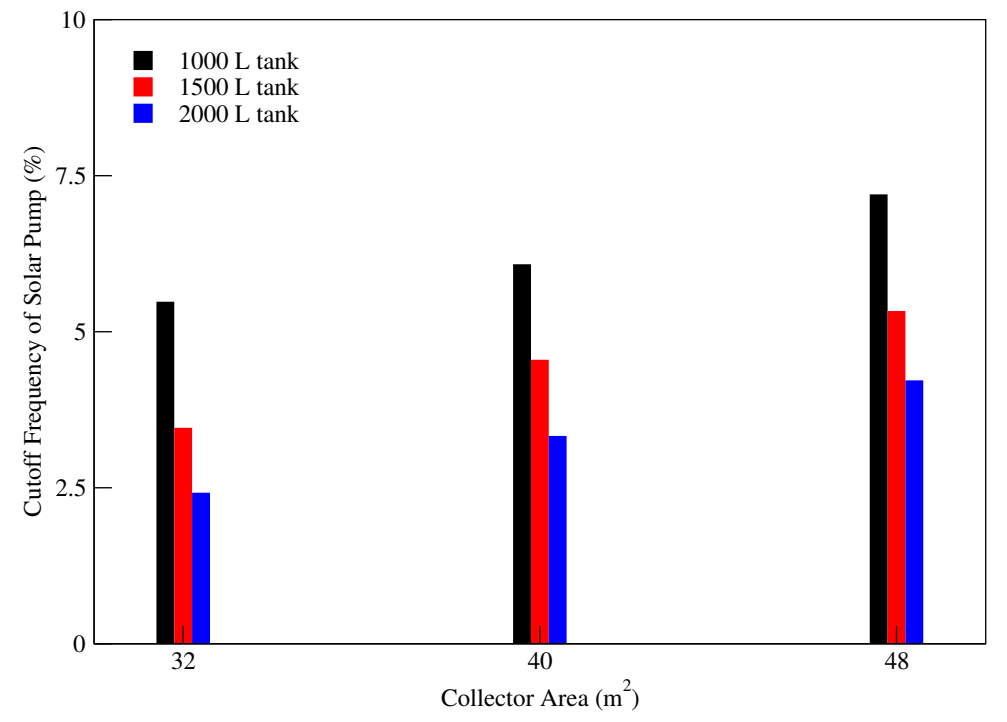

(b) Average DHW consumer

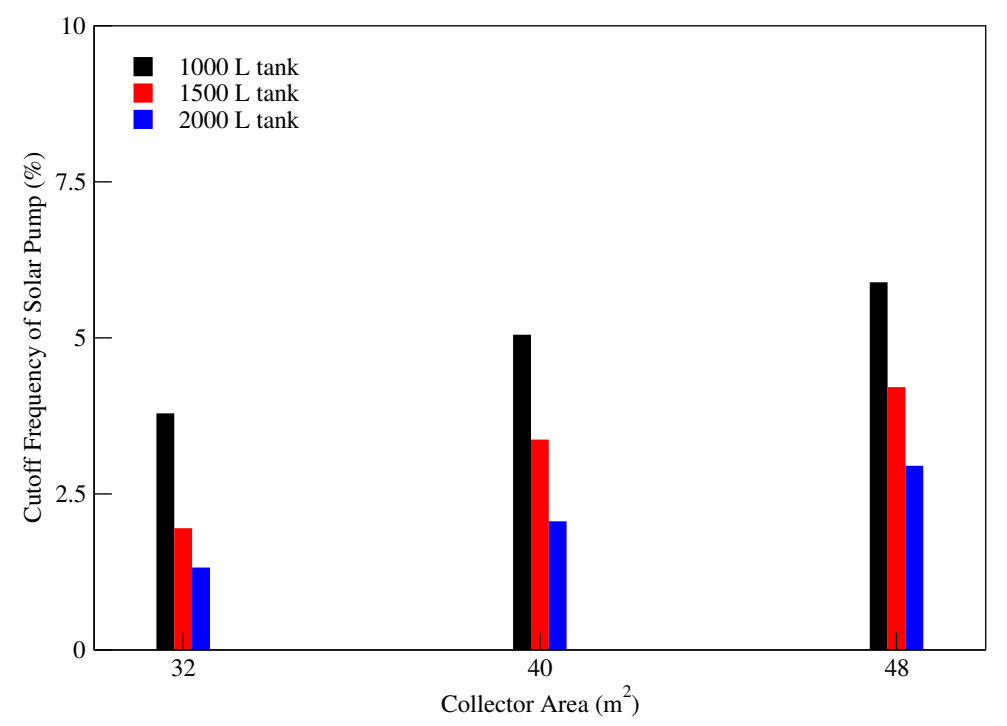

(d) Above average DHW consumer

Figure A.9: Difference in solar pump cutoffs when varying collector area and storage volume for for mid-size 1990 home. 


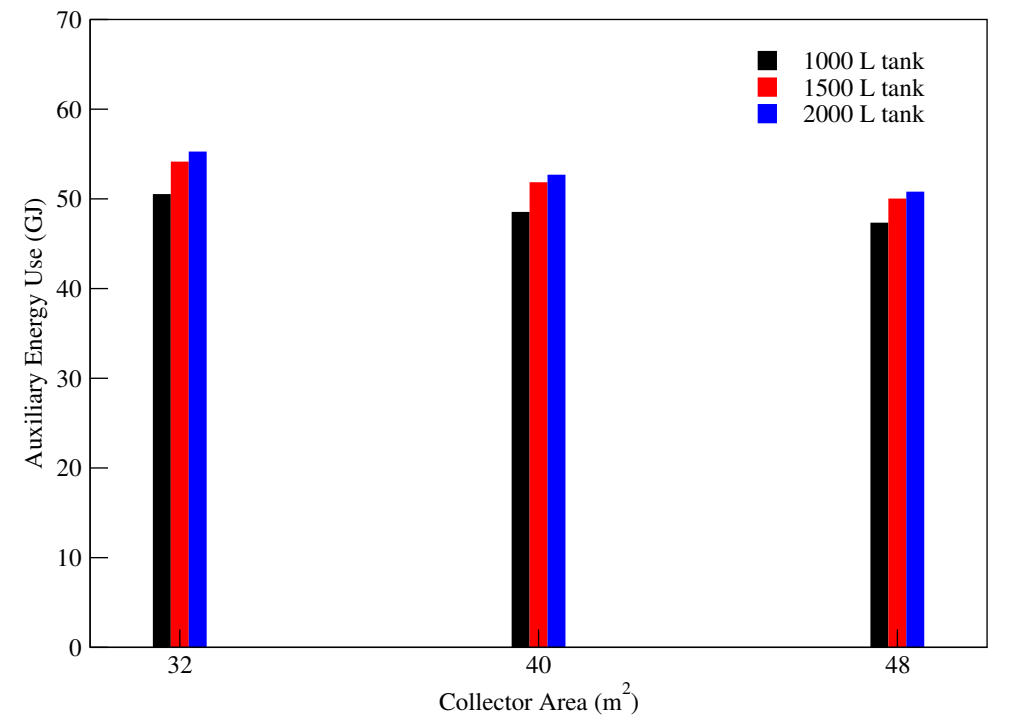

(a) Below average DHW consumer

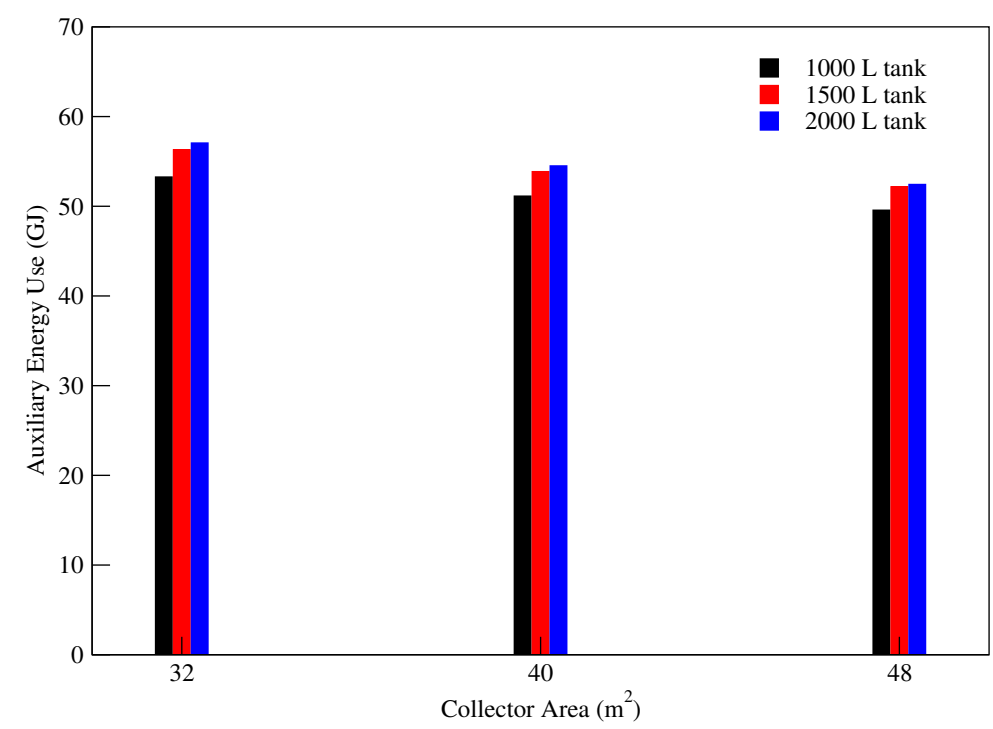

(c) Median DHW consumer

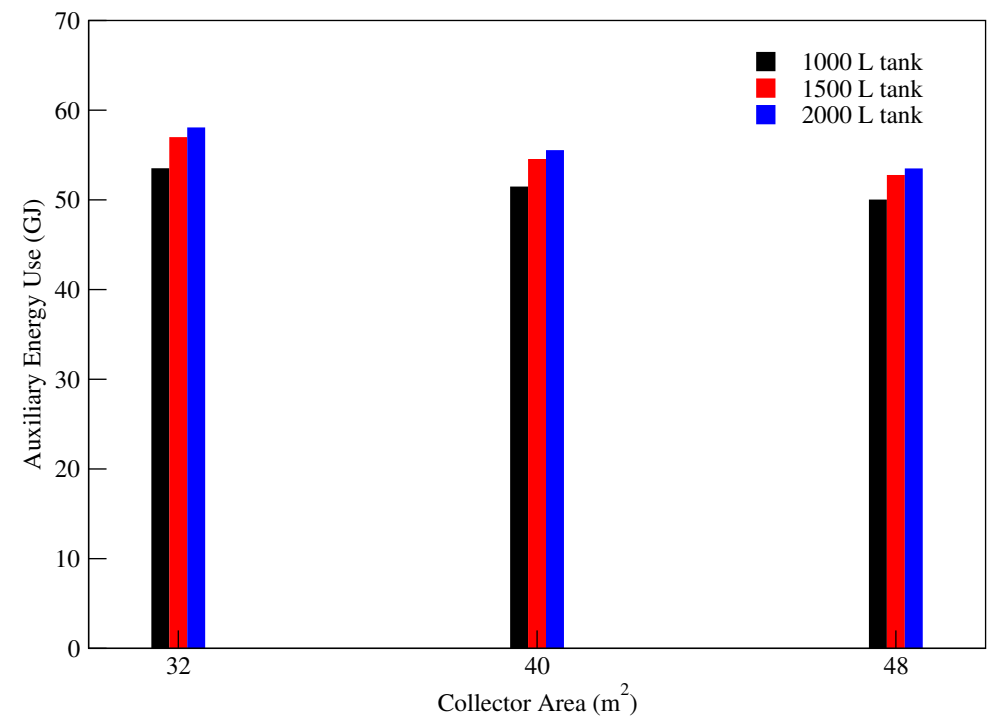

(b) Average DHW consumer

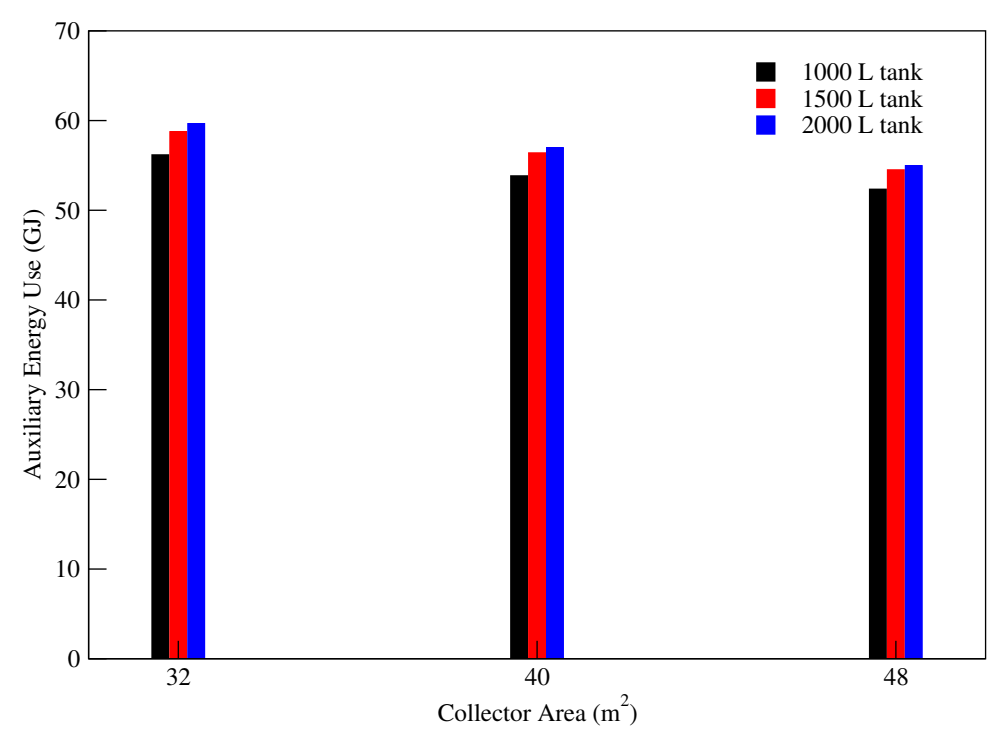

(d) Above average DHW consumer

Figure A.10: Difference in auxiliary energy use when varying collector area and storage volume for for mid-size 1990 home. 


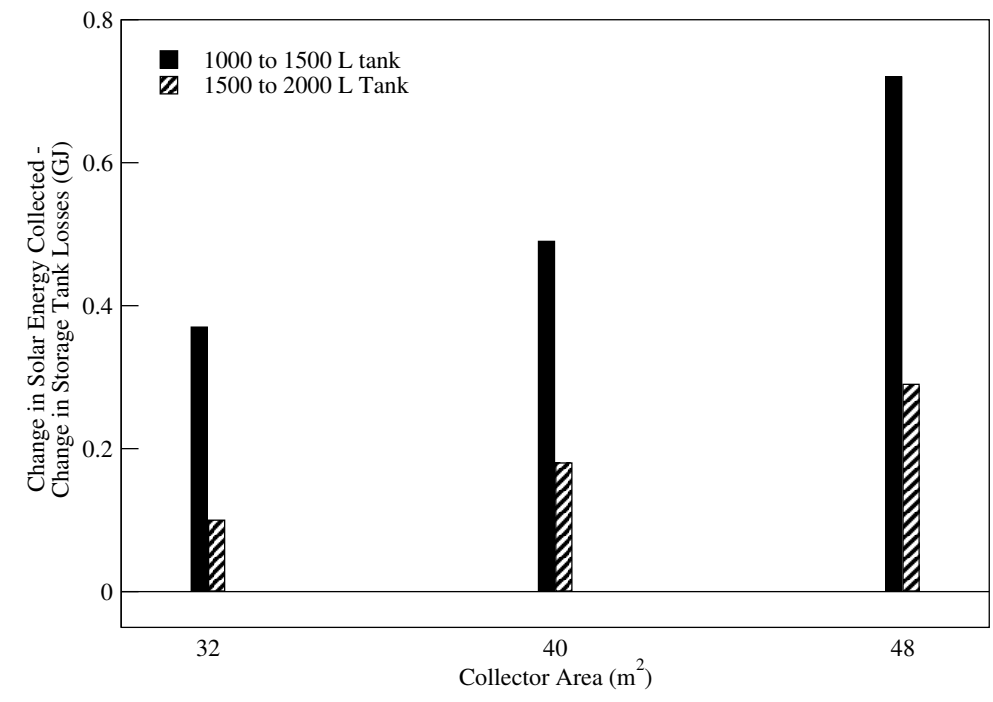

(a) Below average DHW consumer

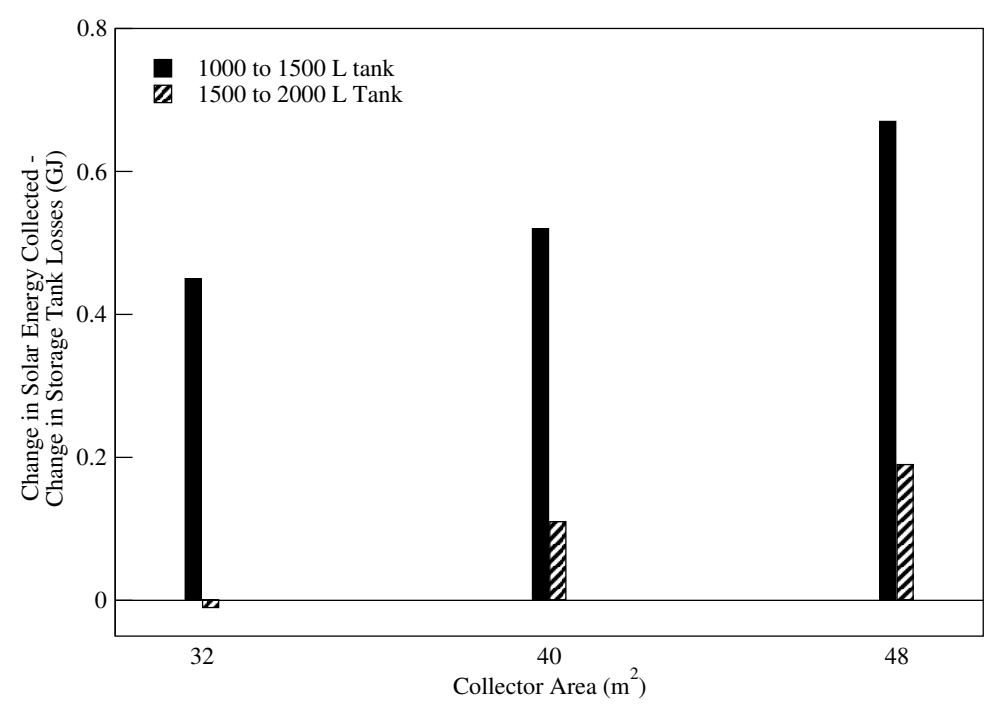

(c) Median DHW consumer

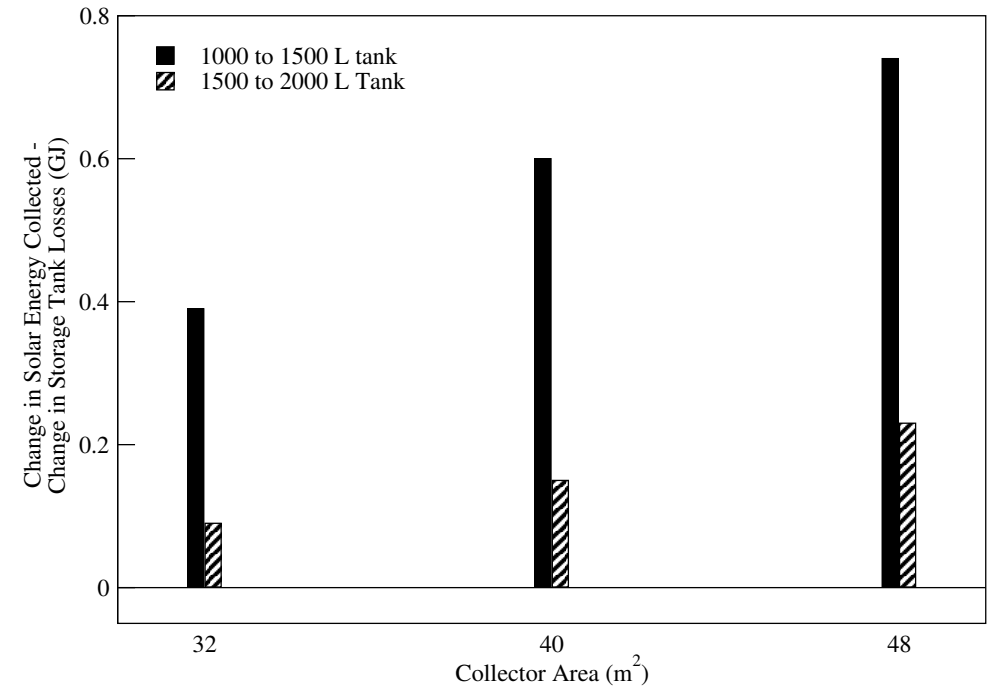

(b) Average DHW consumer

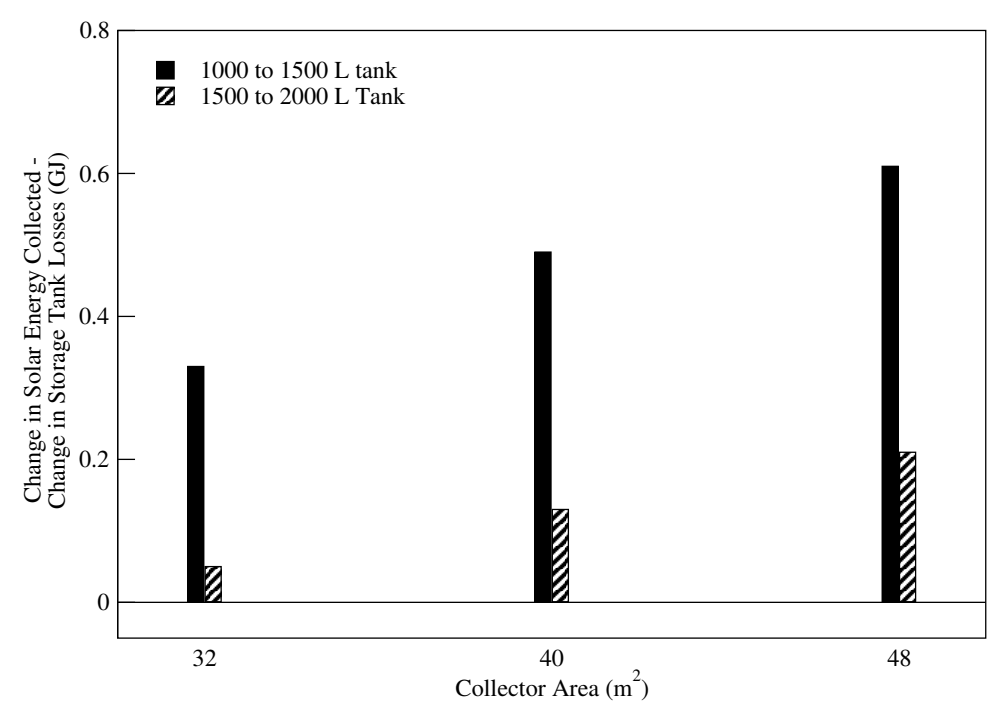

(d) Above average DHW consumer

Figure A.11: Difference in solar energy collected and DHW tank Losses when varying collector area and storage volume for large 1990 home. 


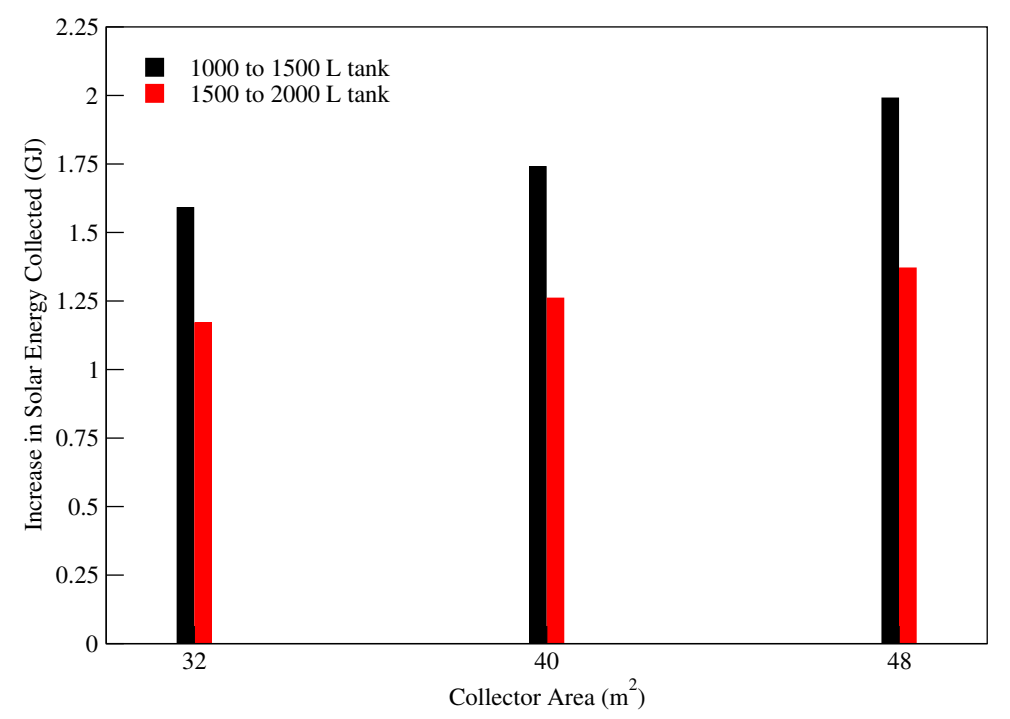

(a) Below average DHW consumer

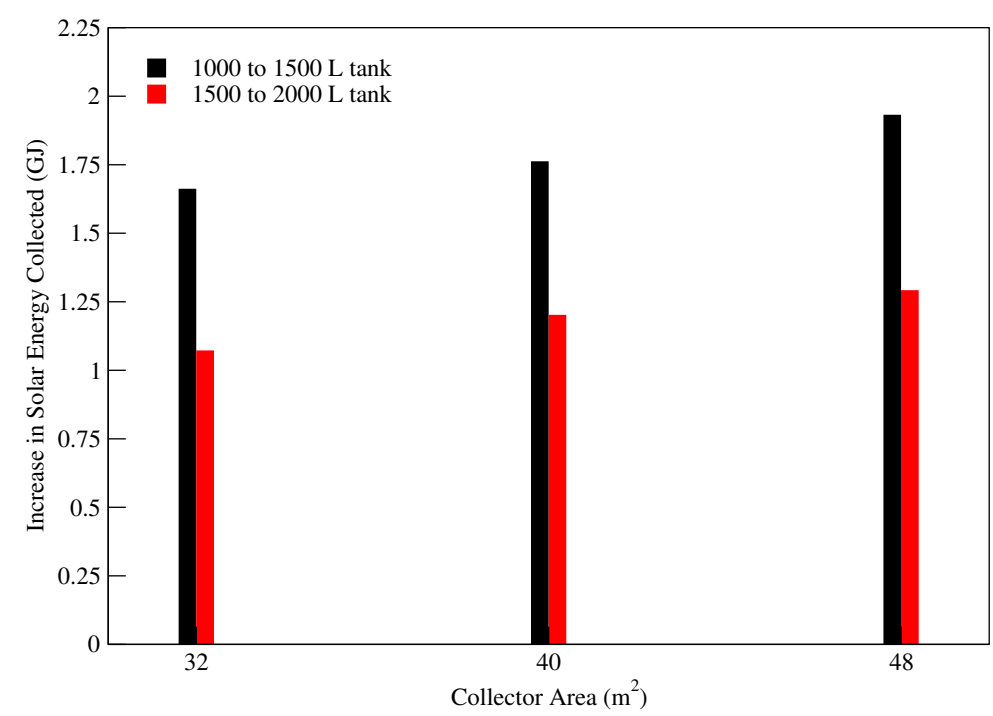

(c) Median DHW consumer

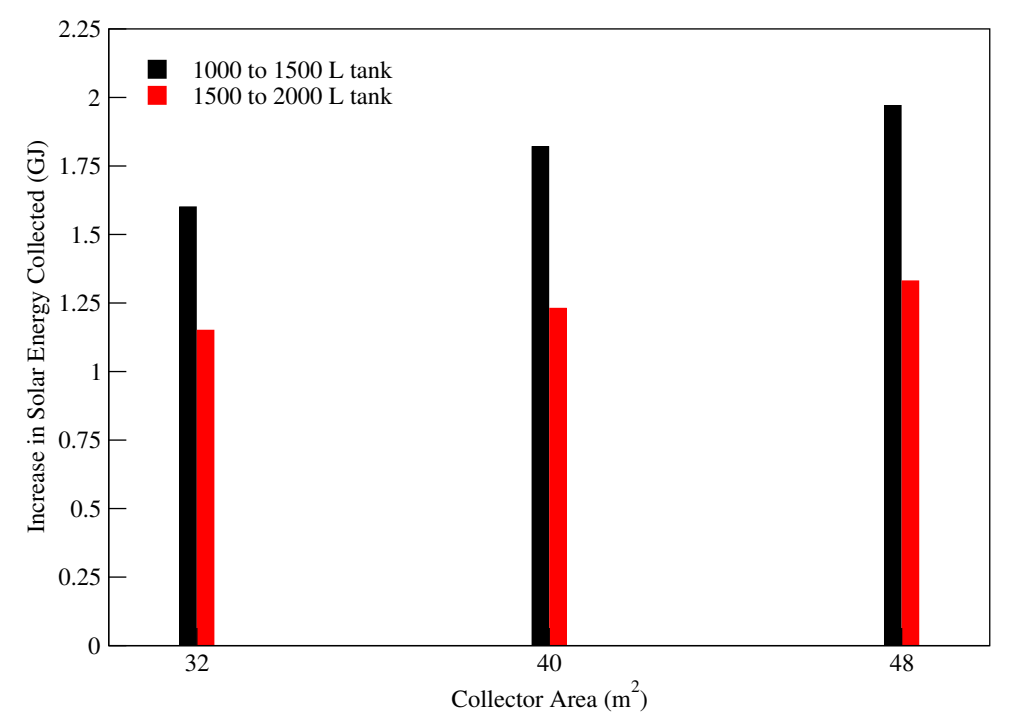

(b) Average DHW consumer

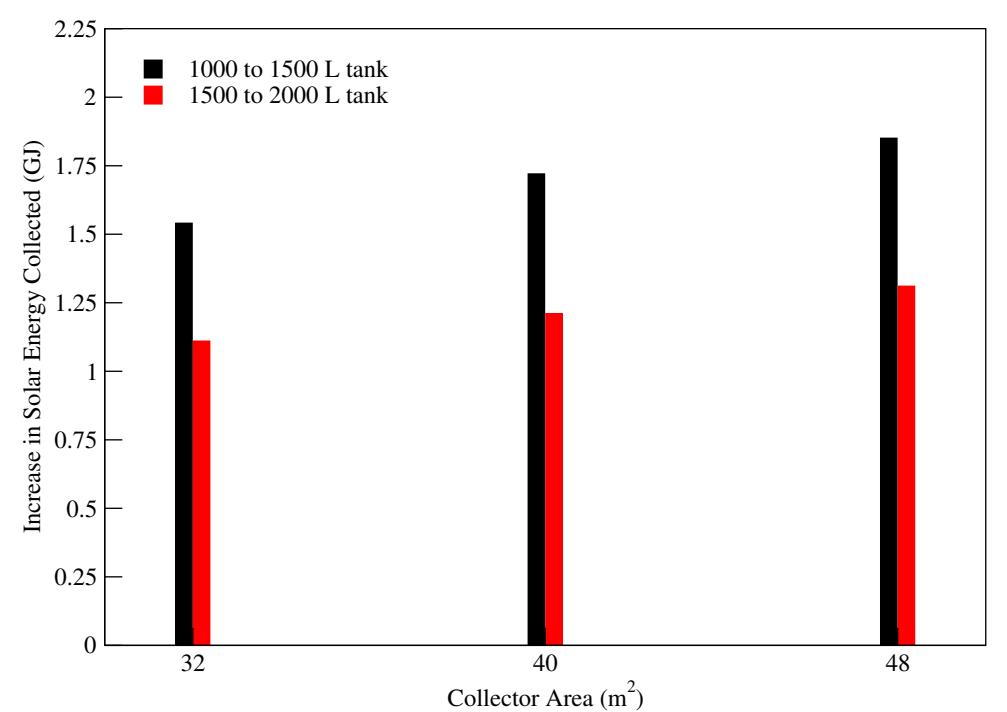

(d) Above average DHW consumer

Figure A.12: Difference in solar energy collected when varying collector area and storage volume for large 1990 home. 


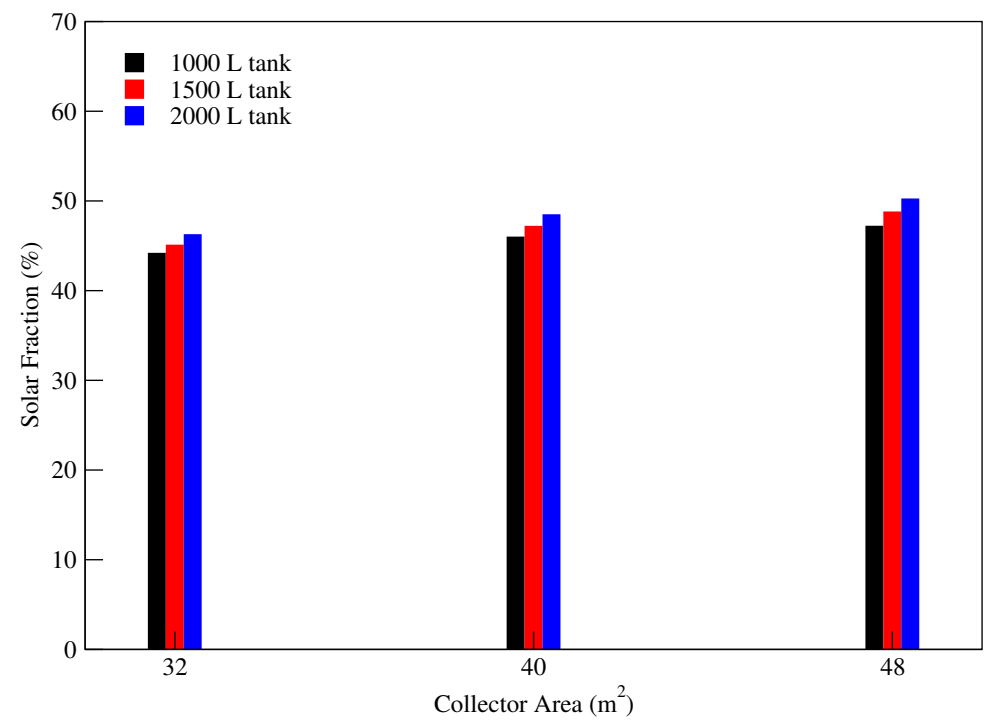

(a) Below average DHW consumer

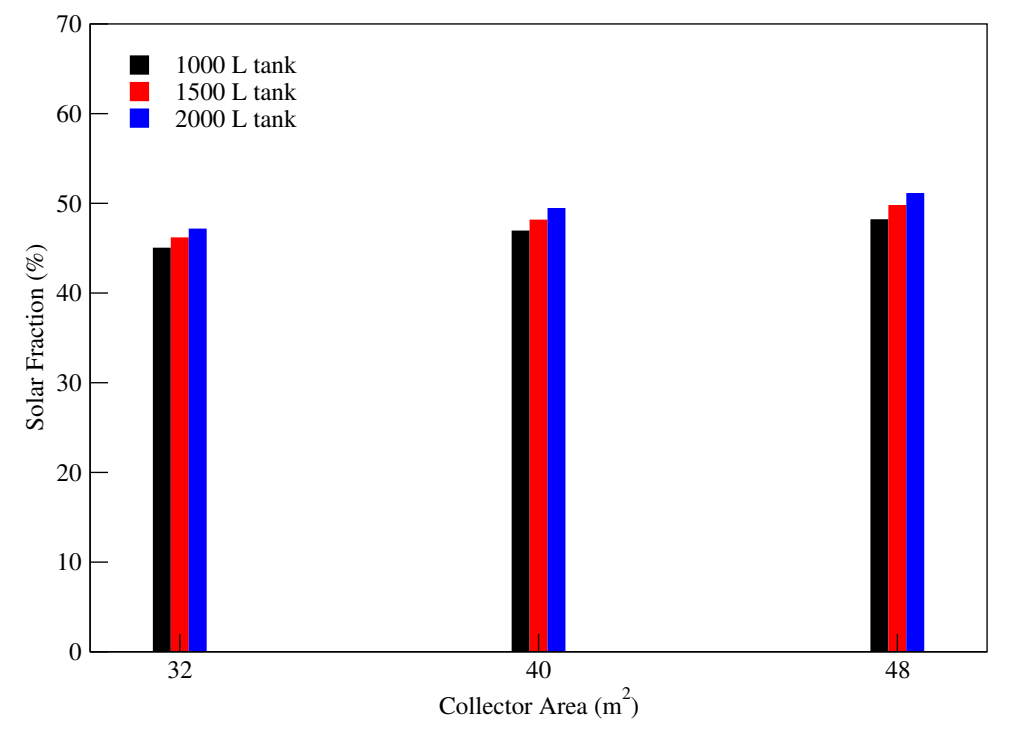

(c) Median DHW consumer

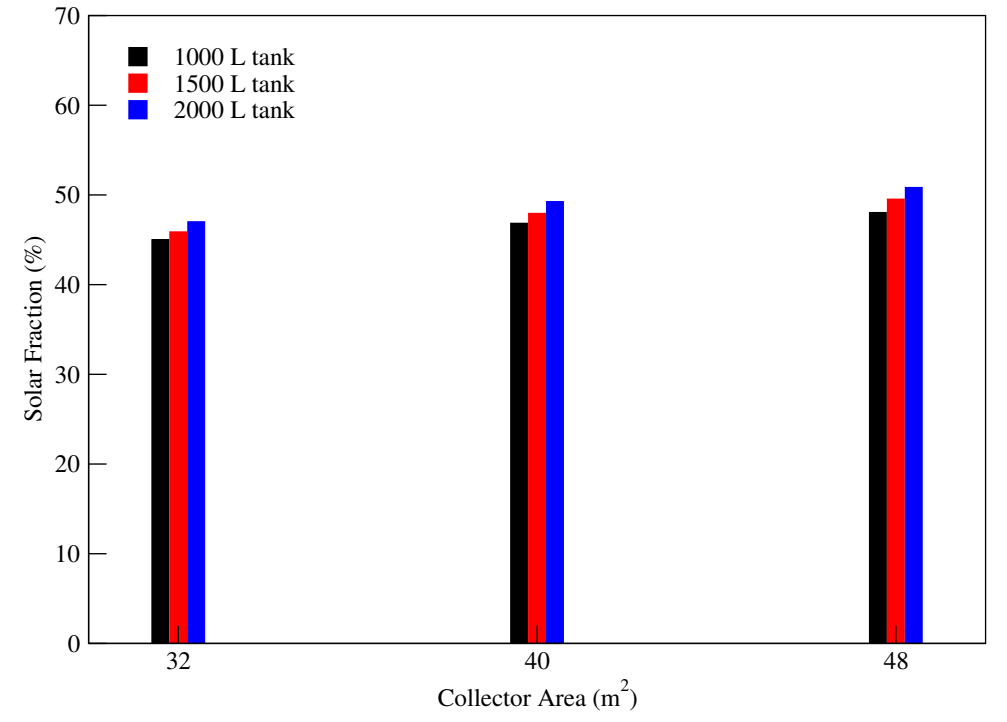

(b) Average DHW consumer

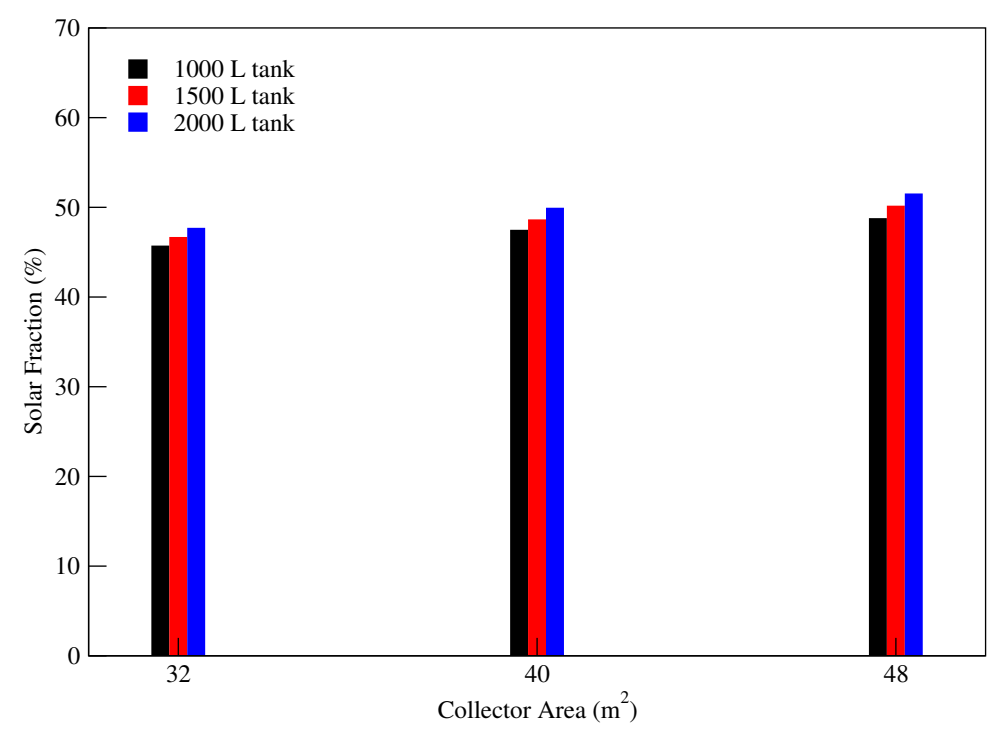

(d) Above average DHW consumer

Figure A.13: Difference in solar fractions when varying collector area and storage volume for large 1990 home. 


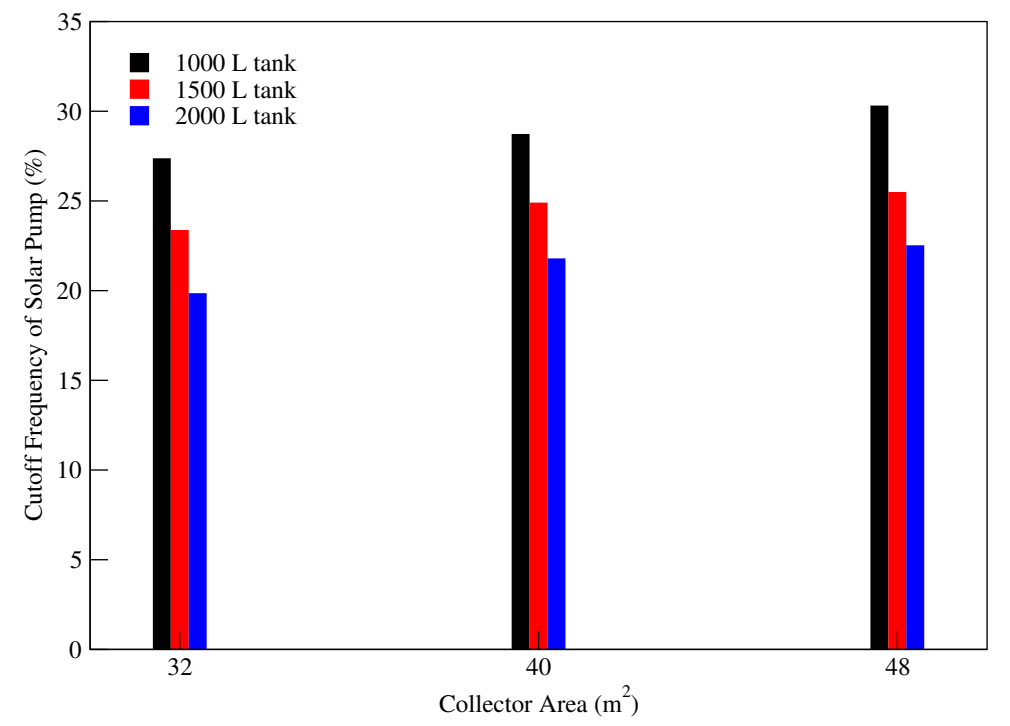

(a) Below average DHW consumer

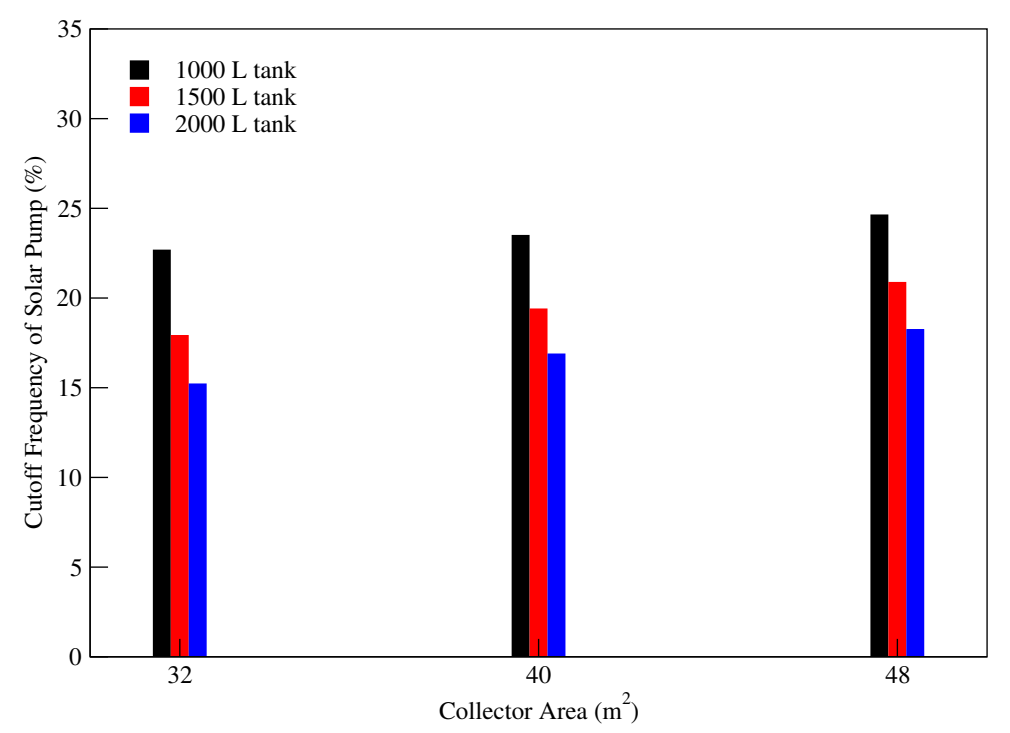

(c) Median DHW consumer

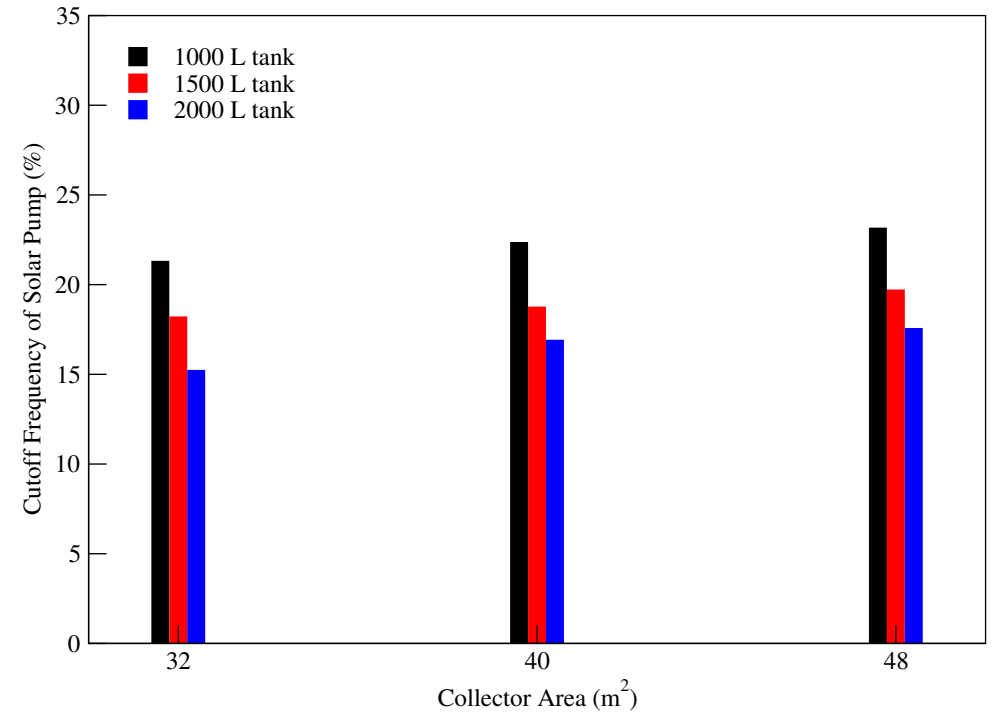

(b) Average DHW consumer

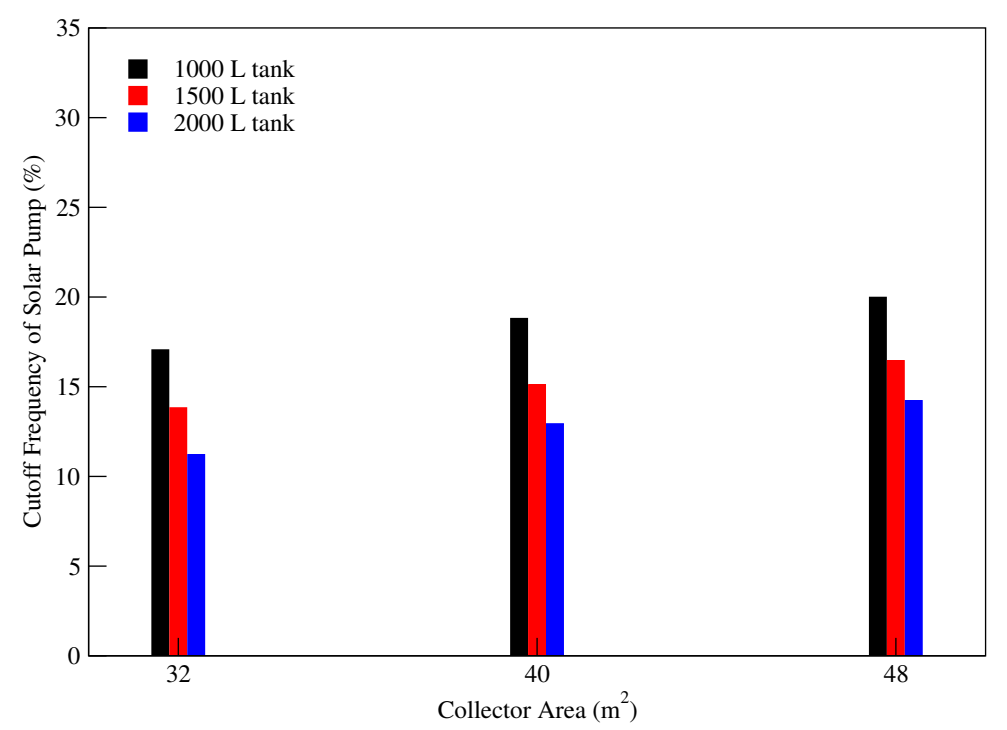

(d) Above average DHW consumer

Figure A.14: Difference in solar pump cutoffs when varying collector area and storage volume for large 1990 home. 


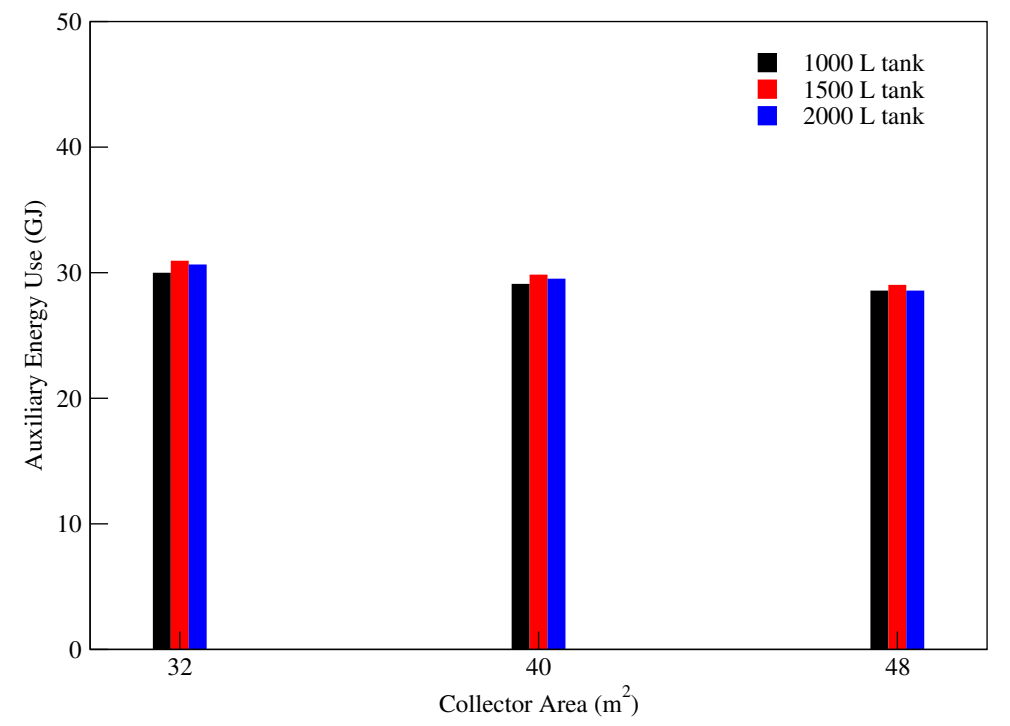

(a) Below average DHW consumer

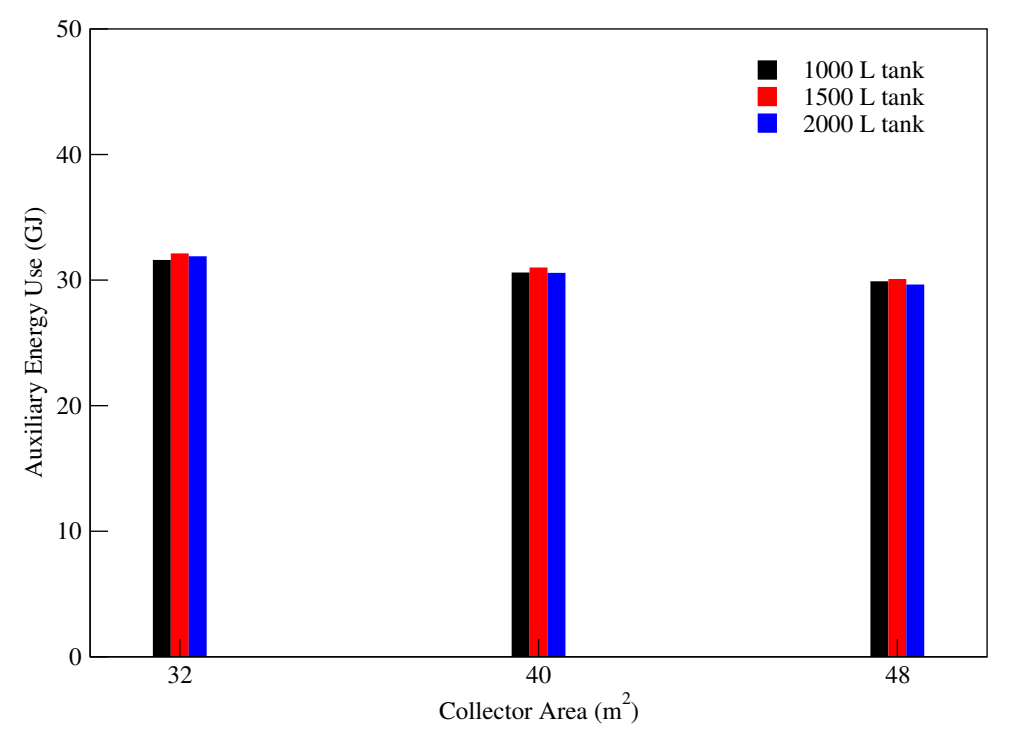

(c) Median DHW consumer

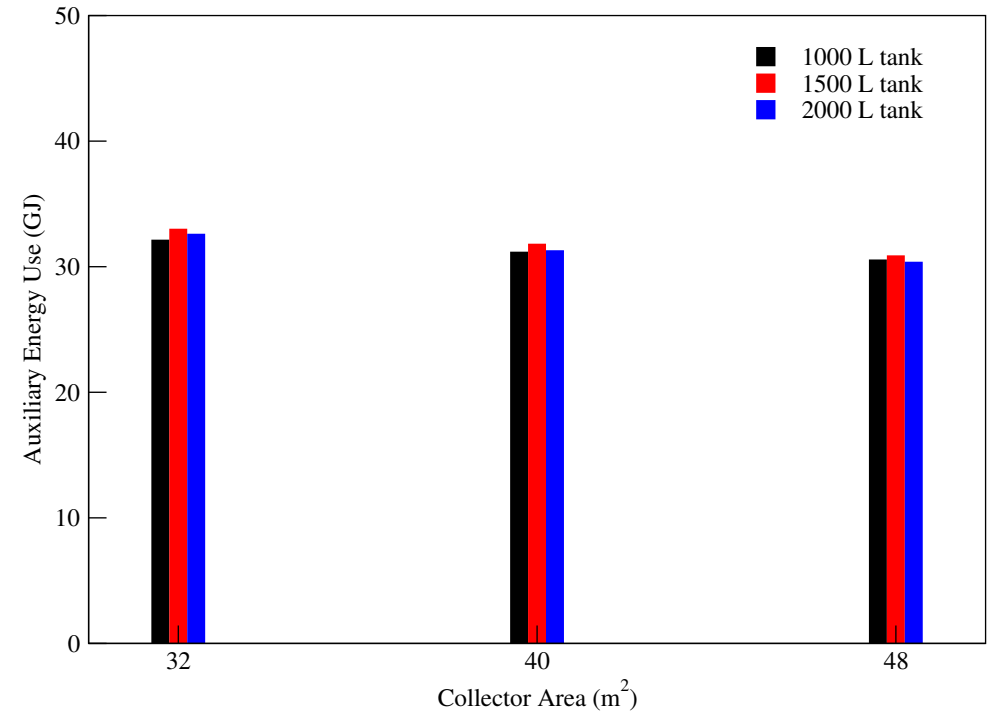

(b) Average DHW consumer

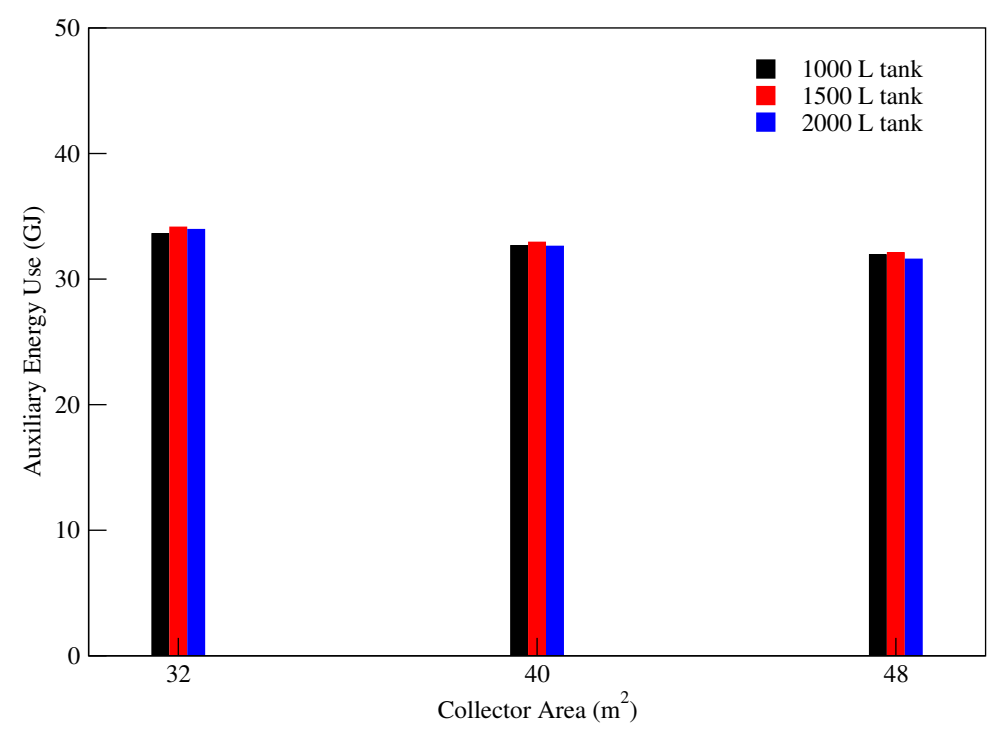

(d) Above average DHW consumer

Figure A.15: Difference in auxiliary energy use when varying collector area and storage volume for large 1990 home. 
Appendix B

Results of System B plant configuration for all Homes Aside from Mid-size 1955 


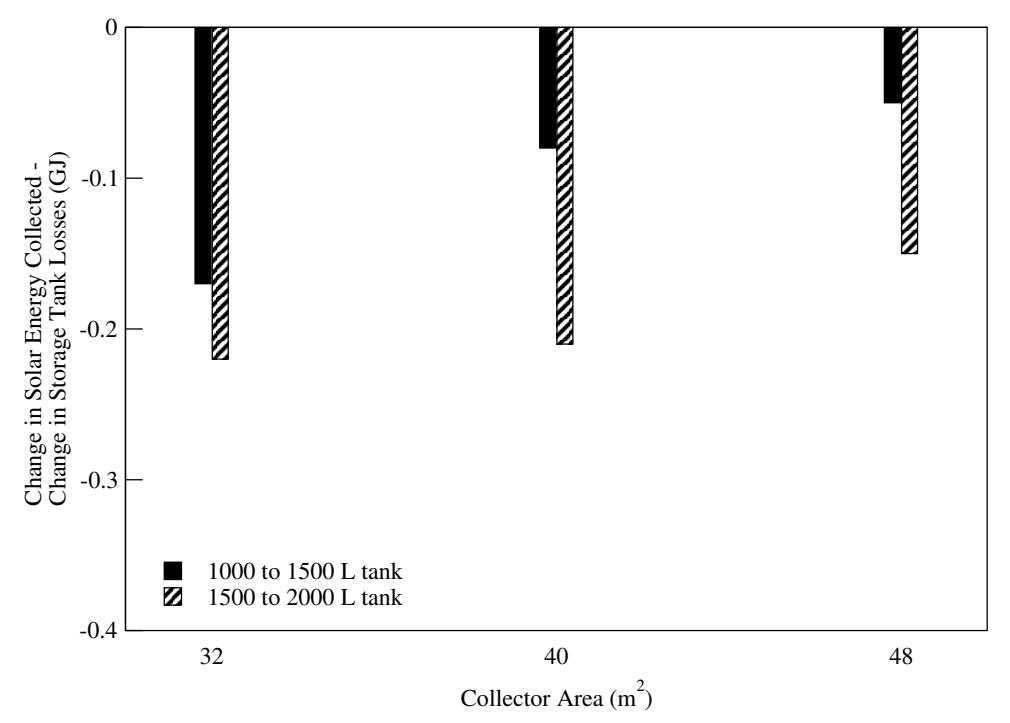

(a) Below average DHW consumer

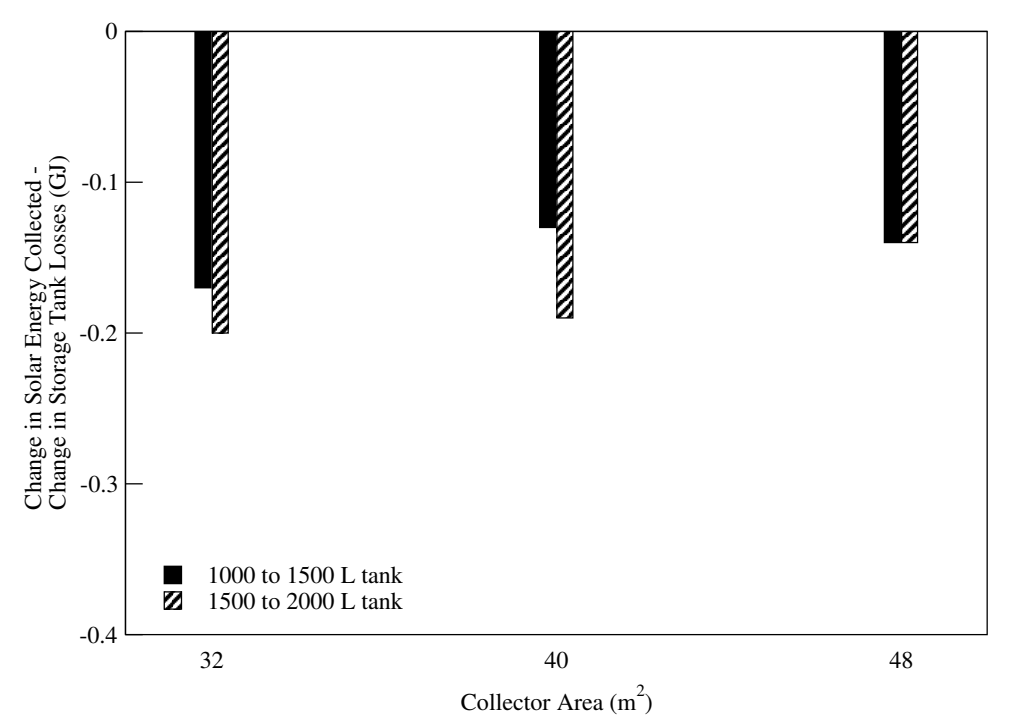

(c) Median DHW consumer

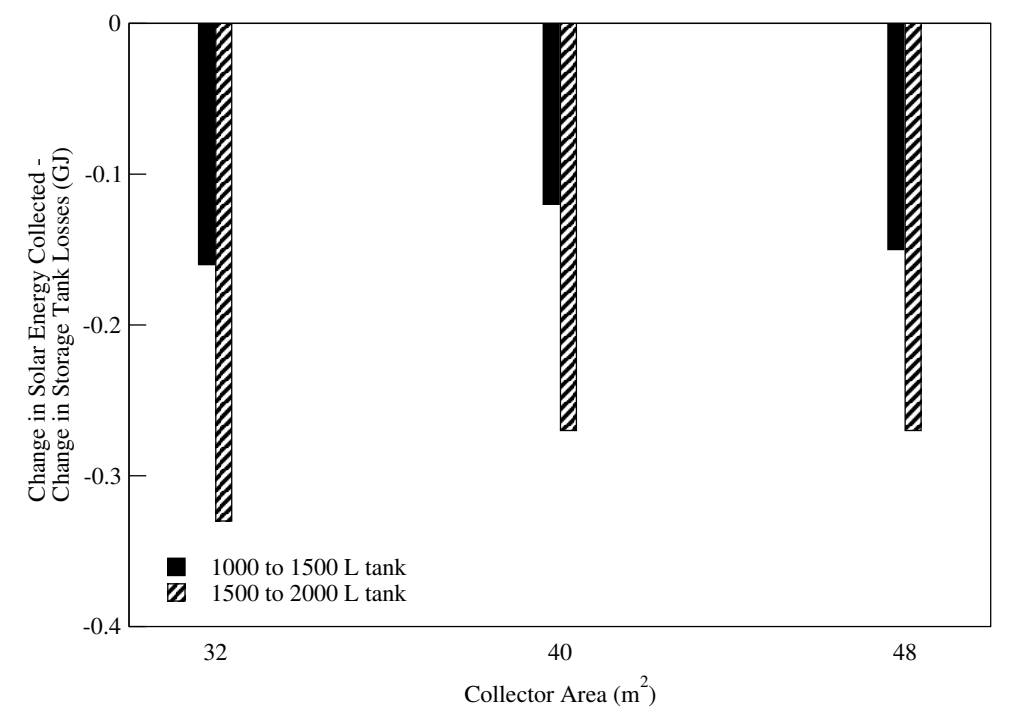

(b) Average DHW consumer

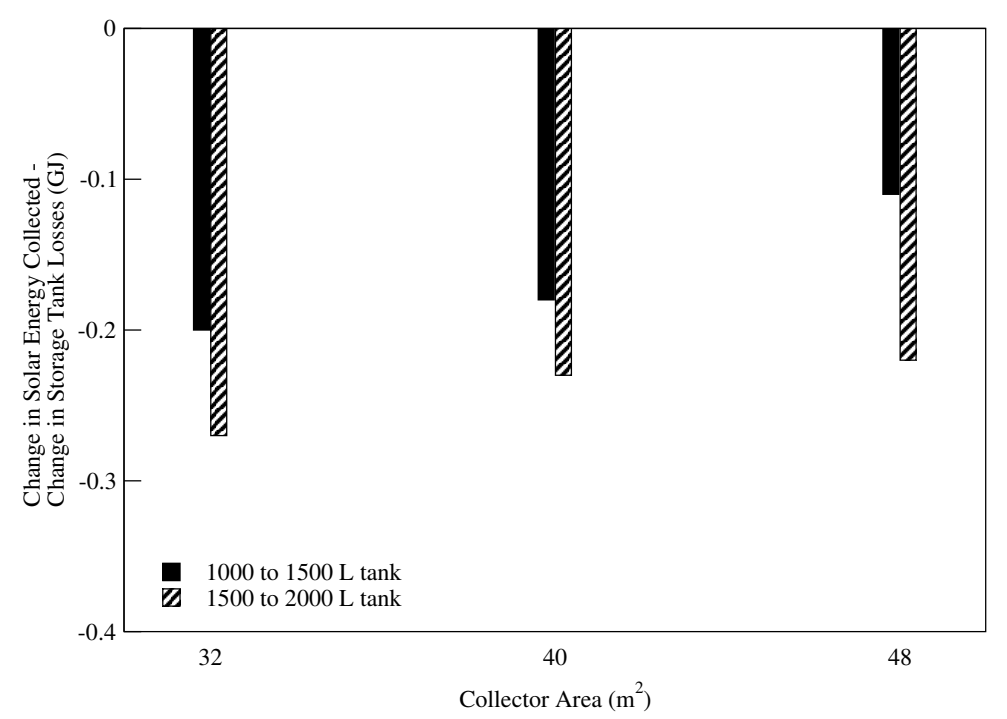

(d) Above average DHW consumer

Figure B.1: Difference in solar energy collected and DHW tank Losses when varying collector area and storage volume for mid-size 1974 home. 


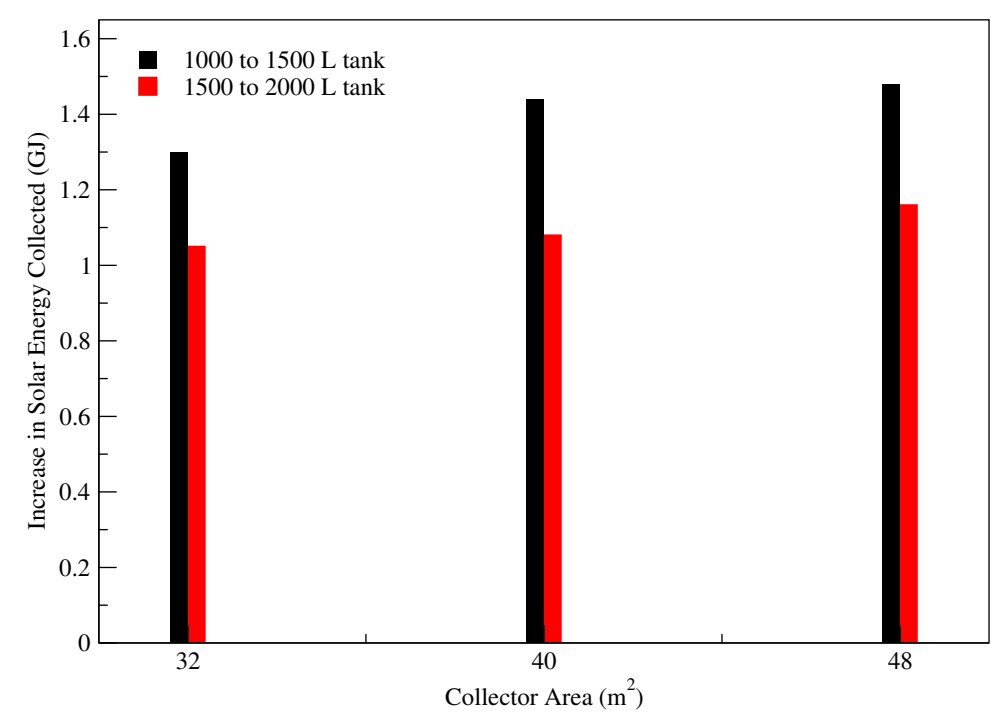

(a) Below average DHW consumer

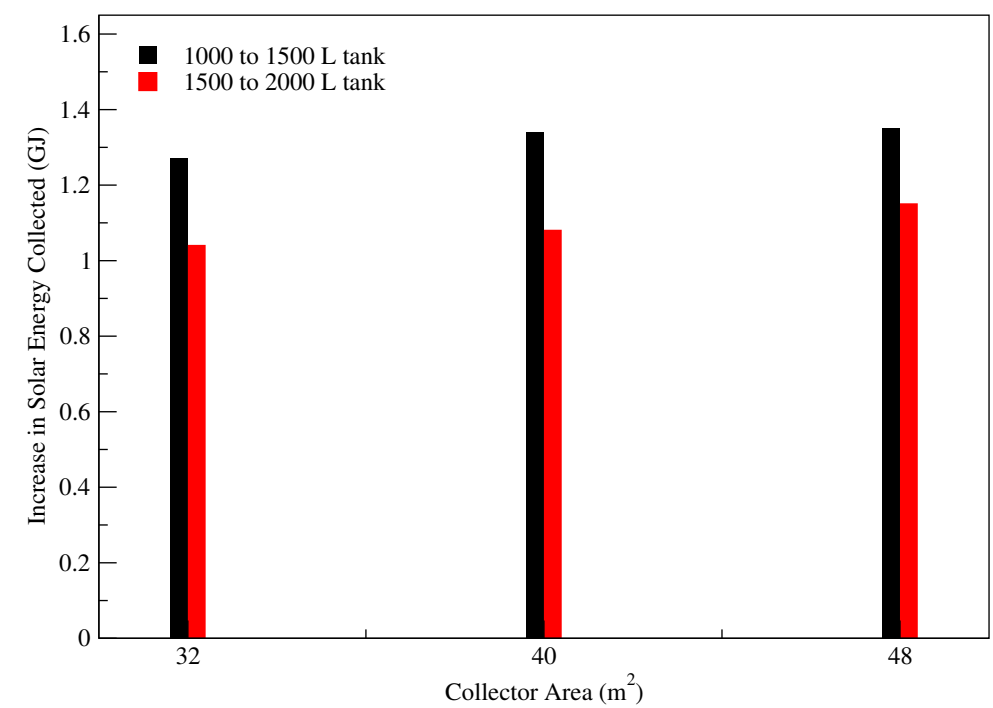

(c) Median DHW consumer

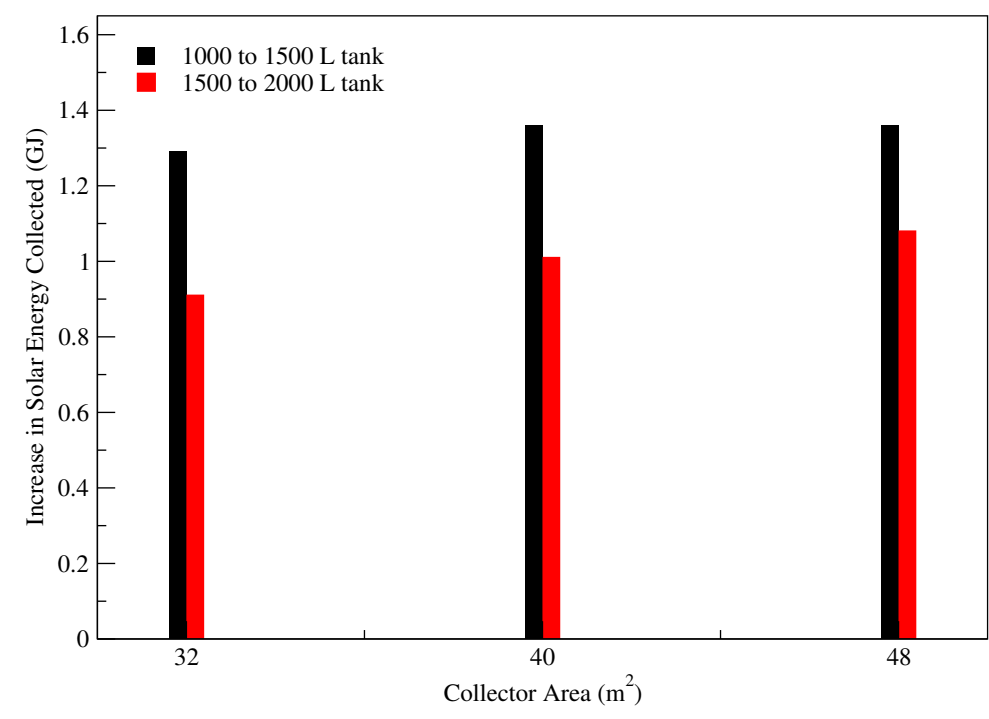

(b) Average DHW consumer

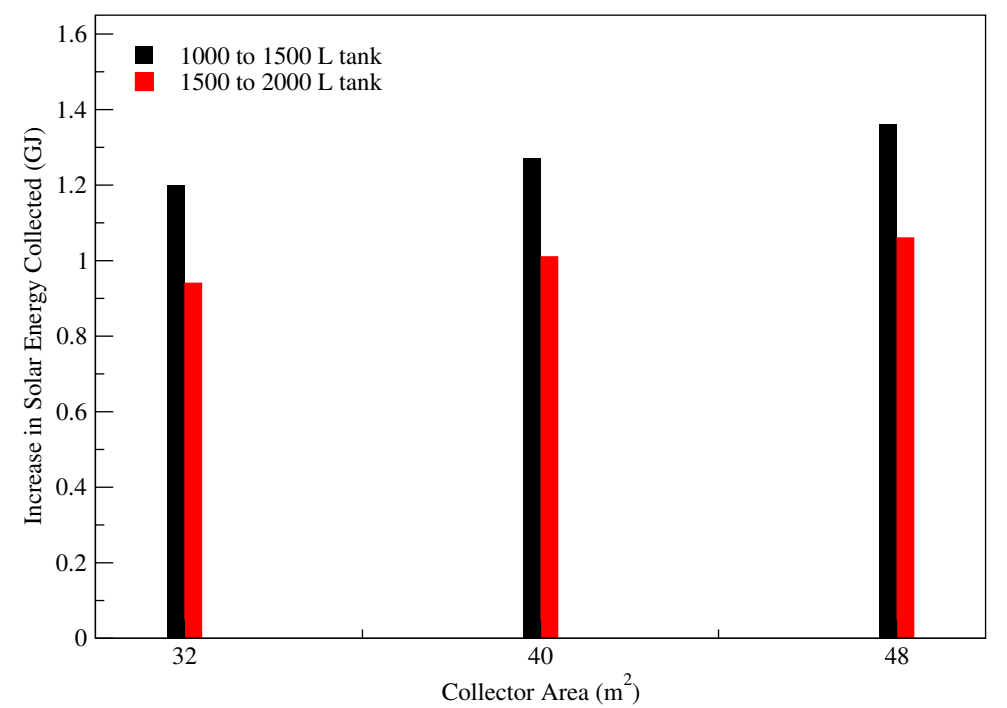

(d) Above average DHW consumer

Figure B.2: Difference in solar energy collected when varying collector area and storage volume for mid-size 1974 home. 


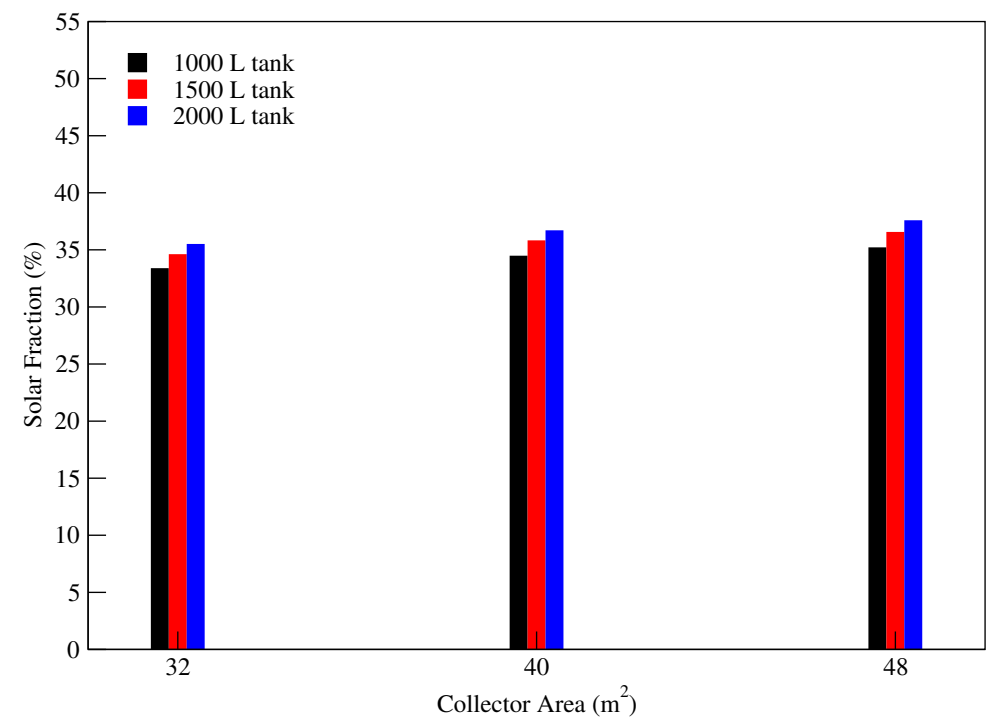

(a) Below average DHW consumer

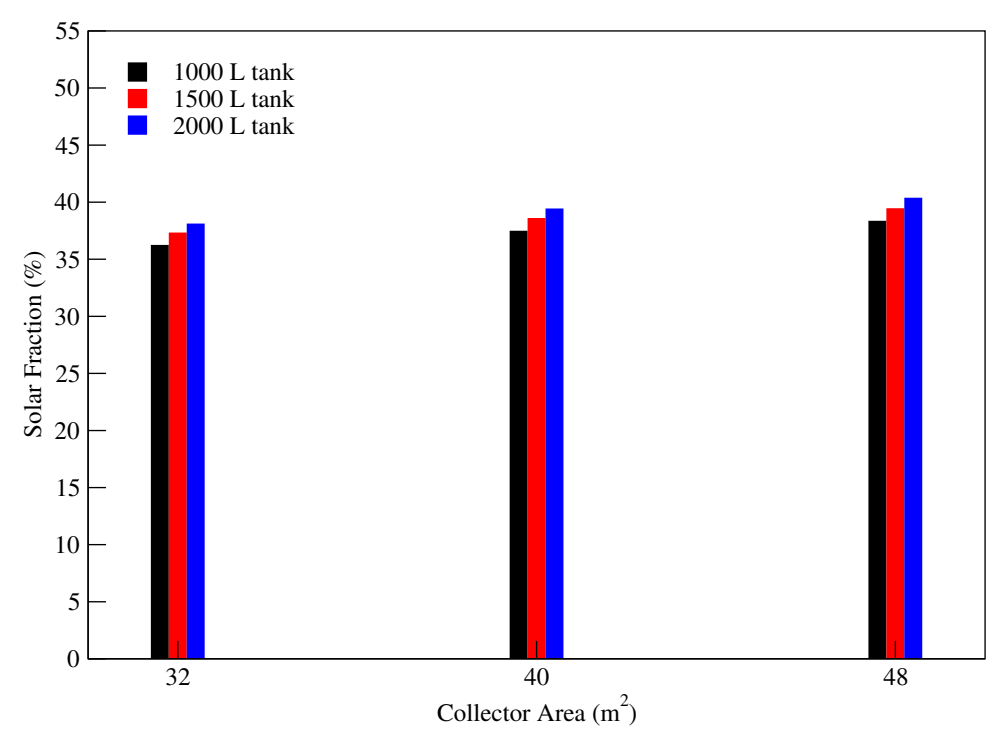

(c) Median DHW consumer

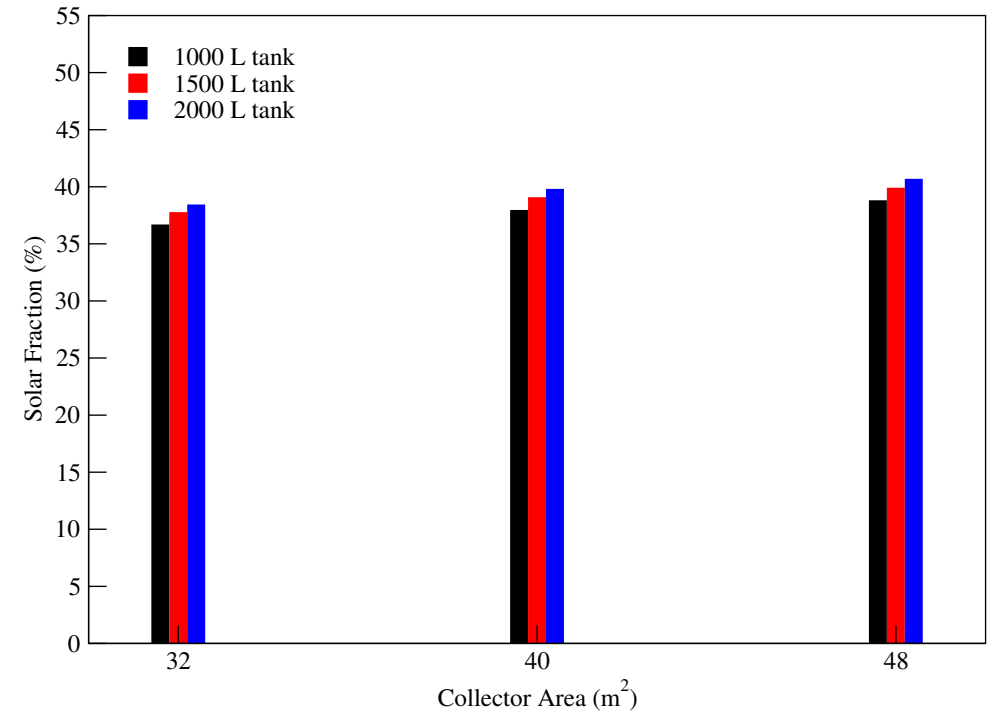

(b) Average DHW consumer

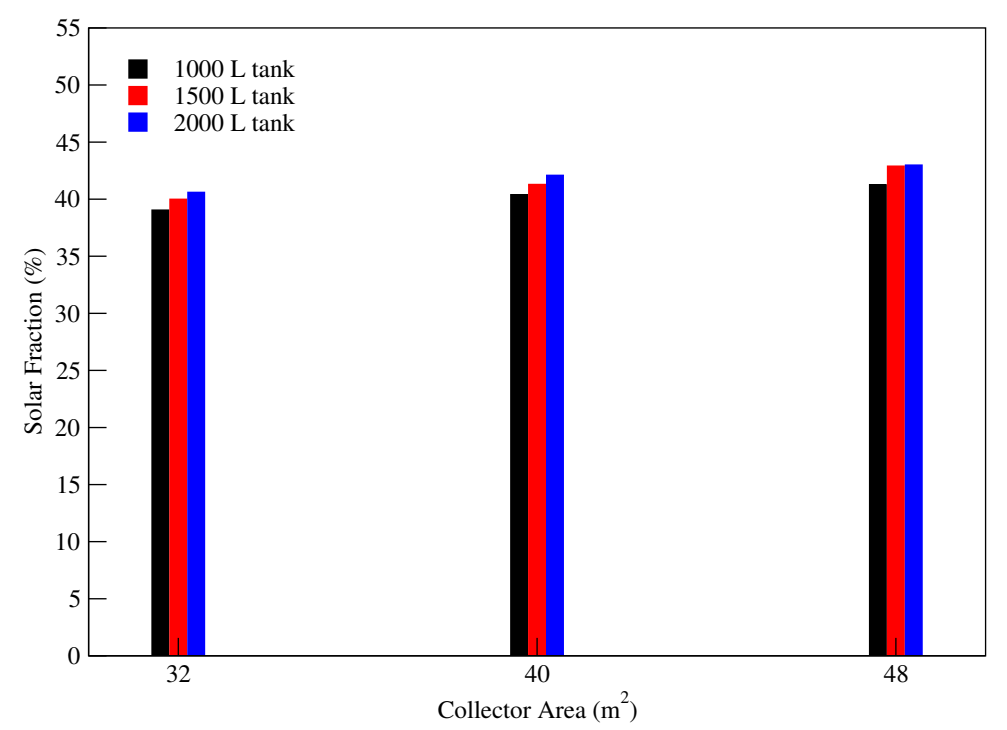

(d) Above average DHW consumer

Figure B.3: Difference in solar fractions when varying collector area and storage volume for mid-size 1974 home. 


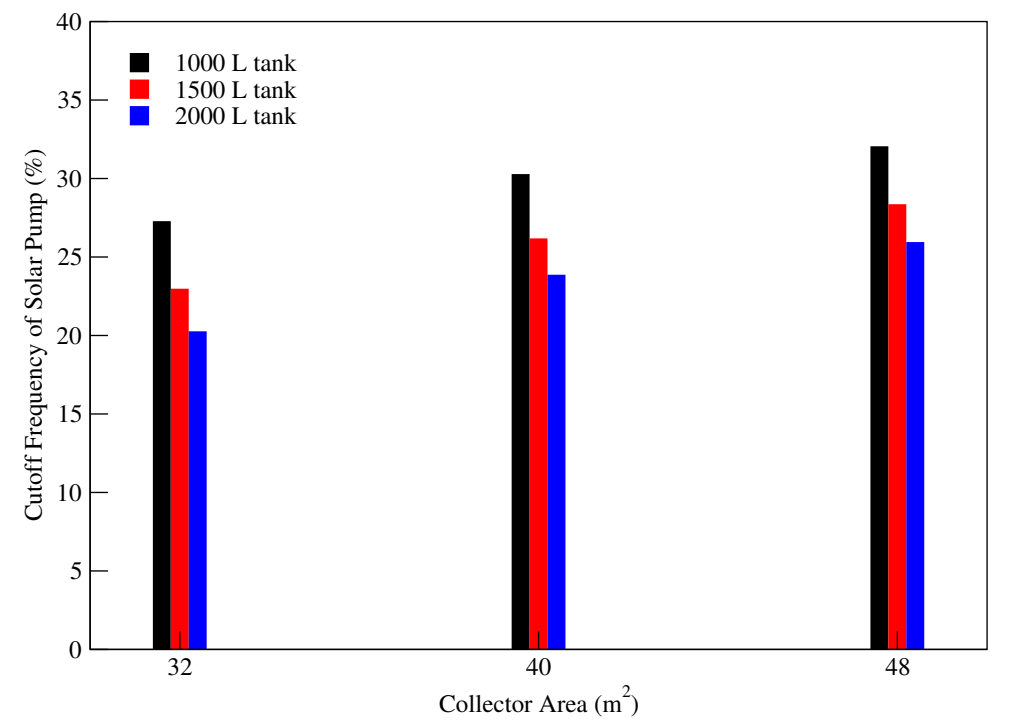

(a) Below average DHW consumer

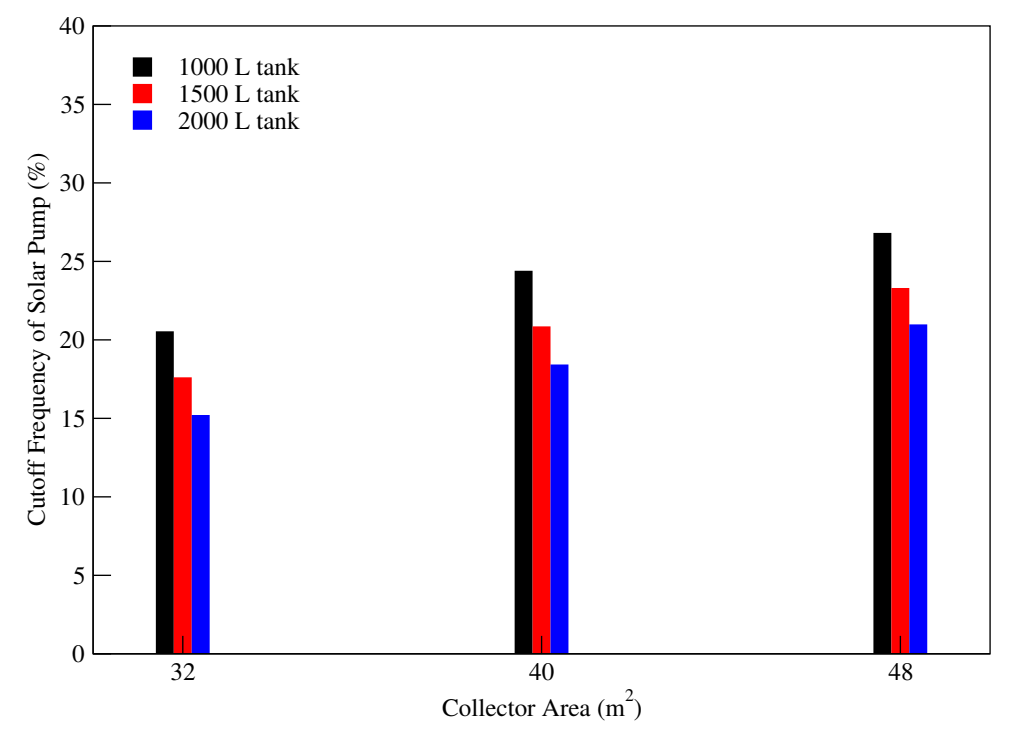

(c) Median DHW consumer

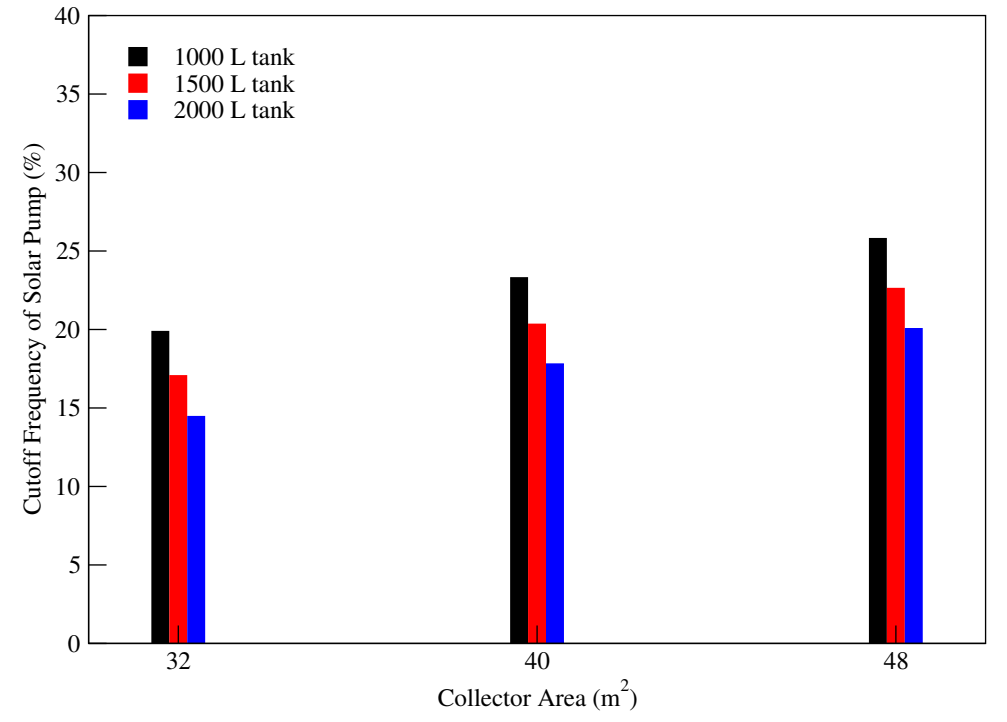

(b) Average DHW consumer

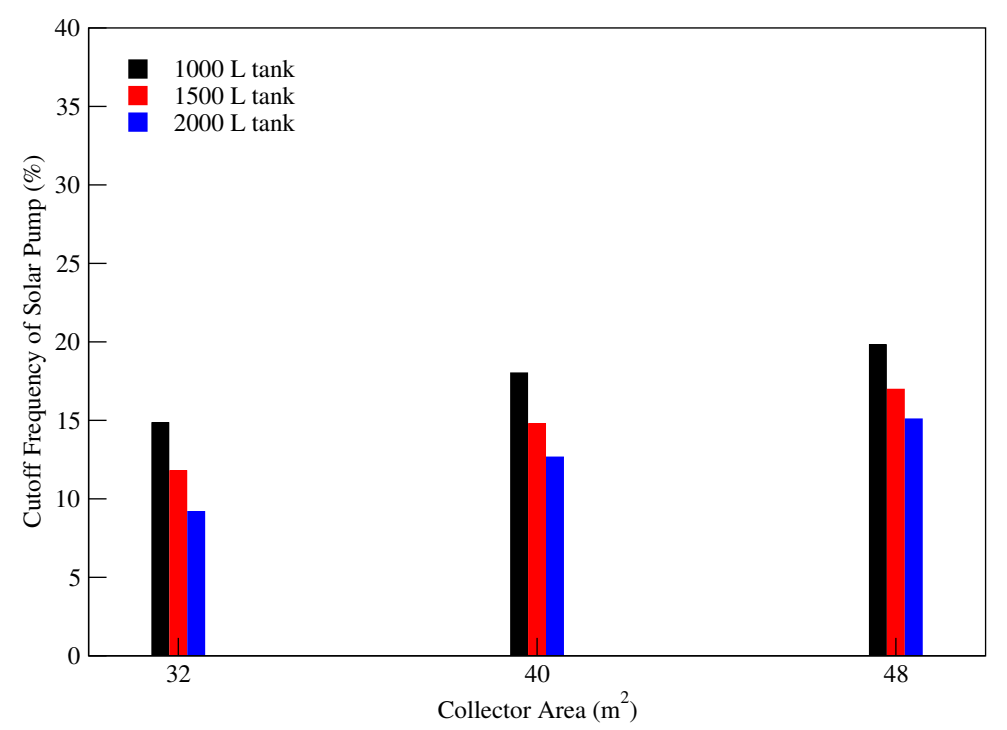

(d) Above average DHW consumer

Figure B.4: Difference in solar pump cutoffs when varying collector area and storage volume for mid-size 1974 home. 


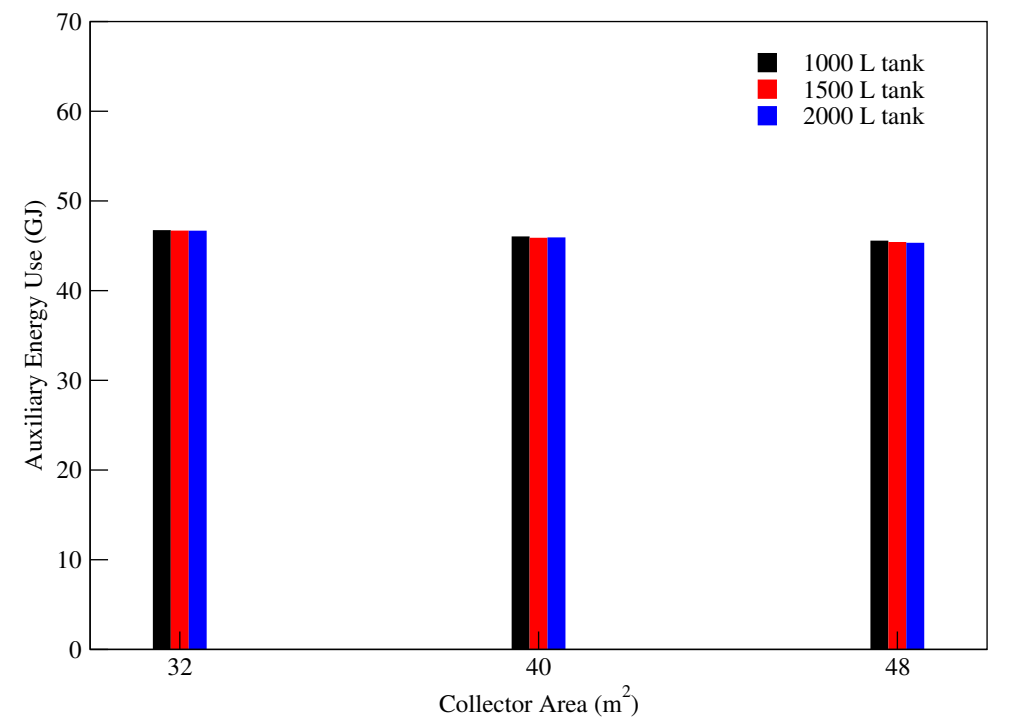

(a) Below average DHW consumer

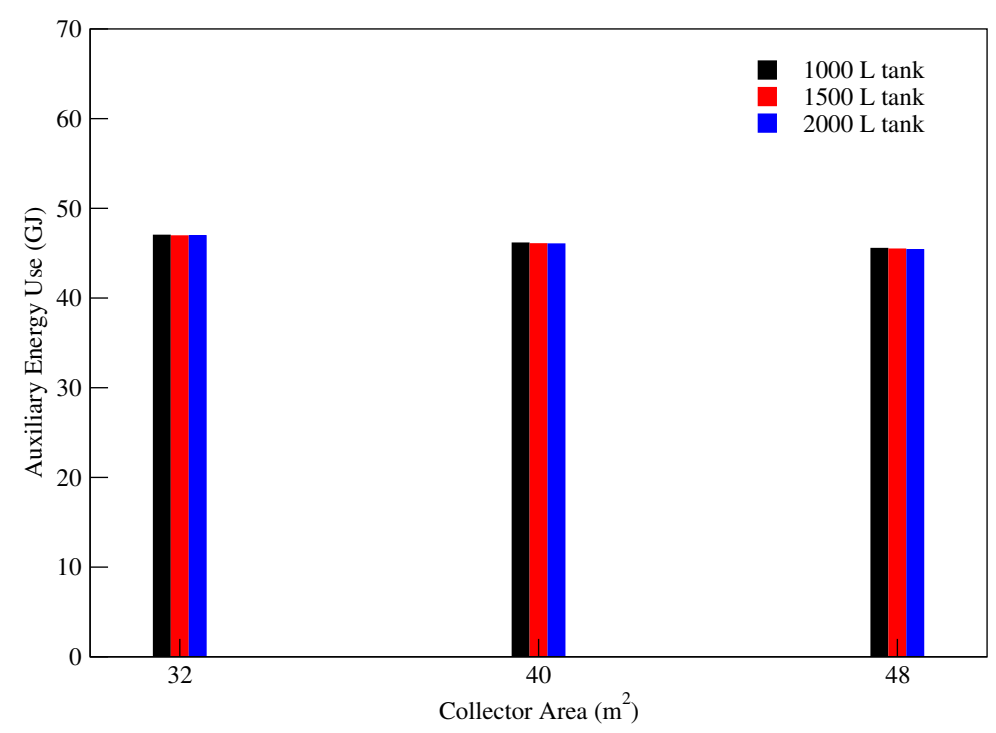

(c) Median DHW consumer

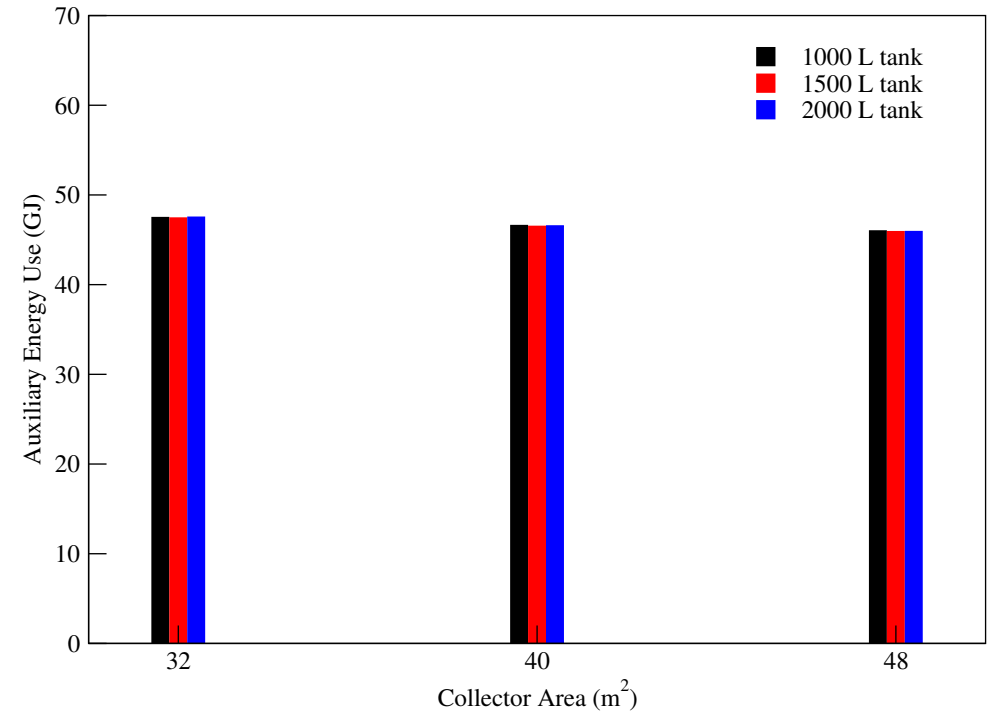

(b) Average DHW consumer

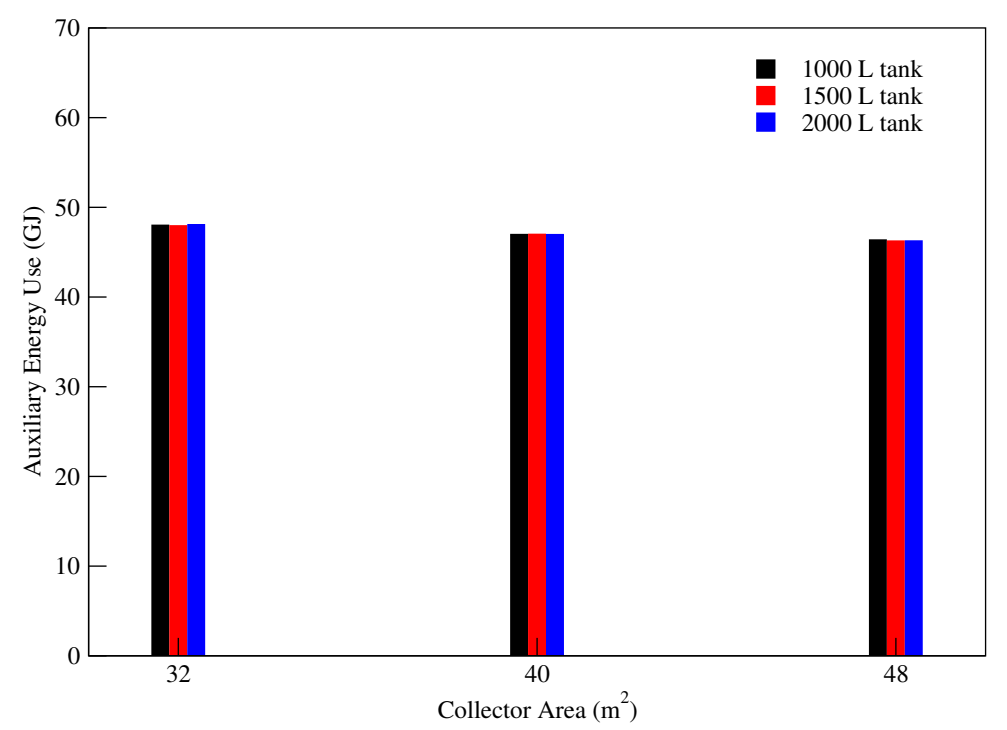

(d) Above average DHW consumer

Figure B.5: Difference in auxiliary energy use when varying collector area and storage volume for mid-size 1974 home. 


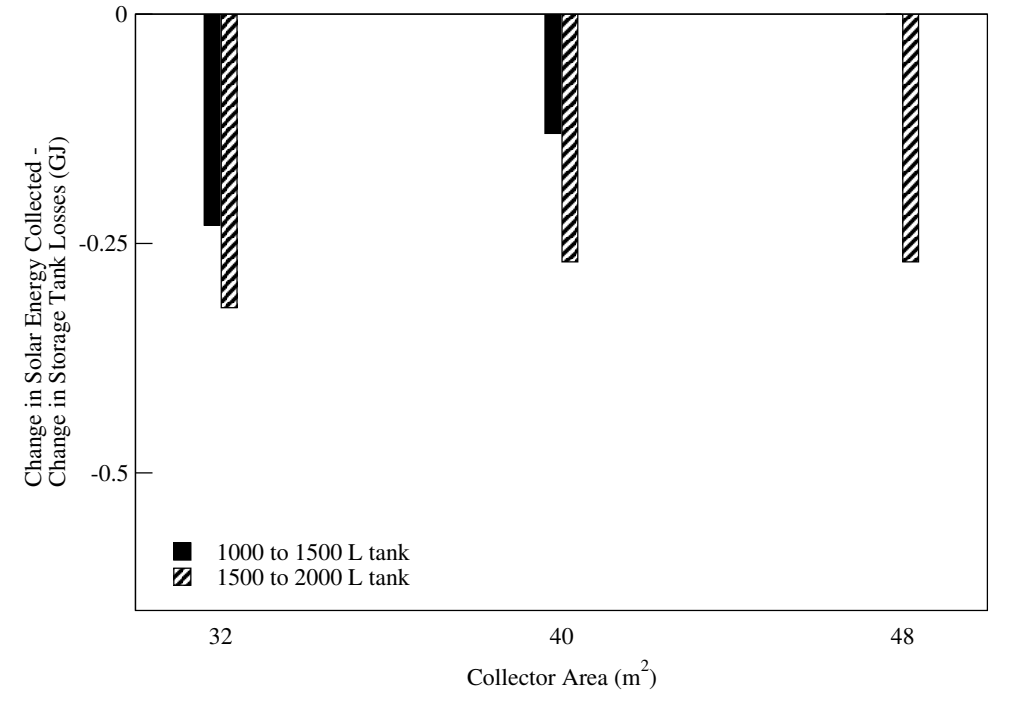

(a) Below average DHW consumer

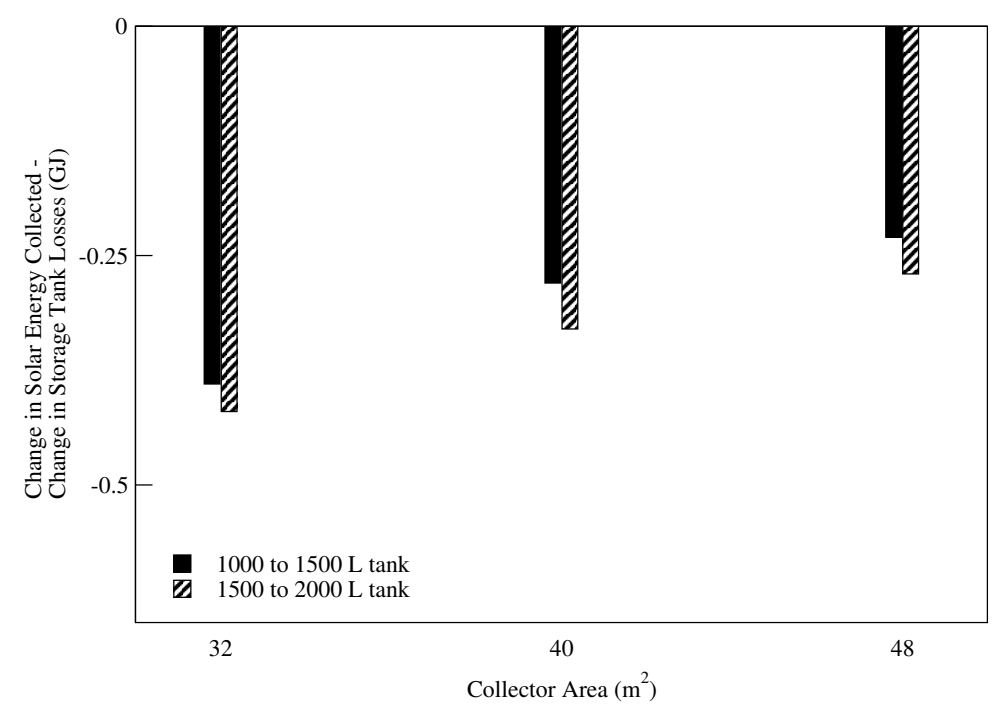

(c) Median DHW consumer

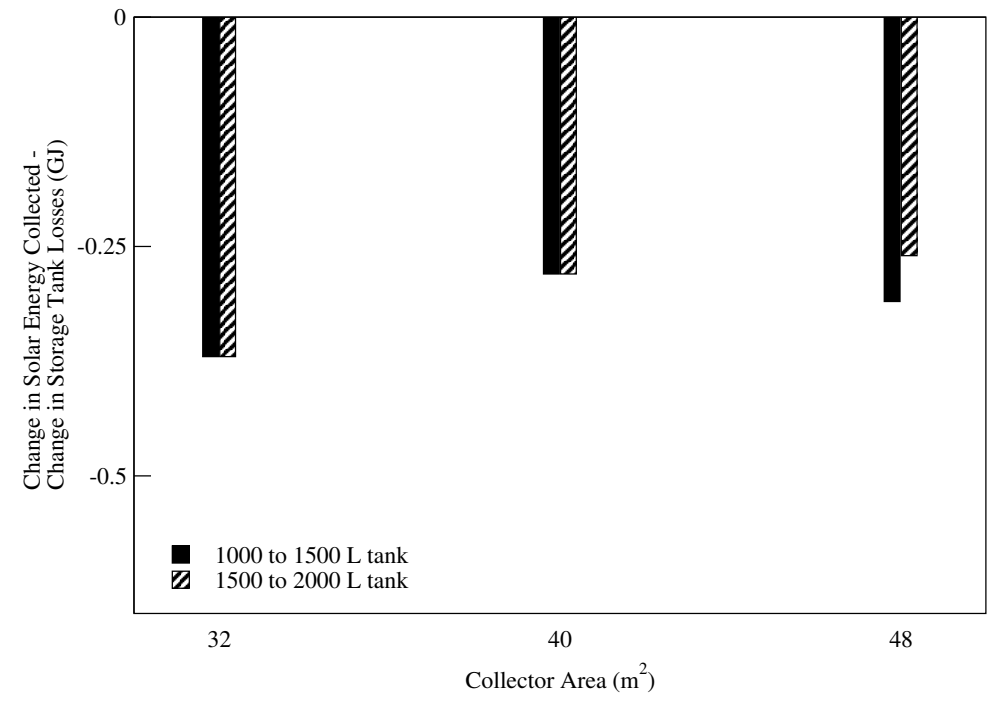

(b) Average DHW consumer

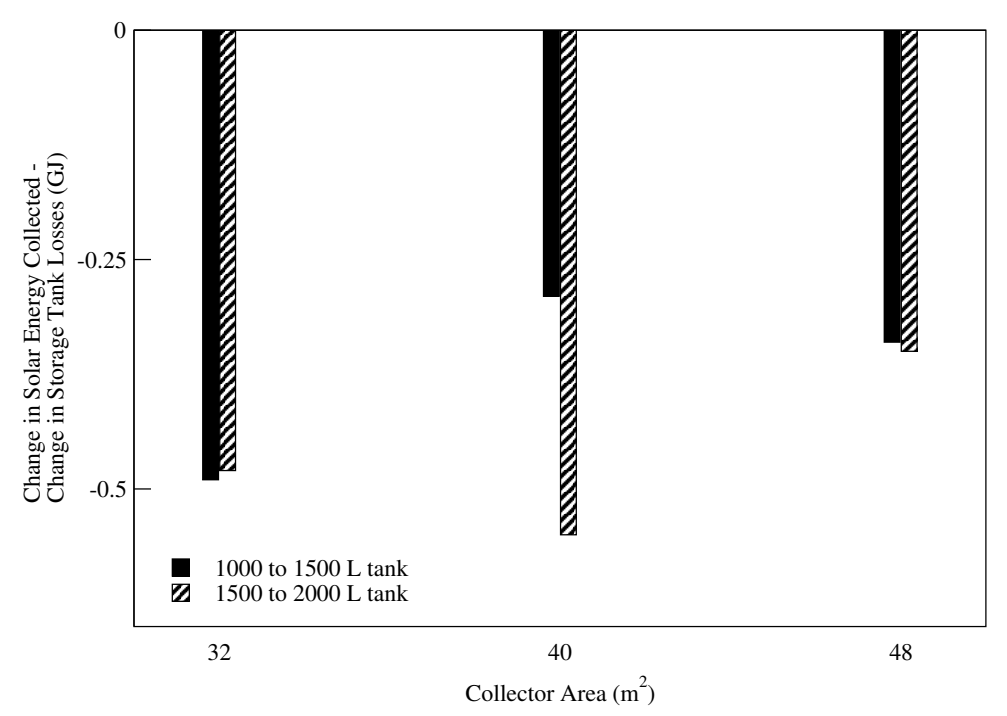

(d) Above average DHW consumer

Figure B.6: Difference in solar energy collected and DHW tank Losses when varying collector area and storage volume for mid-size 1990 home. 


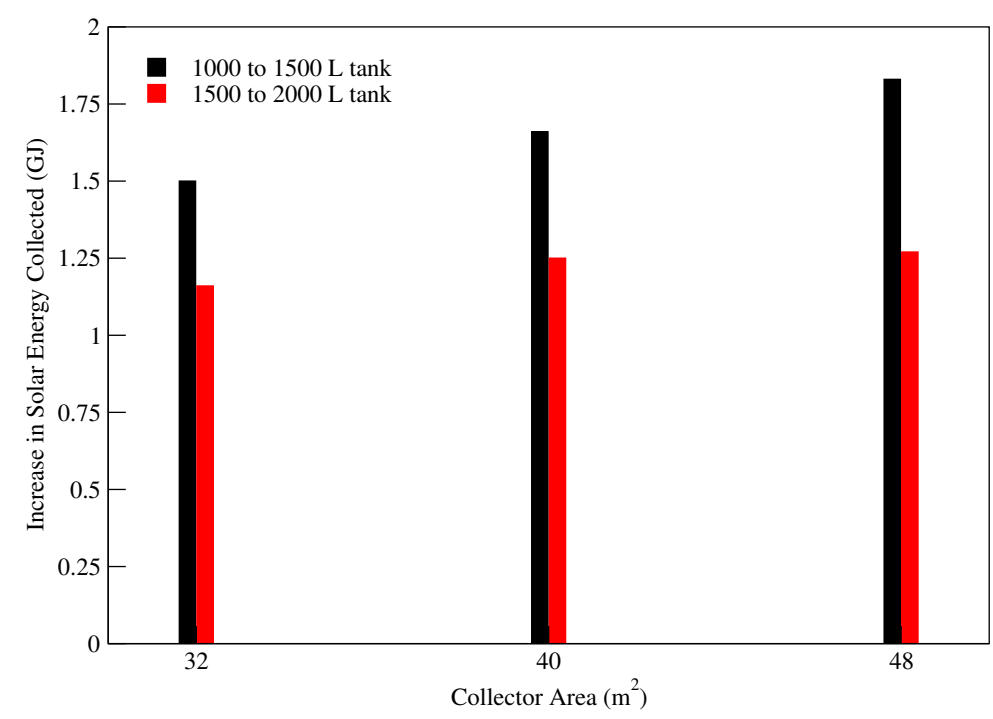

(a) Below average DHW consumer

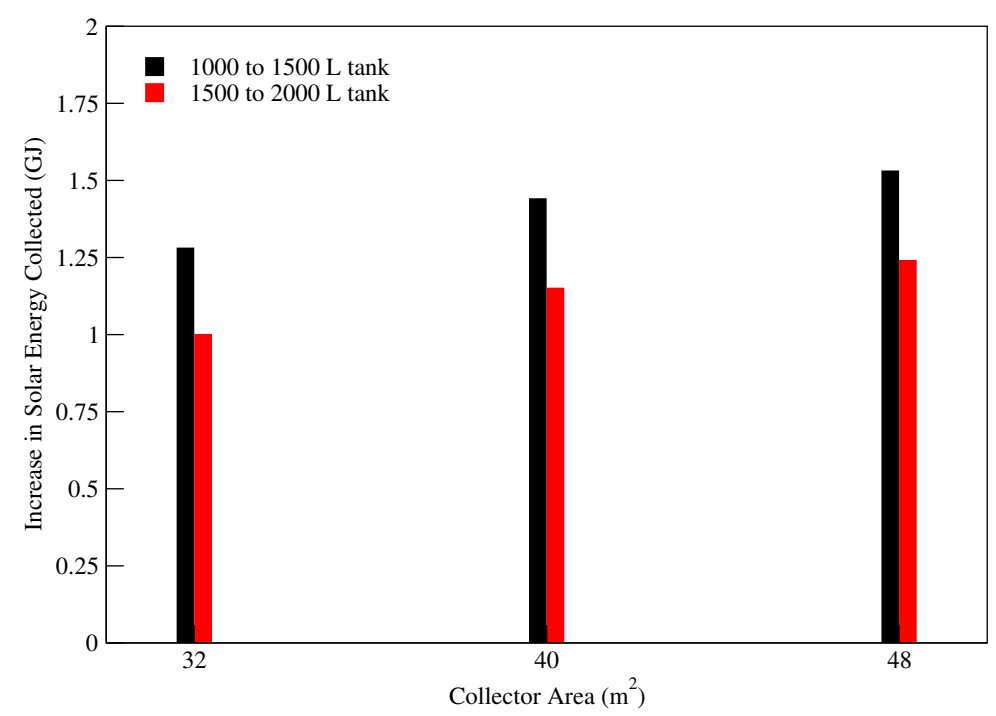

(c) Median DHW consumer

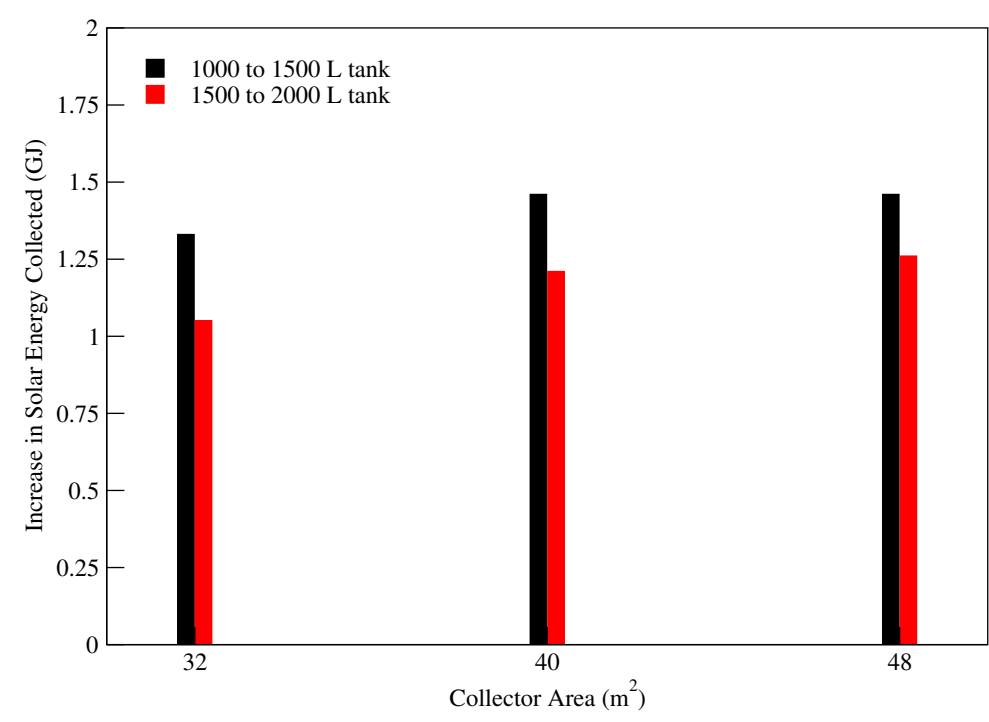

(b) Average DHW consumer

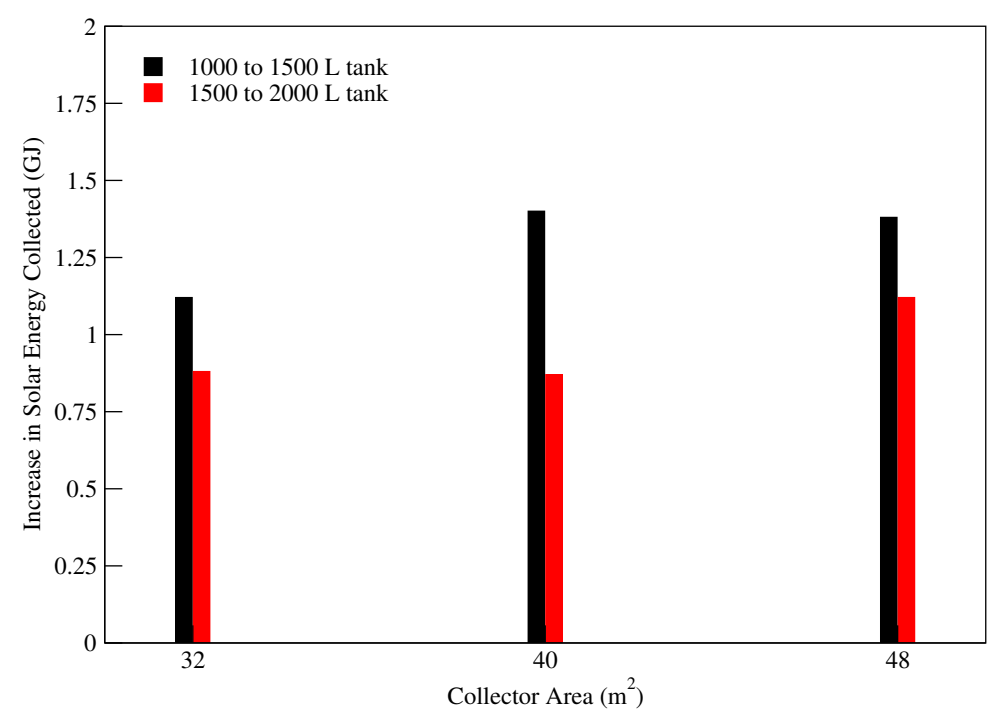

(d) Above average DHW consumer

Figure B.7: Difference in solar energy collected when varying collector area and storage volume for mid-size 1990 home. 


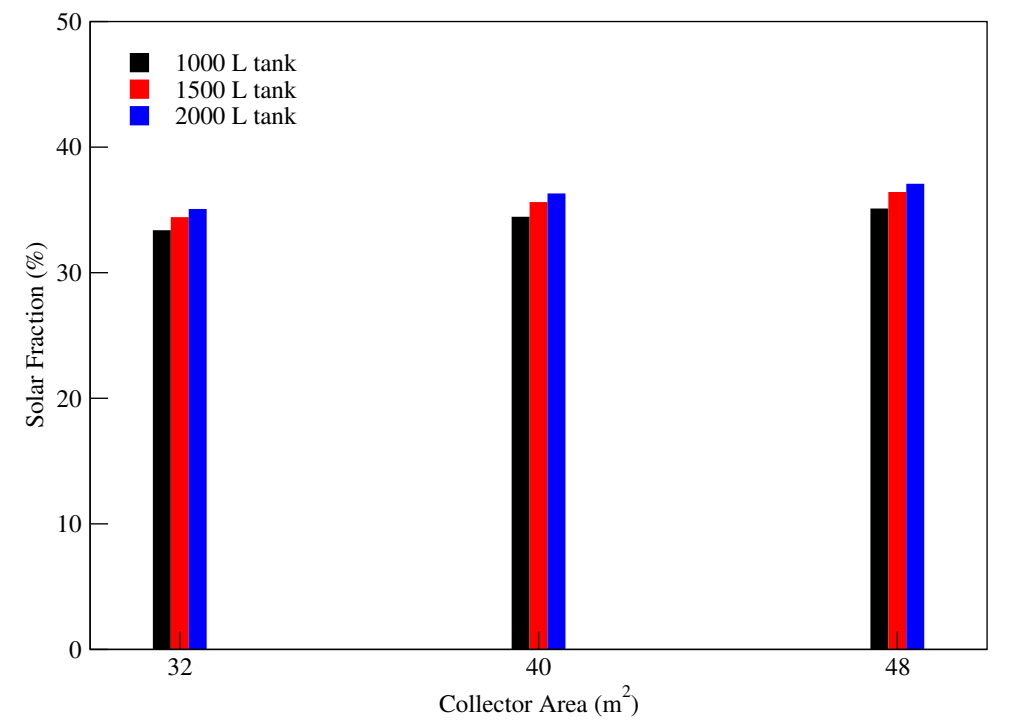

(a) Below average DHW consumer

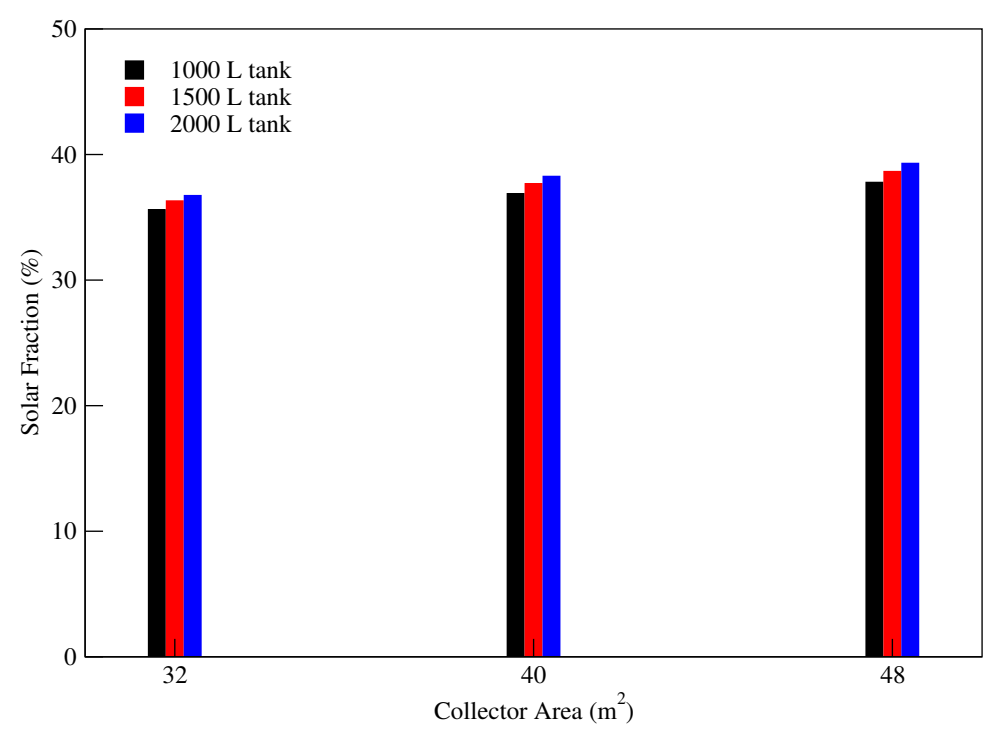

(c) Median DHW consumer

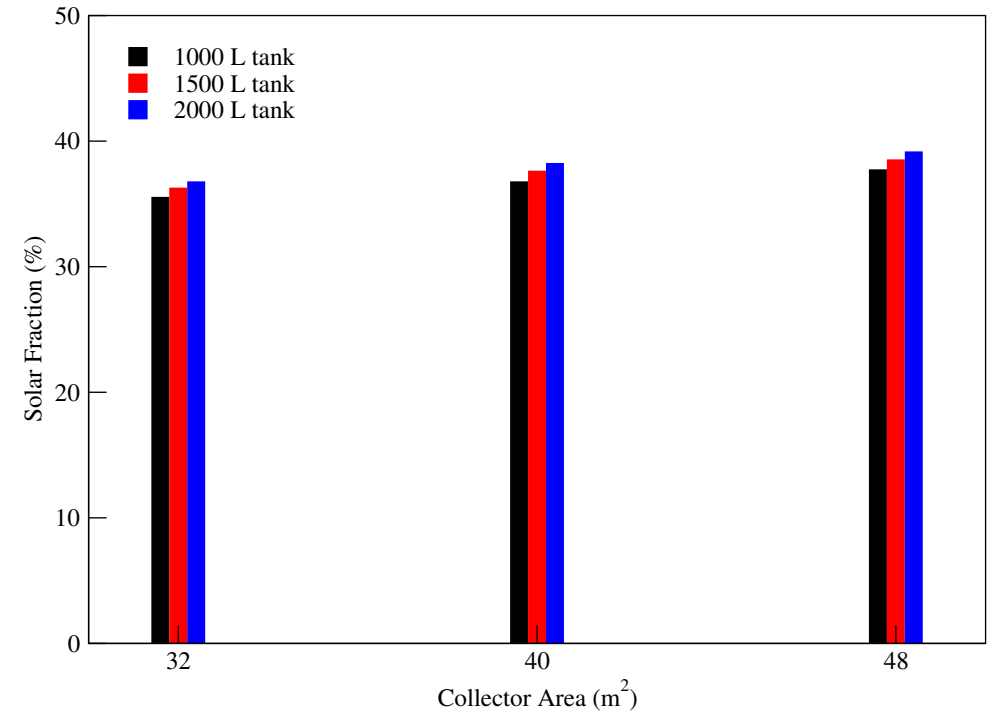

(b) Average DHW consumer

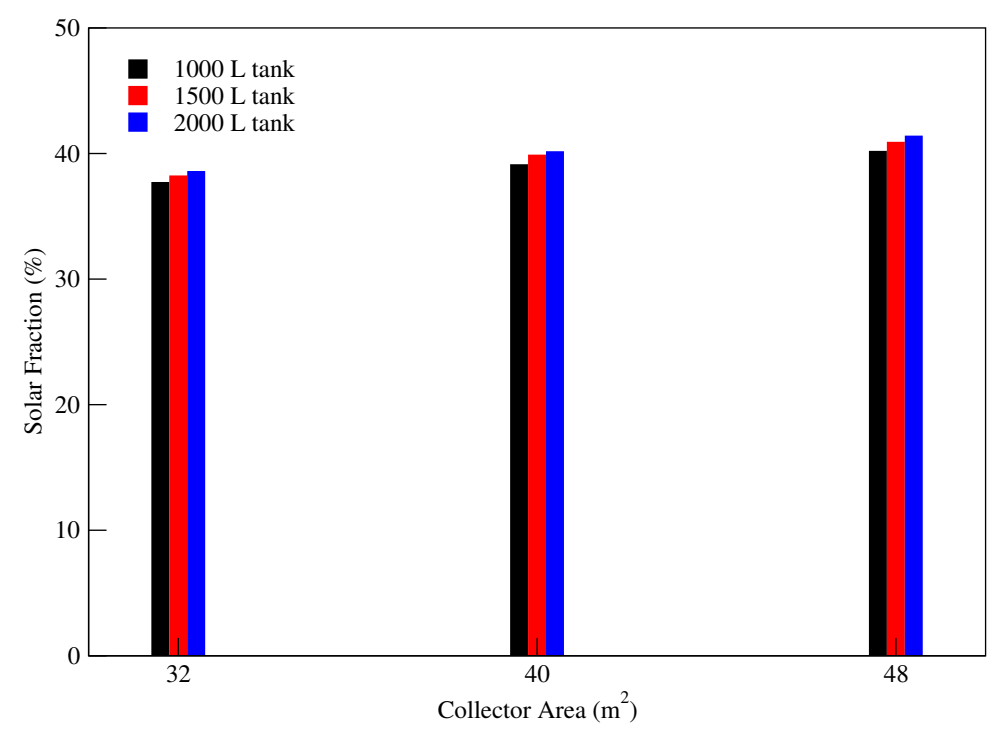

(d) Above average DHW consumer

Figure B.8: Difference in solar fractions when varying collector area and storage volume for mid-size 1990 home. 


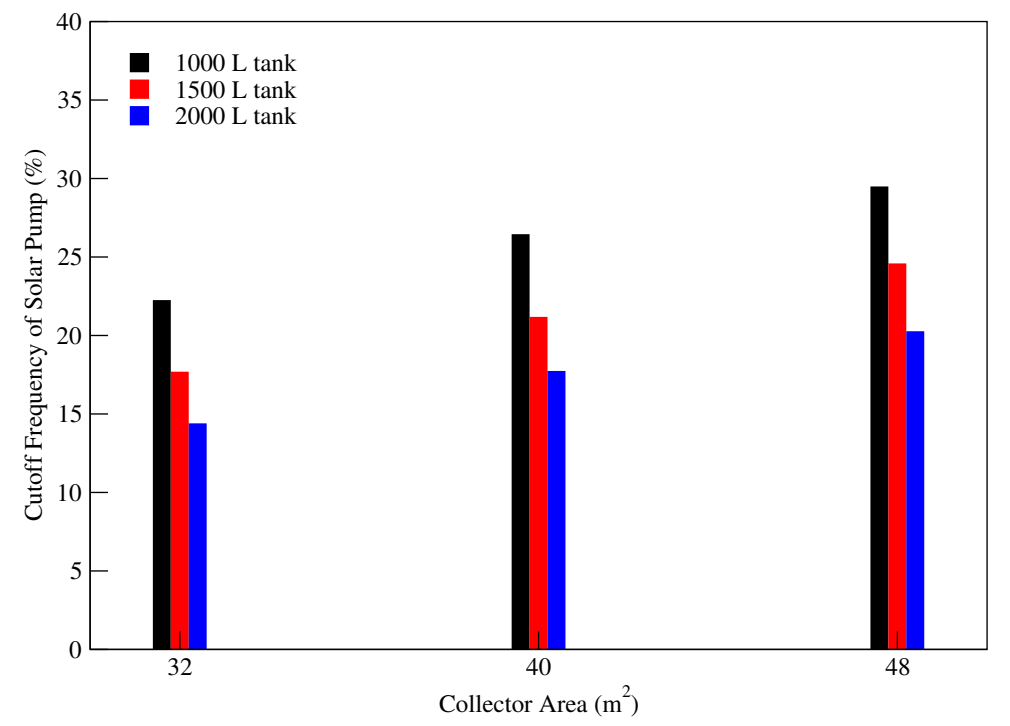

(a) Below average DHW consumer

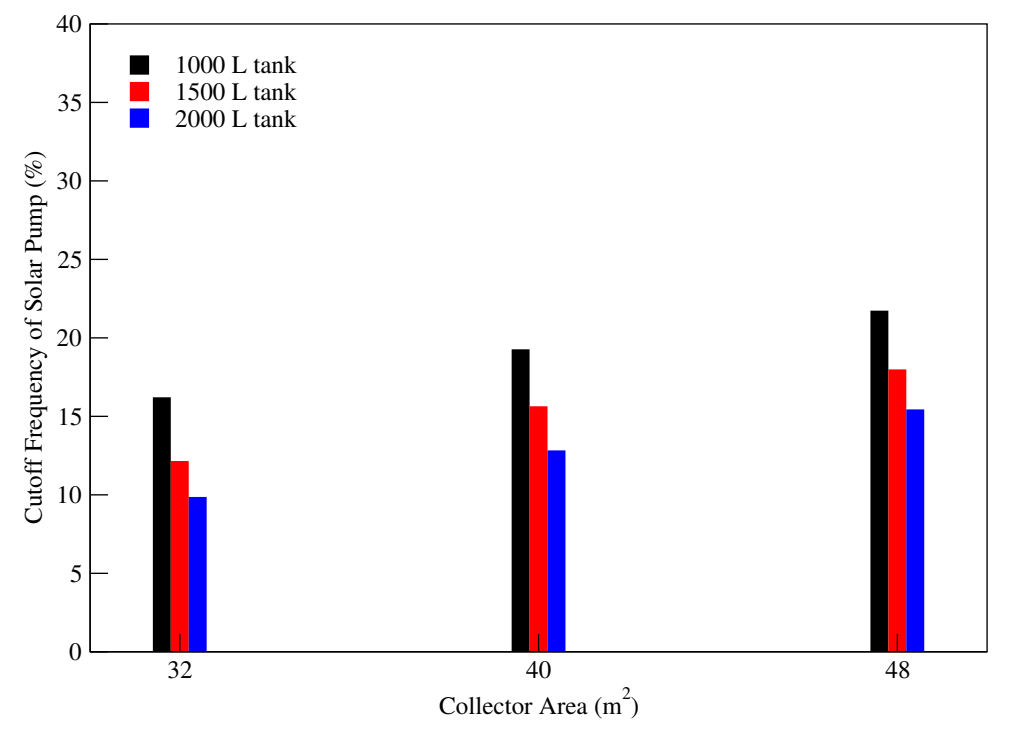

(c) Median DHW consumer

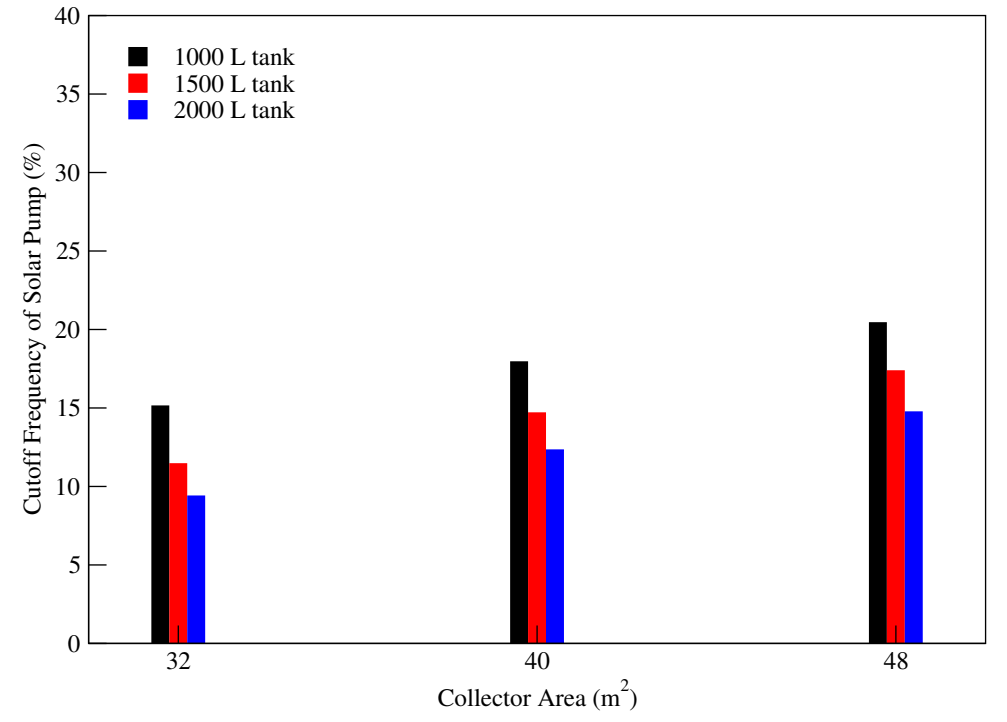

(b) Average DHW consumer

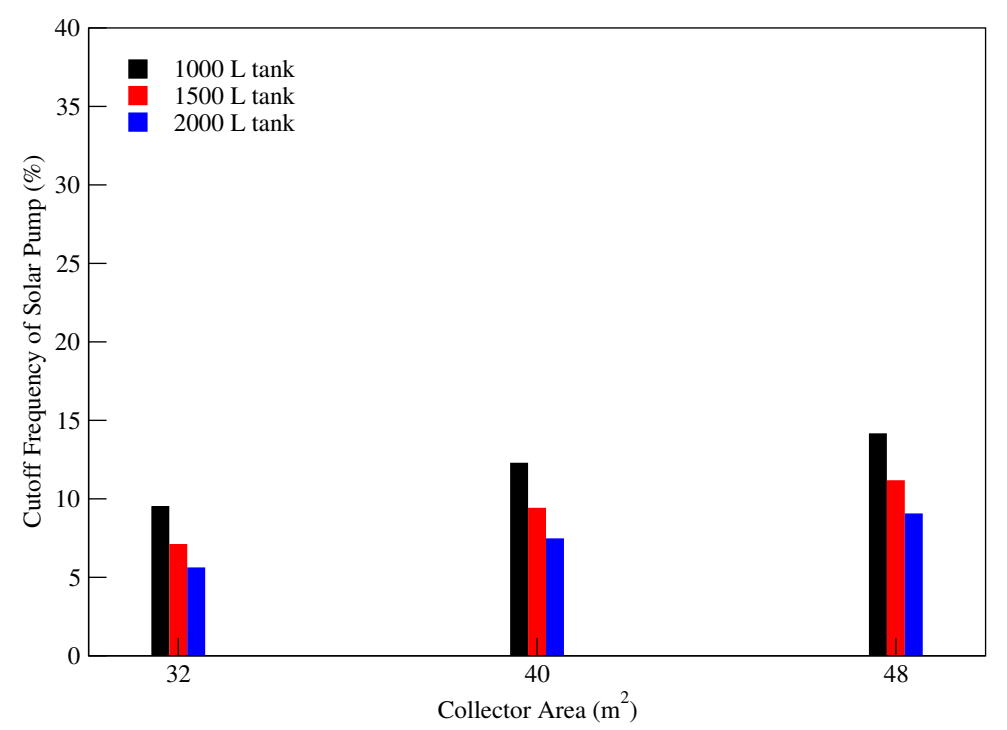

(d) Above average DHW consumer

Figure B.9: Difference in solar pump cutoffs when varying collector area and storage volume for mid-size 1990 home. 


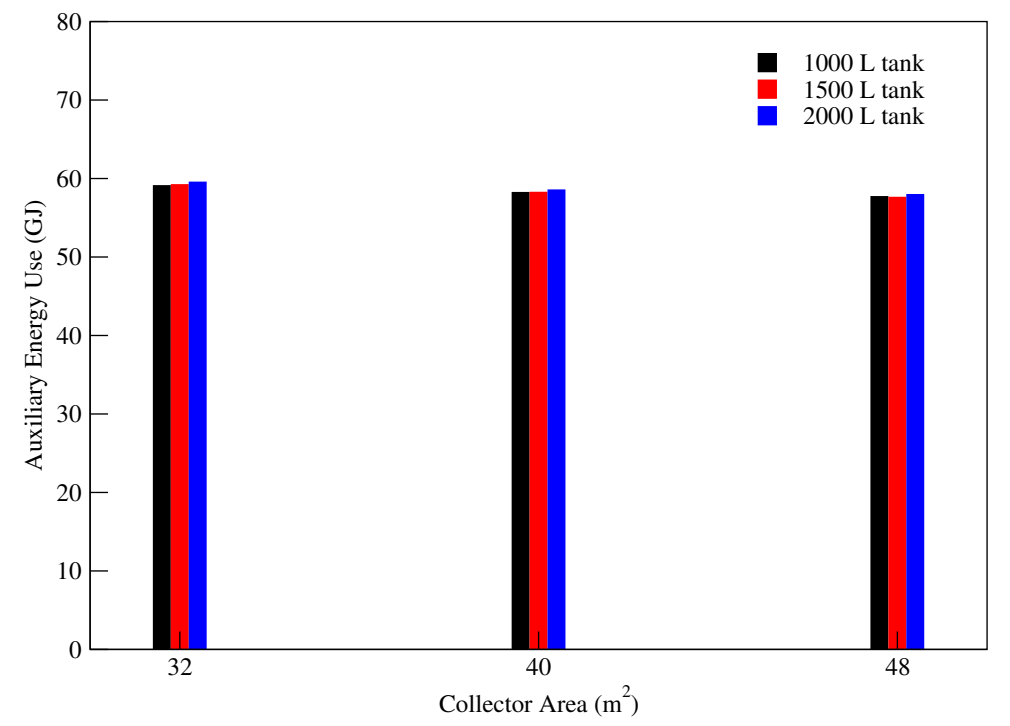

(a) Below average DHW consumer

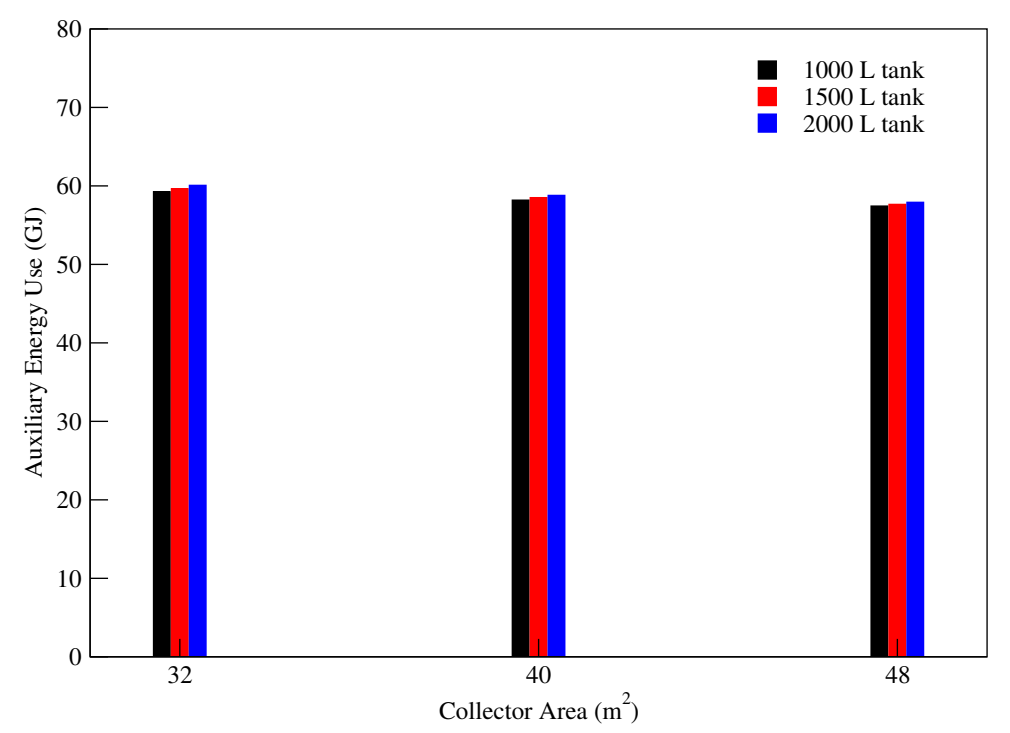

(c) Median DHW consumer

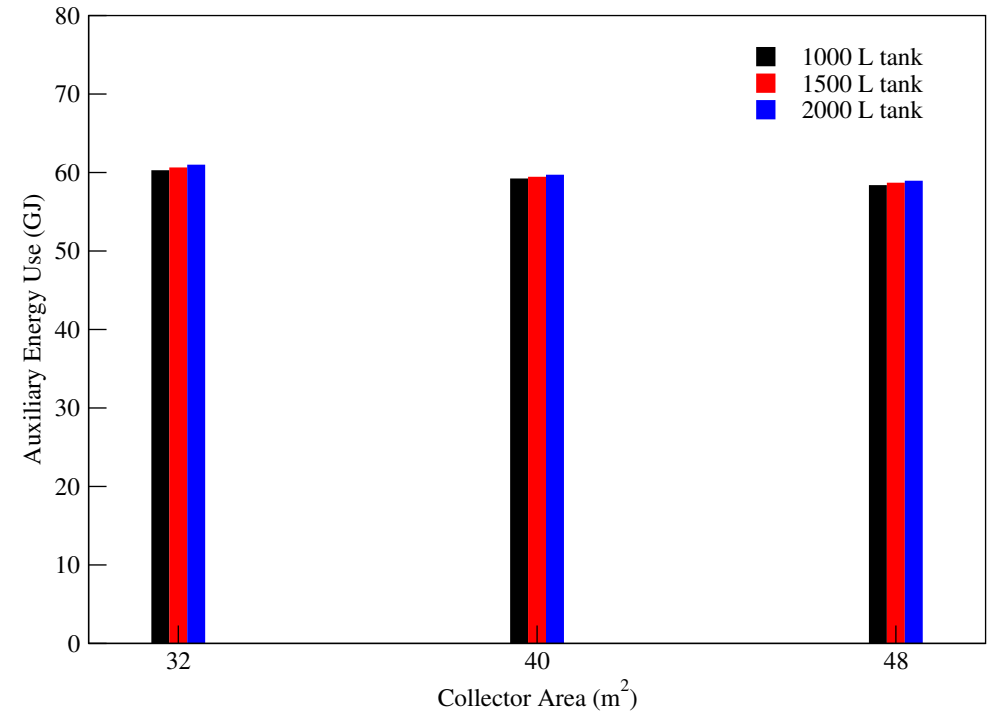

(b) Average DHW consumer

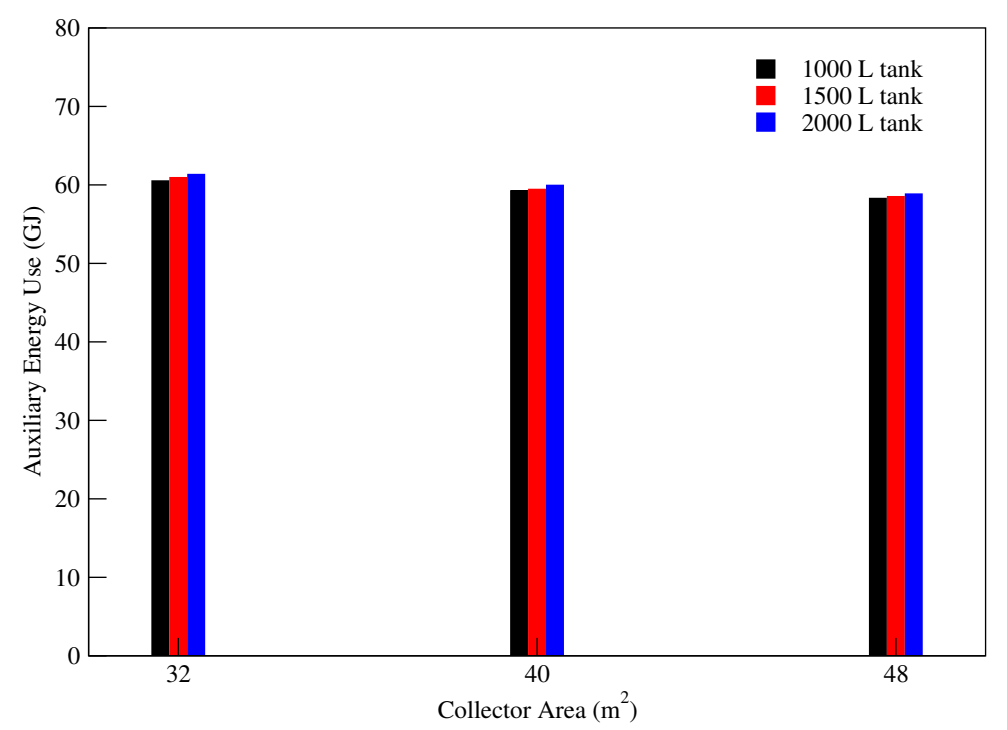

(d) Above average DHW consumer

Figure B.10: Difference in auxiliary energy use when varying collector area and storage volume for mid-size 1990 home. 


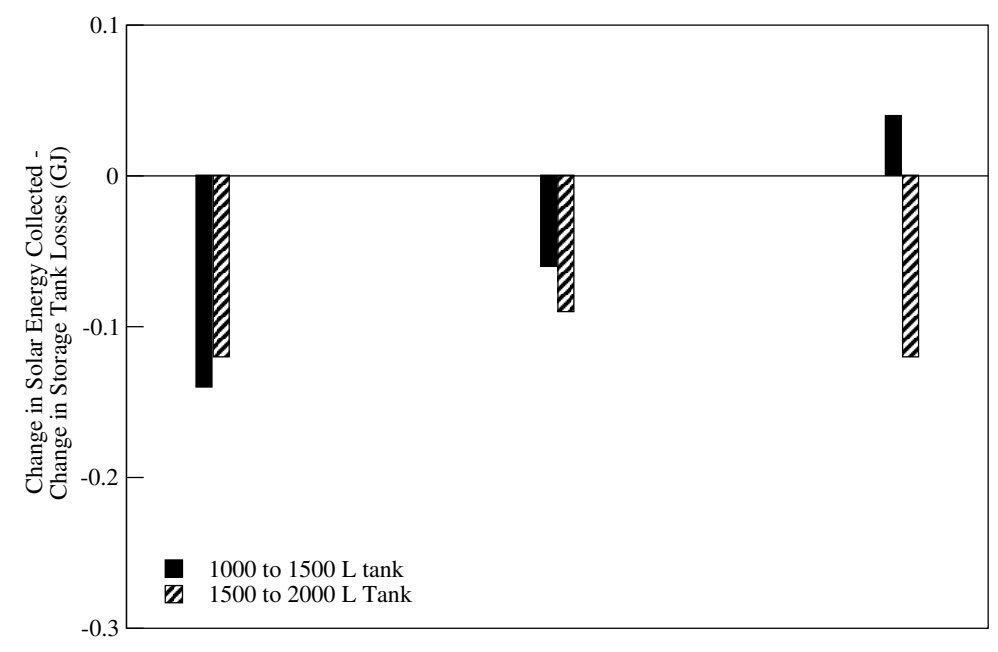

(a) Below average DHW consumer

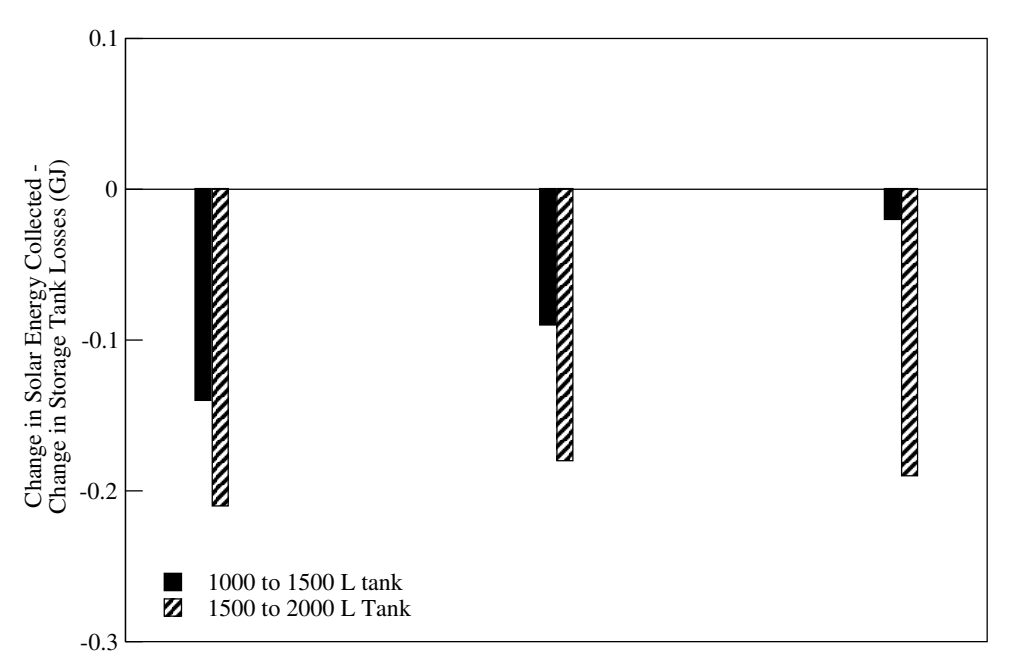

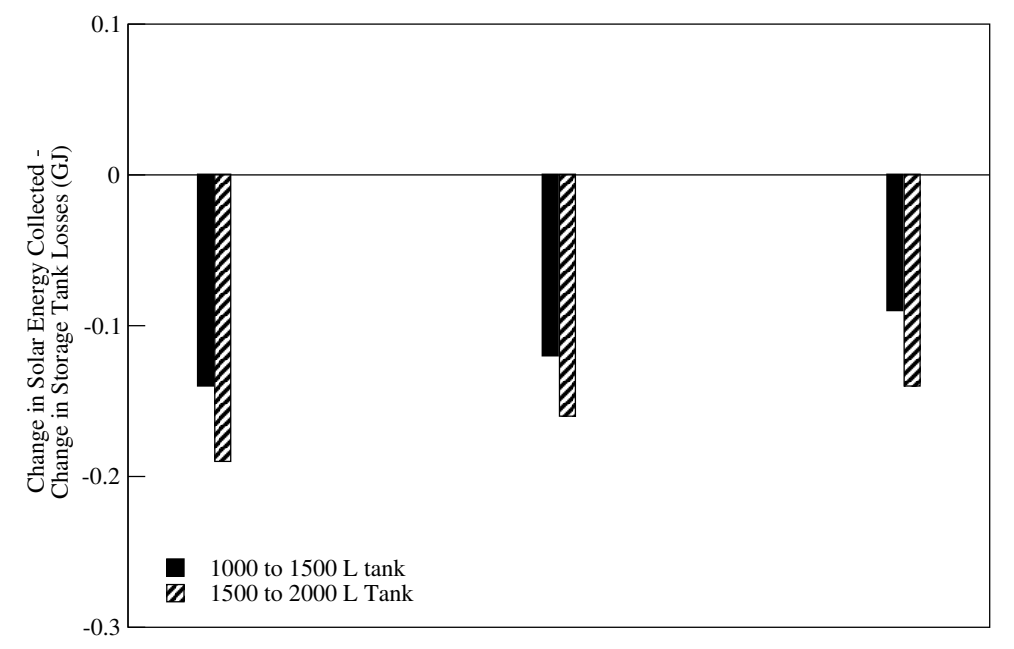

(b) Average DHW consumer

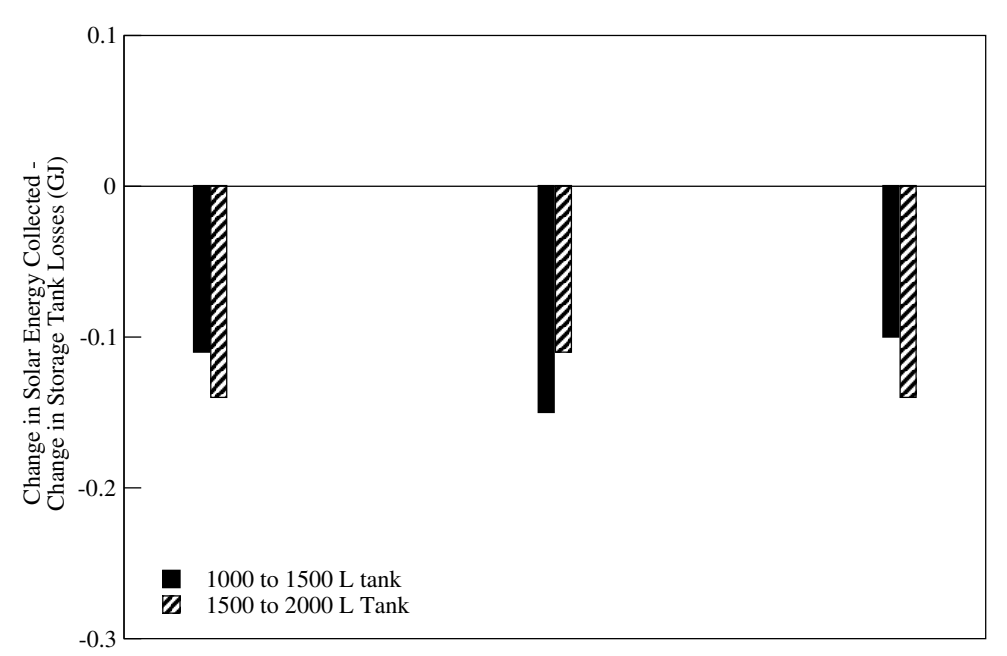

Figure B.11: Difference in solar energy collected and DHW tank Losses when varying collector area and storage volume for large 1990 home. 


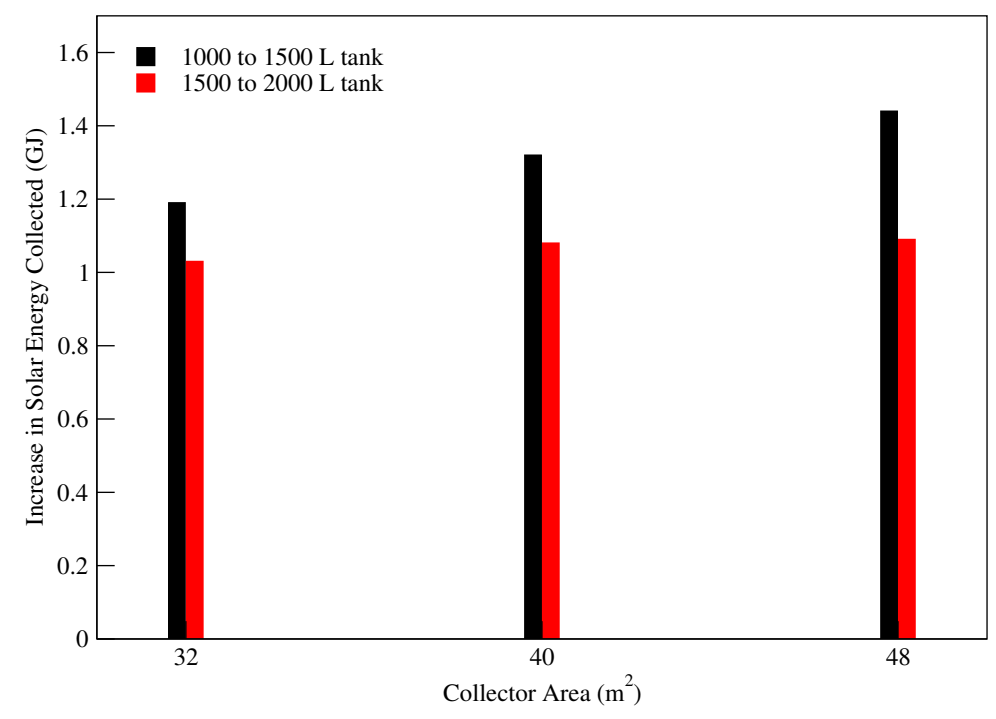

(a) Below average DHW consumer

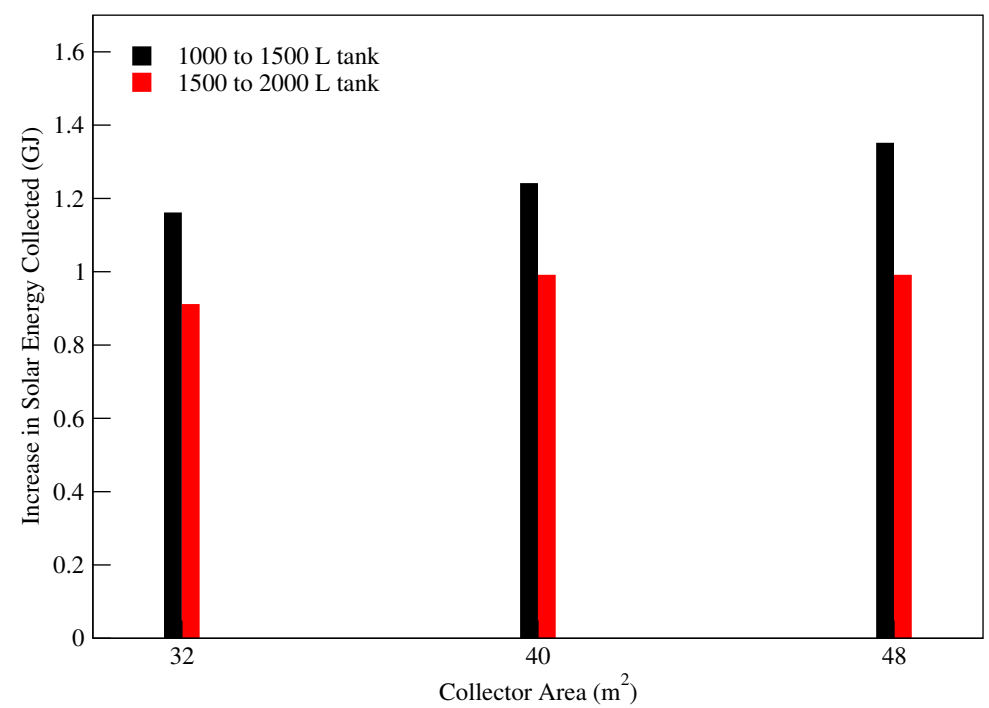

(c) Median DHW consumer

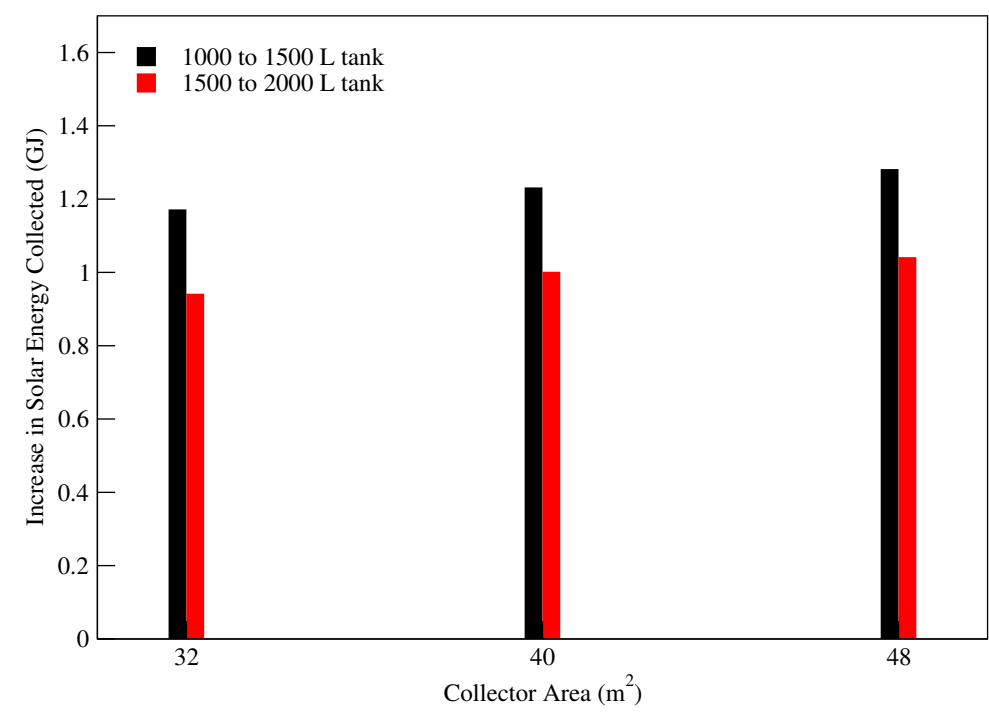

(b) Average DHW consumer

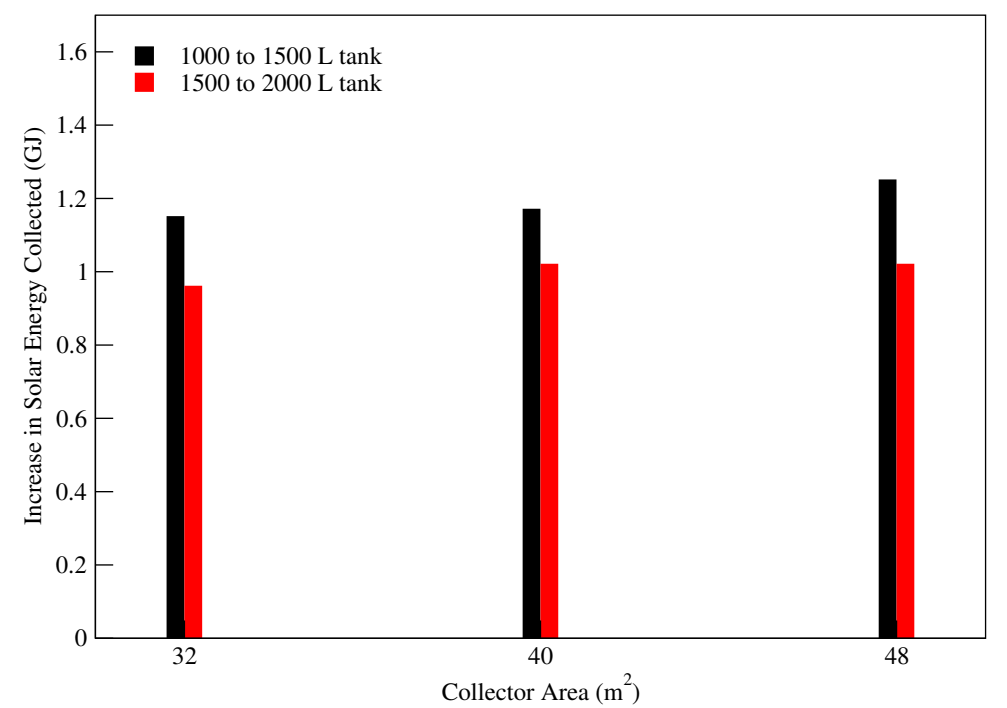

(d) Above average DHW consumer

Figure B.12: Difference in solar energy collected when varying collector area and storage volume for large 1990 home. 


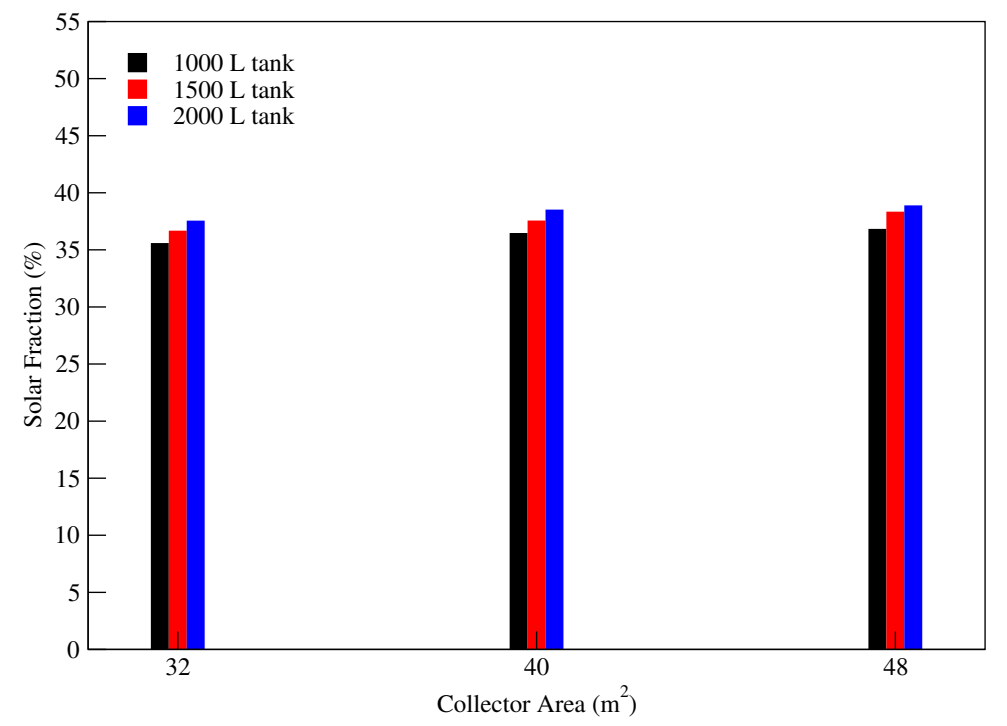

(a) Below average DHW consumer

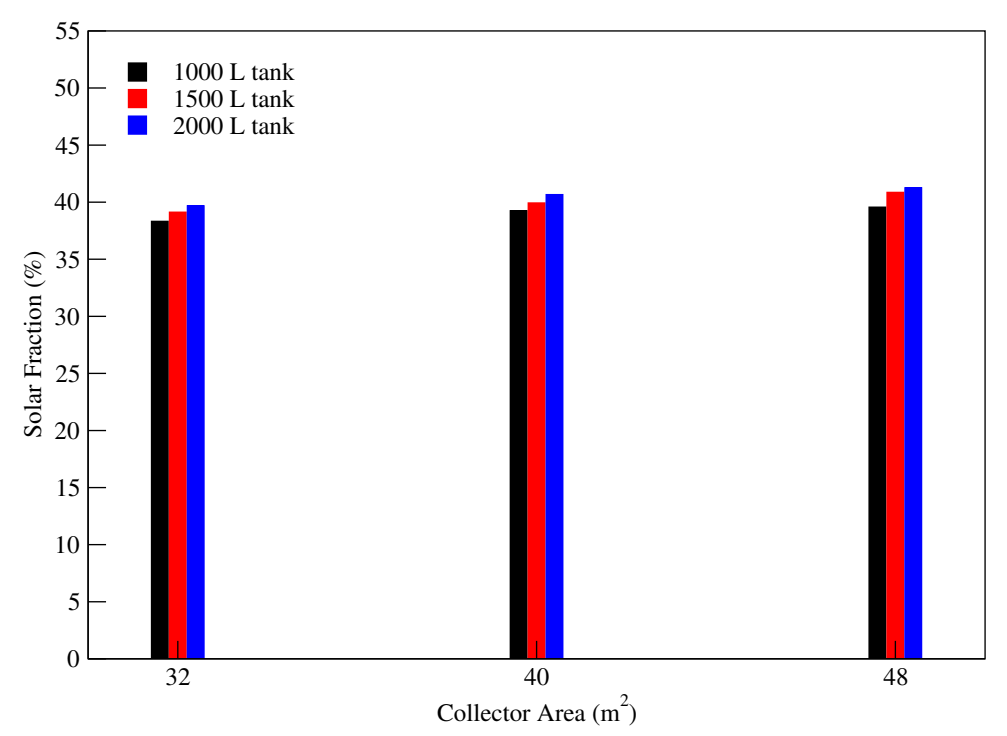

(c) Median DHW consumer

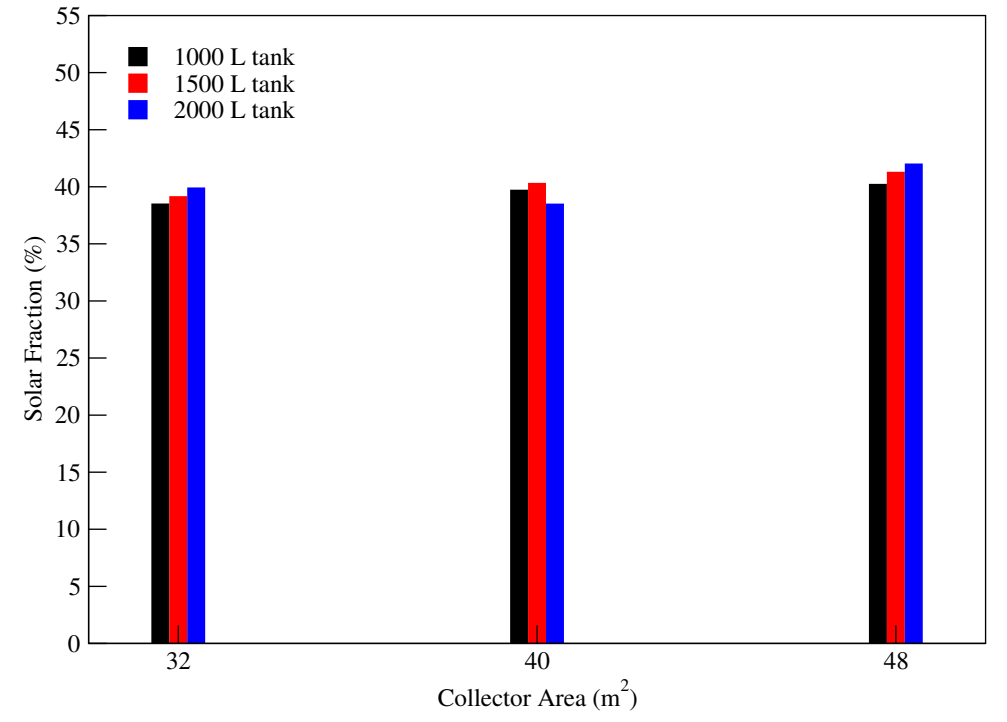

(b) Average DHW consumer

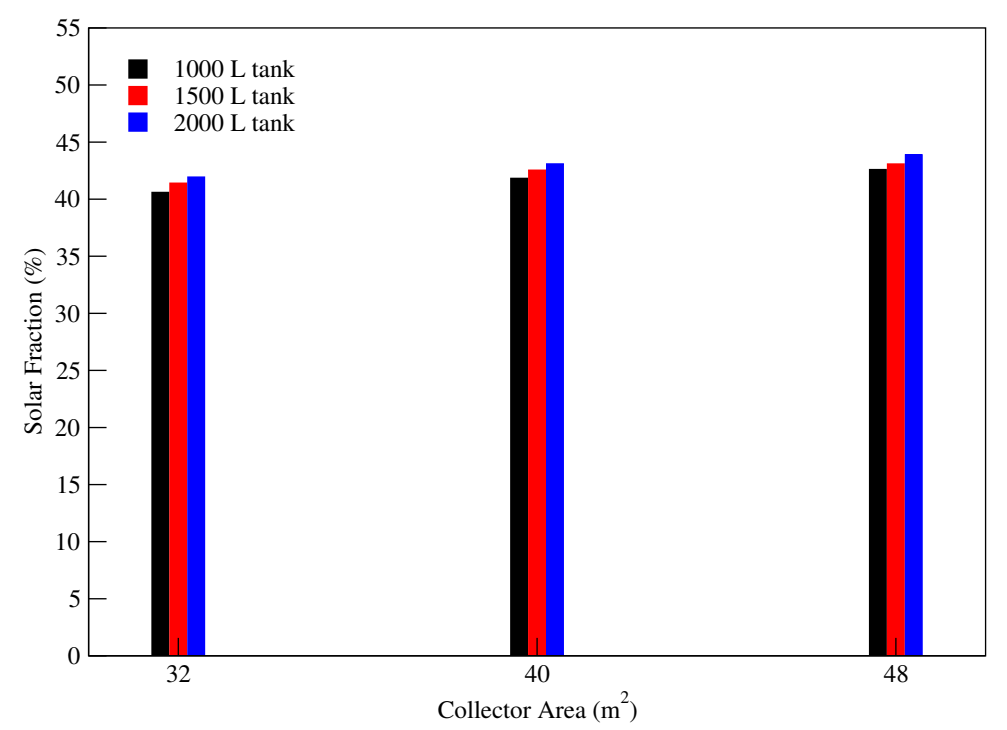

(d) Above average DHW consumer

Figure B.13: Difference in solar fractions when varying collector area and storage volume for large 1990 home. 


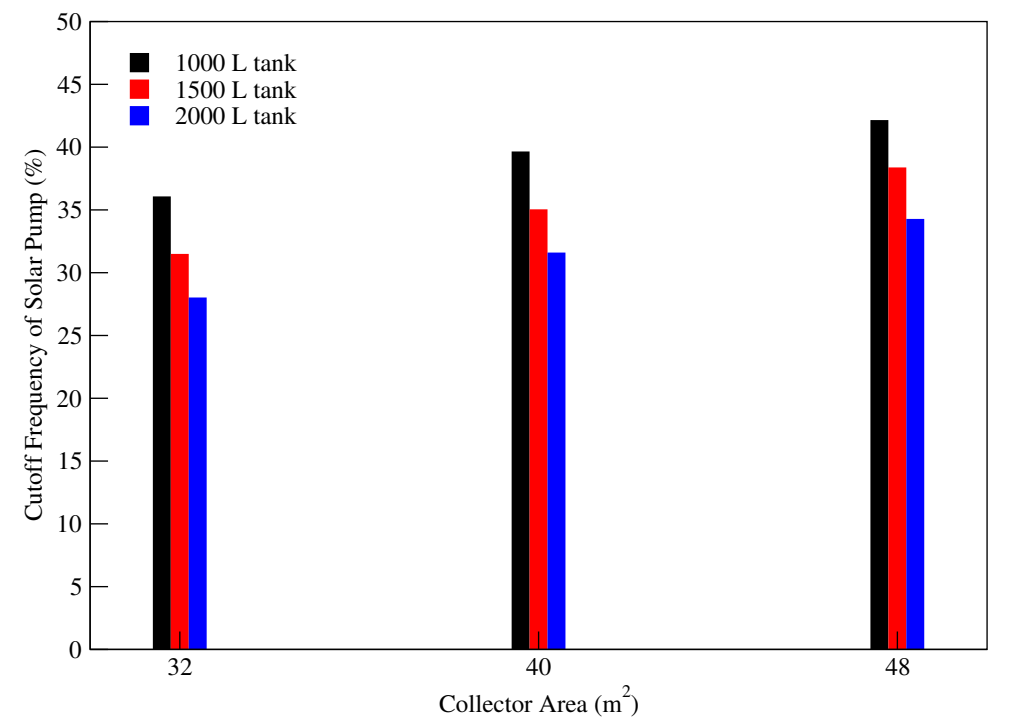

(a) Below average DHW consumer

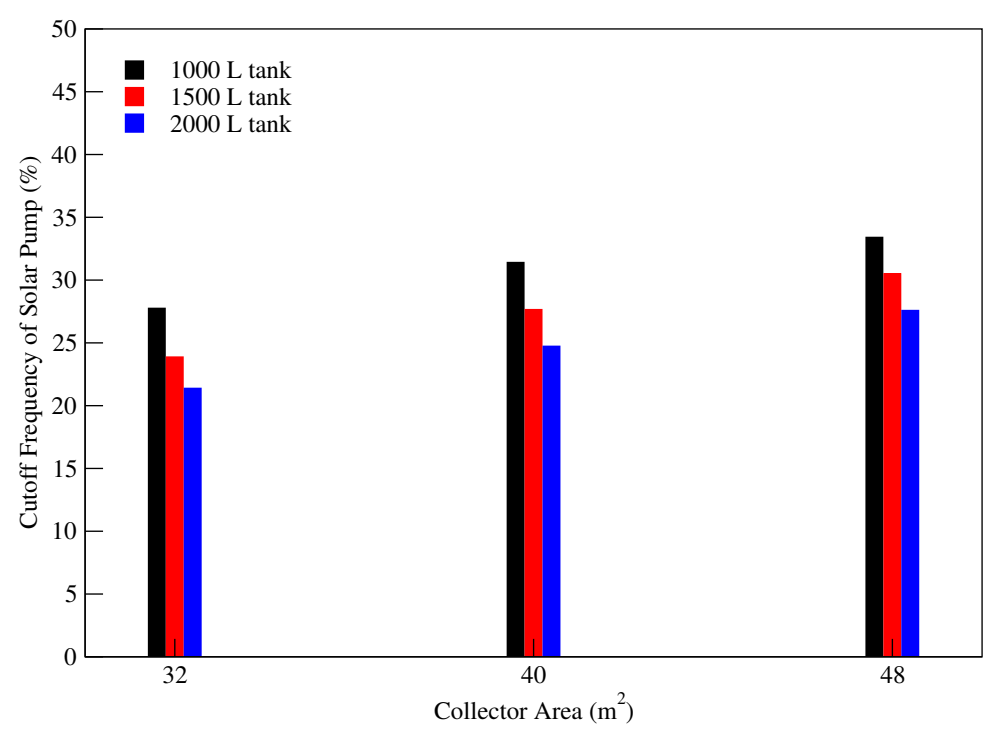

(c) Median DHW consumer

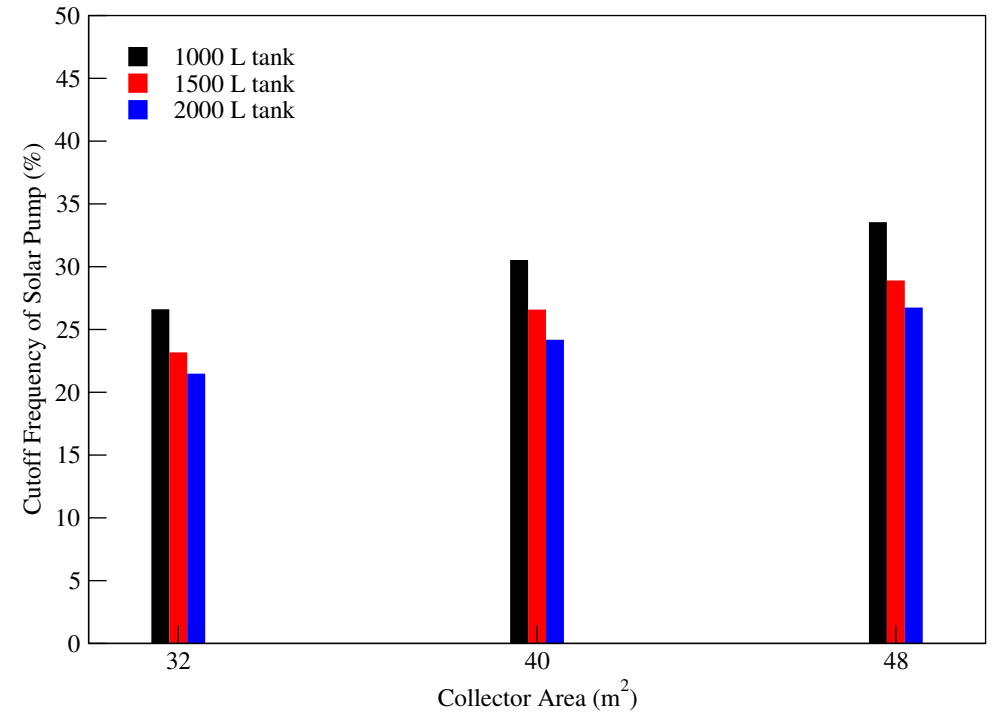

(b) Average DHW consumer

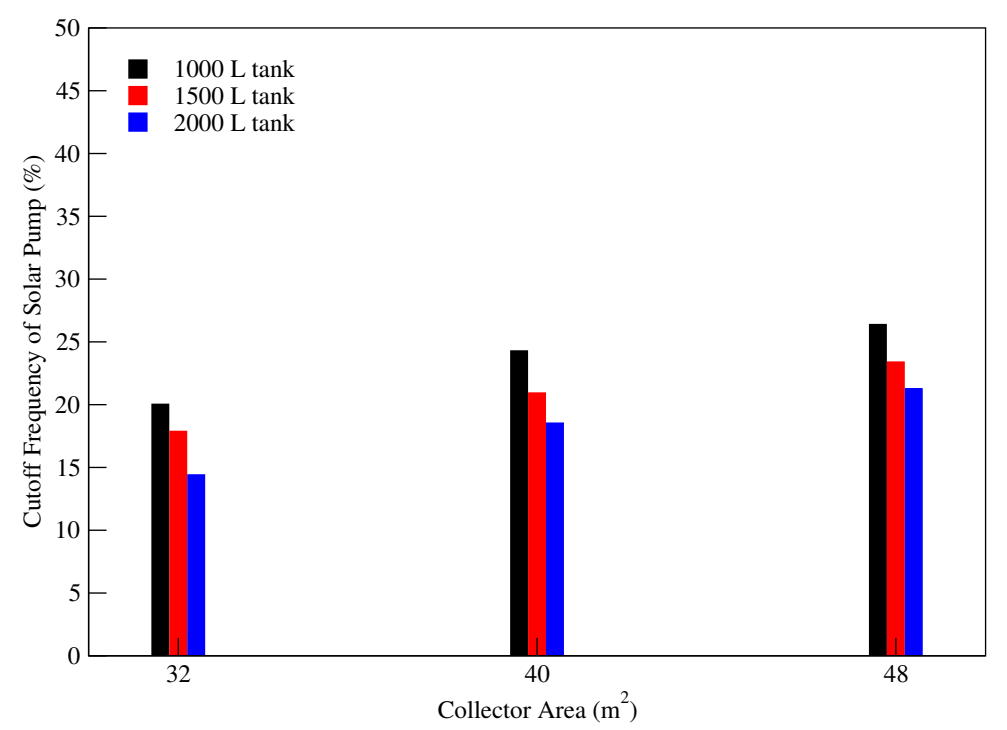

(d) Above average DHW consumer

Figure B.14: Difference in solar pump cutoffs when varying collector area and storage volume for large 1990 home. 


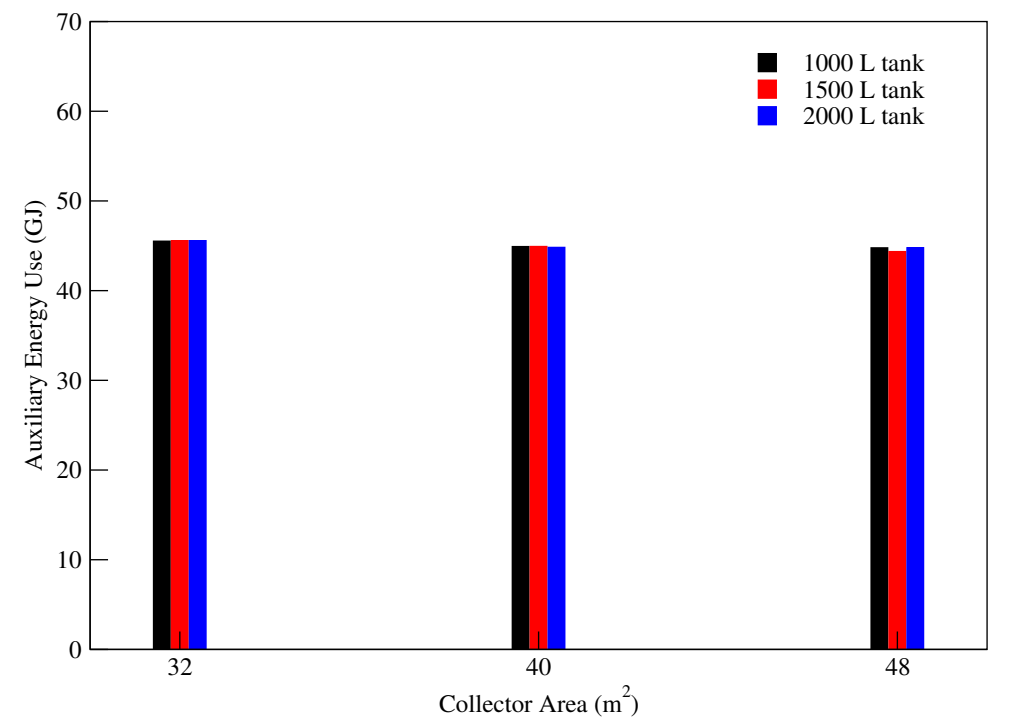

(a) Below average DHW consumer

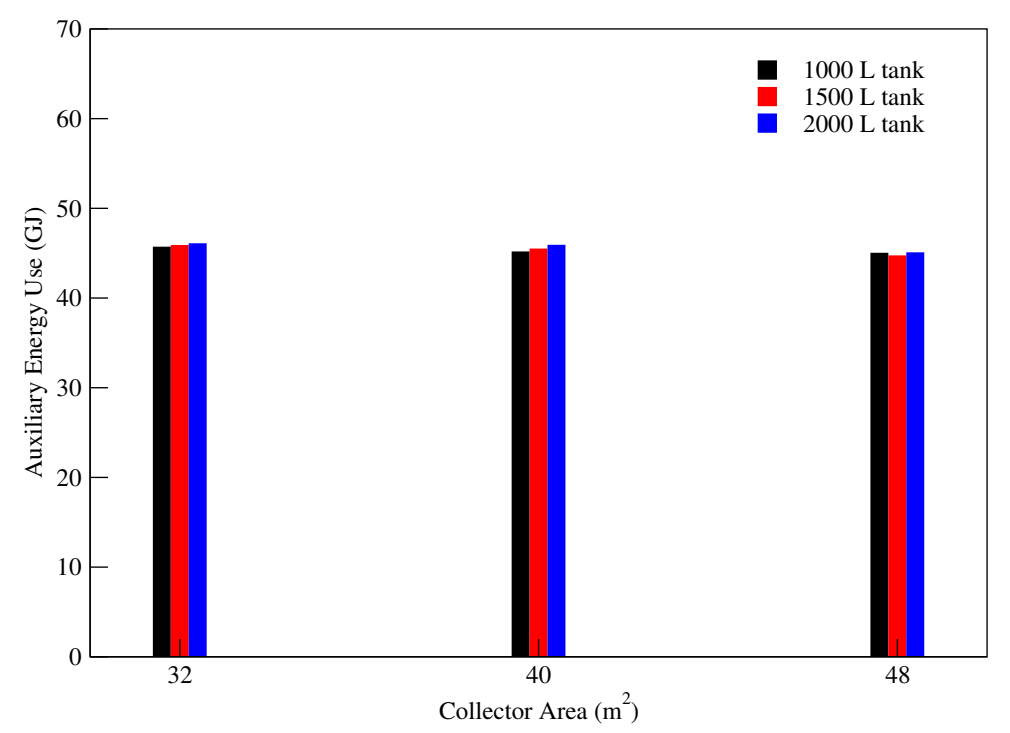

(c) Median DHW consumer

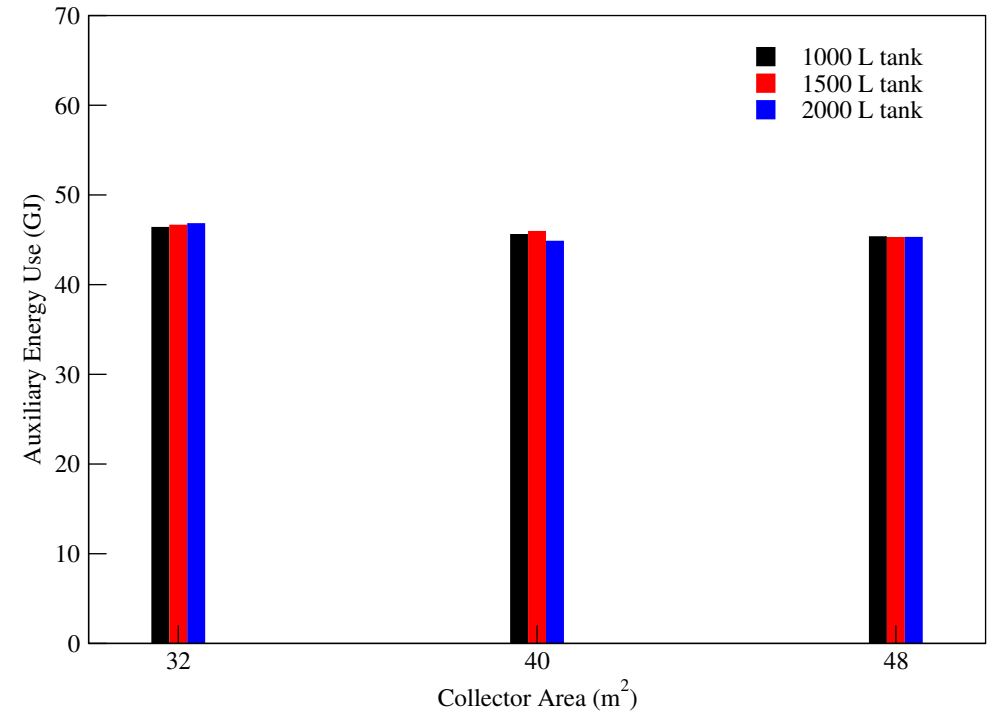

(b) Average DHW consumer

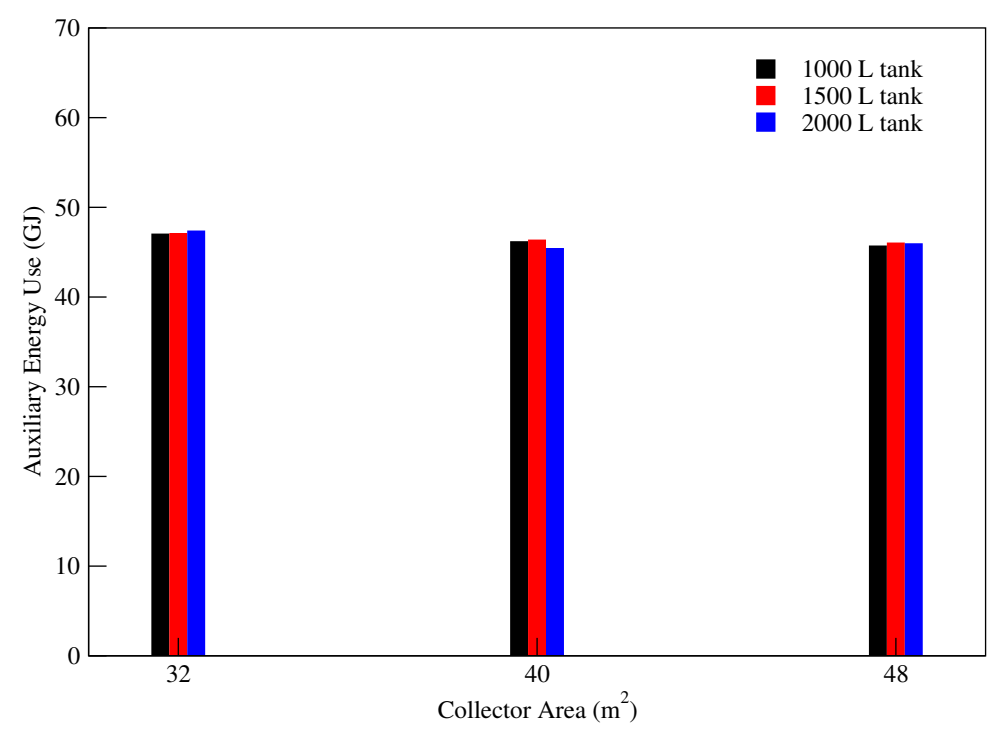

(d) Above average DHW consumer

Figure B.15: Difference in auxiliary energy use when varying collector area and storage volume for large 1990 home. 